\title{
A HOLISTIC APPROACH TO AND AUTOMATION OF WIDE AREA PROTECTION COORDINATION
}

\author{
by \\ Saman Alaeddini \\ Bachelor of Applied Science, University of Toronto, 2014 \\ A thesis \\ presented to Ryerson University \\ in partial fulfillment of the \\ requirements for the degree of \\ Master of Applied Science \\ in the program of \\ Electrical and Computer Engineering
}

Toronto, Ontario, Canada, 2019

(C) Saman Alaeddini, 2019 


\section{Author's Declaration}

\section{AUTHOR'S DECLARATION FOR ELECTRONIC SUBMISSION OF A THESIS}

I hereby declare that I am the sole author of this thesis. This is a true copy of the thesis, including any required final revisions, as accepted by my examiners.

I authorize Ryerson University to lend this thesis to other institutions or individuals for the purpose of scholarly research.

I further authorize Ryerson University to reproduce this thesis by photocopying or by other means, in total or in part, at the request of other institutions or individuals for the purpose of scholarly research.

I understand that my thesis may be made electronically available to the public. 


\title{
Abstract
}

A holistic approach to and automation of wide area protection coordination

2019

\author{
Saman Alaeddini \\ Master of Applied Science \\ Electrical and Computer Engineering \\ Ryerson University
}

The electric power transmission network of today is undergoing significant changes in terms of the operational requirements, connected distributed energy resources technologies, and regulatory requirements. In conjunction with an aging infrastructure, these changes have presented new challenges to utilities in their fundamental mission of providing reliable electrical power to the customers. Thus, protection systems must overcome additional challenges towards safe and reliable operation of the power system. Increased investigation of protection system performance is therefore needed to ensure proper coordination of protective relays. However, the complex and integrated nature of the modern protection and control systems call for more sophisticated modeling and study tools for the simulation and analysis of both the dynamics of the interconnected transmission systems and interactions among numerous sets of intelligent electronic devices. Although the protection technology designed for transmission systems is mature, coordination of devices is still a major challenge. This thesis presents a holistic approach to conducting wide-area protection coordination studies through the use of a practical automation-assisted methodology. The wide area protection coordination solution covers process and data management considerations. It also provides a framework workflow for the execution and review of coordination studies, as well as processing and documentation of results to support reliability improvements. The fundamental concept behind the proposed approach is the utilization of software-based automation in a number of key tasks. Firstly, the execution of large-scale protection system coordination studies can be largely automated through utilization of specialized scripts running within short circuit simulation software packages. Secondly, the vast amounts of data inherent in the protection system coordination study results are processed in a manner that assists protection engineers in the identification and resolution of coordination issues. Finally, user friendly automated study summaries are generated that can be used as a record of protection setting recommendations. The effectiveness of the proposed solution is demonstrated through simulations conducted in the CAPE software environment for short circuit studies.

Keywords: Protection and Control, Protection Coordination, Power System Reliability, Wide Area Protection Coordination, WAPC. 


\section{Acknowledgments}

I want to express my deep gratitude for my supervisor, Dr. Yazdani, for his support and guidance.

\section{Shaghayegh}

Family

Borzoo \& Ginger 


\section{Table of Contents}

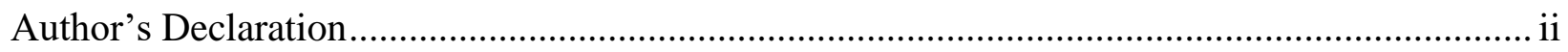

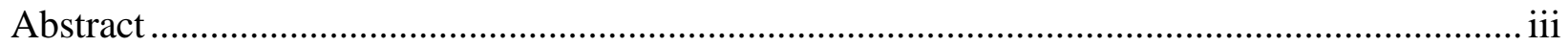

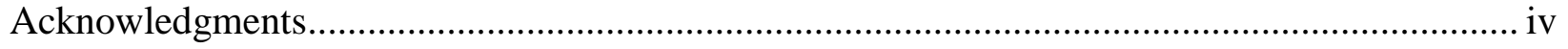

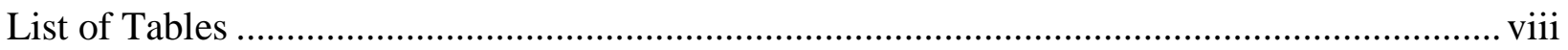

List of Figures …

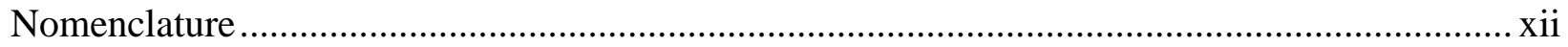

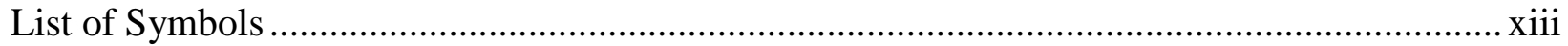

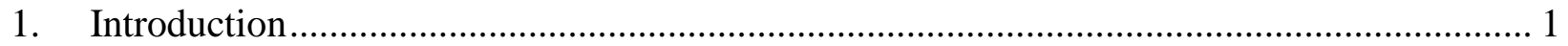

1.1. Background and Motivation................................................................................. 1

1.2. Statement of Problem and Thesis Objectives .............................................................. 2

1.3. Literature Review Pertinent to Thesis Objectives......................................................... 3

1.3.1. The Need for Protection Coordination.............................................................. 3

1.3.2. Challenges Associated with Wide-Area Protection Coordination............................... 6

1.3.3. Existing Methods for Studying Wide-Area Protection Coordination ........................ 7

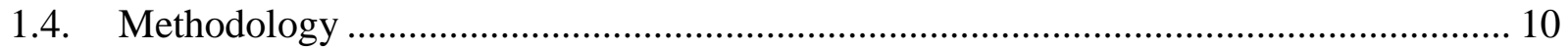

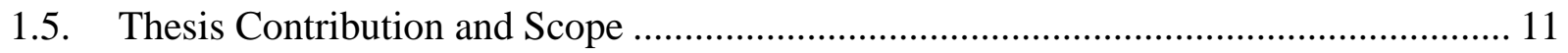

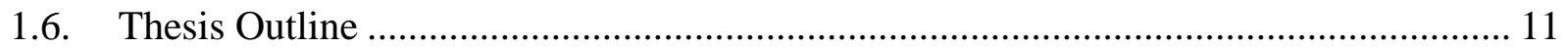

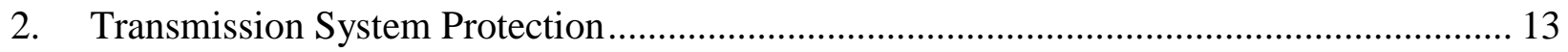

2.1. Transmission Protection Philosophy ...................................................................... 13

2.1.1. Overcurrent Protection.................................................................................... 15

2.1.2. Distance Protection .......................................................................................... 17

2.1.3. Communicated Assisted Protection Scheme ........................................................ 20

2.1.4. Impact of Source Impedance Ratio ................................................................... 21

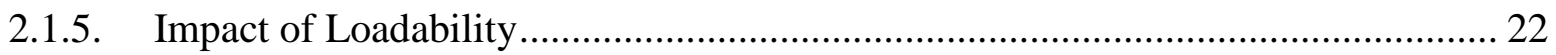

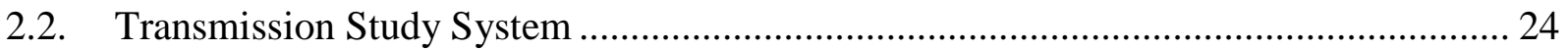

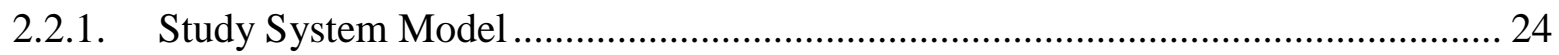

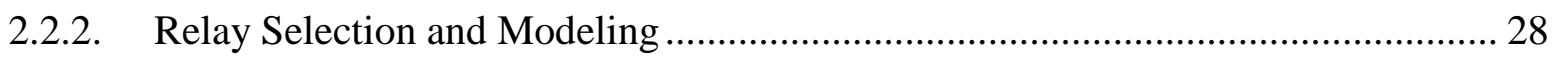

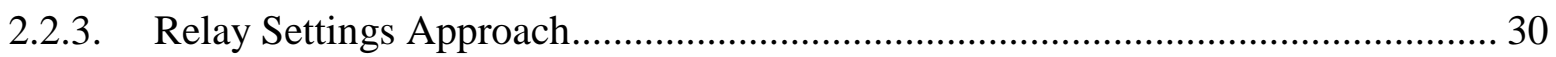

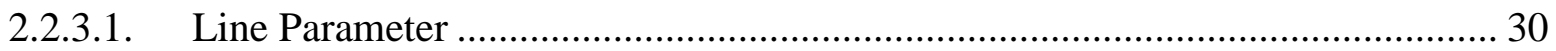

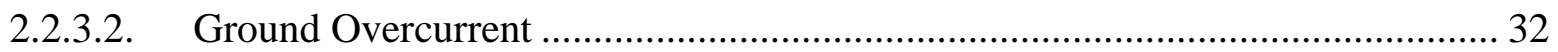

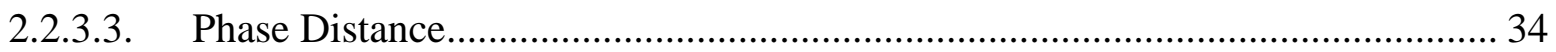

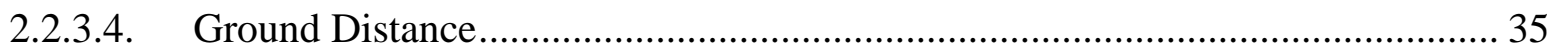

2.2.3.5. Permissive Over-reaching Transfer Trip (POTT) …………………………….... 36 


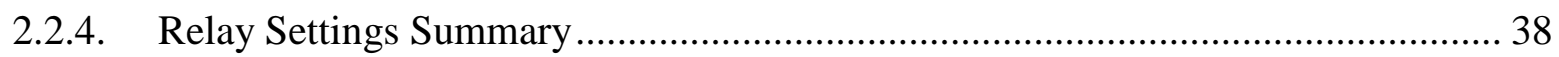

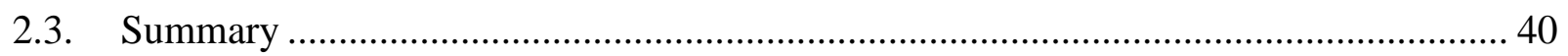

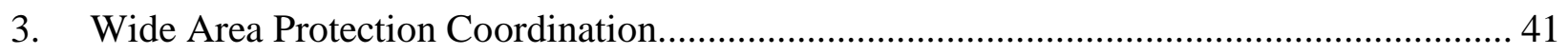

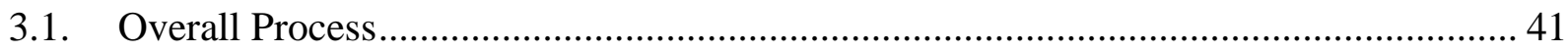

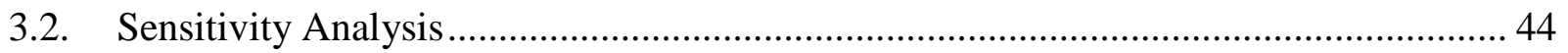

3.2.1. Instantaneous Overcurrent (IOC) .................................................................... 44

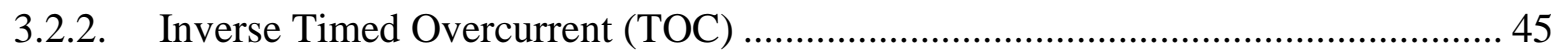

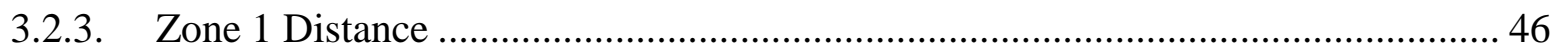

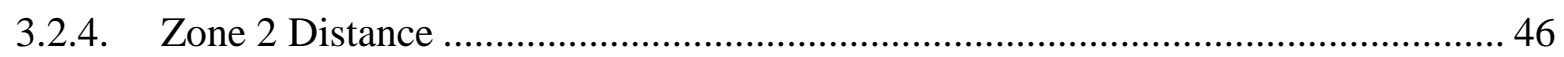

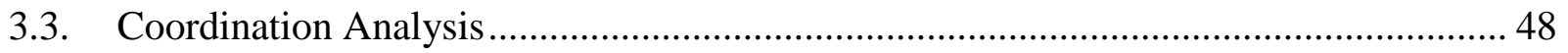

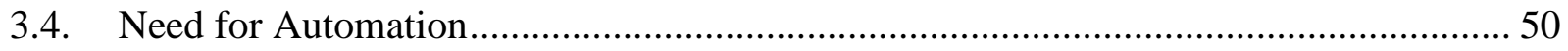

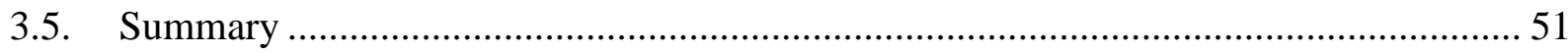

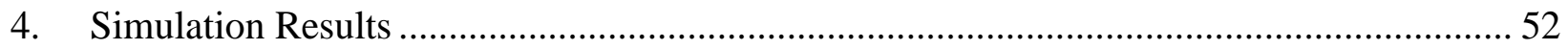

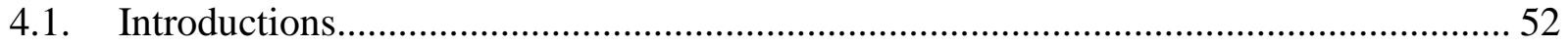

4.2. Test System Configurations ................................................................................ 52

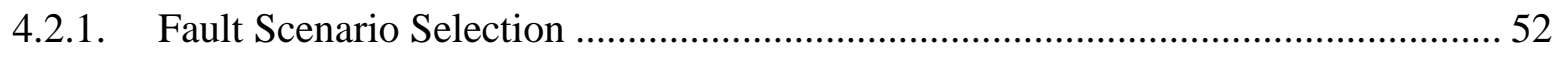

4.2.2. Criteria for Successful Operation......................................................................... 54

4.3. Study Cases and Simulation Results ......................................................................... 54

4.3.1. CASE 1: System normal \& N-1 Contingency Conditions ....................................... 55

4.3.1.1. Telecommunication assisted protection in Service ............................................... 55

4.3.1.2. Telecommunication assisted protection out of Service....................................... 64

4.3.1.3. Resistive Single Line to Ground Faults.......................................................... 76

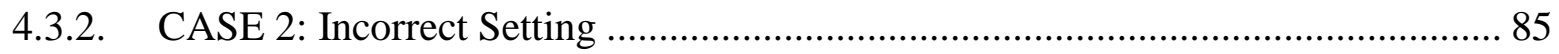

4.3.3. CASE 3: Significant change in Fault Current .......................................................... 92

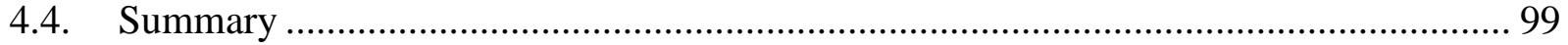

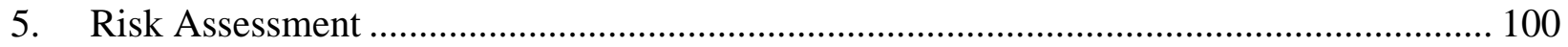

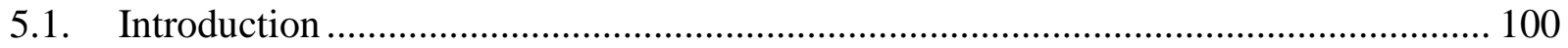

5.2. Transmission Line Sensitivity Risk Assessment.......................................................... 101

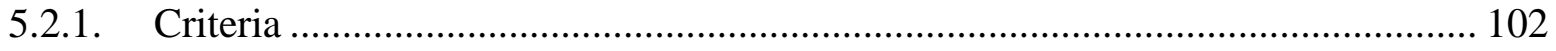

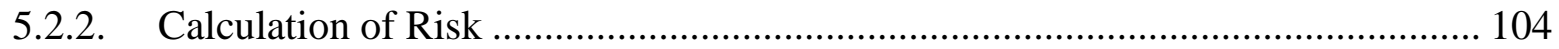

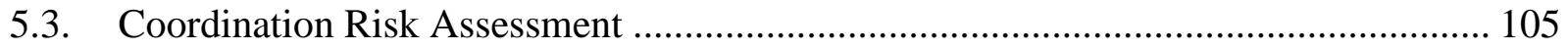

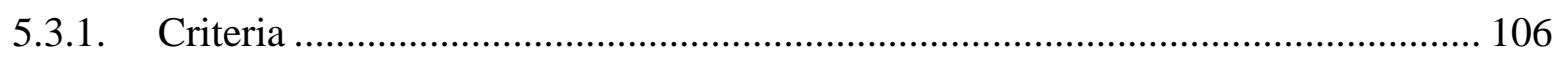

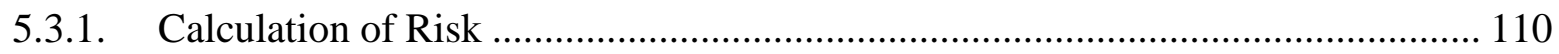

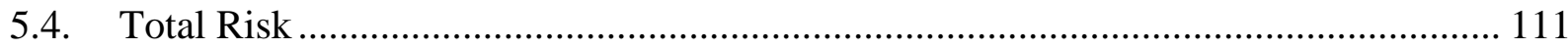




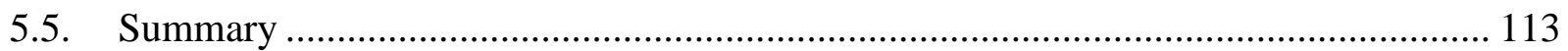

6. Conclusion and Future Work ................................................................................. 114

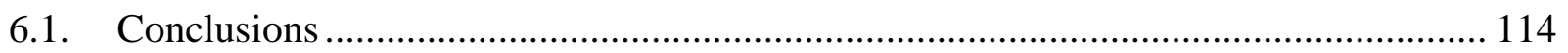

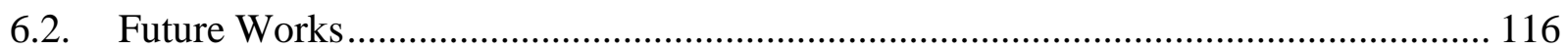

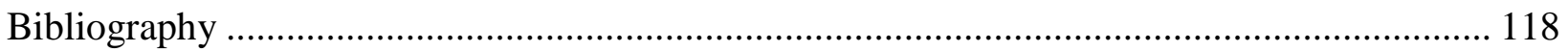




\section{List of Tables}

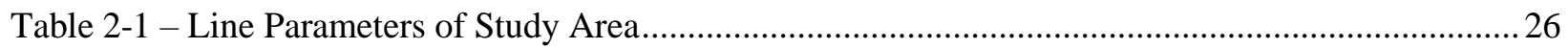

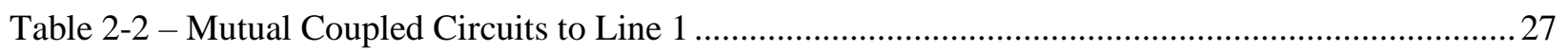

Table 2-3 - ANSI Codes for Protective Functions Utilized in Study [62] ............................................... 30

Table 2-4 - SEL-421 Relay Settings for Lines terminating from Winder Station...................................... 38

Table 2-5 - SEL-421 Relay Settings for Lines terminating from Center Station ..................................... 39

Table 4-1 - Line 1 Fault Clearing Time Results (Pilot In, SLG Bolted Faults) .......................................55

Table 4-2 - Line 1 Test Results: SLG Bolted Remote Close-in, Pilot In, Event 1 ...................................57

Table 4-3 - Line 1 Test Results: SLG Bolted Remote Close-in, Pilot In, Event 2 ..................................58

Table 4-4 - Line 1 Fault Clearing Time Results (Pilot In, TPH Bolted Faults) .......................................58

Table 4-5 - Line 1 Test Results: TPH Local Close-in, Pilot In, Event 1 .................................................. 60

Table 4-6 - Line 1 Test Results: TPH Local Close-in, Pilot In, Event 2 ................................................ 60

Table 4-7 - Line 6 Fault Clearing Time Results (Pilot Out, SLG Bolted Faults)....................................61

Table 4-8 - Line 6 SLG Test Results: Backup POTT Scheme of Line 1 (Winder \& Center) .................... 61

Table 4-9 - Line 6 Test Results: SLG 85\%, XFMR Bank A Outaged, Event 1 ........................................63

Table 4-10 - Line 6 Test Results: SLG 85\%, XFMR Bank A Outaged, Event 2 ..................................... 64

Table 4-11 - Line 1 Fault Clearing Time Results (Pilot Out, SLG Bolted Faults) ....................................65

Table 4-12 - Line 1 Test Results: SLG Bolted Remote Close-in, Pilot Out, Event 1 ..............................66

Table 4-13 - Line 1 Test Results: SLG Bolted Remote Close-in, Pilot Out, Event 2 ..............................67

Table 4-14 - Line 1 Fault Clearing Time Results (Pilot Out, TPH Bolted Faults) ....................................6 68

Table 4-15 - Line 1 Test Results: TPH Local Close-in, Pilot Out, Event 1 ............................................ 70

Table 4-16 - Line 1 Test Results: TPH Local Close-in, Pilot Out, Event 2 ........................................... 70

Table 4-17 - Line 6 Fault Clearing Time Results (Pilot Out, TPH Bolted Faults) .................................... 71

Table 4-18 - Line 6 TPH Test Results: Backup 21P2T Element of Line 1 at Winder ..............................71

Table 4-19 - Line 6 Test Results: TPH 85\%, XFMR Bank A Outaged, Event 1 ..................................... 73

Table 4-20 - Line 6 Test Results: TPH 85\%, XFMR Bank A Outaged, Event 2 ................................... 73

Table 4-21 - Line 6 Test Results: Sliding TPH Faults at 5\% Increments, XFMR Bank A Outaged ......... 75

Table 4-22 - Line 1 Fault Clearing Time Results (Pilot In, SLG-5 Ohms Faults) ................................... 76

Table 4-23 - Line 1 Fault Clearing Time Results (Pilot In, SLG-10 Ohms Faults) .................................76

Table 4-24 - Line 1 Fault Clearing Time Results (Pilot Out, SLG-5 Ohms Faults).................................77

Table 4-25 - Line 1 Fault Clearing Time Results (Pilot Out, SLG-10 Ohms Faults)................................77

Table 4-26 - Line 1 and 6 Overcurrent Protection - Resistive SLG Faults (10 Ohms) ............................78

Table 4-27 - Line 1 Overcurrent \& Distance Protection - Resistive SLG Faults (10 Ohms)....................81 
Table 4-28 - Line 6 Fault Clearing Time Results (Pilot Out, SLG-5 Ohms Faults)................................. 82

Table 4-29 - Line 6 Fault Clearing Time Results (Pilot Out, SLG-10 Ohms Faults)................................ 82

Table 4-30 - Line 6 SLG (5 Ohms) Test Results: Backup POTT Scheme of Line 1 (Winder \& Center).. 82

Table 4-31 - Line 6 SLG (10 Ohms) Test Results: Backup POTT Scheme of Line 1 (Winder \& Center) 83

Table 4-32 - Line 6 Test Results: SLG 10 Ohms 15\%, System Normal, Event 1................................... 84

Table 4-33 - Line 6 Test Results: SLG 10 Ohms 15\%, System Normal, Event 2................................. 85

Table 4-34 - Line 1 Fault Clearing Time Results (Pilot In, All Faults) - Incorrect Setting.....................87

Table 4-35 - Line 1 Fault Clearing Time Results (Pilot Out, All Faults) - Incorrect Setting ................... 88

Table 4-36 - Line 1 Fault Clearing Time Results (Pilot In, All Faults) - Incorrect Setting...................... 89

Table 4-37 - Line 1 TPH Test Results: All Backup Zone 2 Phase Distance near Winder Station............. 89

Table 4-38 - Line 1 Test Results: SLG 85\%, Line 6 Outaged, Event 1 .............................................91

Table 4-39 - Line 1 Fault Clearing Time Results (Pilot In, All Faults) - Gen Change.............................93

Table 4-40 - Line 1 Fault Clearing Time Results (Pilot Out, All Faults) - Gen Change ...........................94

Table 4-41 - Line 1 SLG Test Results: Instantaneous Ground Overcurrent at Bio Station ......................95

Table 4-42 - Line 1 Test Results: Backup Line 6 Ground 67GI_IOC Element ......................................98

Table 4-43 - Line 1 Test Results: Backup Line 6 Ground 67GT_TOC Element...................................... 98

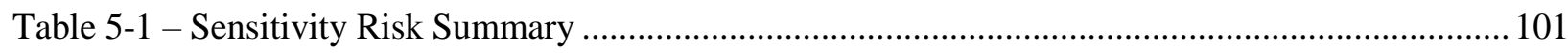

Table 5-2 - Sensitivity Risk Weight - Element Multiplier.................................................................. 102

Table 5-3 - Sensitivity Risk Weight - Condition Multiplier.............................................................. 103

Table 5-4 - Sensitivity Risk Weight - Element Reach Ranges ........................................................... 103

Table 5-5 - Sensitivity Risk Weight - Element Reach Multiplier......................................................... 104

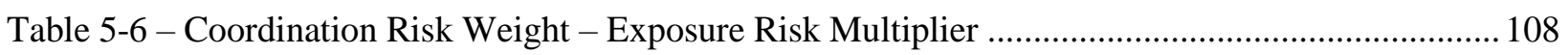

Table 5-7 - Coordination Risk Weight - Mis-Coordination Time Risk Multiplier................................. 108

Table 5-8 - Coordination Risk Weight - Fault Type Risk Multiplier .................................................... 109

Table 5-9 - Coordination Risk Weight - Fault Type Risk Multiplier ..................................................... 109

Table 5-10 - Total Risk Categorization Limits .................................................................................. 112 


\section{List of Figures}

Figure 1-1 - Primary System Model Utilized for Wide Area Protection Coordination ........................... 10

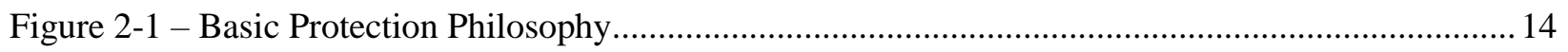

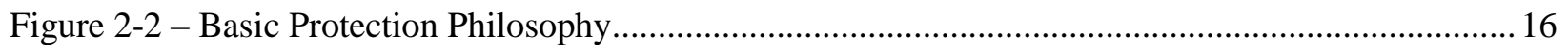

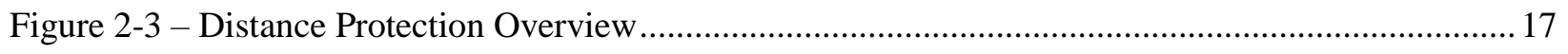

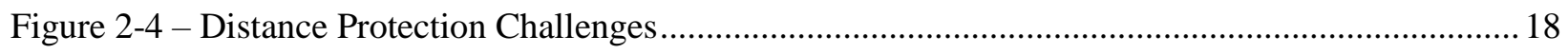

Figure 2-5 - Mho versus Quad Distance Characteristics with Load Blinder........................................... 19

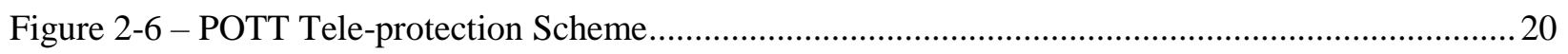

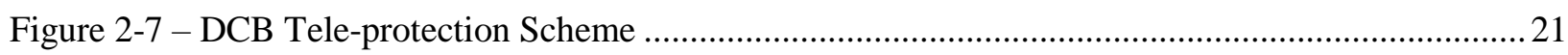

Figure 2-8 - Primary Network Selected for Coordination Study ......................................................22

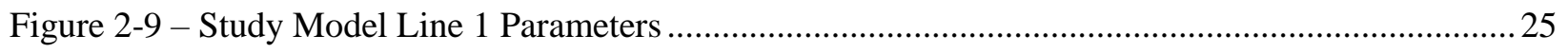

Figure 2-10 - Sequence Networks \& Impact of Mutual Coupling for Single Line to Ground Fault [60] ..27

Figure 2-11 - Various timers in the digital relay with internal supervision .............................................29

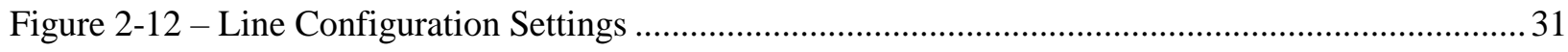

Figure 2-13 - Residual Ground Instantaneous Overcurrent Setting ...................................................... 32

Figure 2-14 - Residual Ground Inverse Timed Overcurrent Setting .....................................................33

Figure 2-15 - Mho Phase Distance Element Reach Settings .................................................................... 34

Figure 2-16 - Mho Phase Distance Element Reach Settings ................................................................... 35

Figure 2-17 - Zero-Sequence Compensation Factor Settings.............................................................. 36

Figure 2-18 - Permissive Over-reach Transfer Trip ............................................................................... 37

Figure 3-1. Wide Area Protection Coordination Solution Process Diagram ........................................... 41

Figure 3-2. IOC Sensitivity Test Description ……............................................................................ 45

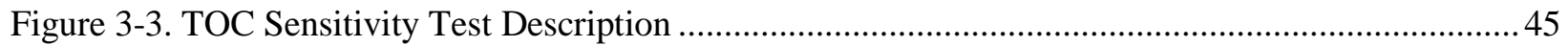

Figure 3-4 - Zone 1 Distance Sensitivity Test Description ....................................................................46

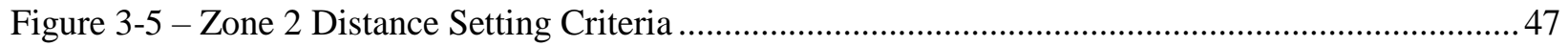

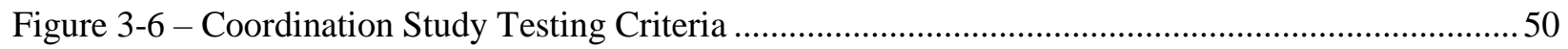

Figure 4-1 - Line 1 Test Condition: SLG Bolted Remote Close-in, Pilot In............................................56

Figure 4-2 - Line 1 Test Condition: TPH Local Close-in, Pilot In...........................................................59

Figure 4-3 - Line 6 Test Condition: SLG 85\%, XFMR Bank A Outaged................................................ 62

Figure 4-4 - Line 1 Test Condition: SLG Bolted Remote Close-in, Pilot Out .........................................6 65

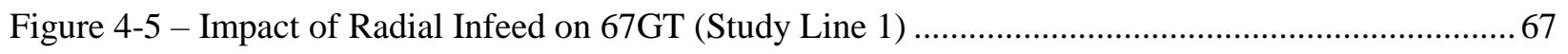

Figure 4-6 - Line 1 Test Condition: TPH Local Close-in, Pilot In.......................................................... 69

Figure 4-7 - Line 6 Test Condition: TPH 85\%, XFMR Bank A Outaged............................................... 72 
Figure 4-8 - Line 2 Test Result: TPH 85\%, XFMR Bank A Outaged - Primary/Backup Distance .......... 74

Figure 4-9 - Line 1 and 6 Overcurrent Protection - Resistive SLG Faults (10 Ohms) ............................ 79

Figure 4-10 - Line 1 Distance Protection - Resistive SLG Faults (10 Ohms) ......................................... 80

Figure 4-11 - Line 6 Test Condition: SLG 10 Ohms 15\%, System Normal ............................................ 84

Figure 4-12 - Incorrect Setting Simulation Scenario - Zone 1 Distance Timers ..................................... 86

Figure 4-13 - Primary versus Backup Distance Protection - Winder Substation ...................................90

Figure 4-14 - Increased Generation Simulation Scenario - Hartwell Dam GSUs .................................92

Figure 4-15 - Line 1 Test Condition: SLG 0\%, XFMR Bank A Outaged..............................................96

Figure 4-16 - Backup IOC \& TOC Protection - Bio Substation..............................................................97

Figure 5-1 - Example of High Risk Coordination Violation.............................................................. 106

Figure 5-2 - Example of Low Risk Coordination Violation................................................................. 106

Figure 5-3 - Coordination Risk Weight - CTI Risk Multiplier .............................................................. 107

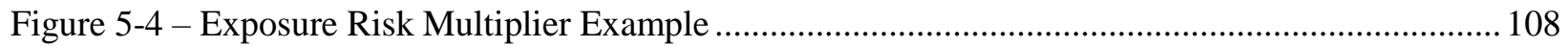

Figure 5-5 - Coordination Relative Risk Summary - Low Risk Mis-operation ..................................... 110

Figure 5-6 - Coordination Relative Risk Summary - High Risk CTI Violation .................................... 111

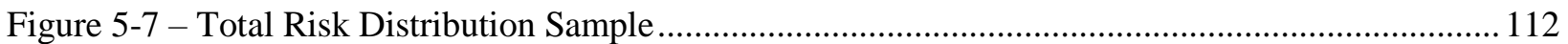




\section{Nomenclature}

$\mathrm{AC}$ : alternating current

CAPE: Computer Aided Protection Engineering

CT: current transformer

CTI: coordination time interval

DCB: directional comparison blocking

DER: distributed energy resources

DLG: double-line-to-ground fault

GSU: Generator Step Up

LL: line-to-line fault

LTE: Long Term Emergency Loading

NERC: North American Electric Reliability Council

P\&C: protection and control

PRC: protection and control

POTT: permissive over-reaching transfer trip

SEL: Schweitzer Engineering Laboratories

SIR: source impedance ratio

SLG: single-line-to-ground fault

STE: Short Term Emergency Loading

TPH: three-phase fault

TT: transfer trip

VT: voltage transformer 


\section{List of Symbols}

$310_{\text {Relay: }}$ Three times zero sequence current read by protective relay

CTR: CT ratio

$I_{L T E}$ : Long Term Emergency Loading Current

$I_{\text {Relay: }}$ Current read by protective relay

$I_{S T E}$ : Short Term Emergency Loading Current

$k_{0}$ : Zero sequence compensation factor for protective relay

$V_{L-L}$ : Line to Line Voltage

$V_{\text {line base }}$ : Base Line to Neutral Voltage

$V_{\text {Relay: }}$ Voltage read by protective relay

VTR: VT ratio

$X_{0}$ : Zero Sequence Components

$X_{1}$ : Positive Sequence Components

$X_{2}$ : Negative Sequence Components

$Z_{\text {Element }}$ Impedance measured by protective relay distance element

$Z_{\text {Source_SLG: }}$ Source Impedance based on Single-Line-to-Ground Fault

$Z_{\text {Source_TPH: }}$ Source Impedance based on Three-Phase Fault 


\section{Introduction}

\subsection{Background and Motivation}

The modern Power System is a complex and dynamic entity. Electricity is normally generated at considerable distance from where it is used, so it needs to be "transported" to the user. The backbone of this transportation system is an interconnected network of transmission lines. As demand increases, the transmission lines are called upon to transfer more electrical energy, and since the lines have a finite carrying capacity and construction of new transmission lines is an expensive and difficult undertaking, there is a constant effort to maximize the utilization of what is available [1]. As the system is loaded close to, or beyond its operating limits, it becomes vulnerable to collapse, and the highly interconnected nature of the network can result in collapses that impact entire regions such as the major widespread power outage of the northeast United States in 2003, leaving more than 50 million people without power and resulted in an estimated economic cost of over $\$ 6$ billion [2].

Power system protection is a well-established field of study that deals with the protection of the system through the isolation of faulted transmission equipment from the rest of the system. Protection systems are an integral part of the Power System and are designed to monitor conditions, detect abnormalities and react in an autonomous fashion to isolate problems in fractions of a second. The design of these protection systems is a challenging undertaking because reacting at the wrong time or in the wrong way can exacerbate the problem rather than prevent it.

Utility protection engineers are responsible for calculating protection and control device parameters by applying industry and regulatory accepted standards. They are often struck by a reliability design dilemma of dependability versus security of their protection scheme. The system can be designed as dependable with a tendency to operate for all abnormalities when they are expected. However, this approach can result in a higher sensitivity of protection relaying which can ultimately mis-operate for out-of-zone faults, resulting in loss of revenue due to the outage of unnecessary equipment [3]. 
Furthermore, a secure design will have a tendency not to operate for all abnormalities when they are not expected. This approach will result in a lower sensitivity of protection relaying which can ultimately fail to operate for in-zone faults [4]. The impact of inadequate protection system can be highlighted in an incident in Southern California on February 26, 2000. A three-phase fault occurred on a $220 \mathrm{kV}$ bus which resulted in about 300MW of firm demand interruption representing over 110,000 customers. The $220 \mathrm{kV}$ bus differential relay failed to operate for its inzone fault, subsequently all backup system protection operated in order to isolate a local short circuit by removing multiple generation facilities [5].

By applying a comprehensive protection philosophy guide across the entire electrical grid and optimizing protection relaying parameters, one can increase the reliability of the power system and reduce risk of wide area disturbances.

\subsection{Statement of Problem and Thesis Objectives}

The electric power transmission network of today is undergoing significant changes in operational requirements, connected distributed energy resources technologies, and regulatory requirements. The increasing demand for electricity and greater environmental awareness has resulted in the proliferation of new technologies such as distributed generation, renewable energy sources, and energy storage [6]. In conjunction with an aging infrastructure, these changes to the electrical grid have presented new challenges to utilities in their fundamental mission of providing electrical power. As with the rest of the electrical transmission network, the protection system must also meet these new challenges to continue enabling the safe and reliable operation of the electrical grid.

In particular, the protection system must meet its reliability requirements of dependability and security in the face of changing operational and regulatory environments [7]. To continue meeting these requirements, increased investigation of protection system performance is needed to ensure proper coordination of protective relay operation. However, the complex and integrated protection and control systems of today require more sophisticated modeling and study tools to simulate and analyze the dynamic behavior of interconnected transmission and distribution systems along with the interactions that occur among numerous sets of intelligent electronic devices simultaneously. 
The traditional approach of coordination among relay pairs on adjacent transmission or distribution lines may not ensure the high level of system reliability and performance required by compliance regulations, such as NERC. Although protection technology designed for AC transmission power systems is mature, achieving coordination between each device is still a challenge.

This thesis presents a holistic approach to conducting wide-area protection coordination studies through the use of a practical automation-assisted methodology.

\subsection{Literature Review Pertinent to Thesis Objectives}

This section presents a review of the available literature regarding protection coordination. First, the importance of a properly coordinated protection system is introduced, along with actual and potential consequences if relay coordination is not adequately studied. Next, the challenges associated studying relay coordination are reviewed, particularly in a changing power systems industry. Finally, this section explores the existing methodologies and approaches to studying and achieving wide-area protection coordination, and notes their potential issues.

\subsubsection{The Need for Protection Coordination}

This subsection provides background on protection system requirements and addresses the need for wide-area protection coordination in the power systems industry.

- Protection reliability: Protection systems are designed to achieve reliability in two aspects: dependability and security. Dependability refers to the concept that the protection system will operate correctly, and security refers to the concept that the protection system will not operate incorrectly. In practical terms, relays should operate for faults within their primary zone of protection, but should not operate for faults outside their primary zone of protection or for un-faulted operating conditions [7]. Traditionally, protection systems have prioritized the aspect of dependability over security, to ensure that faults on the electrical transmission system are cleared. However, sacrificing security may result in undesired or unacceptable relay operation, which can potentially lead to severe consequences such as cost penalties or even large-scale blackouts [8]. 
- Sensitivity and contingencies: Protection systems are designed so that relays operate appropriately for their local zones of protection, and also provide backup protection for adjacent zones. The setting of these protective relays needs to be considered carefully in terms of network electrical characteristics, known as sensitivity, and in relation to other protective devices on the system, known as coordination. In addition, system operating conditions need to be taken into account, including normal operating configuration, as well as contingency configurations when portions of the systems are offline for maintenance or other issues. In the US-Canadian blackout of 2003, a protective relay improperly operating on a Zone 3 distance function started a cascade of disconnections on the transmission system that eventually led to voltage collapse and widespread blackout throughout eastern Canada and the United States [9]. In an analysis of blackouts worldwide, most incidents have involved protection devices with wrong or critical settings [10].

- Extended periods without review: Most of the electrical transmission lines in the U.S. are more than fifty years old [11]. Typically, protection coordination is reviewed at the time a relay's settings are developed. However, prior to implementation of the NERC PRC-027 standard, utilities had no regulatory requirement to review coordination of their internal transmission network on a periodic basis. Although protective relays undergo routine maintenance and newer microprocessor-based devices have seen widespread deployment, many older electromechanical relays still exist. During an analysis of substation protection in Brazil, it was found that most critical substations had obsolete protective systems that needed replacement [12]. These devices may not have been subject to a settings review since they were installed, increasing the likelihood of coordination issues with neighboring devices.

- Human errors: One of the most significant causes of relay mis-operations in North America is due to human error, particularly in the design and setting of relays and protective systems. These errors can range from incorrect application of protection functionality to data entry issues when developing relay settings. In successive annual reviews of relay misoperations from 2011 through to 2015, and involving nearly 2000 relay mis-operations per year, the North American Electric Reliability Corporation (NERC) found that the single largest categorization of relay mis-operation year after year was "incorrect 
settings/logic/design errors". This category included both settings and design of the protection system, and the most common relay settings issue was improper coordination timing. Suggested methods of mitigating these issues revolved around improving the human aspect, including more peer review and more extensive fault studies [24-26]. Similar reports by individual regional reliability entities showed similar results [27-28]. Wide-area protection coordination review could potentially catch many of these human errors.

- Regulatory requirements: Utilities today are facing a changing regulatory environment following the large Canada-U.S. blackout in 2003 [13]. The NERC PRC-023 standard requires that protective devices must not operate for emergency loading conditions, necessitating a review of all applicable relay settings. The NERC PRC-027 standard is intended to "maintain the coordination of protection systems... such that the protection systems operate in the intended sequence during faults." This is achieved through the requirement that utilities must perform periodic studies (every six years) to determine coordination of their protective devices for those cases where system fault duties have changed significantly [14].

- Increased penetration of distributed energy resources: To meet the needs of consumers in the future, the penetration of distributed energy resources has been and is projected to continue increasing significantly. In 2012, it was estimated that distributed generation units aggregated almost one-sixth of the capacity of the centralized power plants in the United States [15-16]. The state of California recently passed Bill SB-100, requiring that $100 \%$ of the state's electricity would be generated by renewable sources [17]. Although distributed and renewable generation feature bring significant advantages, they also impose some additional challenges to distribution systems, and even transmission systems in cases of large-scale deployments [18]. The issues of changing power flow and decreased shortcircuit fault currents can have significant impact on protection system performance and reliability [19]. Traditional schemes not directly designed for such scenarios require sensitivity and coordination reviews to minimize the risk of causing wide-area disturbances under stressed conditions. 
Considering the changing operating and regulatory environment under which electric grid protection systems must continue to operate reliably, one can conclude that periodic relay coordination reviews would be highly beneficial to ensuring grid reliability.

\subsubsection{Challenges Associated with Wide-Area Protection Coordination}

Although utilities perform coordination studies when relays are set, a number of challenges preclude the frequent undertaking of wide-area coordination studies that involve significant portions of large transmission networks. This subsection discusses some of these challenges.

- Resource burden: The process of conducting the large number of coordination studies needed to cover large portions of a transmission network imposes significant burden on utility engineering resources. These time and resource intensive activities require protection engineers to perform fault simulations and determine operation of not only the relay under study, but also for all appropriate backup relays that may also operate for a fault scenario. During the development of the PRC-027 standard, this was deemed to be sufficiently burdensome for utilities that the requirement for an initial coordination study upon the standard coming into effect was removed [22].

- Microprocessor relays: In reviews of relay mis-operations by both NERC and individual regional reliability entities, the single biggest cause of relay mis-operations was due to “incorrect setting/logic/design errors." Comments were included regarding microprocessor-based relay devices and the complexity in their functionality and settings requirements. It was suggested that greater number of mis-operations involving microprocessor-based devices may have suggested a less developed understanding of the functionalities and settings of the microprocessor devices [24-28]. These devices contain hundreds of individual tap settings, with software, logic, and data entry formats differing from manufacturer to manufacturer. In [29], the issue of newer microprocessor-based relays was brought up, stating that engineers may be unfamiliar with the devices, especially if utility protection designs were outdated. Managing multiple settings groups in these relays and the need to enter data for hundreds of taps were also noted as potential issues.

- Insufficient manpower: The electric power industry is facing the challenges associated with an aging workforce. It is estimated that a large percentage of the industry workforce may 
become eligible for retirement or may leave the industry by 2021. The current workforce holds an enormous amount of technical and institutional knowledge in supporting the power system, which needs to be transferred to replacements accordingly. However, studies have shown that the number of engineering graduates and skilled workers entering the workforce may not be sufficient to make up for the loss of these retirees. Universities, as the primary producer of power engineering graduates, may be facing their own challenges, with declines in the number of power engineering programs and institutions also dealing with an aging staff soon eligible for retirement. This inability to find replacements could put the ability to maintain reliable operation of the electric grid at risk, as many positions within the power industry require specialized skills and years of training to effectively perform. The manpower issue is exacerbated by the increasing penetration of smart grid and renewable power initiatives, which places further demands on utility resources to support an evolving power system. Finally, a forecasted shift in the utility workforce to increased outsourcing of work to consultants may decrease their own internal resources [30-33].

The challenges associated with the execution of wide-area protection coordination reviews have revolved around the time and effort required - engineer unfamiliarity with newer relay devices and insufficient manpower are both facets of the issue that utilities do not have sufficient trained resources to conduct these studies in addition to their other responsibilities. The inclusion of the automation-based processes proposed in this thesis can potentially mitigate the time and effort required to complete these studies.

\subsubsection{Existing Methods for Studying Wide-Area Protection Coordination}

This subsection presents a summary of literature covering existing techniques and methodologies for protection coordination.

- Setting relays for protection coordination: Existing work has considered improved methodologies to address the issues of protection coordination. In [35], one methodology for achieving protection coordination for overcurrent relays is presented. The process considered protection coordination as an optimization problem, and presented the calculations used to determine appropriate relay settings. In [37], algorithms to achieve 
protection coordination for overcurrent and distance relays are discussed. It should be noted that the cases presented above, and in the majority of literature reviewed [36], the solutions to protection coordination focus on the task of setting the relays to achieve coordination in the first place. Little emphasis or consideration is provided to the capability of evaluating existing protection systems and relay settings for appropriate protection coordination.

- Software assistance: As discussed in the subsection describing challenges associated with wide-area protection coordination review, software-based automation assistance can potentially mitigate the time and effort required for these studies. Existing work has considered the usage of computer-based tools and solutions to assist with the issue of protection coordination. In [38], the inclusion and role of a database management system is discussed, particularly how it can interact with other computer applications, such as short-circuit or protection modules, to determine relay settings that achieve protection coordination. In [39], an application tool is presented to assist engineers in determining the coordination of overcurrent and distance relays. This tool includes a graphical user interface to represent the system configuration and parameters, a database of relay characteristics, and integrated short-circuit functionality. However, execution of a coordination study is still largely a manual effort, with engineers needing to manually specify fault locations and interpret results.

- Approach to wide-area protection coordination: An approach to wide-area coordination study is presented in [40]. This approach includes considerations for system boundaries, operating conditions, data management, coordination criteria, study and fault parameters, and definition of strategy for maintain selectivity between primary and backup elements. Suggested automation assistance takes the form of Excel-based calculation spreadsheets, as well as the utilization of tools built into the selected short-circuit software platform (if they exist), to determine appropriate relay coordination. It should be noted that the proposed calculation spreadsheets are intended to determine relay performance using shortcircuit data entered by the user. Although this may work effectively for smaller cases, the need to manually enter values into a spreadsheet is not ideal for analysis of a large number of faults. 
- Automated coordination study: Approaches for protection coordination study utilizing significant automation-assistance are presented in [42-44]. These methodologies utilize an application integration approach, where a front-end application containing protection analysis algorithms integrates with a short-circuit application and database management system to obtain fault data and protection data respectively. The presented application the capability to automatically apply large numbers of faults on multiple lines, and can determine resulting relay operations for each of the faults. Different system conditions can be specified, as well as fault location step sizes and impedances. The resulting relay performance is visually presented on a three-variable plot showing the line (y-axis), the fault location in terms of percent distance down the line under study (x-axis), and the relay operating time for that fault (color code). It should be noted that only actual relay operation events are determined, and coordination time interval (CTI) violations of marginal cases are ignored.

- Automated coordination study in a single application: In contrast to the methodologies in the previous point, a single-application approach to automated wide-area protection coordination is presented in [45]. This approach utilities macros in a single database-based application that also features built-in short-circuit capability, as well as the system and protection relay models. The coordination macros have the capability to apply multiple faults along any line, with different fault types and impedances, as well as under different system conditions (normal operation and contingencies). Moreover, this methodology distinguishes between primary protection and backup protection levels, enabling the evaluation of backup relay performance with respect to required coordination time intervals. The results are presented in a summary table stating relay coordination, with details for each fault event provided in text files. However, a large amount of data is generated with these simulations, with the user left to interpret the results.

From the reviewed literature, the issue of studying wide-area protection coordination in efficient and effective manners has been considered. However, each of the approaches and methodologies presented in this section have limitations or drawbacks, which can range from requiring significant manual effort to outputting a confusing amount of data to review. This thesis presents an approach to wide-area protection coordination that emphasizes study comprehensiveness, including 
evaluation of coordination time intervals and assessment of severity of issues, through extensive use of automation.

\subsection{Methodology}

In order to achieve the objectives of this thesis, first a transmission line system is proposed. The system represents a typical looped transmission topology representing an $115 \mathrm{kV}$ and $230 \mathrm{kV}$ network provided as a Computer Aided Protection Engineering (CAPE) model. CAPE software is a practical method for transmission utilities to assist in modeling their electrical transmission network's protection systems. It is a steady state simulation platform specializing on powerful protection engineering engine [46]. Figure 1-1 represents the transmission model to be analyzed.

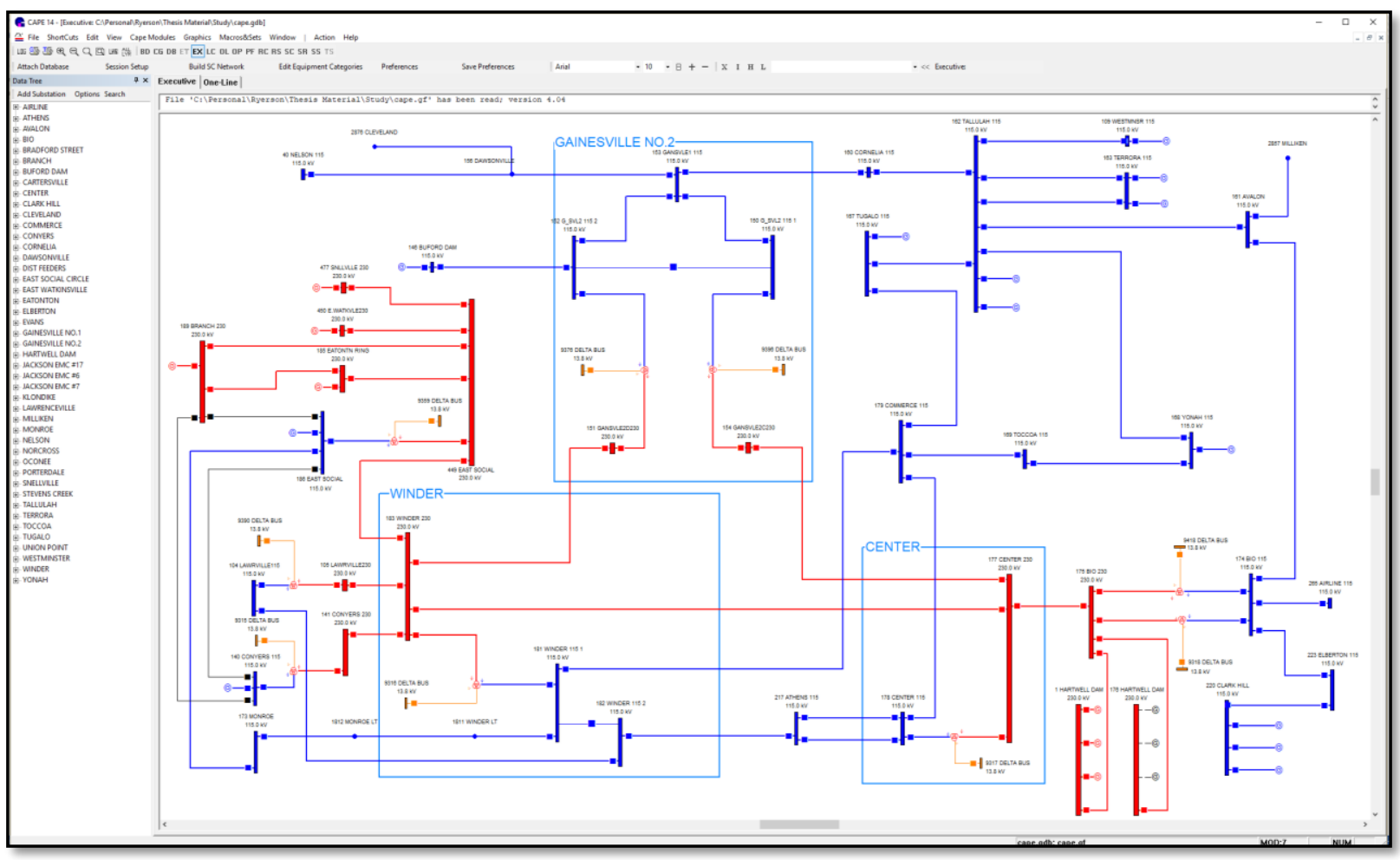

Figure 1-1 - Primary System Model Utilized for Wide Area Protection Coordination

Next, a typical transmission protective relay manufactured by Schweitzer Engineering Laboratories (SEL), a popular vendor in North America is selected. The protective function parameters are calculated for the simulation area and prepared using AcSELerator QuickSet 
software which interfaces with the physical relays [47]. These calculated setting files are then imported into the CAPE primary model for protection coordination studies.

Last, relay coordination across the study area is required. Protection performance will be evaluated under numerous fault scenarios including various fault location, fault type, fault resistance, and relay failure conditions under system normal and contingencies.

\subsection{Thesis Contribution and Scope}

As outlined in this chapter of the thesis, maintaining protection coordination for a transmission network is a challenge. While a number of current approaches proposed in the literature review, there exists a lack of an established practical wide area protection coordination system. Therefore, this thesis focuses on addressing the above-mentioned challenges and requirements by proposing a new process which can assist in achieving a reliable protection coordination.

The contribution of this thesis will highlight the need for such holistic assessment of protection coordination even if a strict set of best practices and protection philosophy is utilized to calculate relay settings.

A process focusing on a series of automation assisted techniques will be explored to relieve the protection engineer from the tedium of running individual fault conditions and instead focus their attention on mitigating problems found. This allows actionable recommendations and optimized protection settings to be issued for correction as a direct cause of performing such holistic wide area protection coordination studies.

\subsection{Thesis Outline}

This thesis is organized as follows:

Chapter 2 focuses on industry accepted transmission line protection philosophy. This deep understanding of best practices is required in order to properly define the holistic wide area protection coordination solution. Furthermore, the second chapter presents the detailed primary and protection CAPE model prepared for simulation. 
Chapter 3 describes the overall holistic wide area protection coordination method. It will list the requirements for achieving optimal settings. Four major stages - model, study, analyze, and report of the overall solution will be listed. The focus of the thesis will be the study stage and a comprehensive sensitivity and coordination solution will be described in depth. Last, the need for automation of the overall solution will be discussed.

Chapter 4 presents the results obtained from the simulation of the proposed process described in chapter 3. The CAPE model described in chapter 2 will be utilized. The case studies selected are designed to subject the model to significant stressed conditions. The case studies are divided into three groups. First, correct settings recently calculated for the model are stressed under system normal and N-1 contingency conditions with/without POTT scheme activated for bolted and resistive faults. Next, a human error scenario for one of the relay elements with incorrect settings is reviewed using the proposed solution. Lastly, the same protection system utilized in case 1 is reviewed under a significant change in the primary fault current simulating the future changes in the Transmission topology.

Chapter 5 discusses a proposed methodology behind quantification of relative risk scores for transmission sensitivity studies, transmission coordination studies, and the philosophy behind the management of the risk data and the classification into risk categories.

Chapter 6 offers a conclusion to the thesis. It will provide lessons learned and provides suggestions for future improvements to the research for the major stages of model, analyze, and report not studied in depth. Last it will highlight the potential for the overall proposed solution for transforming from an off-line steady state process into real-time transient based applications which can support the future of protection and control industry. 


\section{Transmission System Protection}

\subsection{Transmission Protection Philosophy}

There are various technical techniques debated by the industry; various protective solutions offered by competing vendors; and various regional approaches based on lessons learned in the field of transmission protection. However, they all are governed by the following two fundamental rules:

$\underline{\text { Rule 1: Detect \& clear a system fault as quickly as possible }}$

Any system disturbance such as permanent tree falling on a conducting tower to create a permanent short circuit or a temporary lightning strike on a substation must be detected and cleared in a few cycles. These result in the need of fast processing protective devices [48].

Rule 2: Clear the system fault with minimal impact to the transmission network.

A transmission network is broken down into many transmission lines terminating between two or more high voltage substations. Therefore, many of these protective devices are installed at every transmission line termination. These devices should be designed as such to remove only the faulted transmission equipment and not react to a fault on adjacent transmission lines to further outage healthy equipment: called protection mis-operation [48].

Figure 2-1 represents the struggle between the two stated rules. A protection scheme at each end of a transmission line terminal is required to protect $100 \%$ of its respective line as soon as possible as stated by rule 1 (faults F1 and F2 for line 1). However, the challenge lies with the same protective scheme at breaker 1 location not operating faster than line 2 protection for faults (F3) on the adjacent transmission line (i.e.101\%) as stated by rule 2 . The challenge with most of the popular protective functionalities is the uncertainty with exact calculation of the fault location. 
This results in an uncertain zone, typically the last $20 \%$ of a transmission line where the device may not be able to differentiate the end of its respective zone of protection and the beginning of the next under other contingency conditions [3]. This uncertainty is the cause of many factors such as current/voltage transformer accuracy, representation of the power system model used to calculate protection settings, accuracy and errors in the protective device itself, and many more.

In order to ensure success of rule 2, common protection philosophy requires an additional timed delay functions for the relaying at breaker 1 covering fault $\mathrm{F} 2$ to coordinate with relaying at breaker 3 and differentiate between faults F2 and F3.

Communication assisted protective elements between breakers 1 and 2 can allow a significantly faster clearing time for fault F2 at breaker 1. However, in the absence of such tele-protection systems due to cost or reliability, it is expected to set all timed delay parameters between elements at breakers 1 and 3 with adequate time margin.

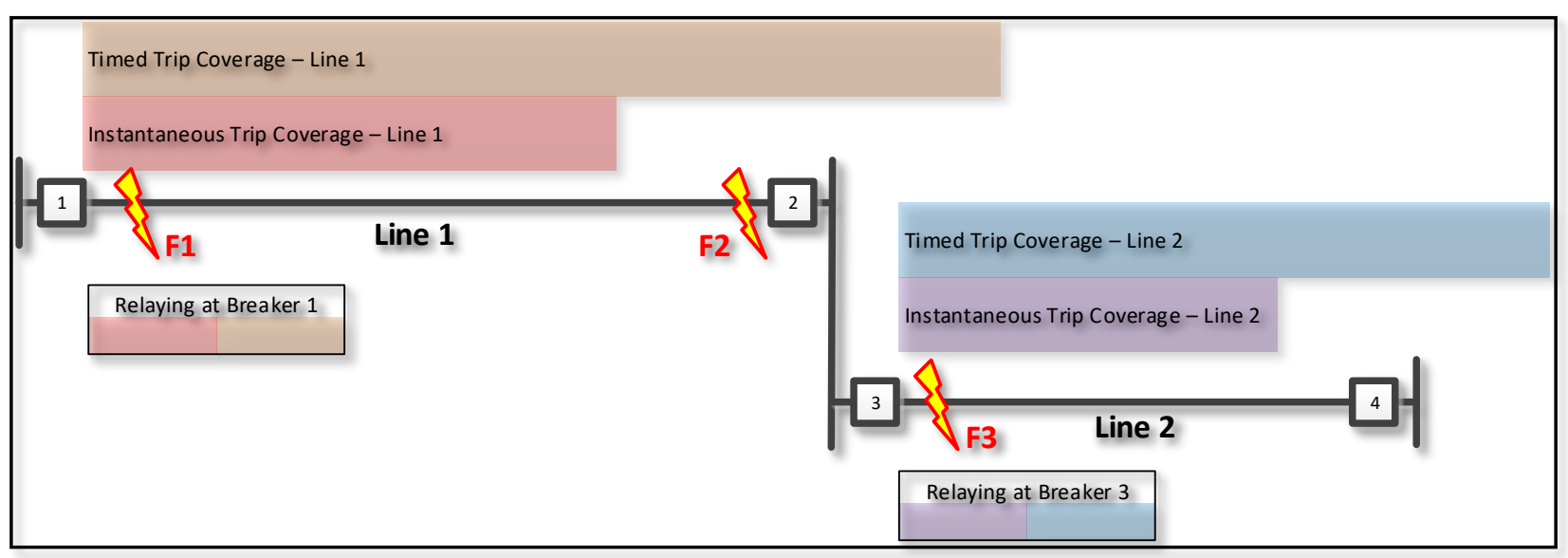

Figure 2-1 - Basic Protection Philosophy

To summarize, the ideal protection scenario for breakers 1 and 3 are as follows:

- Fault F1 = Cleared by relaying at breaker 1 instantaneously

- Fault F2 = Cleared by relaying at breaker 1 with time delay (preference would be to clear instantaneously but not possible without additional communication equipment)

- Fault F3 = Cleared by relaying at breaker 3 instantaneously, cleared by relaying at breaker 1 with a time delay (if Relaying 2 fails) 


\subsubsection{Overcurrent Protection}

Overcurrent protection is based on the protective relay calculating current flow of the transmission line by monitoring the power system current. This requires the protective device to have an accurate measurement of the transmission line side current with the aid of current transformers. It is the most common type of protection in the power system industry due to its low cost and ease of use [4]. The phase overcurrent protection is quite sensitive to load and may mis-operate during heavy load conditions. Ground overcurrent protection, however, is still a viable option especially when it comes to detect a high resistive single line to ground fault [49].

The protection engineer by knowing the transmission system topology can perform short circuit fault analysis at the end of each transmission line. This information can be used to define two categories of overcurrent protection. An under-reaching instantaneous overcurrent element designed to isolate in-zone faults right away (primary function) and an over-reaching inverse timed overcurrent element designed to isolate out-of-zone faults with a time delay (backup function).

\section{$\underline{\text { Instantaneous Overcurrent - IOC }}$}

An instantaneous overcurrent element is typically designed in such a way that it should never overreach its primary transmission line. An in-depth fault analysis can find the maximum fault current observed at the end of the transmission line by the IOC element. The pick-up of such element can then be set with an additional safety margin. This element acts as an instantaneous trip coverage.

$\underline{\text { Timed Overcurrent - TOC }}$

An inverse timed overcurrent element is typically designed for a delayed trip coverage which can over-reach to adjacent transmission lines. The time operation of such element is critical as it must coordinate with all primary and backup protective elements. The time of operation can be adjusted based on three factors of element pick-up, time dial, and inverse characteristic [50].

Although, each protective device can define its own inverse time characteristic, majority of the popular vendors provide multiple curve characteristics options defined by IEEE and IEC. The most common curve types are defined as [51]:

- Moderately Inverse

- Standard Inverse 
- Inverse

- Very Inverse

- Extremely Inverse

The inverse characteristics are defined in such a way that with the time delay of the TOC element increases with decreasing fault current. The fault current reading at the current transformer location decreases when the fault is moved away from the terminal. Therefore, the further the fault from the TOC element, the slower it will operate. The relationship of primary and backup IOC/TOC functions are represented in Figure 2-2. The primary protection has to be set in such a way that there will be adequate time of operation margin. As a general rule, the TOC curves should never cross to ensure coordination margin is met [50].

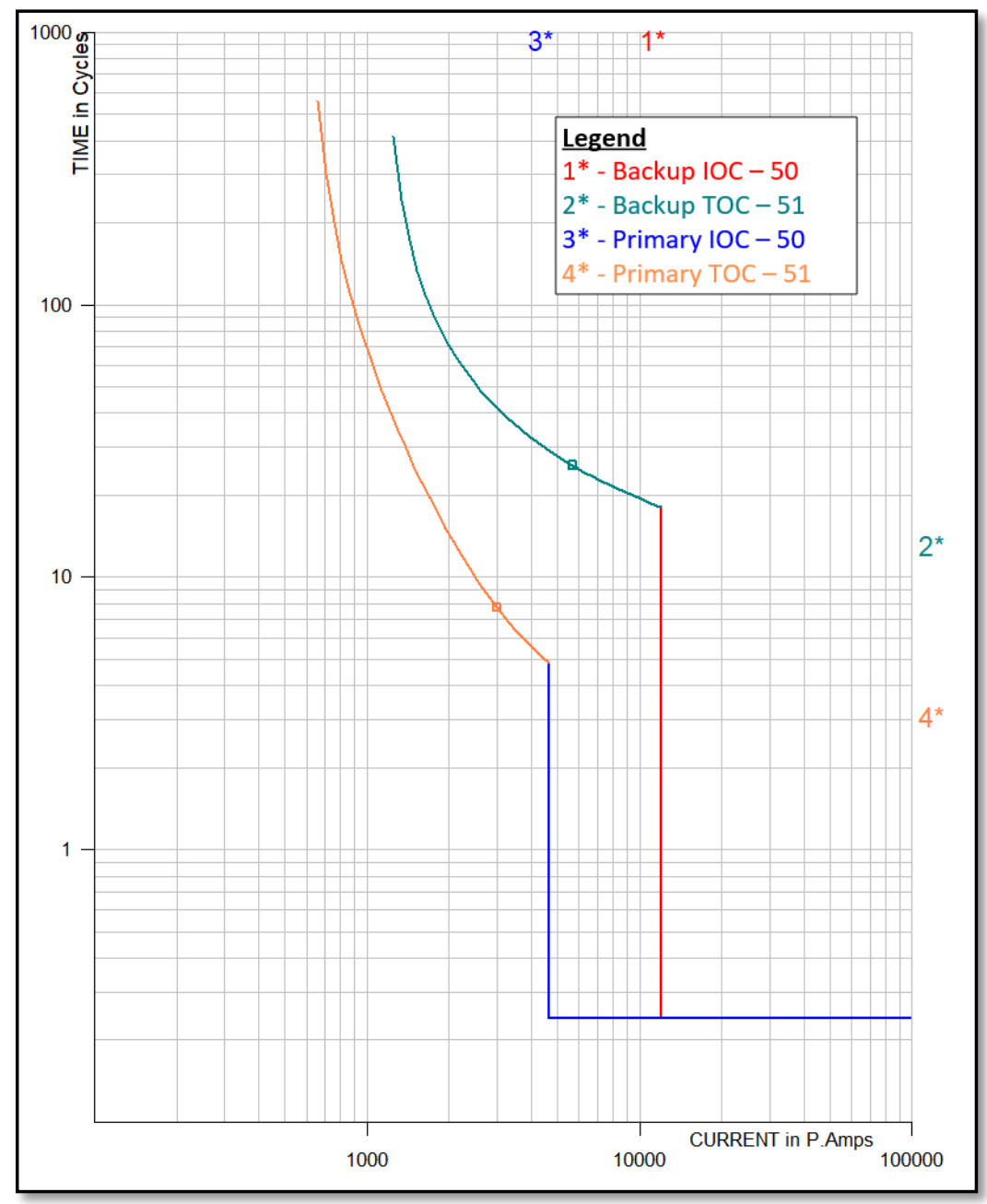

Figure 2-2 - Basic Protection Philosophy 


\subsubsection{Distance Protection}

Distance protection is ultimately based on the protective relay calculating impedance of the transmission line by monitoring the power system voltage and current. This requires the protective device to have an accurate measurement of the bus voltage and transmission line side current with the aid of current and voltage transformers. The current transformer must be dedicated and installed on the transmission line side, but the voltage transformer can be either line side or on the actual bus supplying multiple transmission lines [3-4].

The protection engineer by knowing the transmission line impedance can set the protective relay in such a way to isolate an internal fault if the device measures impedance with the ratio less than its preset value. When an internal fault occurs within the transmission line, it creates a short circuit and therefore reduces the respective line's measured impedance from the remote terminal. This can be best represented in an R-X diagram (see Figure 2-3). Typically, a protective relay install on the local terminal will have a tripping region. If an in-zone fault occurs, the protective relay can issue a trip signal to the circuit breaker when the calculated impedance is within this tripping region. The tripping region is typically set based on proportions of the transmission line under protection (lines are primarily inductive as seen on the R-X Diagram).

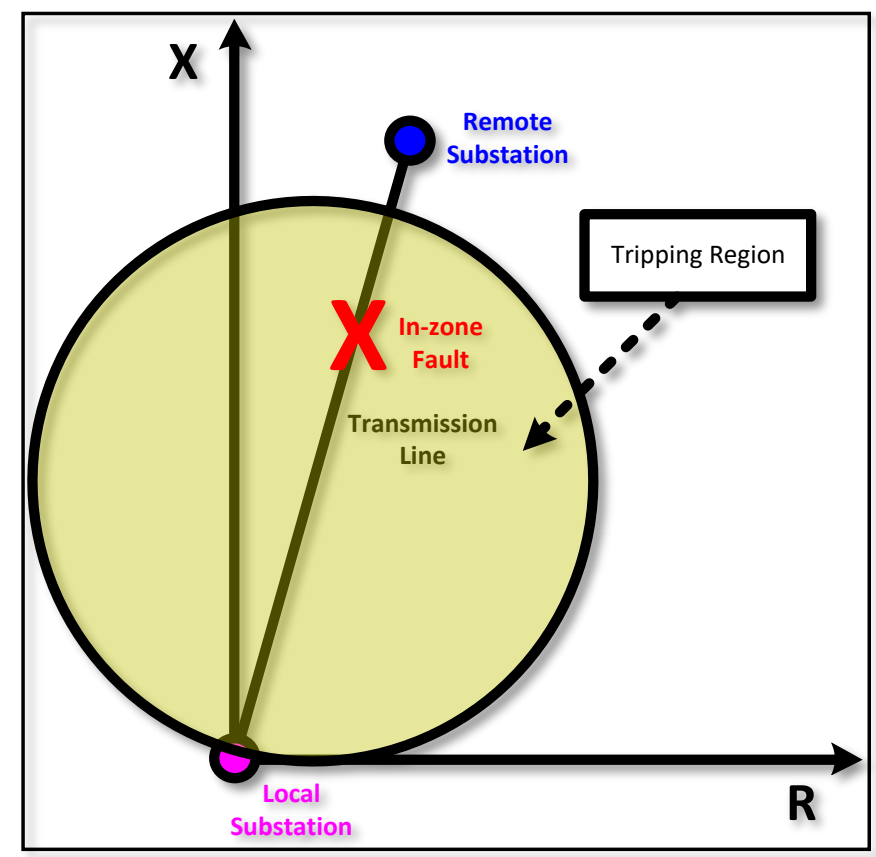

Figure 2-3 - Distance Protection Overview 
There are various standardized tripping region characteristics commonly used in the industry. The main challenges with distance relaying is dealing with 1) resistive system faults as well as 2) differentiating between a faulted condition and the actual load running through the transmission line. In Figure 2-4, the tripping region will have be to set too large in order to see resistive faults. This will result in the tripping region to see adjacent transmission lines terminating from the remote substation (may not be desirable as this line will be tripped for out of zone faults if it has no time delay). This will also result in the large tripping region isolating the breaker on load by mistake as the two regions intersect [3].

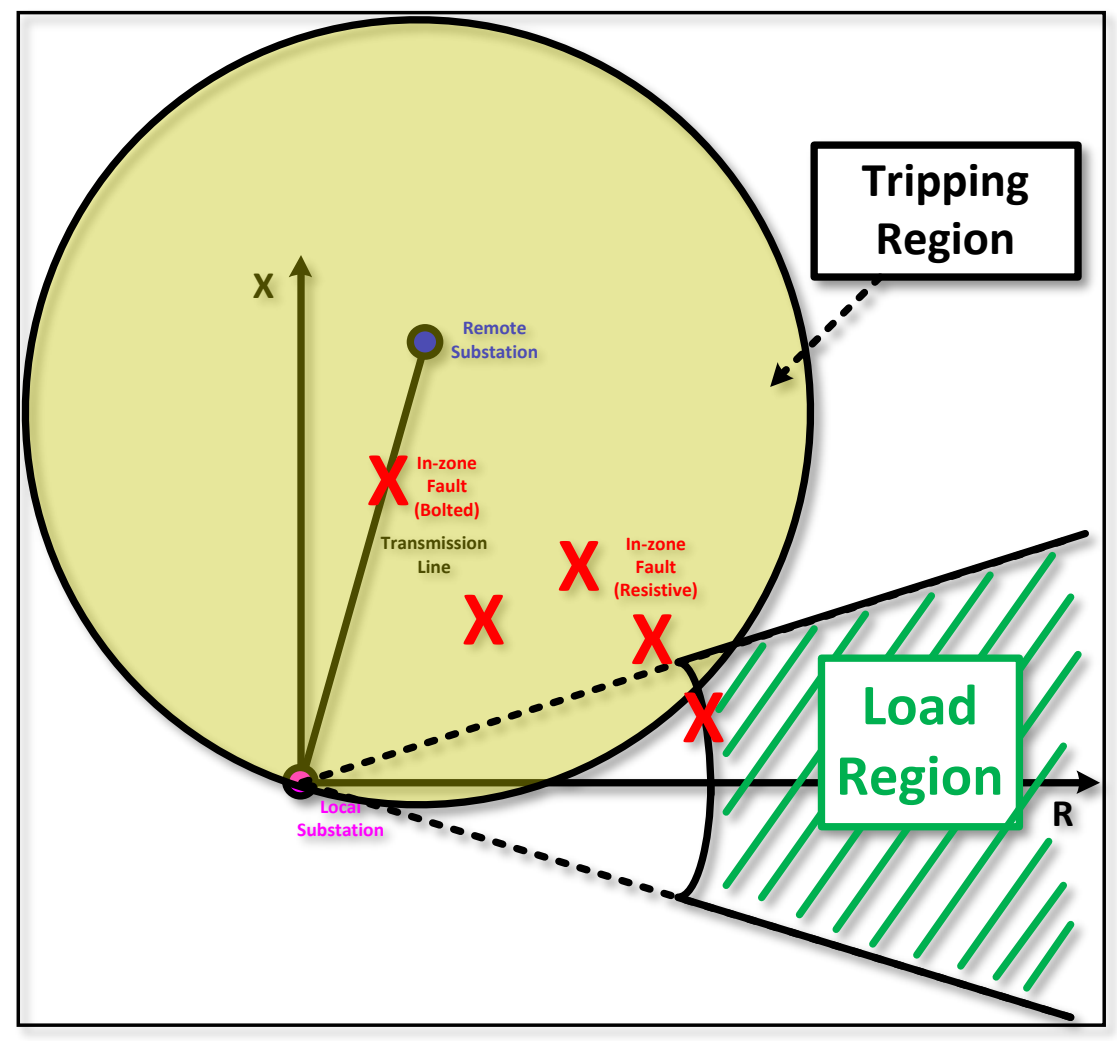

Figure 2-4 - Distance Protection Challenges

In order to satisfy these contradictory objectives, the following approaches are required (Figure 2-5):

\section{Staggered Tripping Zones}

Creating multiple tripping zones and assigning time delays to the larger tripping zones will resolve the issue of misbehaving on adjacent transmission lines. This delay will allow the adjacent 
protective devices to isolate the fault before the larger time-delay elements mis-operate for out-ofzone faults. They are still necessary to be enabled as backup protection in case the adjacent transmission line is unable to clear the out of zone fault.

\section{Multiple Tripping Characteristic (Mho versus Quad)}

Resistive faults occur when the transmission line is shorted with ground (Single or Double Line to Ground Faults). This allows the protective devices to differentiate resistive faults with the loading region as load is observed similar to a three-phase condition. Therefore, for phase protection, a Mho circle tripping characteristics is desired (sees less into the $\mathrm{R}$ axis where load is observed) compared to a more complex QUAD characteristic for ground protection (sees most into the $\mathrm{R}$ axis to capture all resistive faults) [52].

\section{$\underline{\text { Load Blinders }}$}

For phase distance protection, additional blocking elements may be required for the largest Mho circle to ensure it does not mis-operate for loading conditions [53].

\begin{tabular}{|l|l|}
\hline Mho Characteristic & Quad Characteristic \\
\hline $\begin{array}{l}\text { Typically for Phase Protection } \\
\text { (three-phase, line to line faults - bolted) }\end{array}$ & $\begin{array}{l}\text { Typically for Ground Protection } \\
\text { (Single-line-to-ground, Double-line-to- } \\
\text { ground faults - Bolted or resistive) }\end{array}$ \\
\hline Sull
\end{tabular}

Figure 2-5 - Mho versus Quad Distance Characteristics with Load Blinder 
There are several other additional challenges in transmission line protection which can impact the guidelines for setting distance characteristics. Below is a list of some major factors which a protection engineer needs to take into consideration before issuing settings for distance elements [3-4]:

- Mutually Coupled Parallel Lines

- Multi-Terminal Lines

- Short Lines

- Series Compensated Lines

\subsubsection{Communicated Assisted Protection Scheme}

As described in this document, the last $10-20 \%$ of the transmission line is typically cleared with a time delayed zone 2 distant element (typically 20-30 cycle delay). This will be an undesirable reaction to clear faults with such long delay but is necessary not to mis-operate on adjacent system element faults. The aid of communication between the local and remote terminals will allow the protection schemes to clear all in-zone faults quickly [48]. You can imagine a protection scheme where if the local terminal can make a decision to trip for the $80-100 \%$ of the line in-zone faults immediately if it had the knowledge of the remote terminal isolating the fault in its beginning $20 \%$. Two commonly used tele-protection schemes are described below:

\section{$\underline{\text { Permissive Over-reaching Transfer Trip (POTT) }}$}

One popular scheme is the permissive over-reaching transfer trip (POTT) tele-protection scheme. In Figure 2-6, a POTT scheme at terminal 1 is able to clear end of line in-zone faults immediately if its zone 2 element sees the fault as well as the remote terminal's forward looking zone 2 also sees the fault and communicates the signal back to terminal 1. Therefore, a POTT scheme can trip in little as 1-5 cycles (communication delay receiving the signal from the remote terminal) [48].

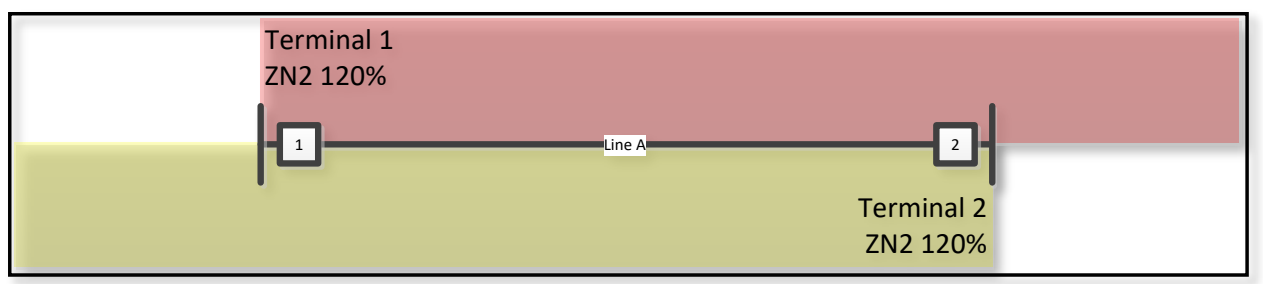

Figure 2-6 - POTT Tele-protection Scheme 


\section{Directional Comparison Blocking (DCB)}

Another popular scheme is the Directional Comparison Blocking (DCB) tele-protection scheme. In Figure 2-7, a DCB scheme at terminal 1 is able to clear end of line in-zone faults immediately if its zone 2 element sees the fault as well as the remote terminal's Reverse looking zone 2 does not see the fault and communicates a block signal back to terminal 1. Therefore, a DCB scheme can trip in little as 1-5 cycles (communication delay receiving the signal from the remote terminal) [48].

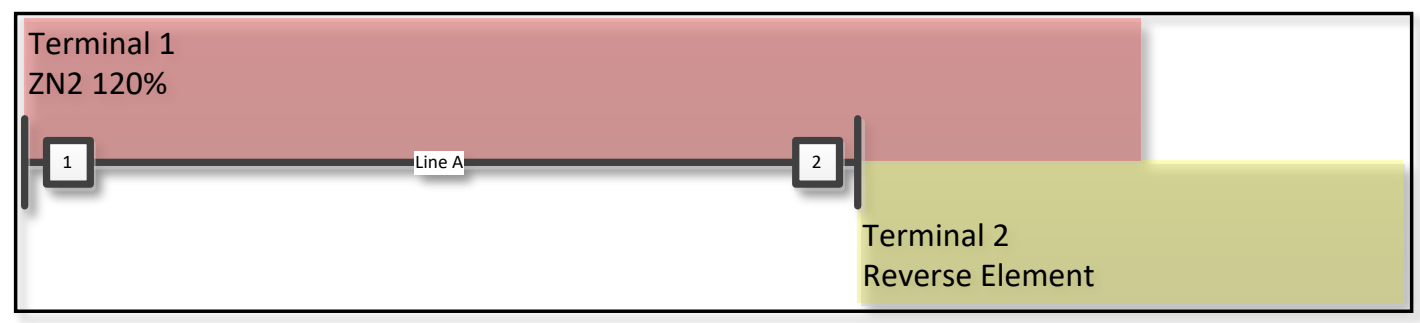

Figure 2-7 - DCB Tele-protection Scheme

When a fault is placed on remote bus to verify that the zone 2 element has the desired reach based on the corresponding apparent $\mathrm{Z}$, this fault is used to verify the operation of the fault detector associated with any reverse-looking distance element found at the remote bus. All reverse-looking elements at the remote bus are required that the reverse element overreaches the $\mathrm{Z} 2$ element from the remote terminal by at least $10 \%$ margin. This ensures no mis-operation of the DCB scheme for out of zone faults (if Zone 2 can see it but reverse element is not large enough to block it).

\subsubsection{Impact of Source Impedance Ratio}

The source impedance ratio - SIR is the ratio of the source impedance to the line positive sequence impedance. The SIR ratio can be significantly different for each terminal of the same transmission line and should be calculated separately for ground and phase faults with worst case N-1 source impedance contingency by applying faults at the remote bus while local bus system equipment is outaged.

The source impedance for a phase fault is then calculated as follows:

$$
Z_{\text {Source_TPH }}=\frac{V_{\text {line base }}-V_{\text {Relay }}}{I_{\text {Relay }}}
$$


Where,

- $\mathrm{V}_{\text {Line base }}$ is the system base phase-to-ground voltage, which defines the perfect source in volts

- VRELAY and IRELAY are the phase-to-ground voltage and current at the relay for a 3-phase fault at the remote bus

Therefore, the SIR for the phase fault loop is then calculated as the ratio of the $\mathrm{Z}_{\text {Source_TPH }}$ and the positive sequence impedance of the line transmission line.

The source impedance for ground fault is calculated similar to the phase fault with the exception of adding the contribution of ground fault current (3I0) multiplied by the zero-sequence compensation factor $(\mathrm{k} 0)$ to the relay current reading.

$$
Z_{\text {Source }_{S L G}}=\frac{V_{\text {line base }}-V_{\text {Relay }}}{I_{\text {Relay }}+k_{0} * 3 I_{0_{\text {Relay }}}}
$$

The SIR ratio highlights the impact of having a strong source on the impedance protection relay with enabled distance elements. The relay reach must meet the minimum criteria of differentiating between the voltage and current reading between the faults at the end of the reach of the zone 1 relay and the remote bus. As an example, the zone 1 distance of an extremely short line set at $85 \%$ can still mis-operate if the voltage discrimination is less than 1 volt and the current discrimination is less than $0.5 \mathrm{amp}$ for faults at the $80 \%$ mark and the remote bus faults (too little of a change for the relay to make a decision accurately). Therefore, most transmission utilities have additional restrictions to reduce the reach of the zone 1 distance (as low as 50\%) if the SIR ratio is high (SIR above 20) [54-55].

\subsubsection{Impact of Loadability}

Following the major blackout of 2003, which left more than 50 million people without power, the PRC-023 Transmission Relay Loadability Standard was issued by North American Electric Reliability Corporation (NERC) to prevent future widespread power outages form occurring [13]. This standard requires utilities to re-evaluate their phase protective relay settings to ensure there is no overlapping of protective elements reach with that of emergency loading and possibility of misoperation during heavy system loading. This must be accomplished with no limitation to 
transmission loadability or interference with the system operators' ability to operate the system close to the stressed system conditions [56].

PRC-023 mandates that protective relay settings for impedance- and overcurrent-based protection schemes (load-responsive phase protection systems) must not violate specified short-term or longterm thermal ratings for transmission facilities. Hence, the protective relays must not operate under the transmission line loading with specified margins for system contingencies. PRC-023 evaluation considers the following conditions to determine applicable load region:

- $150 \%$ of a specified four-hour Long-Term Emergency (LTE) line loading, or

- $115 \%$ of a 15-minute Short-Term Emergency (STE) line loading, with

- System operation at 0.85 per unit voltage under stressed conditions, and

- $\quad \pm 30$ degree load angle per given line terminal at $100 \mathrm{kV}$ or higher voltages

Due to the extensive size and complexity of the transmission systems to be reviewed, verification of compliance has become a major challenge for many utilities. The evaluation process for phase distance elements can be represented as follows:

$$
Z_{\text {element }}<\frac{0.85 V_{L-L}}{1.50 \sqrt{3} I_{L T E}}
$$

Or

$$
Z_{\text {element }}<\frac{0.85 V_{L-L}}{1.15 \sqrt{3} I_{S T E}}
$$

For line relays, the distance protection settings are compared against the calculated impedance representing the line loading specified by PRC-023 and determines whether the relay settings meet standard requirements (four-hour LTE and 15-minute STE line ratings).

For stations which the impedance distance zone curves do intersect the line loading, the PRC-023 loadability fails (see Figure 2-4). This results in two choices for the protection engineer:

- Reduce the reach of the violated distance zone (if possible) which may not be feasible as it was set this large for protecting the transmission line;

- work with planning to limit the transmission of load and therefore no need to make any changes to the protection 
Typically the optimum option is to introduce a load encroachment blocking scheme to the microprocessor relay which can block operation of any issues near the loading region [57].

\subsection{Transmission Study System}

In order to achieve the objectives of this thesis, first a transmission line system is proposed. The system represents a typical looped transmission topology representing an $115 \mathrm{kV}$ and $230 \mathrm{kV}$ network provided as a Computer Aided Protection Engineering (CAPE) model. CAPE software is a practical method for transmission utilities to assist in modeling their electrical transmission network's protection systems.

This is a main tool used by transmission utilities to study the power system protection. CAPE as a software interfaces with a database. Databases are collections of information with some structure for ease of search and retrieval. The database stores data on all the buses, transformers and lines in their system. When protection is modeled in CAPE, it will save information about relays, current transformers and voltage transformers to the connected database file [58].

\subsubsection{Study System Model}

Figure 2-8 represents the transmission model to be analyzed. A set of $230 \mathrm{kV}$ transmission lines neighboring each other are selected as the primary simulation depth. Line 1 between Winder and Center substation is selected as the primary protection scheme under review. In order to accurately assess the protection coordination of line 1 , all protection for adjacent transmission lines terminating at both substations will require modeling. For example for fault on study line 1, primary protection at Center terminal will need to coordinate with back up protection at substations Gainsvle and Bio. Furthermore, primary protection at Winder terminal will need to clear faults faster than any backup protection at substations East Social, Lawrville, Conyers, and Gainsvle. In total, seven transmission lines surrounding two $230 \mathrm{kV}$ substations Winder and Center require protection modeling. 


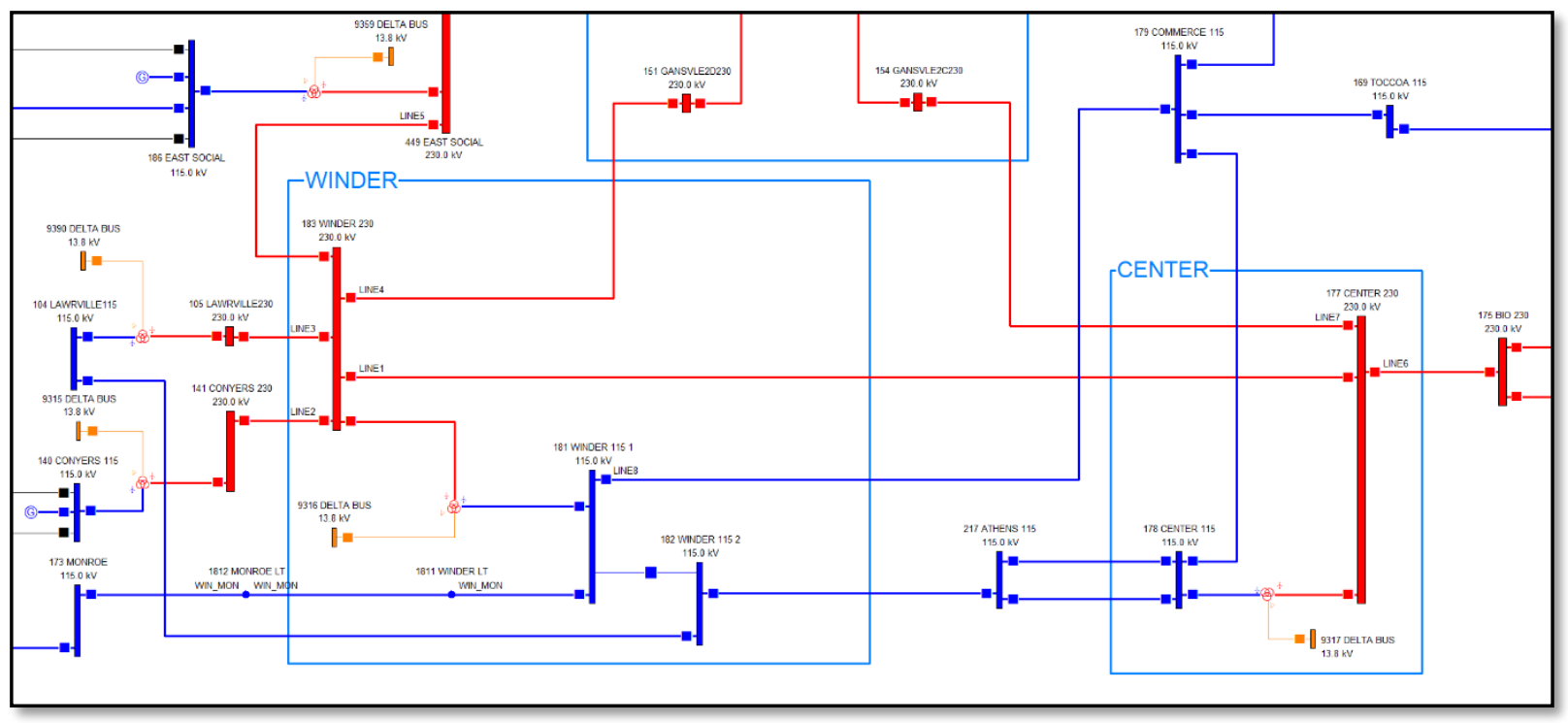

Figure 2-8 - Primary Network Selected for Coordination Study

The parameters for primary line 1 between Center and Winder are represented in Figure 2-9.

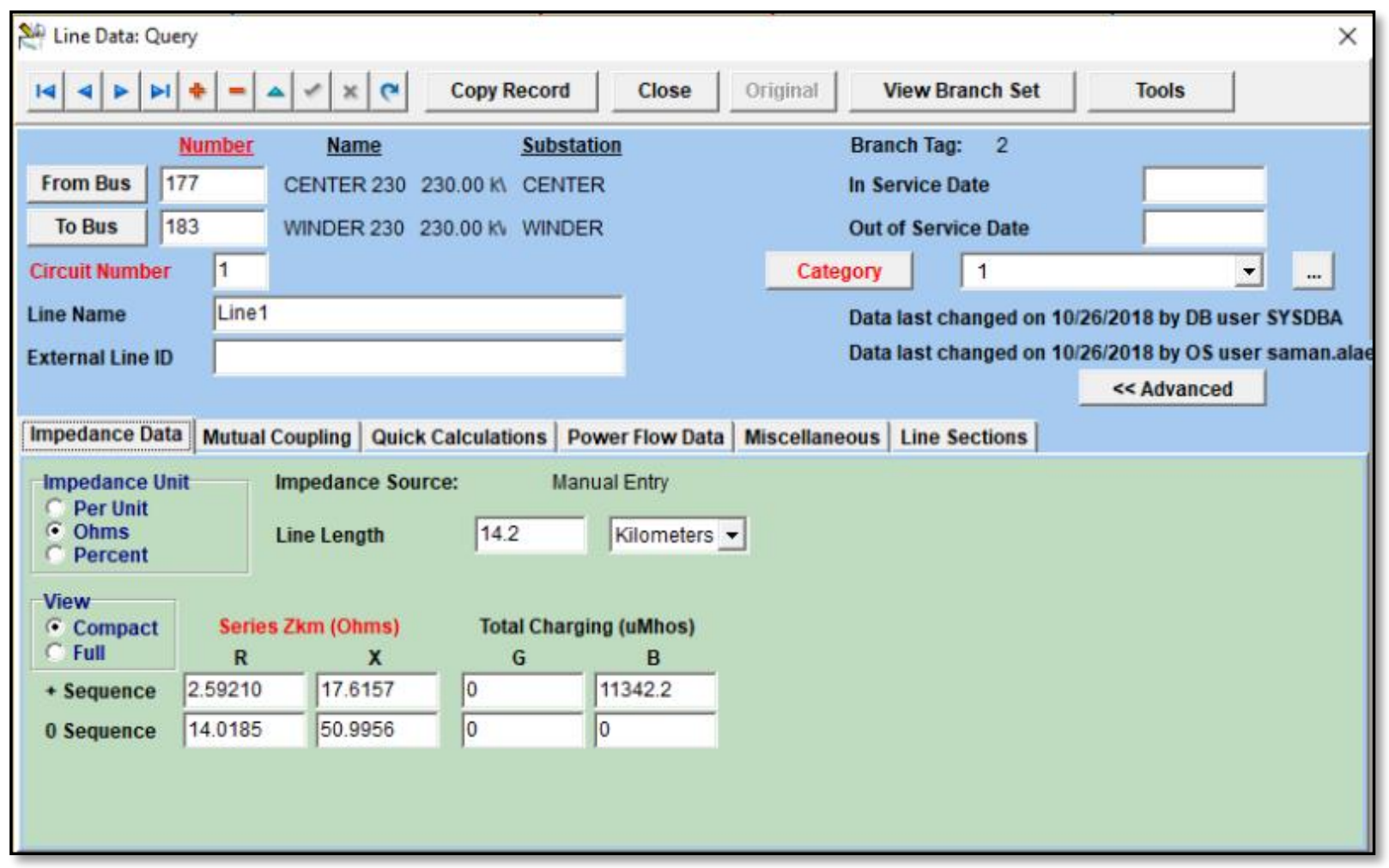

Figure 2-9 - Study Model Line 1 Parameters 
The line impedance is set as 17.81 primary ohms at 81.63 degrees at $230 \mathrm{kV}$.

In most transmission planning studies, the positive sequence of the transmission lines is enough for an in depth analysis. In the field of protection, however, a detailed zero sequence model of the system is rather important in order to accurately assess ground protection for single line to ground short circuit [59]. The resistance and reactance model of all seven transmission lines under the study for their respective positive and zero sequences are represented in Table 2-1.

Table 2-1 - Line Parameters of Study Area

\begin{tabular}{|c|c|c|c|c|c|c|}
\hline Line & Terminal 1 & Terminal 2 & R1 (ohm) & $\mathbf{X 1}$ (ohm) & R0 (ohm) & X0 (ohm) \\
\hline 1 & Winder & Center & 2.5921 & 17.6157 & 14.0185 & 50.9956 \\
\hline 2 & Winder & Conyers & 3.2269 & 21.7948 & 17.3512 & 63.0568 \\
\hline 3 & Winder & Lawrville & 1.3754 & 11.9025 & 10.1039 & 32.0574 \\
\hline 4 & Winder & Gansville & 1.7457 & 15.1294 & 12.8547 & 40.6801 \\
\hline 5 & Winder & East Social & 1.6928 & 18.3034 & 15.3939 & 50.0963 \\
\hline 6 & Center & Bio & 3.6501 & 24.6514 & 19.6259 & 71.3621 \\
\hline 7 & Center & Gansville & 2.2218 & 24.4927 & 18.5679 & 72.473 \\
\hline
\end{tabular}

Additionally, transmission lines terminating at the same substation are often installed in the same right of way. This means that two transmission lines may be installed on the same physical tower as well as near other towers in narrow corridors due to construction cost and lack of available physical space. This results in magnetic mutual induction of lines and introducing additional protection challenges. Mutual coupling affects the zero-sequence networks and associated ground related protection schemes which can respond to it. It can impact polarizing quantities of directional elements as well as ground reach characteristics. Figure 2-10 represents a single line to ground short circuit with the zero sequence network including a mutual impedance accounted for as a voltage source. This mutual coupling impact is not observed in the positive sequence nor does negative sequence network [60]. 


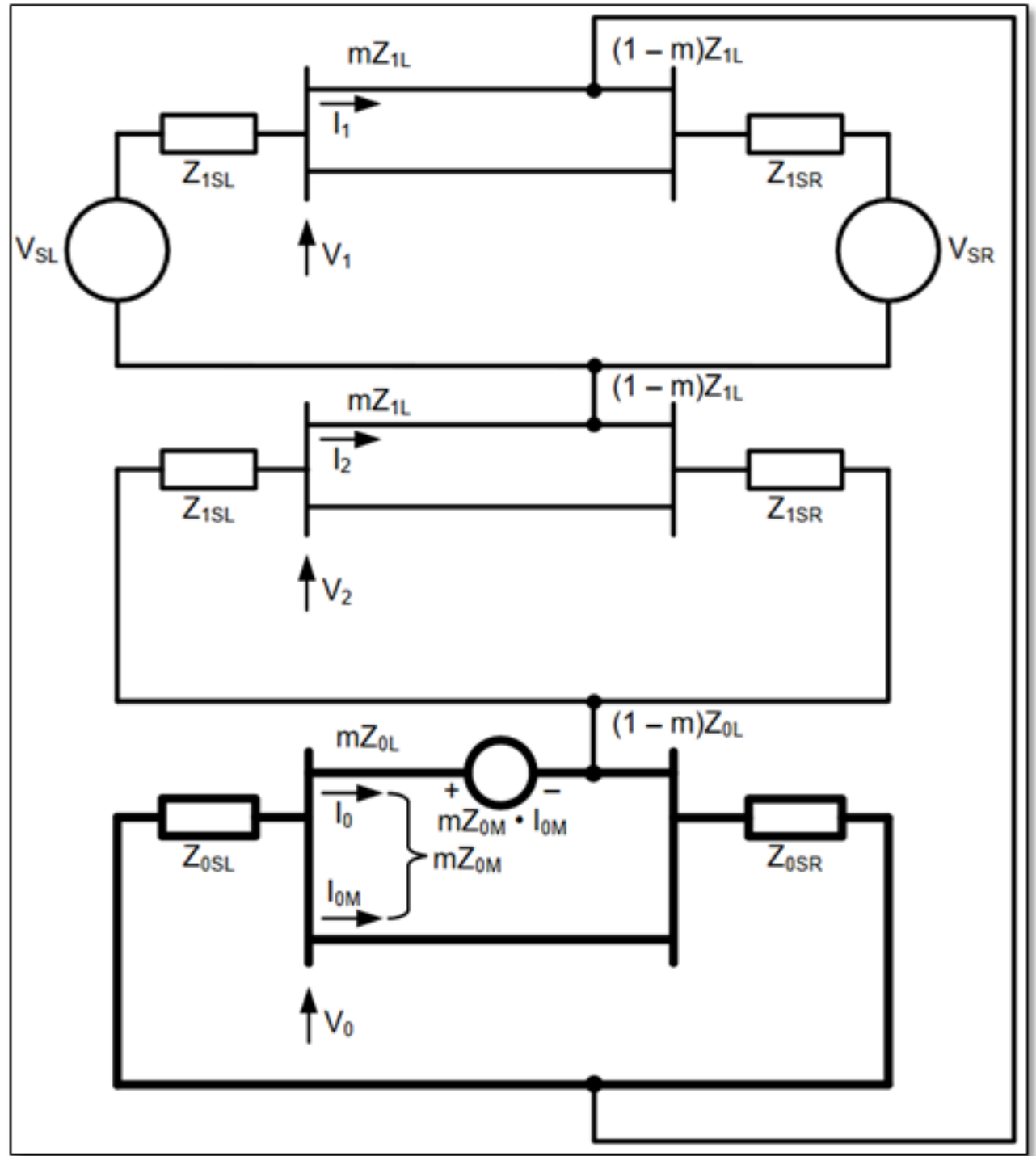

Figure 2-10 - Sequence Networks \& Impact of Mutual Coupling for Single Line to Ground Fault [60]

Table 2-2 represents the mutual coupling model for study line 1 in the CAPE database.

Table 2-2 - Mutual Coupled Circuits to Line 1

\begin{tabular}{|c|c|c|c|c|c|c|c|c|c|c|c|c|c|}
\hline & & From Bus & & & To Bus & & $\begin{array}{c}\text { Self Imp } \\
\text { (per }\end{array}$ & $\begin{array}{l}\text { pedance } \\
\text { unit) }\end{array}$ & & & $\begin{array}{r}\text { Mutual I } \\
\text { (per }\end{array}$ & $\begin{array}{l}\text { mpedance } \\
\text { unit) }\end{array}$ & $\begin{array}{c}\text { Ratio } \\
\text { ( } 8 \text { ) }\end{array}$ \\
\hline & Number & Name & $\mathrm{kV}$ & Number & Name & $\underline{I D}$ & R0 & xo & start & Stop & $\mathrm{R}$ & $\mathrm{x}$ & $\mathrm{zm} / \mathrm{zo}$ \\
\hline Line $1:$ & 154 & GANSVLE2C230 & 230.000 & 177 & CENTER 230 & 1 & 0.035100 & 0.137000 & 0.00000 & 1.00000 & -0.00150 & -0.00700 & 5.0620 \\
\hline Line 2: & 177 & CENTER 230 & 230.000 & 183 & WINDER 230 & 1 & 0.026500 & 0.096400 & 0.00000 & 1.00000 & & & 7.1606 \\
\hline Line 1: & 177 & CENTER 230 & 230.000 & 183 & WINDER 230 & 1 & 0.026500 & 0.096400 & 0.00000 & 1.00000 & 0.002700 & 0.012200 & 12.4982 \\
\hline Line 2: & 179 & COMMERCE 115 & 115.000 & 181 & WINDER $115 \quad 1$ & 1 & 0.103300 & 0.369600 & 0.00000 & 1.00000 & & & 3.2560 \\
\hline
\end{tabular}




\subsubsection{Relay Selection and Modeling}

A transmission line protective digital relay manufactured by Schweitzer Engineering Laboratories (SEL), a popular vendor in North America is selected. A SEL-421 equipment is a high speed distance and directional protection relay. Multiple phase or ground distance and overcurrent elements are available in this digital relay. The protective function parameters are calculated for the simulation area and prepared using AcSELerator QuickSet software which interfaces with the physical relays [47]. These calculated setting files are then imported into the CAPE primary model for protection coordination studies.

Digital relays are processor-based protective devices which utilize programmable algorithms to detect faults on the line. They often have several functions built within the relay, such as distance elements, overcurrent elements and timers. This means a single digital relay is usually enough to completely protect a terminal. Before use, the programmer will set up tripping logic within the relay which controls the interaction of these functions to send a trip signal to the breaker [61].

The relay models impose restrictions on the range of each of these elements. Some taps (especially Enable ones) may be simple bitwise On or Off. Others (such as Reaches) could be any number within a range divisible by a certain value, known as the Step Size. Only valid taps, within the range, will be accepted by protective device and it will show errors otherwise.

The key item to note is that different types of relays have different restrictions on ranges and step sizes. Often, digital relays pose few issues when entering values for a tap. This is because they tend to have greater ranges and smaller step sizes. This can result in a limitation when optimizing relay settings for coordination. In extreme cases, one may need to replace an older generation relay with a new digital device which can allow the proper range and step size for its respective setting.

Each relay model has its own internal logic. For example, digital relays have fault detector elements in the relay which automatically supervise the distance elements. Another example is the timed distance elements. The digital relays have timer elements which are fixed to supervise their respective distance elements as shown in figure Figure 2-11. 


\begin{tabular}{|c|c|c|c|c|c|}
\hline TIMER & Z1GD & 1 & $0 \mathrm{C}$ & & Internal: DIST Z1G 1 \\
\hline TIMER & Z1PD & 1 & $0 \mathrm{C}$ & & Internal: DIST M1P 1 \\
\hline TIMER & Z2GD & 1 & $24 C$ & 21G2T_B & Internal: DIST Z2G 2 \\
\hline TIMER & Z2PD & 1 & $24 \mathrm{C}$ & 21P2T_B & Internal: DIST M2P 2 \\
\hline TIMER & Z3GD & 1 & $0 \mathrm{C}$ & & Internal: DIST Z3G 3 \\
\hline TIMER & Z3PD & 1 & $0 \mathrm{C}$ & & Internal: DIST M3P 3 \\
\hline TIMER & Z4GD & 1 & OFF C & & Internal: DIST Z4G 4 \\
\hline TIMER & Z4PD & 1 & OFF C & & Internal: DIST M4P 4 \\
\hline
\end{tabular}

Figure 2-11 - Various timers in the digital relay with internal supervision

When an element is supervised by another, it will only operate once the supervisor has operated. In the case of a timer, the element will operate after the supervisor has operated plus the time delay. Understanding the concept of internal logic is very important as it highlights the constraint of the physical device. The engineer is not able to change this type of logic. It is a fundamental part of the relay model.

All protective devices such as relays, CTs, VTs, circuit breakers, etc. that are meant to protect the system as a whole and require to be modeled for an assessment of the entire protection system. Every protective relay utilizing distance protection will require a Current Transformer (CT) and Voltage Transformer (VT) connection. The CT and its appropriate turn ratio, will have to be modeled at line side of each terminal. The CT connection winding point is typically $\mathrm{Y}$ and is appropriate for the purpose of modeling [3-4]. The CT turn ratio is standardized at either 1 Amp or 5 Amp secondary. North American standard tends to utilize the 5 Amp secondary relays. The high side ratio of CTs are generally calculated based on maximum short circuit it can pass through the transmission line [3-4].

VT location can differ for each application. Generally, only one VT is installed on the main bus and its reading is shared by every LZOP terminating from the substation. In special applications, similarly to CT installation location, VT can be placed on the line side for each individual terminal [3-4]. For the sample study area, a bus side VT is installed with a turn ratio of 230,000 V primary to $115 \mathrm{~V}$ secondary.

Once a style has been selected, the next most important thing to do is connect the CTs and VTs to the new relay. An ANSI code for protective functions is often utilized to communicate the protective functionality among peers. For example, a code of 21P1 can be assigned for a Zone 1 of the phase distance protection. This code can be used to identify an impedance protection 
function which trips for phase faults without any intentional time delay. Table 2-3 represents the relevant ANSI codes to be utilized in the study cases.

Table 2-3 - ANSI Codes for Protective Functions Utilized in Study [62]

\begin{tabular}{|c|l|}
\hline Device Designation & Description \\
\hline $\mathrm{P}$ & Phase Relay \\
\hline $\mathrm{G}$ & Ground Relay \\
\hline 21 & Distance Relay \\
\hline 32 & Directional Power Relay \\
\hline 50 & Instantaneous Overcurrent Relay \\
\hline 51 & Ac Time Overcurrent Relay \\
\hline 67 & Ac Directional Overcurrent Relay \\
\hline
\end{tabular}

\subsubsection{Relay Settings Approach}

Using the criteria described in chapter 2.1, fourteen relays and seven tele-protection schemes were prepared for the transmission system. The following sections describe how the individual relay taps are set in preparation of the protection model for the study cases.

\subsubsection{Line Parameter}

Due to safety reasons, protective relays operate at low current range of 0 to 5 amps and voltage range of 100 to 125 volts. This requires all settings to be converted from primary to secondary [3$4]$.

The primary and secondary positive sequence magnitude $(\mathrm{Z} 1)$ is defined as,

$$
\begin{gathered}
Z 1_{\text {magnitude }_{\text {primary }}}=\sqrt{R_{1}{ }^{2}+X_{1}^{2}} \\
Z 1_{\text {magnitude }_{\text {secondary }}}=\frac{C T R}{V T R} Z 1_{\text {magnitude }_{\text {primary }}}
\end{gathered}
$$

The positive sequence angle (Z1) is defined as,

$$
Z 1_{\text {angle }}=\tan ^{-1} \frac{X_{1}}{R_{1}}
$$


Furthermore, the primary and secondary zero sequence magnitude (Z0) is defined as,

$$
\begin{gathered}
Z 0_{\text {magnitude }_{\text {primary }}}=\sqrt{R_{0}^{2}+X_{0}^{2}} \\
Z 0_{\text {magnitude }_{\text {secondary }}}=\frac{C T R}{V T R} Z 0_{\text {magnitude }_{\text {primary }}}
\end{gathered}
$$

The zero sequence angle (Z0) is defined as,

$$
Z 0_{\text {angle }}=\tan ^{-1} \frac{X_{0}}{R_{0}}
$$

With a selected CT ratio of 120 (600:5 amps) and VT ratio of 2000 (230000:115 volts), the settings for Center terminal of Line 1 for line parameter elements are shown in Figure 2-12.

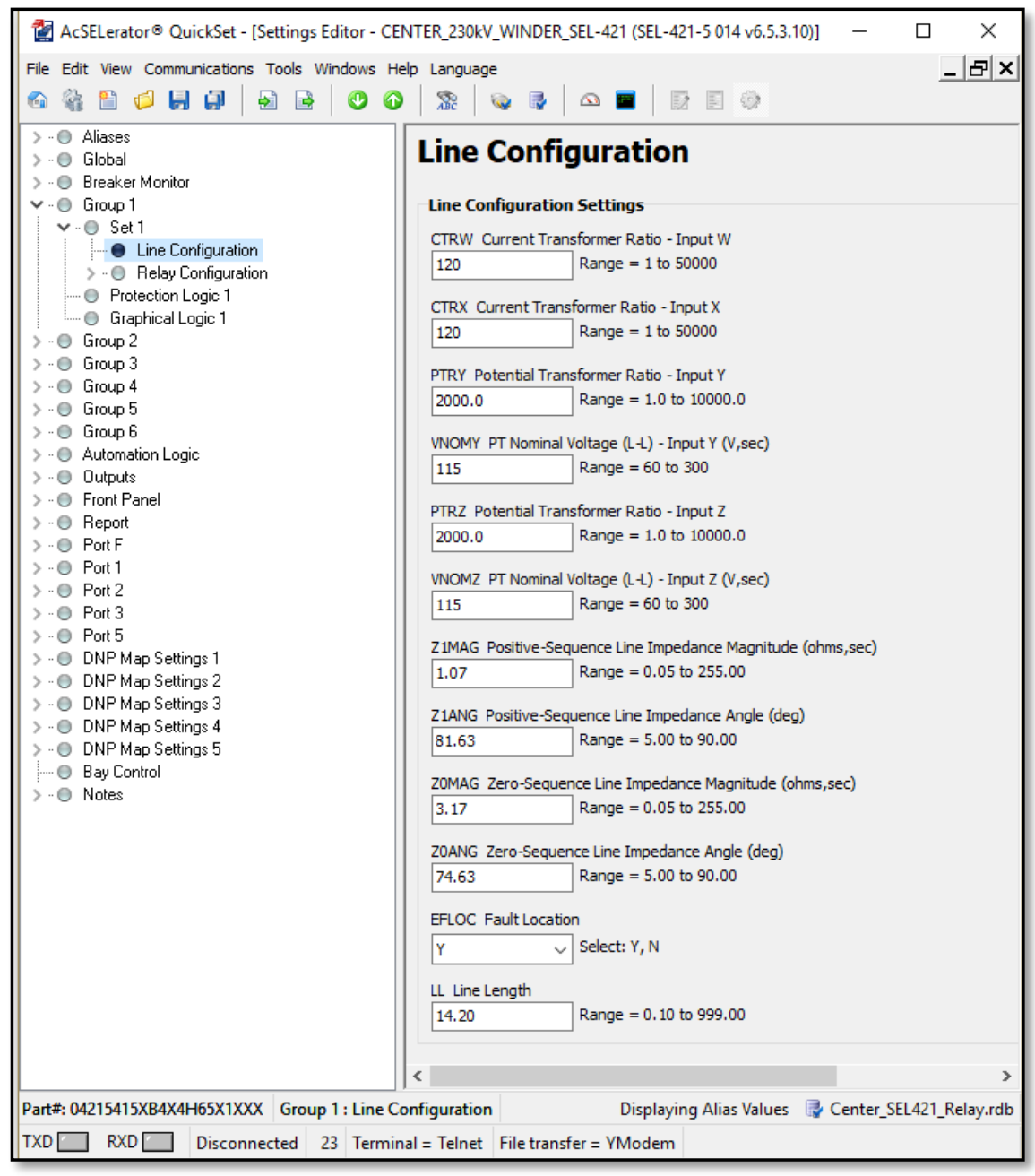

Figure 2-12 - Line Configuration Settings 


\subsubsection{Ground Overcurrent}

As described in section 2.1.1, phase overcurrent elements are not required due to their high sensitivity to high load conditions as well as the stability of phase distance to isolate phase related faults. Both instantaneous and timed inverse ground overcurrent elements are activated. There are two instantaneous (50G) elements. The first element is designed to protect the primary line for in zone SLG and DLG faults. The pick-up of the under-reaching instantaneous ground overcurrent element $(50 \mathrm{G} 1 \mathrm{P})$ is defined as,

$$
50 G 1 P=1.25 \frac{I_{\text {Remote SLG Bus Fault primary }}}{C T R}
$$

The second element is enabled as part of the permissive over-reaching transfer trip tele-protection system. The pick-up of the over-reaching instantaneous ground overcurrent element (50G2P) is defined as,

$$
50 G 2 P=0.5 \frac{I_{\text {Remote SLG Bus Fault primary }}}{C T R}
$$

The settings for Center terminal of Line 1 for 50G element are shown in Figure 2-13.

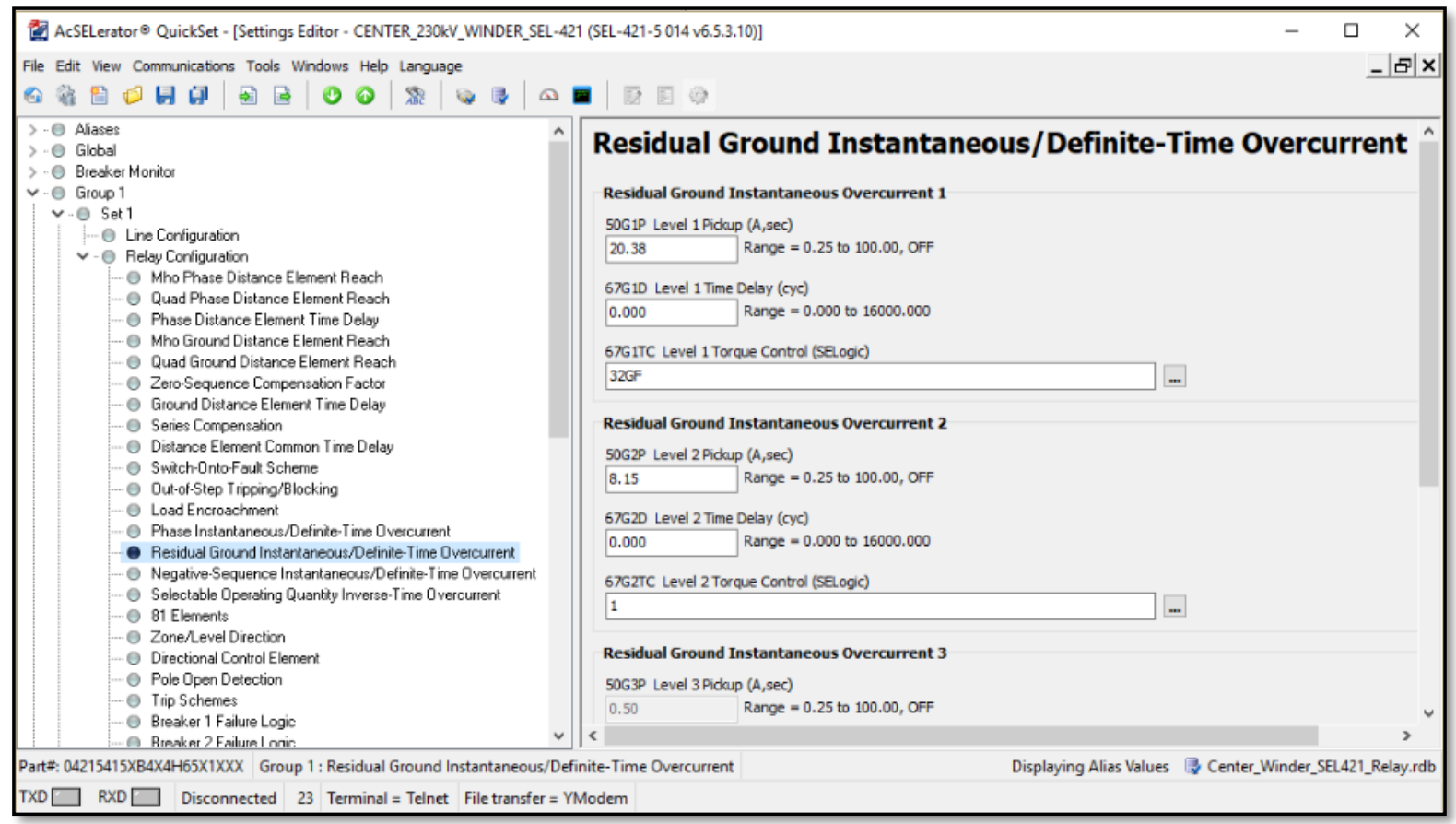

Figure 2-13 - Residual Ground Instantaneous Overcurrent Setting 
The timed inverse ground overcurrent element is designed to protect the primary line for in zone SLG and DLG faults with a time delay. The pick-up of the over-reaching timed ground overcurrent element (51S1P) is defined as,

$$
51 S 1 P=0.5 \frac{I_{\text {Remote } S L G \text { Bus Fault primary }}}{C T R}
$$

In contrast to the $50 \mathrm{G}$ element, $51 \mathrm{~S} 1$ requires additional time dial tap to be set. The IEEE curve characteristic of very inverse was selected [63]. A time delay of 25 cycles for a remote SLG fault under normal condition is desired. The time dial (51S1TD) of 51P element is defined as,

$$
51 S 1 T D=\frac{O p_{S e c}}{0.0226+\frac{0.0104}{I_{M u l t}{ }^{(0.02-1)}}}
$$

The current multiple is selected as 2 times using the following formula,

$$
I_{M u l t}=\frac{I_{\text {Remote_SLG }}}{C T R(51 S 1 P)}
$$

The settings for Center terminal of Line 1 for $51 \mathrm{G}$ element are shown in Figure 2-14.

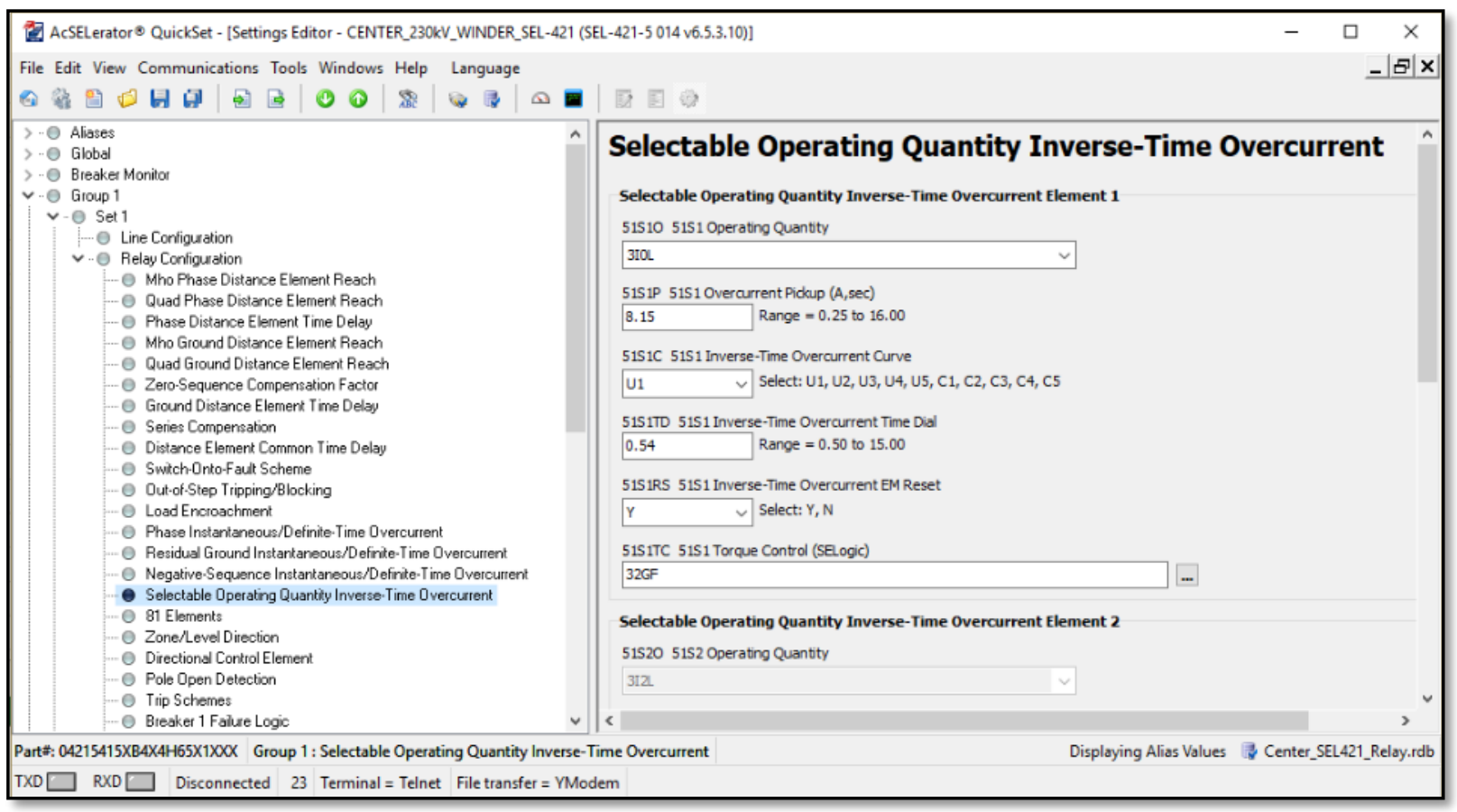

Figure 2-14 - Residual Ground Inverse Timed Overcurrent Setting 


\subsubsection{Phase Distance}

As described in section 2.1.2, three phase distance zones are adequate to protect a transmission line. The under-reaching phase distance zone 1 is designed to protect the primary line instantaneously. The reach of the Mho phase distance zone 1 characteristic (Z1P) is defined as,

$$
Z 1 M P=0.8 Z 1_{\text {magnitude }} \text { secondary }
$$

The over-reaching phase distance zone 2 is designed to protect the primary line with a time delay. The reach of the Mho phase distance zone 2 characteristic $(\mathrm{Z} 2 \mathrm{P})$ is defined as,

$$
Z 2 M P=1.2 Z 1_{\text {magnitude }} \text { secondary }
$$

A third reverse phase distance element is enabled as part of the permissive over-reaching transfer trip tele-protection system. The pick-up of the over-reaching phase distance element $(\mathrm{Z} 3 \mathrm{P})$ is defined as,

$$
Z 3 M P=-1.2 Z 1_{\text {magnitude }} \text { secondary }
$$

The time delay for phase zone two is set similar to time delay inverse overcurrent element. The settings for Center terminal of Line 1 for 21PT elements are shown in Figure 2-15.

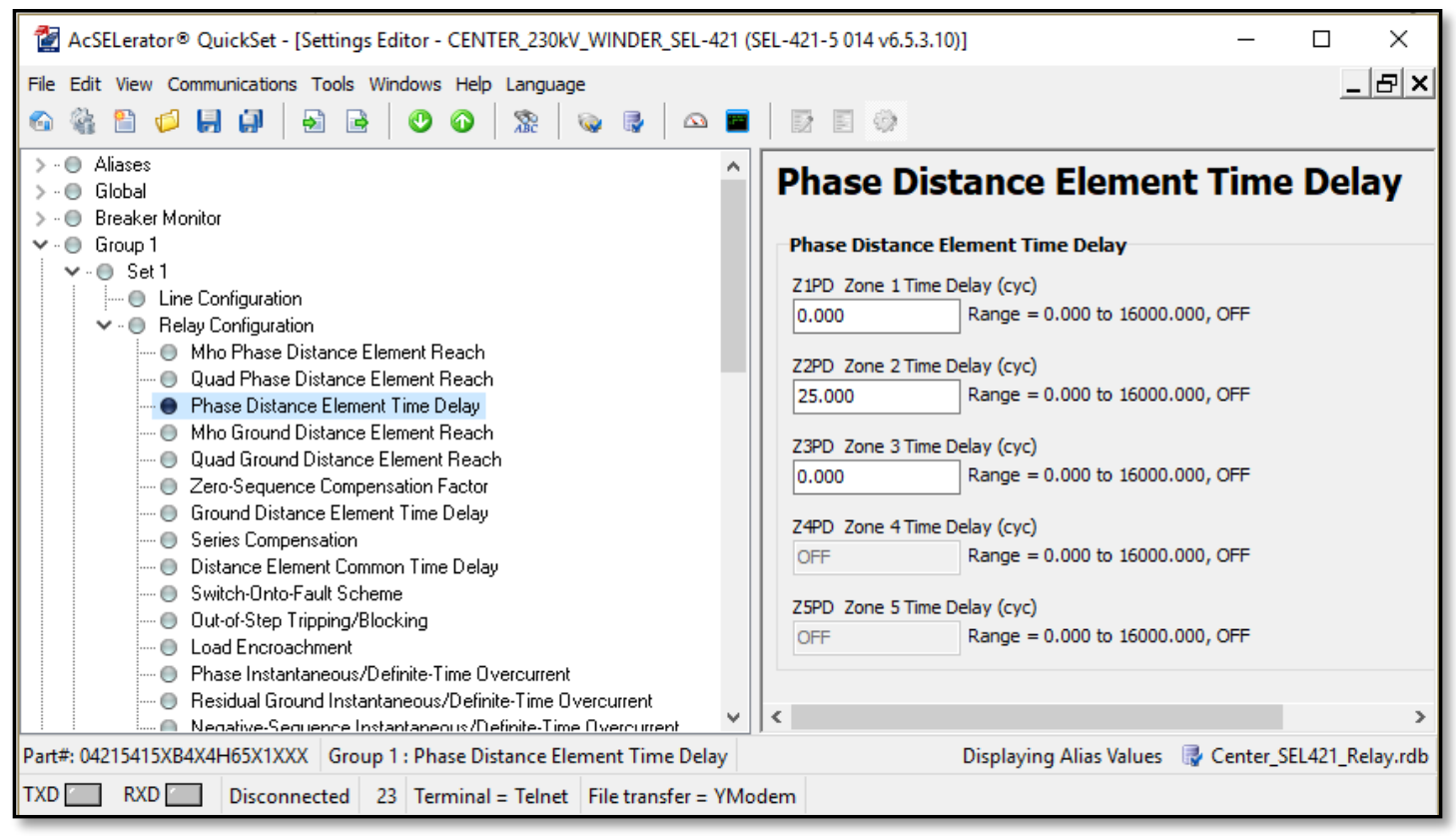

Figure 2-15 - Mho Phase Distance Element Reach Settings 
The settings for Center terminal of Line 1 for 21P elements are shown in Figure 2-16.

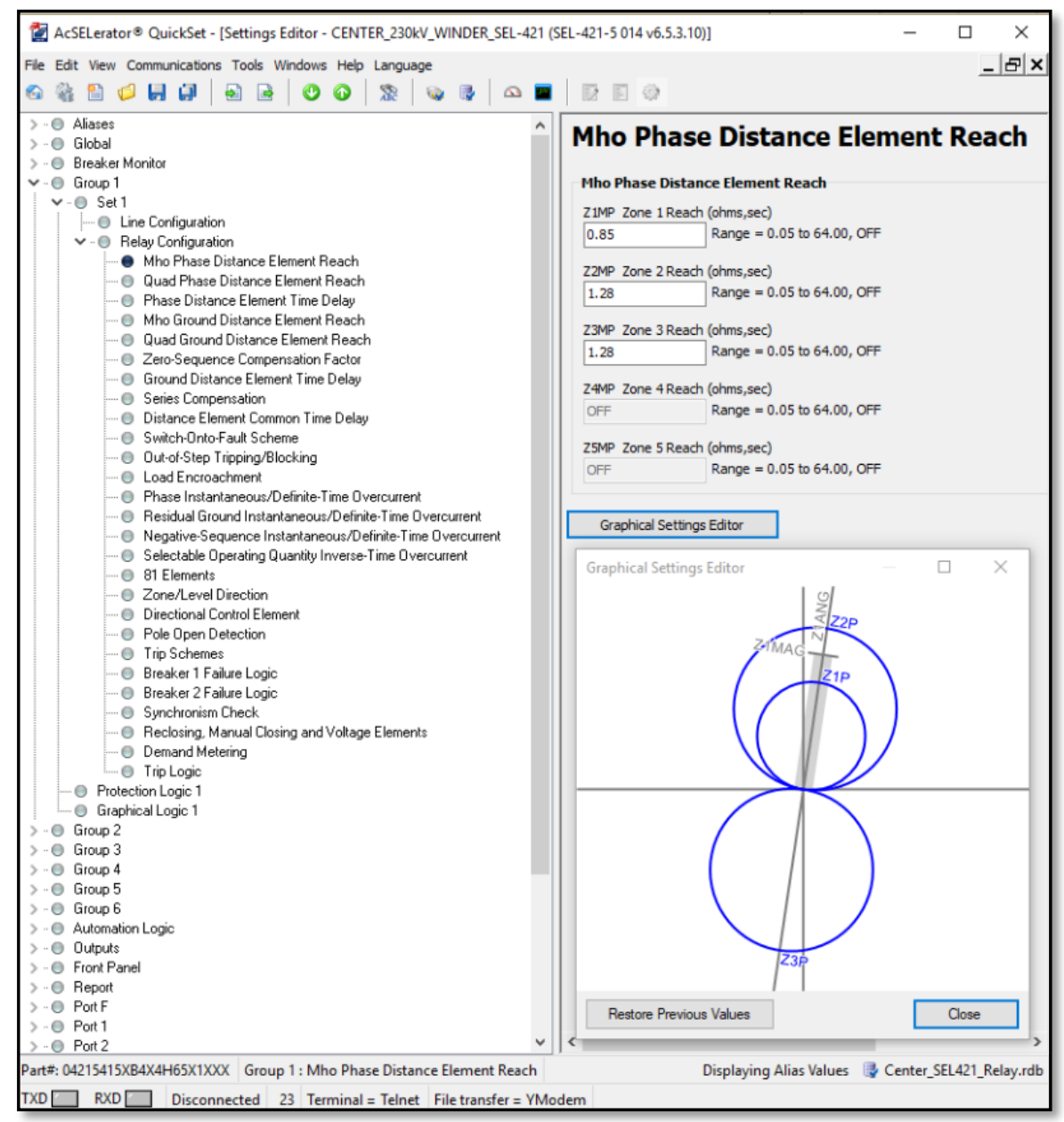

Figure 2-16 - Mho Phase Distance Element Reach Settings

\subsubsection{Ground Distance}

As described in section 2.1.2, the three ground distance reach can be set similarly as phase distance zones. The reach of the Mho ground distance zone 1 to 3 characteristics $(\mathrm{Z} 1 \mathrm{P}-\mathrm{Z3P})$ are defined as,

$$
\begin{aligned}
& Z 1 M G=0.8 Z 1_{\text {magnitude }_{\text {secondary }}} \\
& Z 2 M G=1.2 Z 1_{\text {magnitude }_{\text {secondary }}} \\
& Z 3 M G=-1.2 Z 1_{\text {magnitude }_{\text {secondary }}}
\end{aligned}
$$


Furthermore, a zero sequence compensation factor is required for the reach of the ground distance elements. This will adjust the current and voltage readings of the relay to accurately assess in-zone faults. The zero sequence compensation factor $(\mathrm{k} 0)$ is defined as,

$$
k 0=\frac{Z 0}{3(Z 1-1)}
$$

The settings for Center terminal of Line 1 for $\mathrm{k} 0$ elements are shown in Figure 2-17.

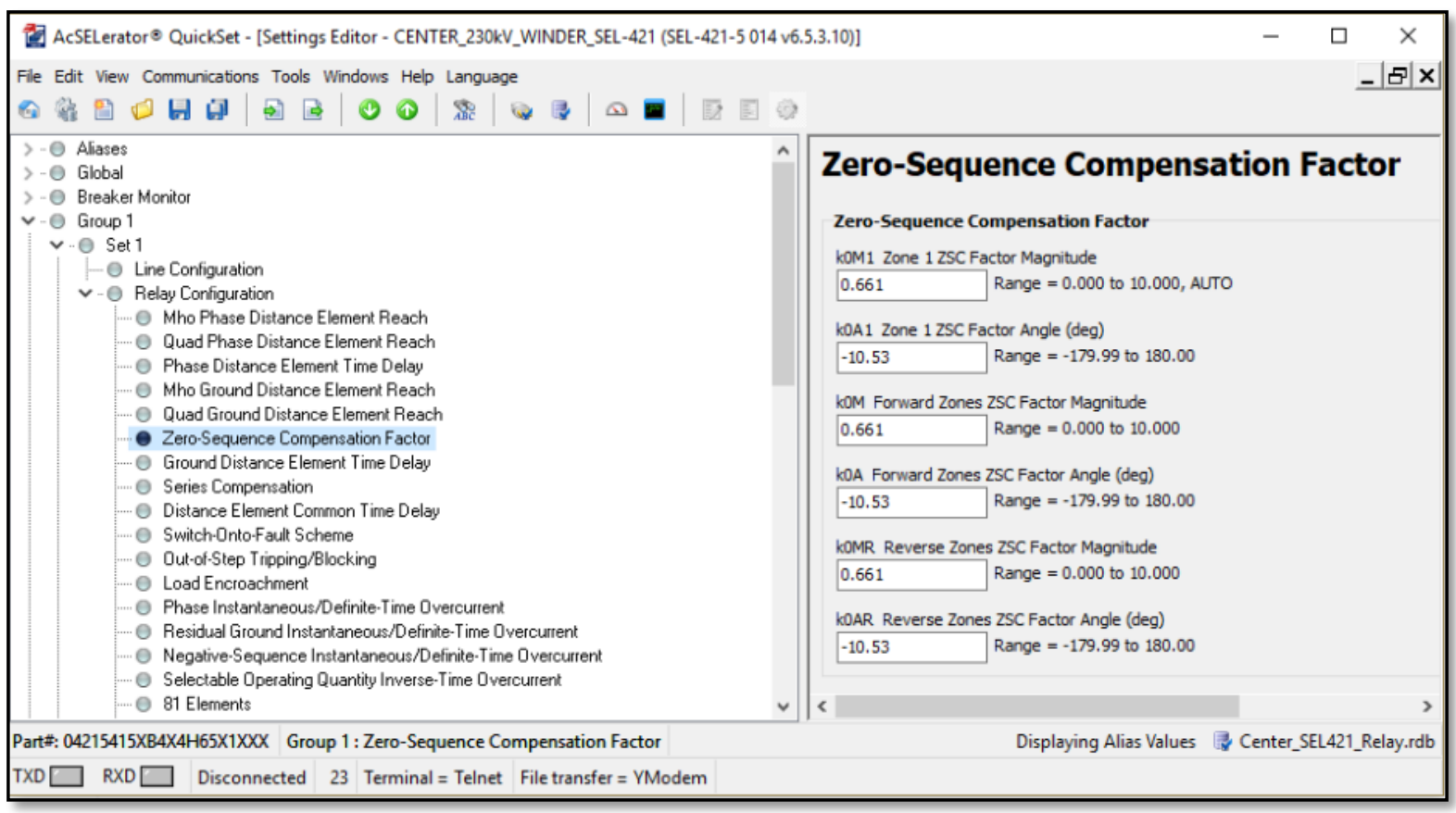

Figure 2-17 - Zero-Sequence Compensation Factor Settings

\subsubsection{Permissive Over-reaching Transfer Trip (POTT)}

As described in section 2.1.3, the permissive over-reaching transfer trip (POTT) scheme requires an over-reaching element from each terminal end. Ten elements are selected for the designed POTT scheme. A phase and ground zone 2 forward distance elements as well as an over-reaching $50 \mathrm{G}$ element. The instantaneous overcurrent is designated for resistive ground faults which may lie outside of the distance Mho characteristics. Furthermore, a phase and ground reverse distance elements are selected optionally as current reversal guards. This increases the security of the POTT scheme to ensure the fault is in-zone of the selected transmission line. The control logic for POTT protection scheme of Center-Winder Line 1 is shown in Figure 2-18. 


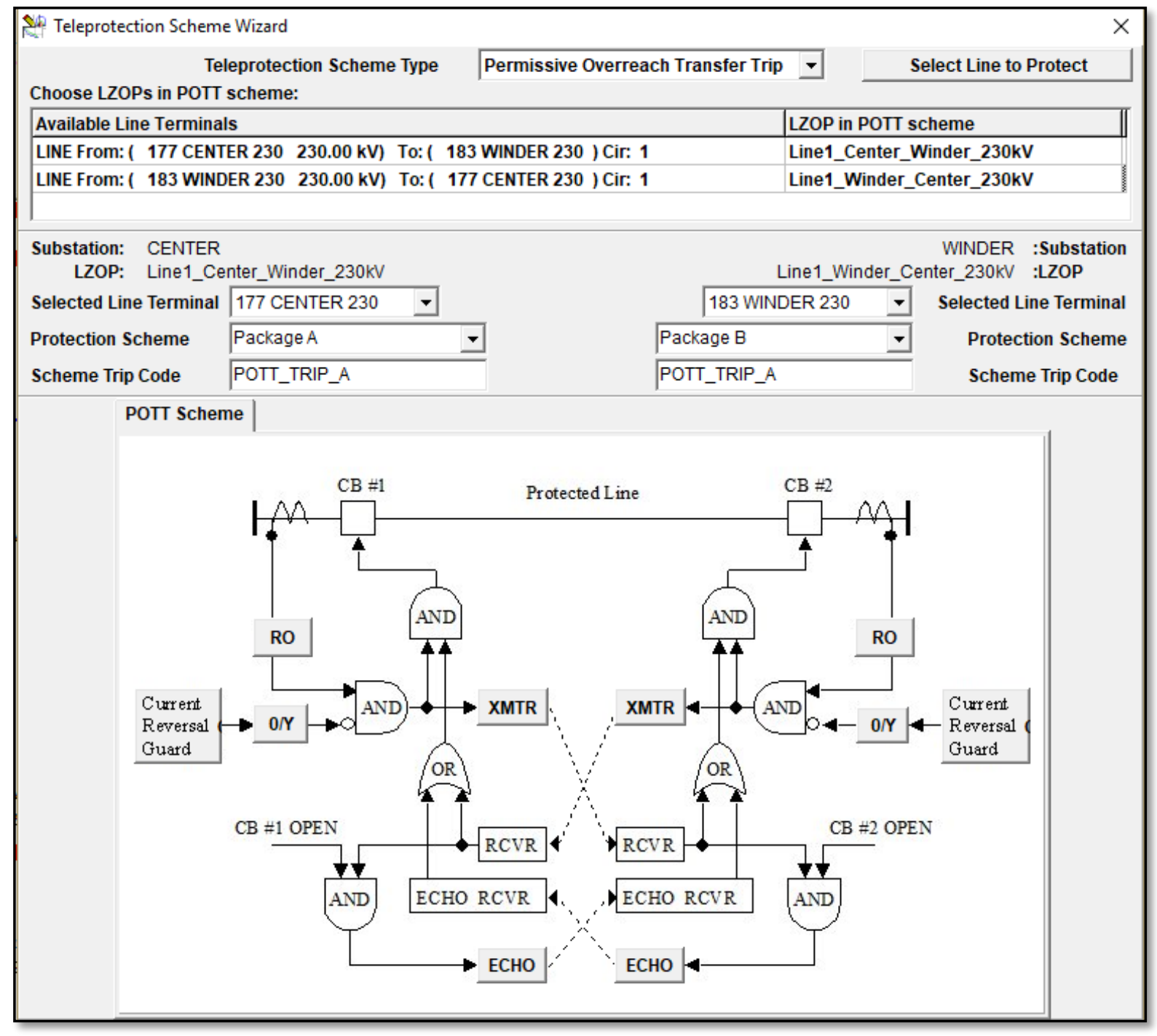

Figure 2-18 - Permissive Over-reach Transfer Trip 


\subsubsection{Relay Settings Summary}

Using the formulation described in section 2.2.3, the relay settings for every terminal of selected seven transmission lines are calculated. The settings of all taps for each line terminating from Winder and Center substations are summarized in Table 2-4 and Table 2-5.

Table 2-4 - SEL-421 Relay Settings for Lines terminating from Winder Station

\begin{tabular}{|c|c|c|c|c|c|c|c|c|}
\hline Line & 2 & 2 & 3 & 3 & 4 & 4 & 5 & 5 \\
\hline From Terminal & Winder & Conyers & Winder & Lawrville & Winder & Gansville & Winder & East Social \\
\hline Remote Terminal & Conyers & Winder & Lawrville & Winder & Gansville & Winder & East Social & Winder \\
\hline R1 (ohm) & 3.2269 & 3.2269 & 1.3754 & 1.3754 & 1.7457 & 1.7457 & 1.6928 & 1.6928 \\
\hline $\mathrm{X} 1$ (ohm) & 21.7948 & 21.7948 & 11.9025 & 11.9025 & 15.1294 & 15.1294 & 18.3034 & 18.3034 \\
\hline $\mathrm{RO}$ (ohm) & 17.3512 & 17.3512 & 10.1039 & 10.1039 & 12.8547 & 12.8547 & 15.3939 & 15.3939 \\
\hline $\mathrm{X} 0$ (ohm) & 63.0568 & 63.0568 & 32.0574 & 32.0574 & 40.6801 & 40.6801 & 50.0963 & 50.0963 \\
\hline Remote Bus Fault SLG (Prim Amps) & 2132.8 & 2289.1 & 3729.4 & 3664.3 & 3326.2 & 1438.6 & 2976.2 & 2668 \\
\hline CTR & 240 & 240 & 240 & 240 & 120 & 120 & 240 & 240 \\
\hline VTR & 2000 & 2000 & 2000 & 2000 & 2000 & 2000 & 2000 & 2000 \\
\hline Z1MAG (Sec ohm) & 2.64 & 2.64 & 1.44 & 1.44 & 0.91 & 0.91 & 2.21 & 2.21 \\
\hline Z1ANG (deg) & 81.58 & 81.58 & 83.41 & 83.41 & 83.42 & 83.42 & 84.72 & 84.72 \\
\hline ZOMAG (Sec ohm) & 7.85 & 7.85 & 4.03 & 4.03 & 2.56 & 2.56 & 6.29 & 6.29 \\
\hline ZOANG (deg) & 74.61 & 74.61 & 72.51 & 72.51 & 72.46 & 72.46 & 72.92 & 72.92 \\
\hline Z1MP (Sec ohm) & 2.11 & 2.11 & 1.15 & 1.15 & 0.73 & 0.73 & 1.77 & 1.77 \\
\hline Z2MP (Sec ohm) & 3.17 & 3.17 & 1.73 & 1.73 & 1.09 & 1.09 & 2.65 & 2.65 \\
\hline Z3MP (Sec ohm) & 3.17 & 3.17 & 1.73 & 1.73 & 1.09 & 1.09 & 2.65 & 2.65 \\
\hline Z1PD (cycle) & 0 & 0 & 0 & 0 & 0 & 0 & 0 & 0 \\
\hline Z2PD (cycle) & 25 & 25 & 25 & 25 & 25 & 25 & 25 & 25 \\
\hline Z3PD (cycle) & 0 & 0 & 0 & 0 & 0 & 0 & 0 & 0 \\
\hline Z1MG (Sec ohm) & 2.11 & 2.11 & 1.15 & 1.15 & 0.73 & 0.73 & 1.77 & 1.77 \\
\hline Z2MG (Sec ohm) & 3.17 & 3.17 & 1.73 & 1.73 & 1.09 & 1.09 & 2.65 & 2.65 \\
\hline Z3MG (Sec ohm) & 3.17 & 3.17 & 1.73 & 1.73 & 1.09 & 1.09 & 2.65 & 2.65 \\
\hline Z1GD (cycle) & 0 & 0 & 0 & 0 & 0 & 0 & 0 & 0 \\
\hline Z2GD (cycle) & 25 & 25 & 25 & 25 & 25 & 25 & 25 & 25 \\
\hline Z3GD (cycle) & 0 & 0 & 0 & 0 & 0 & 0 & 0 & 0 \\
\hline k0M1 & 0.66 & 0.66 & 0.661 & 0.661 & 0.61 & 0.61 & 0.628 & 0.628 \\
\hline k0A1 (deg) & -10.47 & -10.47 & -16.82 & -16.82 & -16.92 & -16.92 & -18.03 & -18.03 \\
\hline 50G1P (Sec amp) & 11.11 & 11.92 & 19.42 & 19.08 & 34.65 & 14.99 & 15.5 & 13.9 \\
\hline 50G2P (Sec amp) & 4.44 & 4.77 & 7.77 & 7.63 & 13.86 & 5.99 & 6.2 & 5.56 \\
\hline 51S1P (Sec amp) & 4.44 & 4.77 & 7.77 & 7.63 & 13.86 & 5.99 & 6.2 & 5.56 \\
\hline 51S1TD & 0.54 & 0.54 & 0.54 & 0.54 & 0.54 & 0.54 & 0.54 & 0.54 \\
\hline
\end{tabular}


Table 2-5 - SEL-421 Relay Settings for Lines terminating from Center Station

\begin{tabular}{|l|c|c|c|c|c|c|}
\hline Line & 1 & 1 & 6 & 6 & 7 & 7 \\
\hline From Terminal & Winder & Center & Center & Bio & Center & Gansville \\
\hline Remote Terminal & Center & Winder & Bio & Center & Gansville & Center \\
\hline R1 (ohm) & 2.5921 & 2.5921 & 3.6501 & 3.6501 & 2.2218 & 2.2218 \\
\hline X1 (ohm) & 17.6157 & 17.6157 & 24.6514 & 24.6514 & 24.4927 & 24.4927 \\
\hline R0 (ohm) & 14.0185 & 14.0185 & 19.6259 & 19.6259 & 18.5679 & 18.5679 \\
\hline X0 (ohm) & 50.9956 & 50.9956 & 71.3621 & 71.3621 & 72.4730 & 72.4730 \\
\hline Remote Bus Fault SLG (Prim Amps) & 2269.3 & 2247.5 & 1896.8 & 1980.7 & 1364.7 & 1242.6 \\
\hline CTR & 120 & 120 & 240 & 240 & 120 & 120 \\
\hline VTR & 2000 & 2000 & 2000 & 2000 & 2000 & 2000 \\
\hline Z1MAG (Sec ohm) & 1.07 & 1.07 & 2.99 & 2.99 & 1.48 & 1.48 \\
\hline Z1ANG (deg) & 81.63 & 81.63 & 81.58 & 81.58 & 84.82 & 84.82 \\
\hline Z0MAG (Sec ohm) & 3.17 & 3.17 & 8.88 & 8.88 & 4.49 & 4.49 \\
\hline Z0ANG (deg) & 74.63 & 74.63 & 74.62 & 74.62 & 75.63 & 75.63 \\
\hline Z1MP (Sec ohm) & 0.86 & 0.86 & 2.39 & 2.39 & 1.18 & 1.18 \\
\hline Z2MP (Sec ohm) & 1.28 & 1.28 & 3.59 & 3.59 & 1.78 & 1.78 \\
\hline Z3MP (Sec ohm) & 1.28 & 1.28 & 3.59 & 3.59 & 1.78 & 1.78 \\
\hline Z1PD (cycle) & 0 & 0 & 0 & 0 & 0 & 0 \\
\hline Z2PD (cycle) & 25 & 25 & 25 & 25 & 25 & 25 \\
\hline Z3PD (cycle) & 0 & 0 & 0 & 0 & 0 & 0 \\
\hline Z1MG (Sec ohm) & 0.86 & 0.86 & 2.39 & 2.39 & 1.18 & 1.18 \\
\hline Z2MG (Sec ohm) & 1.28 & 1.28 & 3.59 & 3.59 & 1.78 & 1.78 \\
\hline Z3MG (Sec ohm) & 1.28 & 1.28 & 3.59 & 3.59 & 1.78 & 1.78 \\
\hline Z1GD (cycle) & 0 & 0 & 0 & 0 & 0 & 0 \\
\hline Z2GD (cycle) & 25 & 25 & 25 & 25 & 25 & 25 \\
\hline Z3GD (cycle) & 0 & 0 & 0 & 0 & 0 & 0 \\
\hline k0M1 & 0.661 & 0.661 & 0.66 & 0.66 & 0.687 & 0.687 \\
\hline k0A1 (deg) & -10.53 & -10.53 & -10.46 & -10.46 & -13.63 & -13.63 \\
\hline 50G1P (Sec amp) & 23.64 & 23.41 & 9.88 & 10.32 & 14.22 & 12.94 \\
\hline 50G2P (Sec amp) & 9.46 & 9.36 & 3.95 & 4.13 & 5.69 & 5.18 \\
\hline 51S1P (Sec amp) & 9.46 & 9.36 & 3.95 & 4.13 & 5.69 & 5.18 \\
\hline 51S1TD & 0.54 & 0.54 & 0.54 & 0.54 & 0.54 & 0.54 \\
\hline
\end{tabular}




\subsection{Summary}

Chapter 2 summarized an industry accepted transmission line protection philosophy. It listed how a typical transmission line is protected with the use of ground and phase distance protection as well as ground only overcurrent protection. Challenges and limitations of both overcurrent and distance characteristics was elaborated such as the strong impact of source impedance ratio and high loadability concerns resulting in incorrect operation of phase protective elements.

This deep understanding of best practices is required in order to properly define the holistic wide area protection model. The primary network of the study model was described in depth. Furthermore, the relay settings for 14 devices was calculated based on the primary network and short circuit parameters. The prepared relay settings in their native manufacturer setting file format were uploaded to the CAPE database to define the complete study model required for the subsequent chapters. 


\section{Wide Area Protection Coordination}

\subsection{Overall Process}

The concept of a wide area coordination studies can pose significant challenges to utilities and other applicable entities. In addition to the technical engineering effort associated with the execution of Protection System Coordination Studies, the process also necessitates significant workflow management and data processing considerations. Figure 3-1 represents a proposed process for the execution of Protection System Coordination Studies for transmission network protection systems.

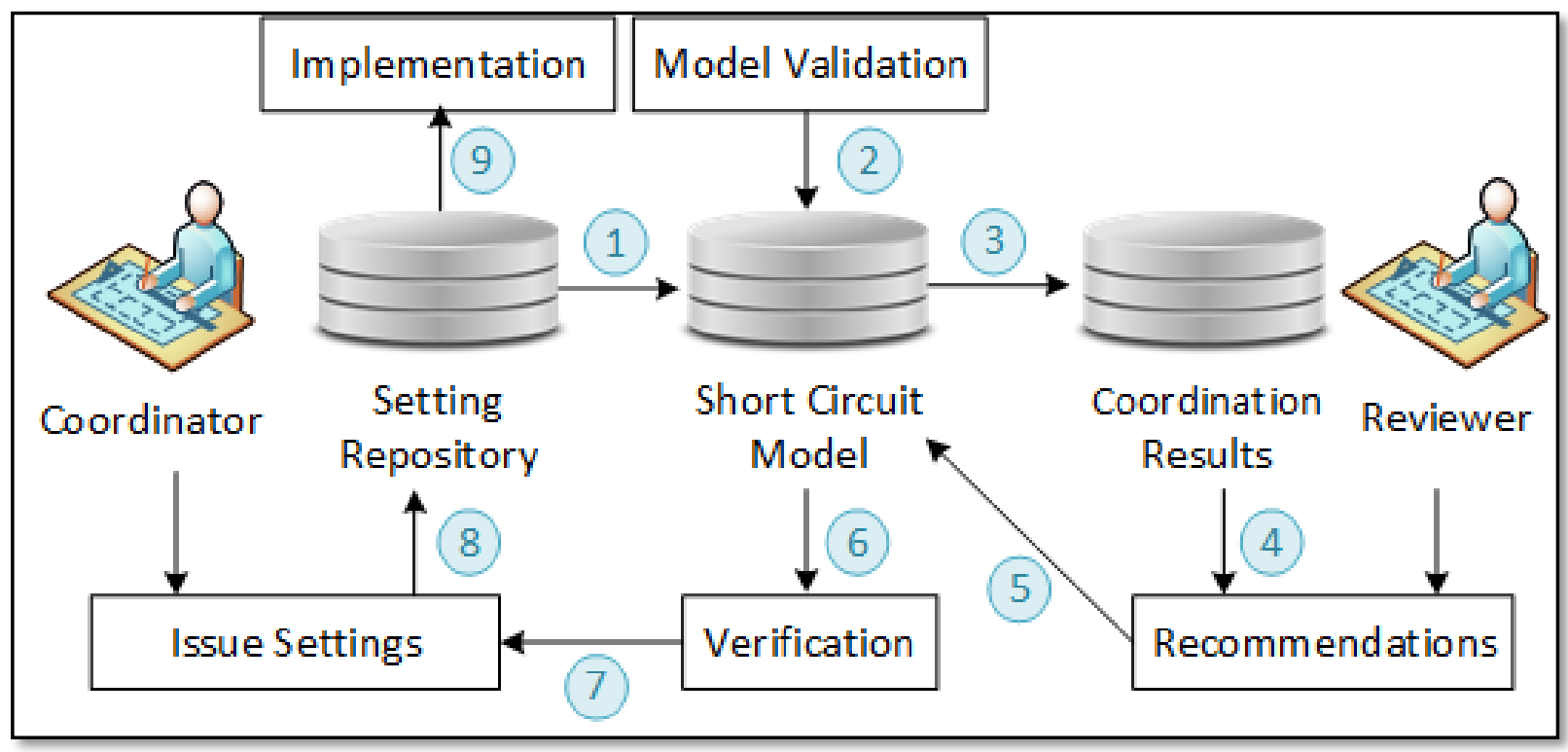

Figure 3-1. Wide Area Protection Coordination Solution Process Diagram

This approach covers process and data management considerations and provides a framework workflow for execution and review of coordination studies, and processing and documentation of results to support Reliability Improvements. The central concept of the approach under discussion is the utilization of software-based automation in a number of key tasks. Firstly, the execution of large-scale Protection System Coordination Studies can be largely automated through utilization 
of specialized scripts running within the short circuit simulation software packages. Secondly, the vast amounts of data inherent in the Protection System Coordination Study results are processed in a manner that assists protection engineers in the identification and resolution of coordination issues. Finally, friendly automated study summaries are generated that can be used as a record of protection setting recommendations.

The proposed solution can be broken into 9 steps:

- Step 1 includes transfer of vendor specific electronic setting files retrieved from transmission substations stored in an asset management database into the short circuit model. This step requires the knowledge of individual relay setting taps that can impact a protection coordination study, requiring them to be modeled. Additionally, the internal relay characteristics will need to be represented such that the model can accurately replicate the behavior of the real-world system.

- Step 2 requires an in-depth model validation prior to conducting short circuit simulations. Manual modeling of a complex protection system including telecommunication based schemes can be very laborious, and can be prone to errors. This aspect has been a barrier in the past for transmission system operators, to build a detail protection model and take advantage of modern protection system analysis tools. Applying thousands of fault simulations take considerable amount of time to complete. A single simple modeling error of a protective function can result in invalidating extensive simulation results in subsequent steps. Therefore, a detailed data and simulation based model validation can assist in reducing the burden of rerunning coordination studies due to modeling errors.

- Step 3 is the execution of protection assessment studies using the short circuit model. This step can be broken into two types of protection studies. First, a relay sensitivity study will focus on evaluating the settings of individual rely elements against the criteria used to select them. This task is a precursor to the coordination study, and it helps discover and correct fundamental settings issues. Next, a coordination study is required to simulate a wide range of fault types, fault locations, and system contingencies to assess the behavior of protection devices one-to-two substations away from the fault. The study utilizes the sequence of events analysis, which allows the user to uncover issues that cannot normally be uncovered through manual fault studies. The coordination study challenges the 
operation of all relays in the selected area to work together as a system under various stressed conditions. The raw results of all studies is best to be collected in a centralized database for further processing. This step is one of the most time consuming as thousands of simulation scenarios will be required for each transmission line.

- Step 4 focuses on analyzing the study results. The centralized study database can be accessed to post process both the sensitivity and coordination studies. The main intention of the condensing of the raw study results is to focus engineer's limited time on solving relay settings problems rather than reviewing millions of pages of raw data to identify the problems. It assists in keeping track of all changes and provides a solution for an entire team to work simultaneously on coordination issues. The front end user interface can access the data repository to facilitate reviewing the results, ranking the recommendations, and generating reports.

- Step 5 includes the transfer of the recommended setting change from the analyzed post processed simulation results back into the short circuit model. This is a predecessor step for being able to ensure that the recommendations are valid. The engineer will now be able to have a record of the original settings of each protective device on the field versus the recommended relay settings to mitigate protection coordination violations.

- Step 6 focuses on validating protection recommendations as a result of the coordination studies before issuing them back to the field. Coordination of a looped transmission network can become a challenge and in some extreme fault scenarios impossible to achieve. During this step, engineer will gain confidence in their recommendations to not only resolve the flagged violations, but also not creating new coordination issues due to their new proposed settings. Steps 3 to 5 can be rerun iteratively until the latest proposed setting changes resolve all mis-coordination without creating any new issues.

- Step 7 is a necessary requirement to translate the overall wide area protection coordination solution into the Transmission utilities internal setting analysis process. All reports generated from the centralized study database ranking the individual recommendations can be evaluated and prioritized by a coordinator and ultimately transformed to the final setting change package required.

- Step 8 follows the data management process put in place for large utilities to cope with handling thousands of protective devices at once. This task focuses on making the proposed 
solution a closed looped process. The recommendations are now translated back into vendor specific electronic settings files. These files are issued to the field prioritized with the help of a coordinator and can be remodeled as original settings back into the short circuit model during step 1 for future studies.

- Step 9 manages all newly issued settings to be retrieved from the asset management database, tested on the physical devices, and ultimately uploaded on the transmission substations. The benefits for a complicated process heavy solution will not be observed unless the recommendation are applied to the field.

A detailed solution for Step 3 of the proposed solution will be investigated in depth. The criteria set for sensitivity and coordination studies will be described in the subsequent sections. Next, multiple study cases using a sample transmission model will be evaluated in Chapter 4 to prove the benefit of a comprehensive wide area protection coordination solution.

\subsection{Sensitivity Analysis}

A relay settings sensitivity check is performed before embarking on the wide-area coordination review so that any violations of fundamental settings criteria will have been identified and dealt with before the final studies. The solution should find all of the protected line ends and perform the checks described below relative to each protected line end on that line.

A sensitivity analysis is developed that can perform automated relay setting checks against their protection settings criteria. The sensitivity study is designed specifically for assessing a transmission line's protection elements. Protection elements that are typically assessed are: instantaneous overcurrent (IOC), inverse-time overcurrent (TOC), and Zone 1-2 of distance elements. For each protection element type being studied, the fault type, location, and the forced system contingencies are customized as required.

\subsubsection{Instantaneous Overcurrent (IOC)}

Instantaneous Overcurrent elements are designed to be under-reaching elements as they act as fast tripping. The ratio of the pick-up current to the largest current measured by the relay for a fault at the remote bus should have a setting of 1.25 or higher (see Figure 3-2). The remote sources are outaged one at a time to capture the highest fault current scenario. Mutually coupled line outaging 
and grounding at both ends are also tested as part of the contingencies for ground IOC elements. Additionally, for multi-terminal lines, the entire third terminal is also outaged separately to check for over-reach of the IOC element to the remaining in-service terminals. The remote sources will also be outaged one at a time in addition to the third terminal.

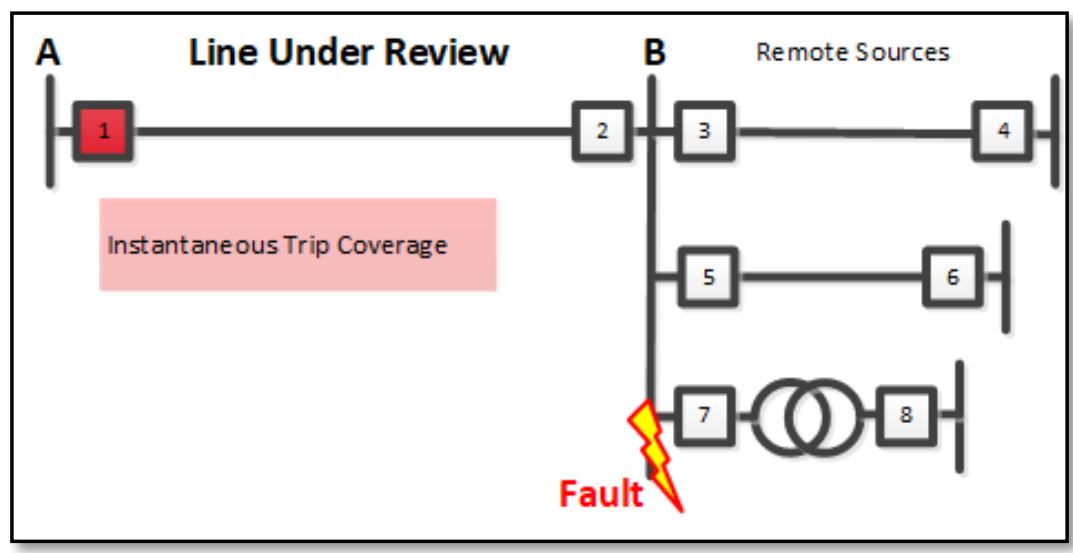

Figure 3-2. IOC Sensitivity Test Description

\subsubsection{Inverse Timed Overcurrent (TOC)}

Inverse Timed Overcurrent elements are designed to be over-reaching elements as they act as a time delayed backup elements. The ratio of minimum acceptable fault-current-to-pick-up-current ratio for selected TOC elements should have a setting of 50\% or lower (See Figure 3-3). The local sources are outaged one at a time to capture the lowest fault current scenario. The mutually coupled line outaging and ground at both ends are also tested as part of the contingencies for ground TOC elements.

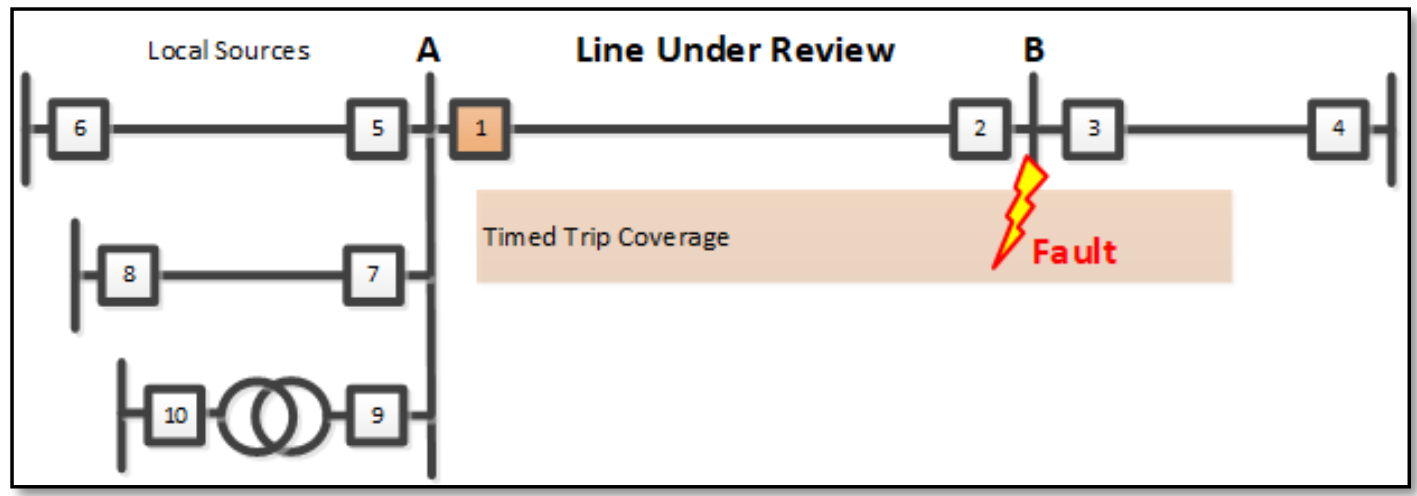

Figure 3-3. TOC Sensitivity Test Description 
Additionally, to ensure the TOC element can always over-reach its protective line, end of line fault at each second remote bus with the breaker at that location open can be applied (radial condition). This sensitivity check looks only at the reach of the TOC element. It is not a coordination study. Issues of coordination with backup elements will be detected by the coordination review studies.

\subsubsection{Zone 1 Distance}

The expected reach of the zone 1 distance element is typically $80 \%$ of the positive-sequence impedance of the protected line. The zone 1 protection is expected to be tripping the breaker instantaneously without any time delay (See Figure 3-4). Therefore, the proposed setting will provide a $20 \%$ safety margin for a zone 1 not to mis-operate on adjacent transmission line faults (out of zone). If the line is a multi-terminal line, however, it must be ensured that zone 1 does not over-reach a remote terminal under the condition that one of the other terminals is entirely outaged.

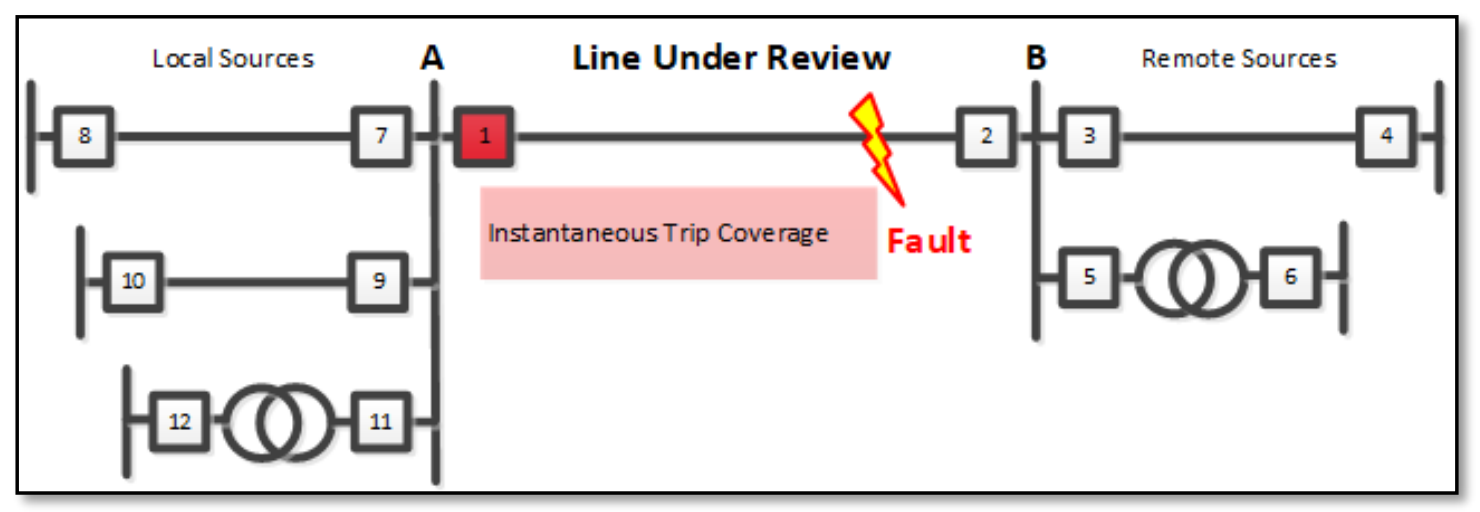

Figure 3-4 - Zone 1 Distance Sensitivity Test Description

This zone 1 reach needs to be tested and comply for system contingencies cases where other system elements such as a transformer or adjacent transmission lines could be outaged for maintenance when the fault occurs. The reach of ground zone 1 can be significantly affected if these system contingencies include outaging another transmission line which is mutually coupled with the study case [3-4].

\subsubsection{Zone 2 Distance}

The expected reach of the zone 2 distance element is typically set to overreach the end of the protected line. Zone 2 reach shall be set to $100 \%$ of the measured apparent impedance of the line 
based on the remote bus fault, plus $50 \%$ of the actual impedance of the shortest line extending from the protected line's remote bus. This reach should:

- Not be less than $120 \%$ of the measured apparent impedance for a fault at the remote bus of the protected line (Fault 1)

- Should not reach through a remote transformer (Fault 2)

In order to determine if the zone 2 element does reach the remote terminal, one test can be calculating the ratio of the reach setting of the relay to the apparent impedance measured by the relay for a fault at that remote terminal. Additionally, to make sure the zone 2 is not reaching above $50 \%$ into the shortest adjacent line, a fault can be applied on the remote bus of every adjacent line.

Similar to zone 1 , the reach of zone 2 needs to be tested and comply for system contingencies cases where other system elements such as a transformer or adjacent transmission lines could be outaged for maintenance when the fault occurs. The reach of ground zone 2 can be significantly affected if these system contingencies include outaging another transmission line which is mutually coupled with the study case [3-4]. This test is done by disconnecting the source (one at a time) at remote bus and test the $50 \%$ reach. With one source outaged, the engineer can determine how far into the adjacent line, the zone 2 elements will reach. Outage of mutual coupling will be considered for ground distance elements. Multiple criteria required for a zone 2 distance elements are illustrated in the Figure 3-5.

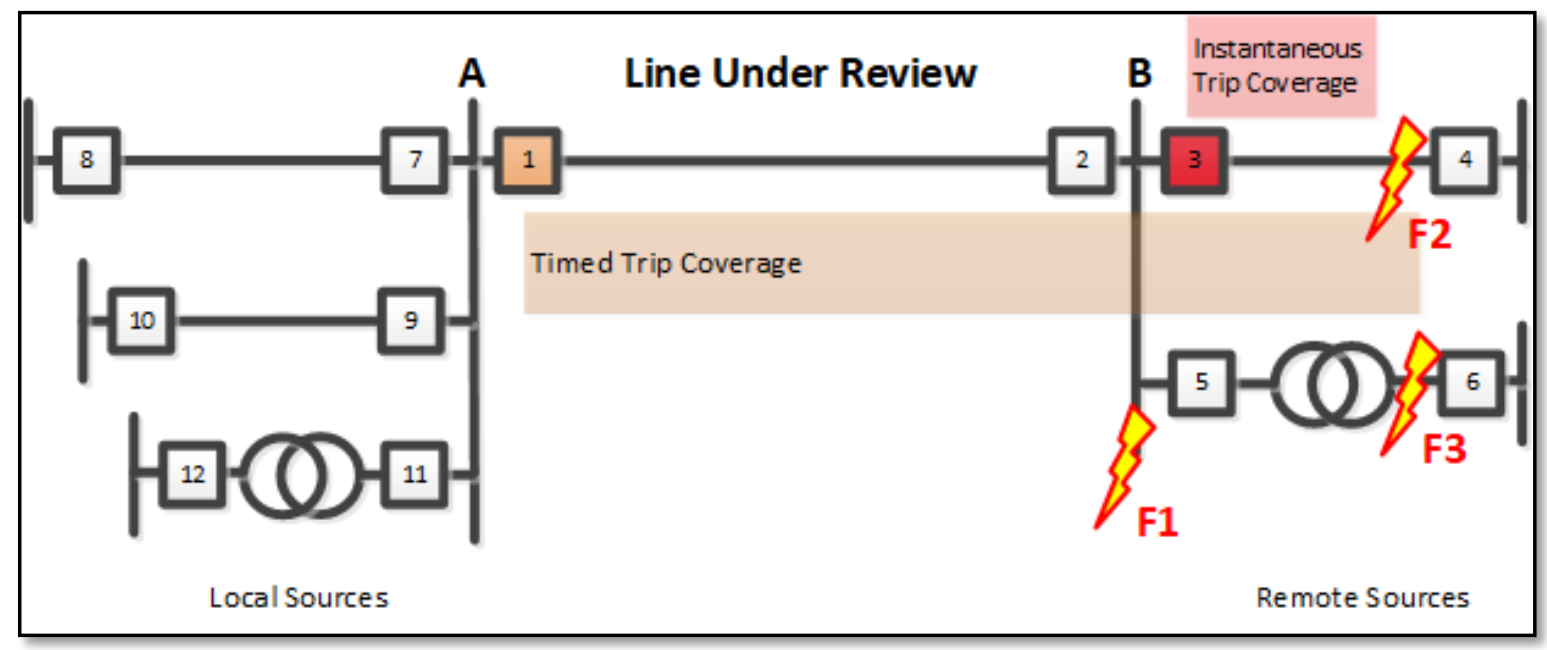

Figure 3-5 - Zone 2 Distance Setting Criteria 
In this example, there will be a challenge setting the breaker 1 Zone 2 tripping range. By setting the device $120 \%$ of line under review apparent impedance, the zone 2 will over-reach breaker 3 Zone 1 instantaneous tripping path. Therefore, for a given Fault 2, you will have a race between Breaker 1 and Breaker 3 zone 2 elements with similar time delays. To avoid this scenario, the protection engineer will be forced to reduce the $120 \%$ margin slightly for its reach to be closer to the $50 \%$ of Breaker 3 [3-4].

\subsection{Coordination Analysis}

A transmission line coordination check is performed that simulates a wide range of fault types, fault locations, and system contingencies and assesses the behavior of protection devices one to two substations away from the fault. The tool should be able to perform a large batch of studies while applying the appropriate faults and system contingencies automatically.

The study captures several kinds of relay settings issues:

- Inadequate Coordination Time Interval (CTI) margins: A backup relay element is predicted to operate too close in time to a primary relay element

- Mis-operation: A backup relay element operates ahead of a primary relay element, and opens its circuit breaker

- Failure to clear a fault: Under certain contingencies, it is possible that a fault on a line cannot be cleared. This may well lead to CTI margin violations or mis-coordination from remote backup relays

The protection coordination review evaluates the protection system as a whole, with options such as tele-protection included in the model of the power system. By systematically challenging the system with different contingencies like outage of primary network components, failure of teleprotection schemes, etc., we can test the time operation of various relay elements in the system.

The coordination studies are designed to uncover situations where remote backup protection is either faster than the primary protection for a given fault and location, or operates too quickly afterwards, i.e. a Coordination Time Interval violation occurs. 
Given the large number of studies that need to be performed, a typical coordination study on a transmission line will include the following scenarios:

- Various types of faults like Single-Line-Ground, Line-to-Line, Double-Line-Ground, and Three-phase, with and without fault resistance

- User-defined fault locations: local close-in, $15 \%, 50 \%, 85 \%$, and remote-close-in, or other arbitrary location, including the high-side of load tap transformers on the line

- Outages of redundant protective relays at the primary location one at a time (Package A versus B evaluation)

- Outages of fast clearing communication assisted tele-protection schemes (pilots)

- Outage of sources of fault current at each terminal of the study line like:
○ Lines
○ Generators
○ Transformers
○ Bus Ties
○ Grounding transformers
○ Mutually coupled lines

Obviously, this is not something that should be done manually for an entire transmission network. Automating the study is a necessity using modern software and programming methods. A graphical representation of these scenarios is represented in Figure 3-6.

For a typical study with the following scenario, an average of $1760(8 \times 5 \times 11 \times 2 \times 2)$ separate fault simulations will be performed for each transmission line under study:

- (4+4) Four bolted faults: SLG, LTL, DLG, and TPH

- $\quad$ Four resistive faults (5 \& 10 ohms SLG \& DLG)

- (5) Five fault locations

- (11) Assume system normal as well as five local and five remote sources to be outaged

- (2) Two protection packages A and B

- (2) With and without pilot protection 


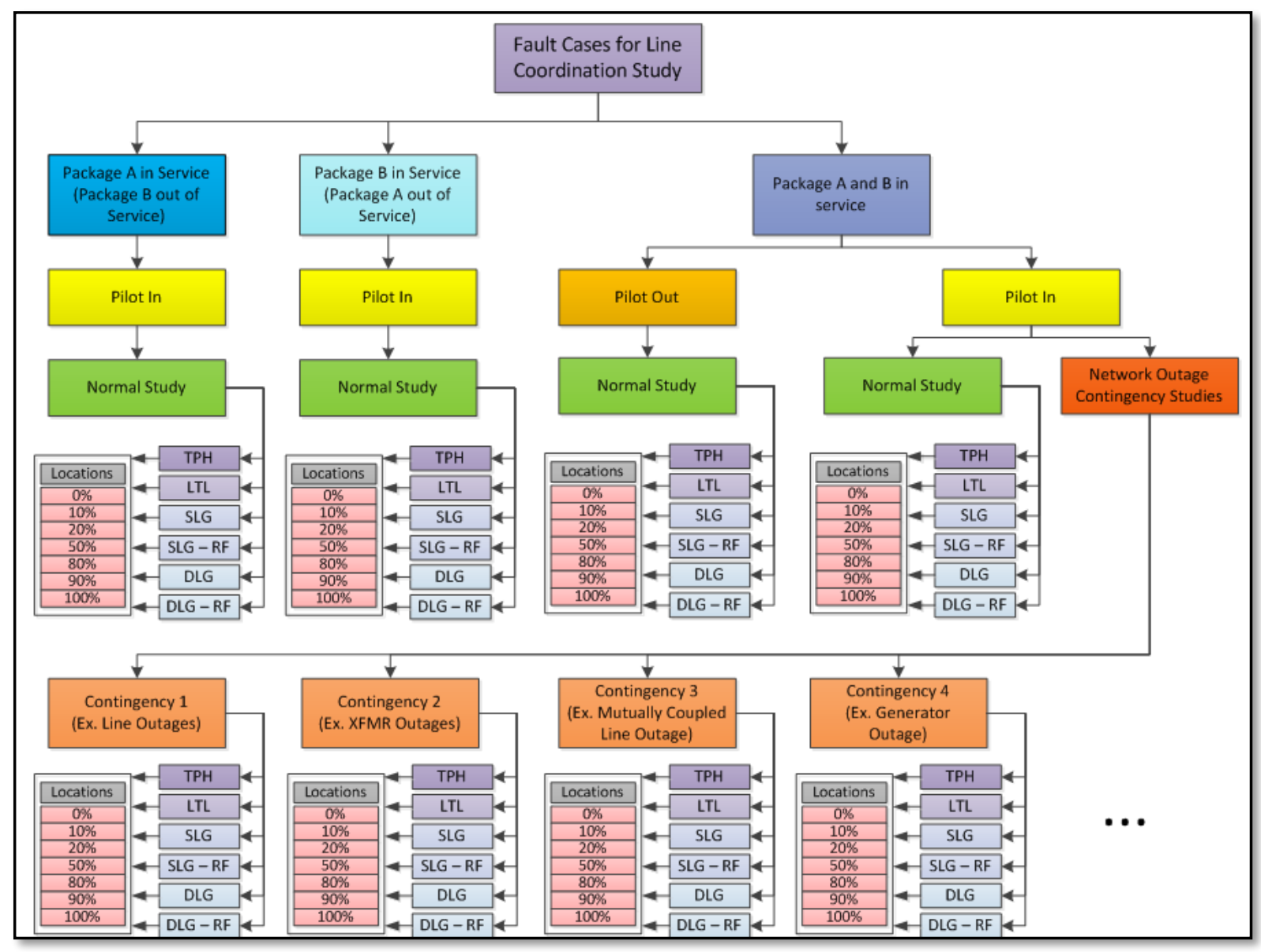

Figure 3-6 - Coordination Study Testing Criteria

\subsection{Need for Automation}

The performance of the 9 steps of the comprehensive wide area protection coordination solution described in chapter 3.1 will be very time consuming. A large collection of data will be produced after modeling hundreds of thousands of devices in a short circuit program and performing thousands of fault scenarios for each transmission line. The closed loop process must be completed with limited effort and fast in order for the recommendations to be useful. The setting changes of relays have to be uploaded to the field in a timely manner since a large backlog of studies will be deemed invalid over time. The transmission system keeps evolving over time and all 9 steps must be performed before a significant change to the primary model occur. Therefore, the use of extensive automation to maintain quality and meet aggressive schedule is required. 
The automation can be divided into four categories:

1) Automation of data entry and validation to eliminate manual entry as much as possible. This will alleviate burden on protection engineers and holistically check for model deficiencies.

2) Automation of the study to enforce protection setting philosophy is applied throughout the transmission network by running thousands of fault scenarios for each study (almost impossible to perform manually)

3) Automation of processing of study output results to condense thousands of pages of raw results and focus the protection engineers time on only areas needing attention

4) Automation of submission of reports and providing statistics by efficiently delivering large amount of study results in an organized manner to facilitate the setting recommendations

Some of these automation routines in the form of scripts and macros were utilized in performing three significant study cases in chapter 4 .

\subsection{Summary}

Chapter 3 described the overall holistic proposed wide area protection coordination solution. Four major stages of model, study, analyze, and report of the overall solution was listed. Furthermore, it listed the requirements for achieving optimal settings. The focus of the thesis which is the study stage of the overall solution presented a comprehensive sensitivity and coordination. Lastly, the need for automation of the overall solution was discussed. 


\section{Simulation Results}

\subsection{Introductions}

Chapters 2 and 3 presented the mathematical checks and a verification methodology for the proposed holistic wide area protection coordination solution. To evaluate the performance of the wide area protection coordination solution and its effectiveness under various system normal and fault contingencies, the prepared transmission model has been simulated and verified in CAPE software environment.

The following sections of this chapter, defines various study cases of the test system configurations and presents the results obtained from simulating the transmission system using holistic wide area protection coordination solution under numerous fault scenarios.

\subsection{Test System Configurations}

The coordination study is run by building the short circuit network of the primary transmission system under a low voltage scenario of using a 0.95 -pu system voltage. For the purpose of the study, all simulations with a simulation depth of 1 , meaning that coordination is only checked between the protection for primary zone of the faulted element and the immediately adjacent backups. A mutual coupling depth of 1 is also used, meaning that coordination is checked between the protection for primary terminal of the faulted line and lines that share mutual coupling with the faulted line.

\subsubsection{Fault Scenario Selection}

In order to accurately assess the protection system of the study case, the specifications of the coordination study are selected as follows:

- System Contingencies: Each of the simulations is performed under system normal conditions and under every possible N-1 contingency except breaker failure. To simulate N-1 system contingencies, primary network elements connected to the element being 
faulted are taken out of service one at a time prior to the simulation. For line fault simulations for example, primary network elements connected at all line terminals such as lines, transformers, shunts, generators, and bus coupler breakers are outaged one at a time. In addition, lines that are mutually coupled to the faulted line or mutually coupled to a line that neighbors the faulted line are also taken out of service one at a time (outaged and grounded).

- Protection Contingencies: Each of the simulations is performed under system normal conditions and under tele-protection assisted scheme (POTT) outaged.

- Fault type: For each element in the study area, the following faults are applied:

○ Single-Line-to-Ground (SLG)

○ Three-Phase-to-Ground (TPH)

- SLG with Resistance - single line to ground faults with $5 \mathrm{ohms}$ fault resistance

- SLG with Resistance - single line to ground faults with $10 \mathrm{ohms}$ fault resistance

- Fault locations:

- Line fault location: On lines, these simulations are done at fault locations of $0.01 \%$, $15 \%, 30 \%, 50 \%, 70 \%, 85 \%$, and $99.99 \%$ of the line, calculated on the basis of the positive-sequence line impedance.

- Included Protection Elements:

○ Pilot Schemes (POTT)

- Line Protection (distance and overcurrent)

- Excluded Protective Elements:

- Transformer and bus differential protection are not investigated; however, the simulations will ensure that backup protection for differential protection meets the minimum CTI requirements considering instantaneous protection operation time of the differential protection for faults within their protective zones.

- Also, excluded from the study are breaker failure coordination, re-closers, electromechanical fault detectors, out-of-step, stub bus protection, voltage and frequency relays, and loss-of-potential. 
- Generator protection is excluded

\subsubsection{Criteria for Successful Operation}

The coordination studies are designed to uncover situations where remote backup protection is either faster than the primary protection for a given fault and location, or operates too quickly afterwards (i.e., a coordination time interval violation occurs).

The CTI is a safety margin that distinguishes between proper backup response and a backup response that could become a mis-operation in real life. This time will be the same number for the evaluation of both distance and overcurrent protective device responses. The required CTI is defined as 12 cycles. Time difference less than the required CTI will be flagged as a coordination problem. The Coordination Time Interval Flag is defined as,

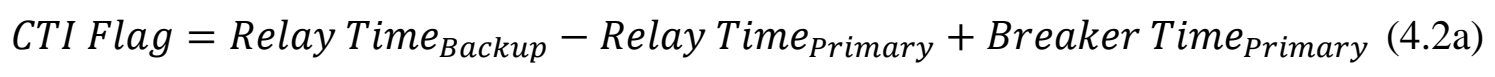

Breaker interrupting time is set as 3 cycles for $230 \mathrm{kV}$. Breaker interrupting time is 5 cycles for MV levels such as $115 \mathrm{kV}$ [64]. Tele-protection delay standard is less than 25 to 30 millisecond. This delay is just the channel interruption, and it does not include any other settable delays within the relays.

\subsection{Study Cases and Simulation Results}

The operation of the proposed wide area protection coordination solution was analyzed in CAPE software environment. The case studies selected are designed to subject the model to significant stressed conditions. The response of the protection system to these stressed conditions are captured and compared to industry expectations. This section presents the obtained results of different simulation scenarios. The abovementioned case studies are divided into three groups. First, correct settings recently calculated for the model are stressed under system normal and N-1 contingency conditions with/without POTT scheme activated for bolted and resistive faults. Next, a human error scenario for one of the relay elements with incorrect settings is reviewed using the proposed solution. Lastly, the same protection system utilized in case 1 is reviewed under a significant change in the primary fault current simulating the future changes in the Transmission topology. 


\subsubsection{CASE 1: System normal \& N-1 Contingency Conditions}

Two individual studies were executed in order to accurately assess the protection scheme utilized for study Line 1 between Winder and Center substations. First, hundreds of faults were applied on Line 1 to evaluate the performance of Line 1 protection as primary (i.e. faster than backup). Next, the same fault scenarios were conducted on Line 6 between Center and Bio substations. The second study is intended to evaluate Line 1 protection as backup (i.e. slower than primary). The topology of the test system and the fault selection scenario described in chapter 4.2 resulted in 546 tests on Line 1 and 392 tests on Line 6 . The lower test conditions performed on Line 6 are due to the lower count of neighboring equipment as N-1 contingency outage situations. As described in Figure 2-8, Line 1 has a total neighboring outages of 6 lines, 2 transformers, and 1 mutually coupled line. However, Line 6 without a direct connection to a large Winder substation ha a total neighboring outages of 3 lines, and 3 transformers. The results of study Line 1 and Line 6 are presented in the following sections.

\subsubsection{Telecommunication assisted protection in Service}

A total of 70 Single-Line-to-Ground faults on Line 1 were applied while the POTT scheme was in service. Table 4-1 lists the total fault clearing time for each simulation. The average clearing time for these faults were quite fast at 68.43 milliseconds. This fast clearing is due to the active communication between both Winder and Center substations through the means of the POTT scheme. No coordination issues were identified for any of the simulations on line 1.

Table 4-1 - Line 1 Fault Clearing Time Results (Pilot In, SLG Bolted Faults)

\begin{tabular}{|c|c|c|c|c|c|c|c|c|c|c|}
\hline \multirow{2}{*}{ Outage } & \multirow{2}{*}{ Pilot } & \multirow{2}{*}{ Fault Type } & \multicolumn{7}{|c|}{ Fault Clearing Time (Seconds) } & \multirow{2}{*}{ Mis-coordination } \\
\hline & & & $0 \%$ & $15 \%$ & $30 \%$ & $50 \%$ & $70 \%$ & $85 \%$ & $100 \%$ & \\
\hline Primary System Normal & $\ln$ & SLG & 0.07 & 0.065 & 0.065 & 0.065 & 0.065 & 0.07 & 0.07 & No \\
\hline XFMR : 177-1317-1( Bank A) & In & SLG & 0.07 & 0.065 & 0.065 & 0.07 & 0.07 & 0.07 & 0.07 & No \\
\hline Line : 177-154-1(LINE7) & $\ln$ & SLG & 0.07 & 0.065 & 0.065 & 0.07 & 0.07 & 0.07 & 0.07 & No \\
\hline Line : 177-175-1(LINE6) & In & SLG & 0.07 & 0.065 & 0.065 & 0.07 & 0.07 & 0.07 & 0.07 & No \\
\hline XFMR : 183-1316-1( Bank C) & In & SLG & 0.07 & 0.065 & 0.065 & 0.07 & 0.07 & 0.07 & 0.07 & No \\
\hline Line : 183-105-1(LINE3) & In & SLG & 0.07 & 0.065 & 0.065 & 0.07 & 0.07 & 0.07 & 0.07 & No \\
\hline Line : 183-141-1(LINE2) & In & SLG & 0.07 & 0.065 & 0.065 & 0.07 & 0.07 & 0.07 & 0.07 & No \\
\hline Line : 183-151-1(LINE4) & In & SLG & 0.07 & 0.065 & 0.065 & 0.07 & 0.07 & 0.07 & 0.07 & No \\
\hline Line : 183-449-1(LINE5) & In & SLG & 0.07 & 0.065 & 0.065 & 0.07 & 0.07 & 0.07 & 0.07 & No \\
\hline Mutual: 179-181-1(LINE8) & In & SLG & 0.07 & 0.065 & 0.065 & 0.07 & 0.07 & 0.07 & 0.07 & No \\
\hline
\end{tabular}


Figure 4-1 represents one test scenario listed in the abovementioned table in depth. The fault scenario is a system normal condition with a bolted SLG fault at $100 \%$ location (remote close-in at Winder substation).

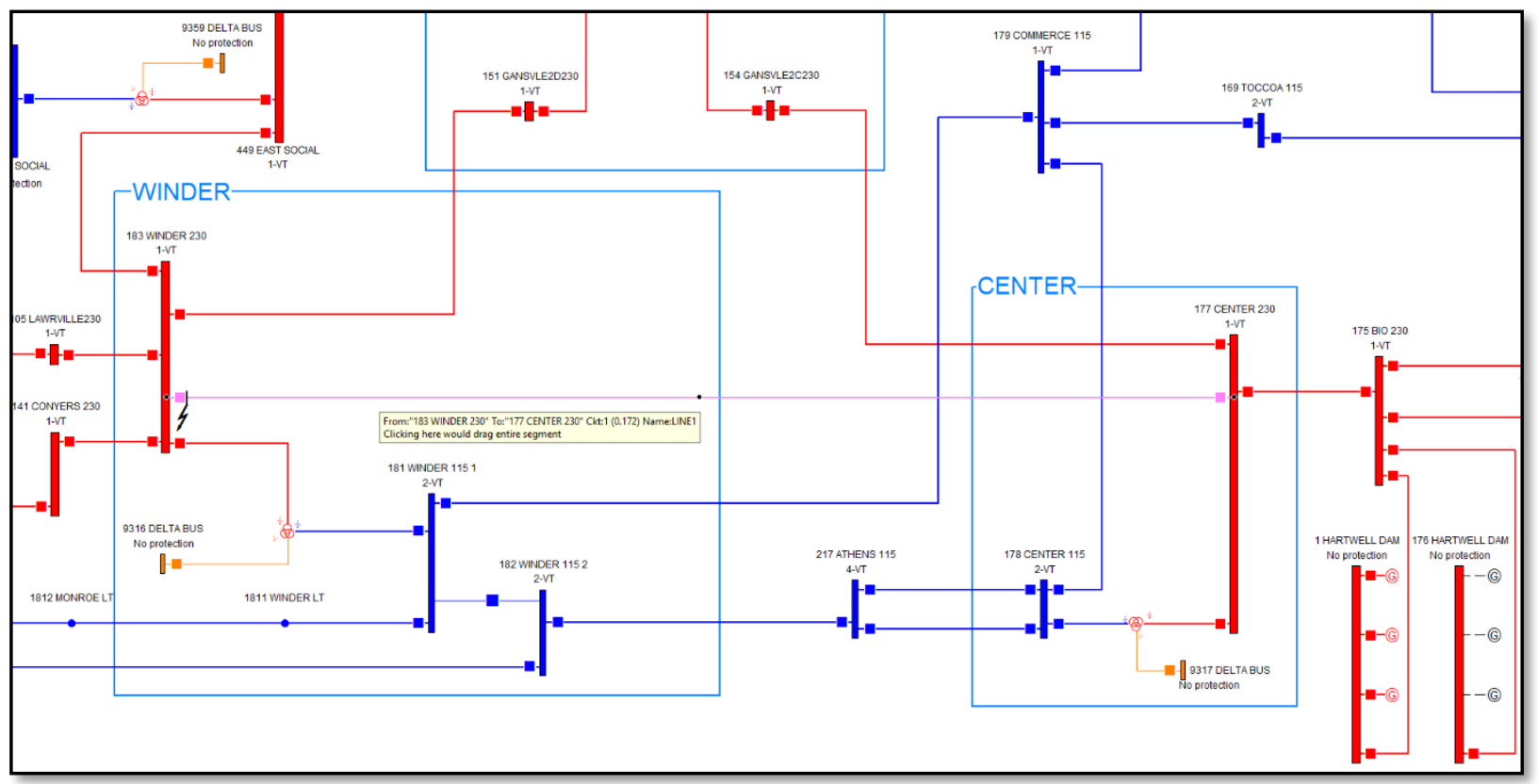

Figure 4-1 - Line 1 Test Condition: SLG Bolted Remote Close-in, Pilot In

The fault is cleared in 70 milliseconds during two sequential breaker events without any backup mis-coordination. Table 4-2 and Table 4-3 summarizes the event operations. During the first event, the primary protection at Winder which is closest to the fault detects the abnormality and issues a trip using its fastest element 67GI at 7 milliseconds. With the breaker opening time set at 58 milliseconds, the primary breaker at Winder Line 1 terminal will open at a total of 65 milliseconds. The fastest primary protection at local Center substation, a directional 50G2 of the POTT scheme observes the fault at 3 milliseconds. Center substation however, cannot issue a trip until the respective POTT trip function from the Winder substation is issued through communication. The delay of 9 milliseconds and the breaker opening time of 58 milliseconds results in a prediction of fault clearing time in event 2 at 70 milliseconds.

Since the fault is at close-in location of Winder substation, it is observed that every backup ground distance zone 2 of adjacent substations looking towards the SLG fault will predict to operate at 
delayed time of 440 milliseconds (Conyers of Line 2, Lawrville of Line 3, Gainsvle of Line 4, and East Social of Line 5).

Table 4-2 - Line 1 Test Results: SLG Bolted Remote Close-in, Pilot In, Event 1

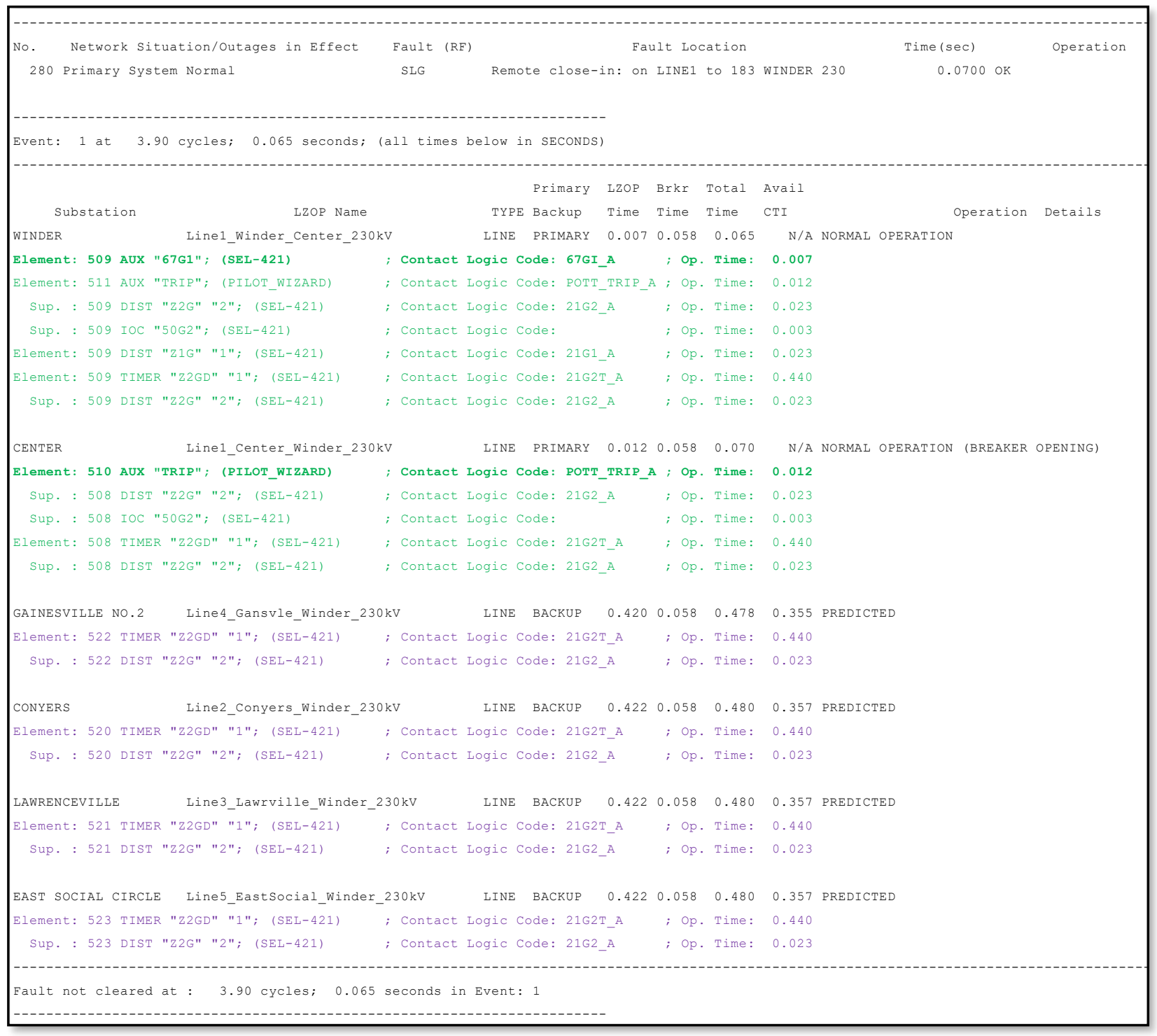

As expected, with the primary breaker of Winder Line 1 opening during event 1 , all backup ground distance zone 2 elements time out and fail to mis-operate. Event 2 lists only the remaining primary protection at Center Line 1 terminal operating at 70 milliseconds without any mis-coordination. 
Table 4-3 - Line 1 Test Results: SLG Bolted Remote Close-in, Pilot In, Event 2

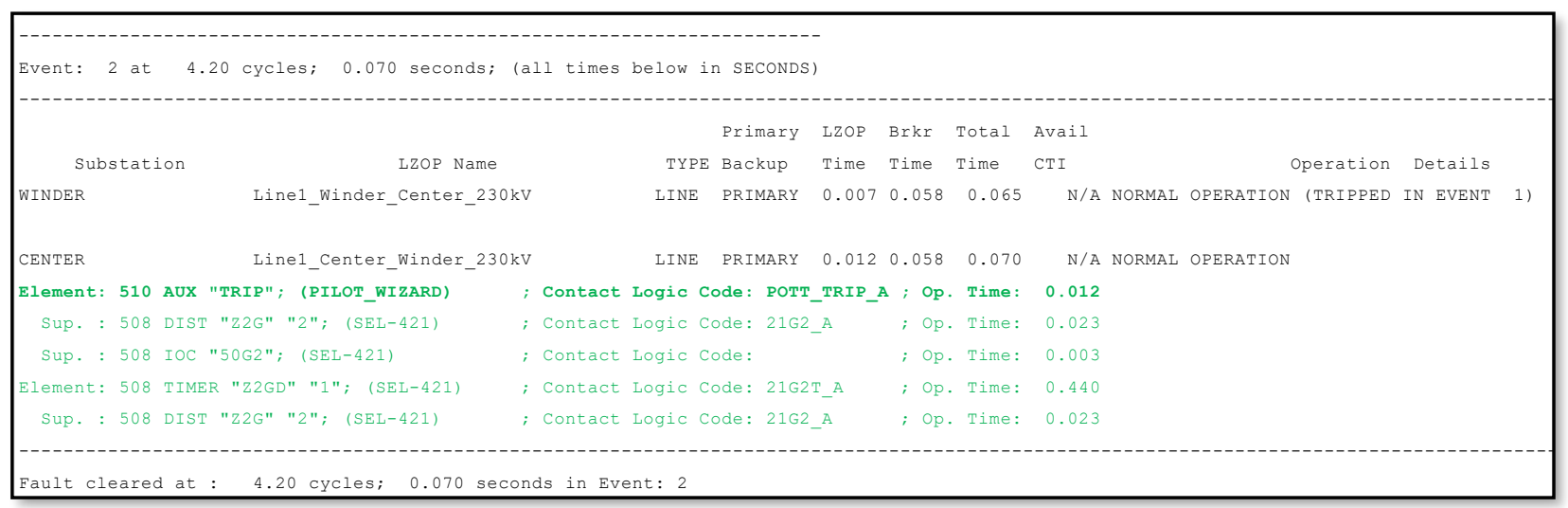

Similarly, a total of 63 Three-Phase faults on Line 1 were applied while the POTT scheme was in service. Table 4-4 lists the total fault clearing time for each simulation. The average clearing time for these faults were quite fast at 83.1 milliseconds. This fast clearing is due to the active communication between both Winder and Center substations through the means of the POTT scheme. The TPH faults were cleared just slightly slower than SLG faults. The POTT scheme uses a ground overcurrent element for its pick-up in addition to distance characteristics to ensure pickup of resistive faults. The lack of a phase overcurrent starter element in the POTT scheme results in a slower average clearing time since distance characteristic evaluation of digital relays is slower than of the overcurrent [48]. No coordination issues were identified for any of the found on line 1.

Table 4-4 - Line 1 Fault Clearing Time Results (Pilot In, TPH Bolted Faults)

\begin{tabular}{|c|c|c|c|c|c|c|c|c|c|c|}
\hline \multirow{2}{*}{ Outage } & \multirow{2}{*}{ Pilot } & \multirow{2}{*}{ Fault Type } & \multicolumn{7}{|c|}{ Fault Clearing Time (Seconds) } & \multirow{2}{*}{ Mis-coordination } \\
\hline & & & $0 \%$ & $15 \%$ & $30 \%$ & $50 \%$ & $70 \%$ & $85 \%$ & $100 \%$ & \\
\hline Primary System Normal & In & $\mathrm{TPH}$ & 0.0867 & 0.0867 & 0.0783 & 0.0783 & 0.0783 & 0.0867 & 0.0867 & No \\
\hline XFMR : 177-1317-1( Bank A) & In & TPH & 0.0867 & 0.0867 & 0.0783 & 0.0783 & 0.0783 & 0.0867 & 0.0867 & No \\
\hline Line : 177-154-1(LINE7) & $\ln$ & TPH & 0.0867 & 0.0867 & 0.0783 & 0.0783 & 0.0783 & 0.0867 & 0.0867 & No \\
\hline Line : 177-175-1(LINE6) & In & TPH & 0.0867 & 0.0867 & 0.0783 & 0.0783 & 0.0783 & 0.0867 & 0.0867 & No \\
\hline XFMR : 183-1316-1( Bank C) & In & TPH & 0.0867 & 0.0867 & 0.0783 & 0.0783 & 0.0783 & 0.0867 & 0.0867 & No \\
\hline Line : 183-105-1(LINE3) & In & TPH & 0.0867 & 0.0867 & 0.0783 & 0.0783 & 0.0783 & 0.0867 & 0.0867 & No \\
\hline Line : 183-141-1(LINE2) & In & TPH & 0.0867 & 0.0867 & 0.0783 & 0.0783 & 0.0783 & 0.0867 & 0.0867 & No \\
\hline Line : 183-151-1(LINE4) & In & TPH & 0.0867 & 0.0867 & 0.0783 & 0.0783 & 0.0783 & 0.0867 & 0.0867 & No \\
\hline Line : 183-449-1(LINE5) & In & $\mathrm{TPH}$ & 0.0867 & 0.0867 & 0.0783 & 0.0783 & 0.0783 & 0.0867 & 0.0867 & No \\
\hline
\end{tabular}


Figure 4-2 represents one test scenario listed in the abovementioned table in depth. The fault scenario is an N-1 contingency with adjacent Line 7 between Gainsvle and Center outaged. There is a TPH fault applied at $0 \%$ location (local close-in at Center substation).

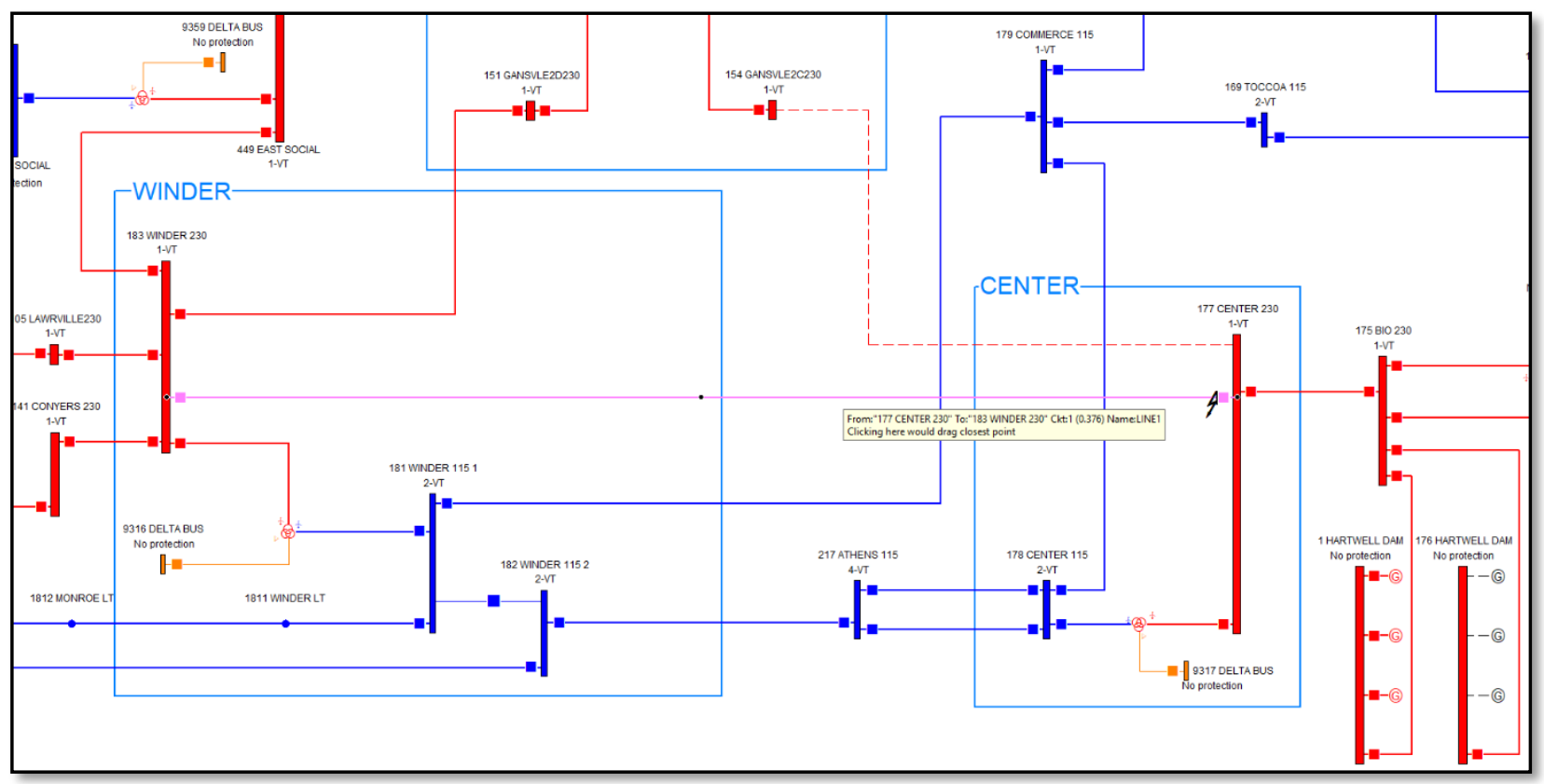

Figure 4-2 - Line 1 Test Condition: TPH Local Close-in, Pilot In

The fault is cleared in 87 milliseconds during two sequential breaker events without any backup mis-coordination. Table 4-5 and Table 4-6 summarizes the event operations. During the first event, the primary protection at Center which is closest to the fault detects the abnormality and issues a trip using its fastest element 21P1 at 20 milliseconds. With the breaker opening time set at 58 milliseconds, the primary breaker at Center Line 1 terminal will open at a total of 78 milliseconds. The fastest primary protection at remote Winder substation, an instantaneous 21P2 of the POTT scheme observes the fault at 20 milliseconds. Winder substation however, cannot issue a trip until the respective POTT trip function from the Center substation is issued through communication. The delay of 8 milliseconds and the breaker opening time of 58 milliseconds results in a prediction of fault clearing time in event 2 at 87 milliseconds.

Since the fault is at close-in location of Center substation, it is observed that every backup phase distance zone 2 of adjacent substations looking towards the TPH fault predict to operate at delayed 
time of 440 milliseconds (Bio of Line 6). It is noted that the backup elements at Gainsvle Line 7 are unable to react to the fault due to the $\mathrm{N}-1$ contingency outage.

Table 4-5 - Line 1 Test Results: TPH Local Close-in, Pilot In, Event 1

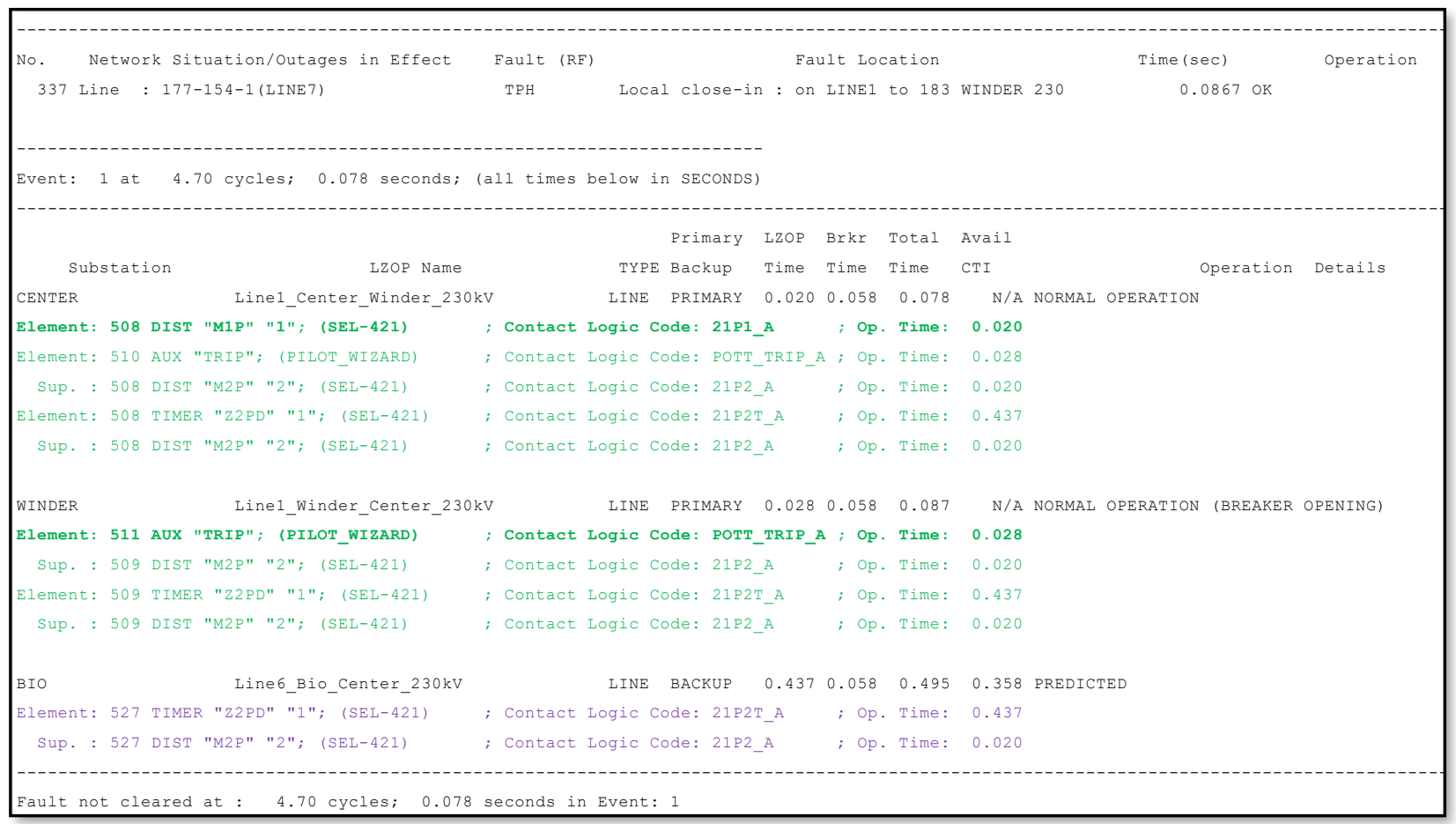

As expected, with the primary breaker of Center Line 1 opening during event 1 , any backup phase distance zone 2 element times out and fails to mis-operate. Event 2 lists only the remaining primary protection at Winder Line 1 terminal operating at 87 milliseconds without any mis-coordination.

Table 4-6 - Line 1 Test Results: TPH Local Close-in, Pilot In, Event 2

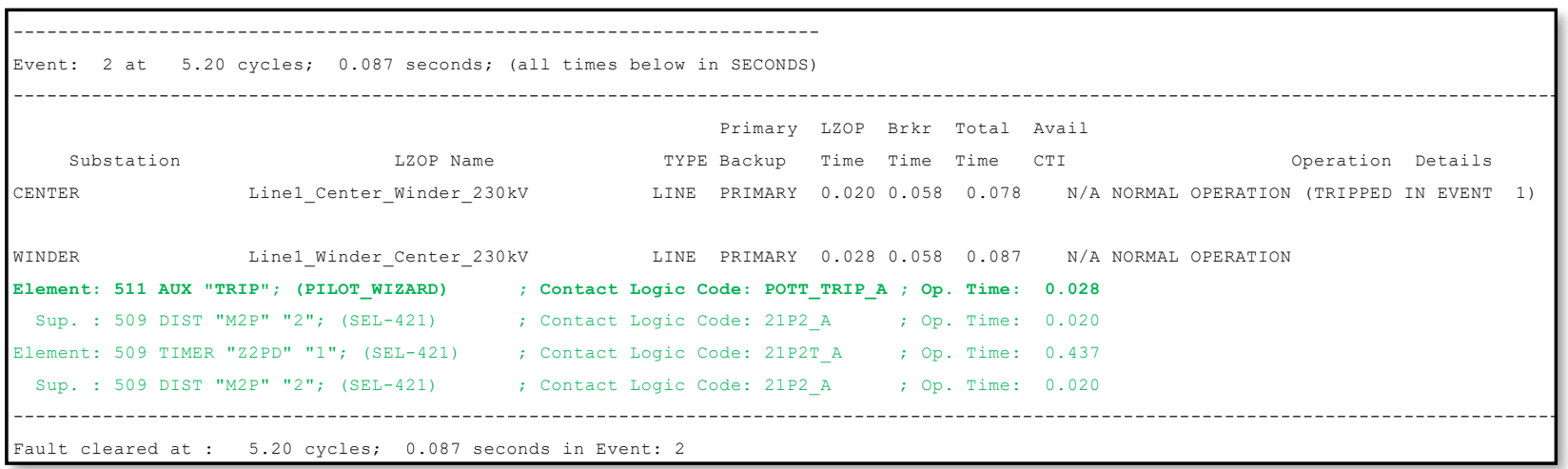


Using the fault clearing results of over 133 fault conditions described above, one can gain confidence in utilizing an optimized protection scheme to clear abnormalities within Line 1. However, the performance of the primary Line 1 protection requires to be setup in such a way that it does not interfere on faults on adjacent equipment as backup protection.

A total of 98 Single-Line-to-Ground faults on Line 6 were applied while the POTT scheme of Line 1 was in service. Table 4-7 lists the total fault clearing time for each simulation (Line 6 Pilots outaged). The average clearing time for these faults were 158.55 milliseconds.

Table 4-7 - Line 6 Fault Clearing Time Results (Pilot Out, SLG Bolted Faults)

\begin{tabular}{|c|c|c|c|c|c|c|c|c|c|c|}
\hline \multirow{2}{*}{ Outage } & \multirow{2}{*}{ Pilot } & \multirow{2}{*}{ Fault Typ } & \multicolumn{7}{|c|}{ Fault Clearing Time (Seconds) } & \multirow{2}{*}{ Mis-coordination } \\
\hline & & & $0 \%$ & $15 \%$ & $30 \%$ & $50 \%$ & $70 \%$ & $85 \%$ & $100 \%$ & \\
\hline Primary System Normal & Out & SLG & 0.1267 & 0.065 & 0.065 & 0.065 & 0.065 & 0.1267 & 0.425 & No \\
\hline XFMR : 177-1317-1 ( Bank A) & Out & SLG & 0.1267 & 0.065 & 0.065 & 0.065 & 0.0817 & INF & 0.4983 & Mis-Op \\
\hline Line : 177-154-1(LINE7) & Out & SLG & 0.1267 & 0.065 & 0.065 & 0.065 & 0.065 & 0.385 & 0.435 & Mis-Op \\
\hline Line : 177-183-1(LINE1) & Out & SLG & 0.1267 & 0.1267 & 0.065 & 0.065 & 0.065 & 0.4433 & 0.4983 & No \\
\hline XFMR : 175-1318-1( Bank \#1) & Out & SLG & 0.1267 & 0.065 & 0.065 & 0.065 & 0.065 & 0.1267 & 0.1267 & No \\
\hline XFMR : 175-1418-1 ( Bank \#3) & Out & SLG & 0.1267 & 0.065 & 0.065 & 0.065 & 0.1267 & 0.1267 & 0.1267 & No \\
\hline Line : 175-176-1() & Out & SLG & 0.4983 & 0.4983 & 0.0817 & 0.0817 & 0.0817 & 0.1433 & 0.4467 & No \\
\hline
\end{tabular}

From the 98 SLG fault scenarios, it was observed that both Winder and Center POTT schemes were misbehaving for 6 of the simulations (see Table 4-8).

Table 4-8 - Line 6 SLG Test Results: Backup POTT Scheme of Line 1 (Winder \& Center)

\begin{tabular}{|c|c|c|c|c|c|c|c|c|}
\hline Pilot & Outages/Test & $0.00 \%$ & $15.00 \%$ & $30.00 \%$ & $50.00 \%$ & $70.00 \%$ & $85.00 \%$ & $100.00 \%$ \\
\hline \multirow{7}{*}{ Enabled } & \multirow{7}{*}{$\begin{array}{l}\text { Primary System Normal } \\
\text { XFMR : 177-1317-1 ( Bank A) } \\
\text { Line : 177-154-1(LINE7) } \\
\text { Line : } 177-183-1 \text { (LINE1) } \\
\text { XFMR : 175-1318-1( Bank \#1) } \\
\text { XFMR : 175-1418-1 ( Bank \#3) } \\
\text { Line : } 175-176-1 \text { ( ) }\end{array}$} & Pass & Pass & Pass & Pass & Pass & Pass & Pass \\
\hline & & Pass & Pass & Pass & Pass & Mis-Op & Mis-Op & Pass \\
\hline & & Pass & Pass & Pass & Mis-Op & Pass & Pass & Pass \\
\hline & & Pass & Pass & Pass & Pass & Pass & Pass & Pass \\
\hline & & Pass & Pass & Pass & Pass & Pass & Pass & Pass \\
\hline & & Pass & Pass & Pass & Pass & Pass & Pass & Pass \\
\hline & & Pass & Pass & Pass & Pass & Pass & Pass & Pass \\
\hline \multirow{7}{*}{ Disabled } & \multirow{7}{*}{$\begin{array}{l}\text { Primary System Normal } \\
\text { XFMR : 177-1317-1( Bank A) } \\
\text { Line : 177-154-1(LINE7) } \\
\text { Line : } 177-183-1 \text { (LINE1) } \\
\text { XFMR : 175-1318-1 ( Bank \#1) } \\
\text { XFMR : } 175-1418-1 \text { ( Bank \#3) } \\
\text { Line : } 175-176-1 \text { ( ) }\end{array}$} & Pass & Pass & Pass & Pass & Pass & Pass & Pass \\
\hline & & Pass & Pass & Pass & Pass & Mis-Op & Mis-Op & Pass \\
\hline & & Pass & Pass & Pass & Mis-Op & Pass & Pass & Pass \\
\hline & & Pass & Pass & Pass & Pass & Pass & Pass & Pass \\
\hline & & Pass & Pass & Pass & Pass & Pass & Pass & Pass \\
\hline & & Pass & Pass & Pass & Pass & Pass & Pass & Pass \\
\hline & & Pass & Pass & Pass & Pass & Pass & Pass & Pass \\
\hline
\end{tabular}


Of the failed conditions, there are mis-operations of these backup POTT elements only when there is an N-1 contingency of Line 7 or Transformer Bank A outages. Also, the failed simulations only occur at three distinct locations of $50 \%$ for Line 7 outage, as well as 70-85\% for Transformer Bank A outage.

Figure 4-3 represents one of the six test scenarios listed in the abovementioned table in depth. The fault scenario is an N-1 contingency with Transformer Bank A outaged. There is a SLG fault applied at $85 \%$ location (measured from Center towards Bio substation).

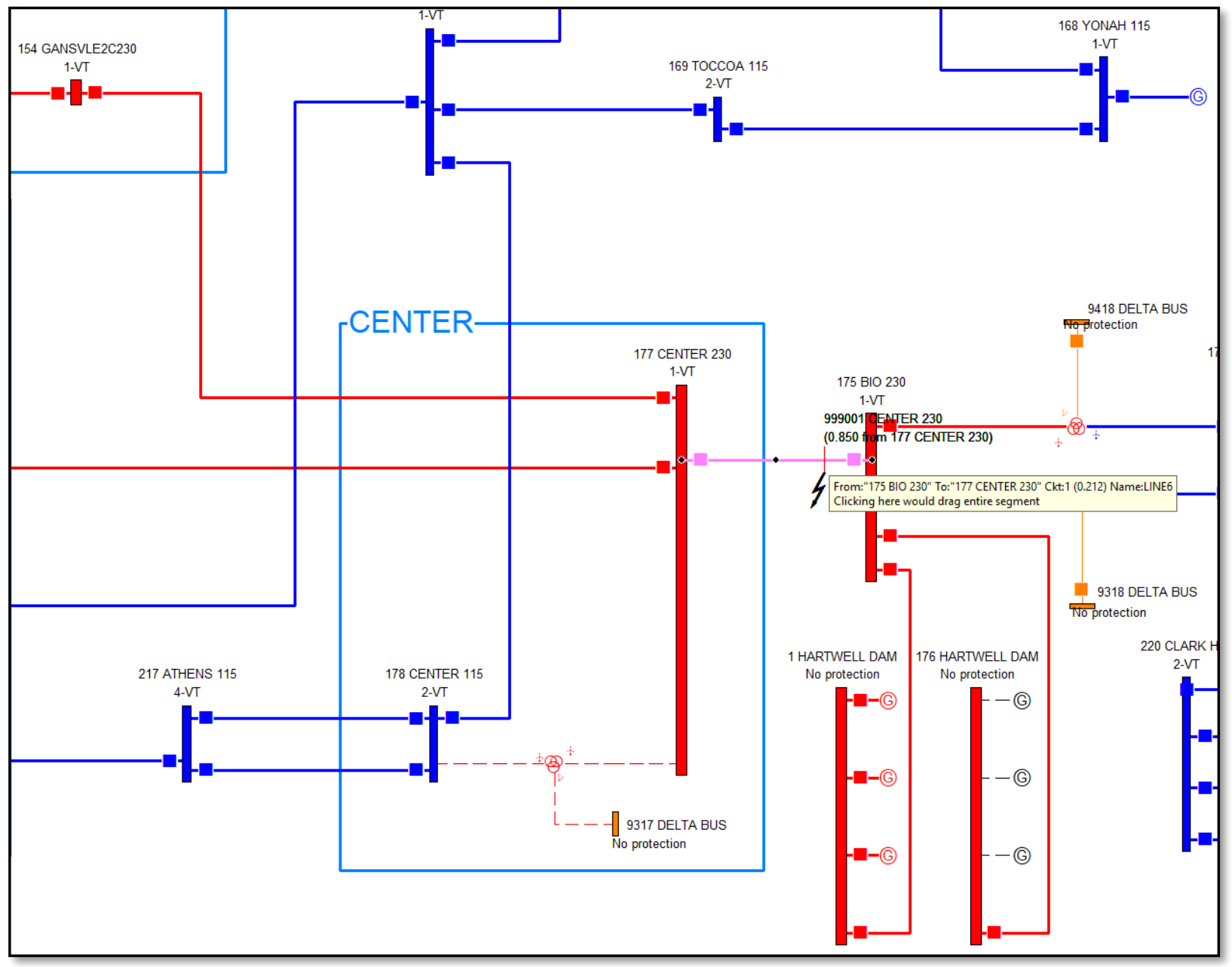

Figure 4-3 - Line 6 Test Condition: SLG 85\%, XFMR Bank A Outaged

The fault is not cleared during two sequential breaker events as there is a backup mis-coordination of POTT schemes at Center and Winder Line 1 terminals. Table 4-9 and Table 4-10 summarizes the event operations. During the first event, the primary protection at Bio which is closest to the 
fault detects the abnormality and issues a trip using its fastest element 67GI at 7 milliseconds. With the breaker opening time set at 58 milliseconds, the primary breaker at Bio Line 6 terminal will open at a total of 65 milliseconds.

The fastest primary protection at remote Center substation, a time delayed 21P2T observes the fault at 440 milliseconds. Considering the breaker opening time of 58 milliseconds results in a prediction of fault clearing time in event 2 at 492 milliseconds.

However, during Event 1, both POTT schemes at Winder and Center Line 1 terminals report an operation of 70 milliseconds (including breaker opening). It is reported that the directional 50G2 elements at both Line 1 terminal ends tend to react to this out-of-zone fault. This results in the initiation of the POTT handshake and the prediction of mis-operation of both terminal ends.

Table 4-9 - Line 6 Test Results: SLG 85\%, XFMR Bank A Outaged, Event 1

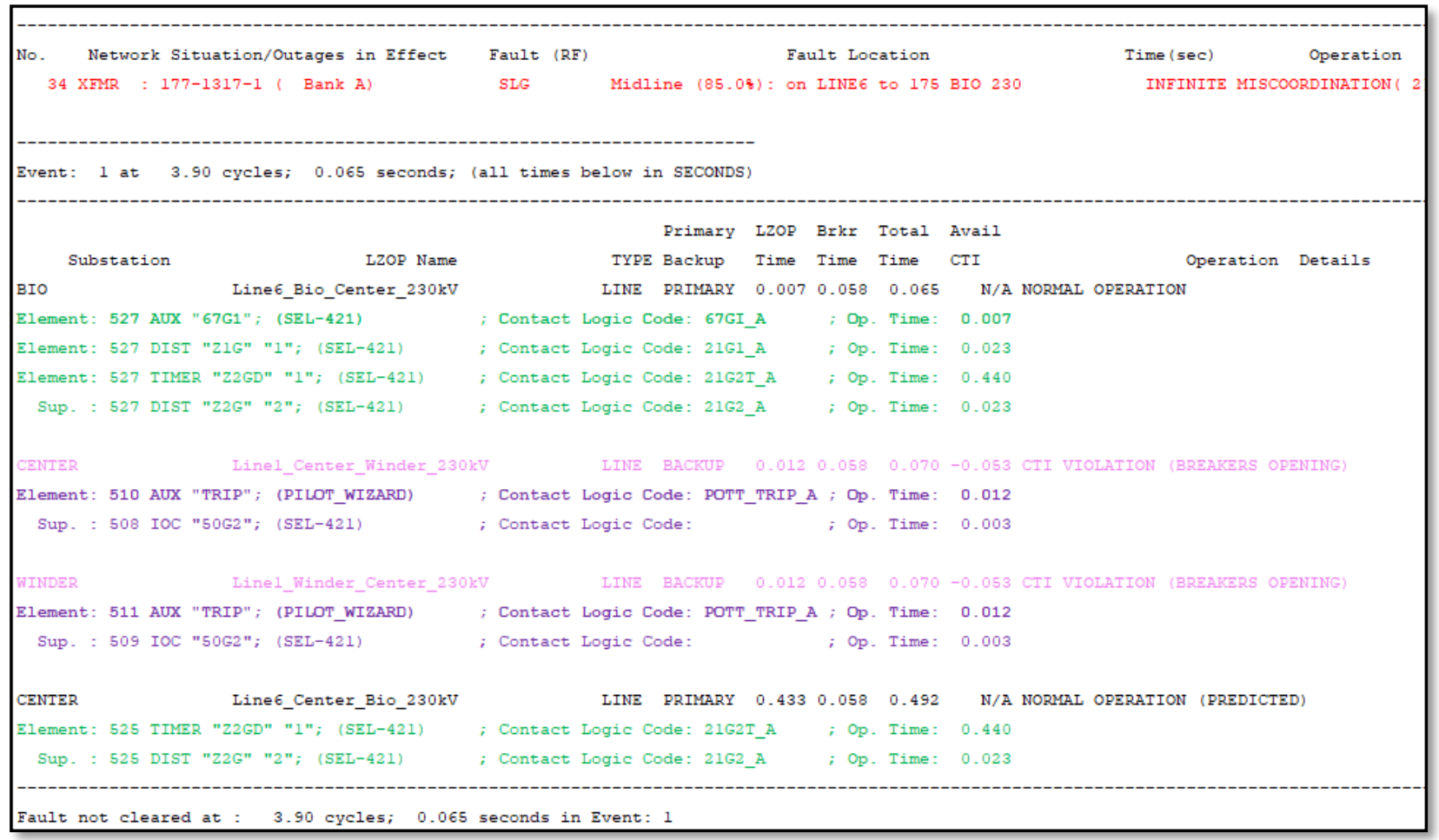

As expected, both Line 1 terminals report a mis-operation during Event 2, while the slower primary phase distance zone 2 element at Center Substation continues to time until fault is cleared at Event 3 at 558 milliseconds. Due to the fast reaction of backup POTT scheme, the same mis-operation will be reported even if primary POTT scheme of study Line 6 is activated. 
Table 4-10 - Line 6 Test Results: SLG 85\%, XFMR Bank A Outaged, Event 2

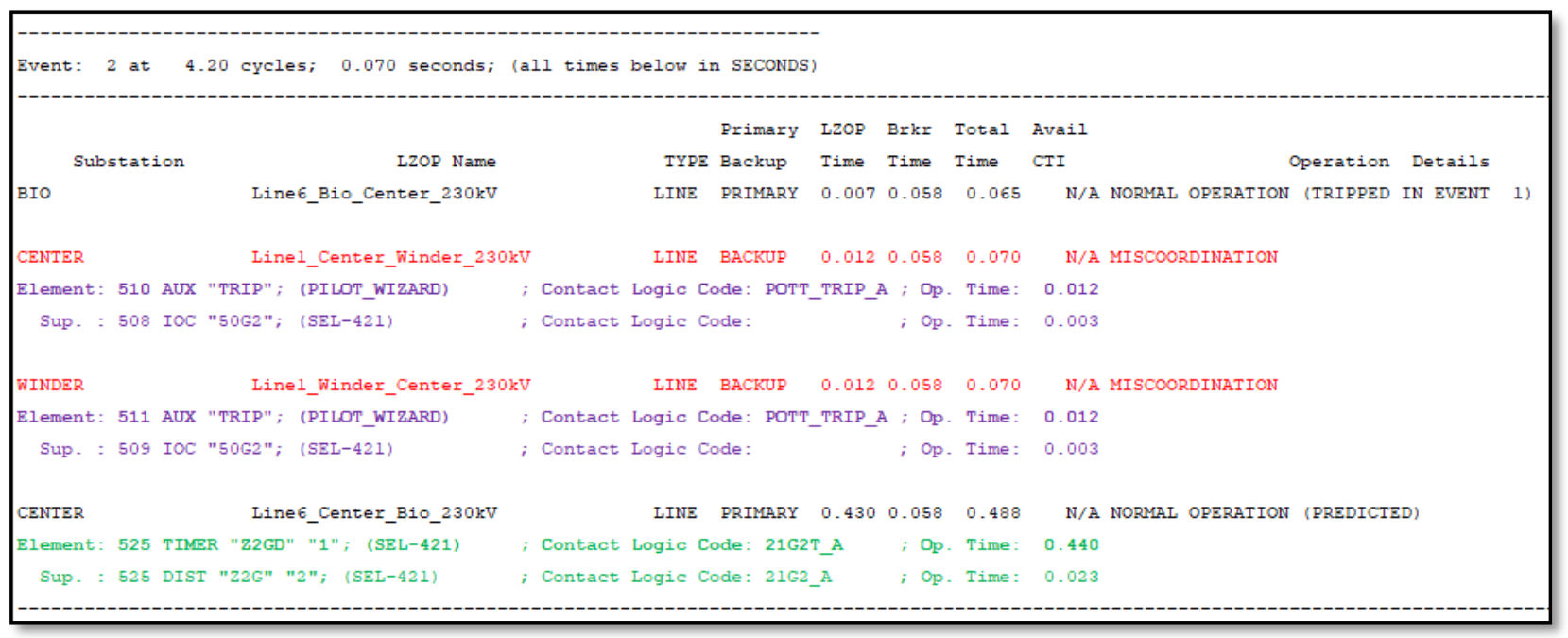

This unusual reaction of a directional overcurrent element to operate for a fault behind its CT is observed in cases where an N-1 contingency can result in a significant change in the topology and short circuit current. Digital relays often utilize negative and zero sequence components in their algorithm to decide on directionality of a fault [4]. With the outage of Transformer Bank A in the study system, a large zero sequence contributor is no longer active which can result in such a misoperation. The fault currents and symmetrical components subjected to multiple fault scenarios result in a pocket of $51 \%$ to $99 \%$ which a mis-operations may occur. After further hardware in the loop testing to validate the simulations with flagged mis-operations, a possible solution based on the system topology would be to replace the POTT scheme with a secure DCB scheme instead with a reverse directional ground overcurrent blocking [48].

\subsubsection{Telecommunication assisted protection out of Service}

A total of 70 Single-Line-to-Ground faults on Line 1 were applied while the POTT scheme was out of service. Table 4-11 lists the total fault clearing time for each simulation. The average clearing time for these faults were 149.42 milliseconds. This impact of the delayed clearing time due to the outage of pilot scheme was approximately 80 milliseconds slower than its counterpart described in chapter 4.3.1.1. Upon absence of primary telecommunication assisted protection, it is still expected for protection to be well coordinated. Even with the slower average clearing time, there was no coordination issues identified for any of the found on line 1. 
Table 4-11 - Line 1 Fault Clearing Time Results (Pilot Out, SLG Bolted Faults)

\begin{tabular}{|c|c|c|c|c|c|c|c|c|c|c|}
\hline \multirow{2}{*}{ Outage } & \multirow{2}{*}{ Pilot } & \multirow{2}{*}{ Fault Typ } & \multicolumn{7}{|c|}{ Fault Clearing Time (Seconds) } & \multirow{2}{*}{ Mis-coordination } \\
\hline & & & $0 \%$ & $15 \%$ & $30 \%$ & $50 \%$ & $70 \%$ & $85 \%$ & $100 \%$ & \\
\hline Primary System Normal & Out & SLG & 0.1267 & 0.065 & 0.065 & 0.065 & 0.065 & 0.1267 & 0.4 & No \\
\hline XFMR : 177-1317-1 ( Bank A) & Out & SLG & 0.1267 & 0.065 & 0.065 & 0.0817 & 0.0817 & 0.4983 & 0.4983 & No \\
\hline Line : 177-154-1(LINE7) & Out & SLG & 0.1267 & 0.065 & 0.065 & 0.065 & 0.065 & 0.1267 & 0.4183 & No \\
\hline Line : 177-175-1(LINE6) & Out & SLG & 0.1267 & 0.1267 & 0.065 & 0.065 & 0.0817 & 0.4417 & 0.4933 & No \\
\hline XFMR : 183-1316-1( Bank C) & Out & SLG & 0.1267 & 0.1267 & 0.065 & 0.065 & 0.065 & 0.1267 & 0.4017 & No \\
\hline Line : 183-105-1(LINE3) & Out & SLG & 0.1267 & 0.1267 & 0.065 & 0.065 & 0.065 & 0.1267 & 0.4017 & No \\
\hline Line : 183-141-1(LINE2) & Out & SLG & 0.1267 & 0.1267 & 0.065 & 0.065 & 0.065 & 0.1267 & 0.4017 & No \\
\hline Line : 183-151-1(LINE4) & Out & SLG & 0.1267 & 0.1267 & 0.065 & 0.065 & 0.065 & 0.1267 & 0.3983 & No \\
\hline Line : 183-449-1(LINE5) & Out & SLG & 0.1267 & 0.1267 & 0.065 & 0.065 & 0.065 & 0.1267 & 0.4 & No \\
\hline Mutual: 179-181-1(LINE8) & Out & SLG & 0.1267 & 0.065 & 0.065 & 0.065 & 0.065 & 0.1267 & 0.405 & No \\
\hline
\end{tabular}

Figure 4-4 represents one test scenario listed in the abovementioned table in depth. The fault scenario is a system normal condition with a bolted SLG fault at $100 \%$ location (remote close-in at Winder substation).

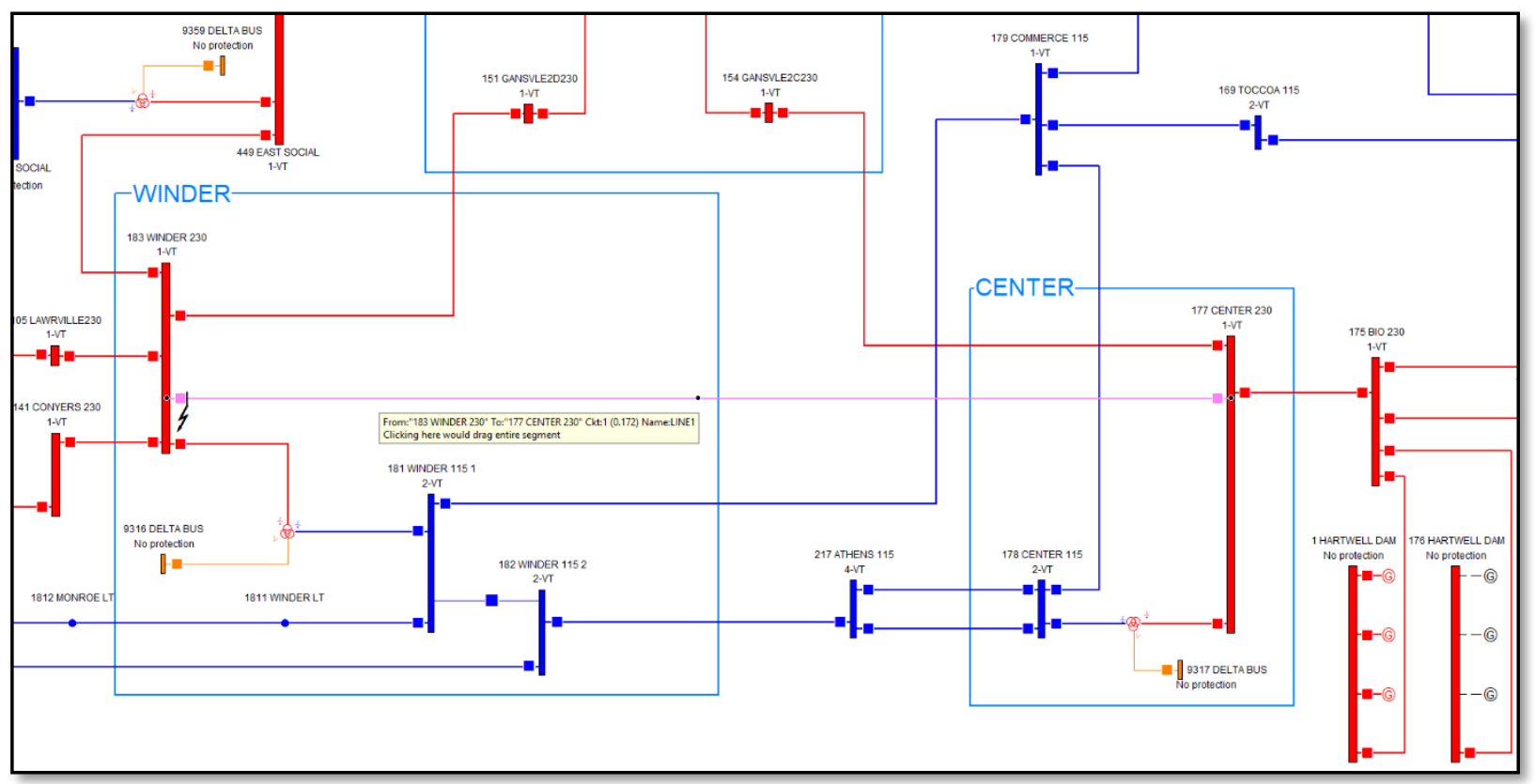

Figure 4-4 - Line 1 Test Condition: SLG Bolted Remote Close-in, Pilot Out

The fault is cleared in 400 milliseconds during two sequential breaker events without any backup mis-coordination. Table 4-12 and Table 4-13 summarizes the event operations. During the first event, the primary protection at Winder Substation which is closest to the fault detects the abnormality and issues a trip using its fastest element 67GI at 7 milliseconds. With the breaker 
opening time set at 58 milliseconds, the primary breaker at Winder Line 1 terminal will open at a total of 65 milliseconds.

The fastest primary protection at local Center substation, a timed delayed ground distance zone 2 element $(21 \mathrm{G} 2 \mathrm{~T})$ observes the fault at 422 milliseconds. Considering the breaker opening time of 58 milliseconds results in a prediction of fault clearing time in event 2 at 480 milliseconds.

Since the fault is at close-in location of Winder substation, it is observed that other backup ground distance zone 2 of adjacent substations looking towards the SLG fault predict to operate at delayed time of 440 milliseconds (Conyers of Line 2, Lawrville of Line 3, Gainsvle of Line 4, and East Social of Line 5).

Table 4-12 - Line 1 Test Results: SLG Bolted Remote Close-in, Pilot Out, Event 1

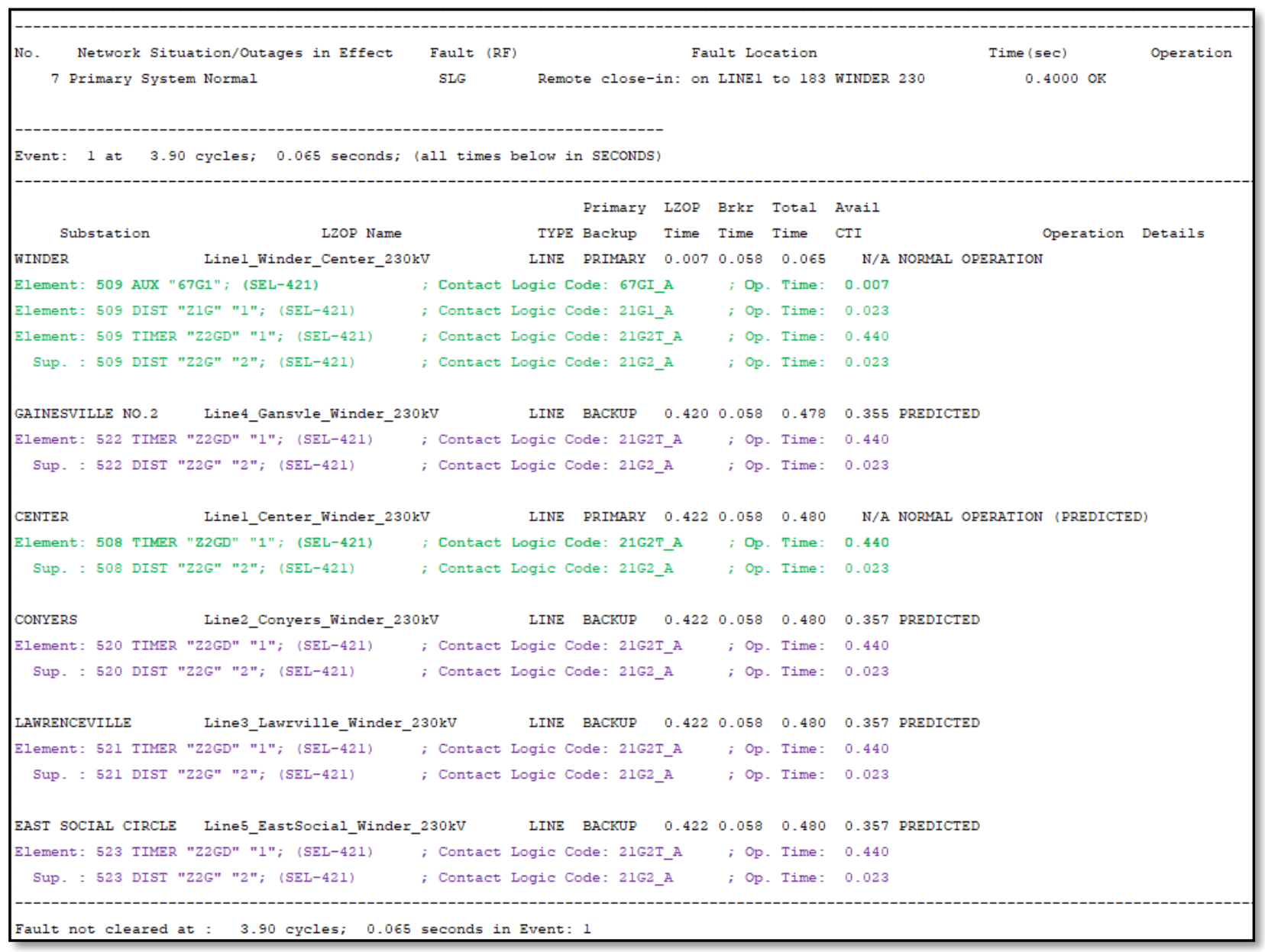


As expected, with the primary breaker of Winder Line 1 opening during event 1 , all backup ground distance zone 2 elements time out and fail to mis-operate. Event 2 lists only the remaining primary protection at Center Line 1 terminal operating at 400 milliseconds without any mis-coordination.

Table 4-13 - Line 1 Test Results: SLG Bolted Remote Close-in, Pilot Out, Event 2

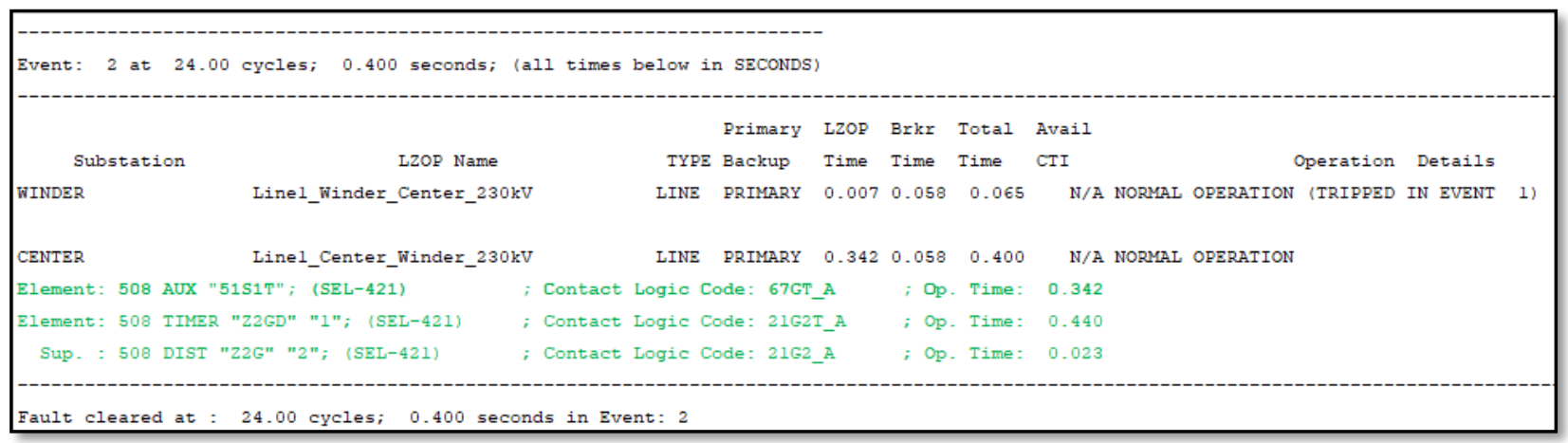

When the breaker at Winder Line 1 is opened during Event 1, Line 1 becomes radial. This results in an increase of the fault current read at the Center terminal as all fault current at Winder substation will be routed to the local terminal. The fault current at Center terminal is increased from 2366 amps to 2898 amps when Winder breaker is isolated in Figure 4-5 (transitional sequence between Event 1 and Event 2). This significant increase in fault current assists the primary protection as the inverse timed delayed ground overcurrent element at Center terminal is now able to detect the fault and clear faster than the predicted Event 1 at 400 milliseconds.

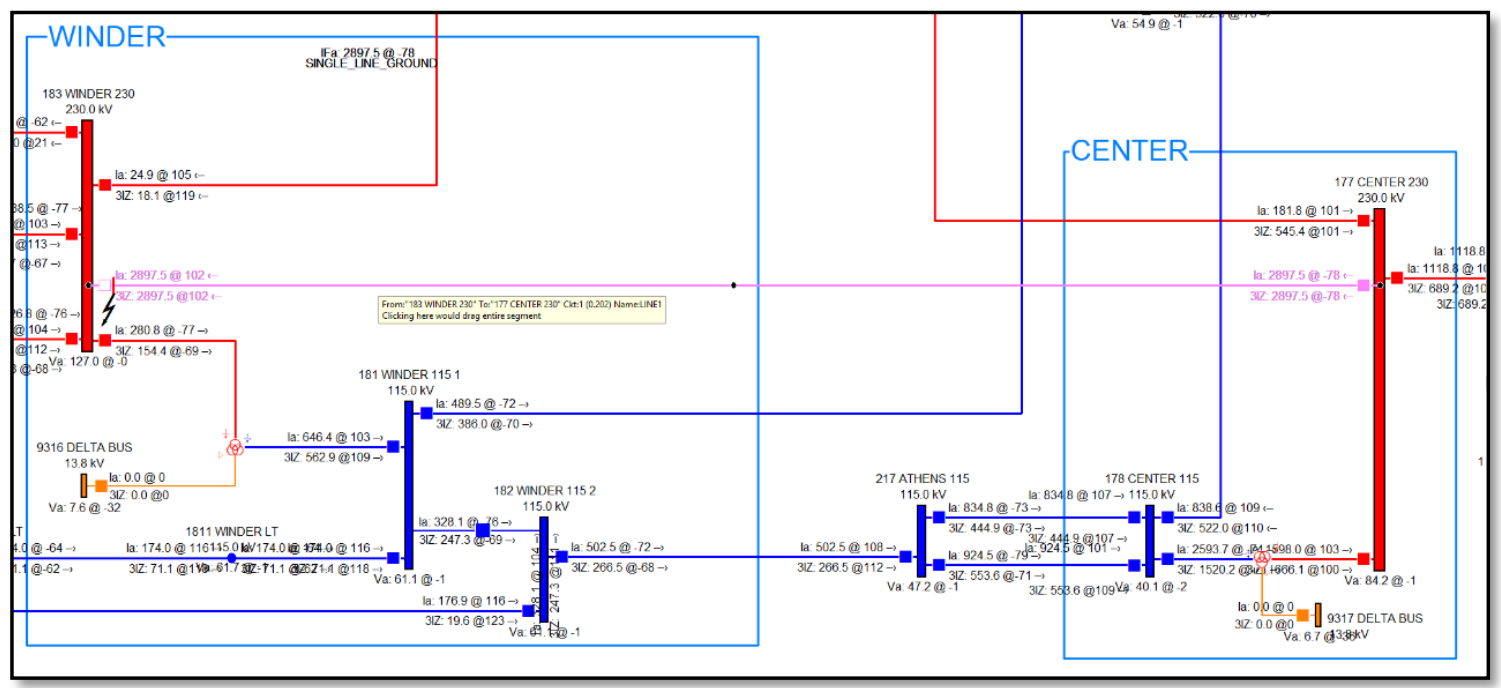

Figure 4-5 - Impact of Radial Infeed on 67GT (Study Line 1) 
Similarly, a total of 63 Three-Phase faults on Line 1 were applied while the POTT scheme was out of service. Table 4-14 lists the total fault clearing time for each simulation. The average clearing time for these faults were 316.41 milliseconds. This impact of the delayed clearing time due to the outage of pilot scheme was approximately 233 milliseconds slower than its counterpart described in chapter 4.3.1.1. In the absence of any phase overcurrent protection, the delayed clearing time difference is significantly higher for TPH faults compared to ground related abnormalities. Upon absence of primary telecommunication assisted protection, it is still expected for protection to be well coordinated. Even with the slower average clearing time, there was no coordination issues identified for any of the found on line 1.

Table 4-14 - Line 1 Fault Clearing Time Results (Pilot Out, TPH Bolted Faults)

\begin{tabular}{|c|c|c|c|c|c|c|c|c|c|c|}
\hline \multirow{2}{*}{ Outage } & \multirow{2}{*}{ Pilot } & \multirow{2}{*}{ Fault Type } & \multicolumn{7}{|c|}{ Fault Clearing Time (Seconds) } & \multirow{2}{*}{ Mis-coordination } \\
\hline & & & $0 \%$ & $15 \%$ & $30 \%$ & $50 \%$ & $70 \%$ & $85 \%$ & $100 \%$ & \\
\hline Primary System Normal & Out & TPH & 0.495 & 0.495 & 0.0783 & 0.0783 & 0.0783 & 0.495 & 0.495 & No \\
\hline XFMR : 177-1317-1( Bank A) & Out & TPH & 0.495 & 0.495 & 0.0783 & 0.0783 & 0.0783 & 0.495 & 0.495 & No \\
\hline Line : 177-154-1(LINE7) & Out & TPH & 0.495 & 0.495 & 0.0783 & 0.0783 & 0.0783 & 0.495 & 0.495 & No \\
\hline Line : 177-175-1(LINE6) & Out & TPH & 0.495 & 0.495 & 0.0783 & 0.0783 & 0.0783 & 0.495 & 0.495 & No \\
\hline XFMR : 183-1316-1( Bank C) & Out & TPH & 0.495 & 0.495 & 0.0783 & 0.0783 & 0.0783 & 0.495 & 0.495 & No \\
\hline Line : 183-105-1(LINE3) & Out & TPH & 0.495 & 0.495 & 0.0783 & 0.0783 & 0.0783 & 0.495 & 0.495 & No \\
\hline Line : 183-141-1(LINE2) & Out & TPH & 0.495 & 0.495 & 0.0783 & 0.0783 & 0.0783 & 0.495 & 0.495 & No \\
\hline Line : 183-151-1(LINE4) & Out & TPH & 0.495 & 0.495 & 0.0783 & 0.0783 & 0.0783 & 0.495 & 0.495 & No \\
\hline Line : 183-449-1(LINE5) & Out & TPH & 0.495 & 0.495 & 0.0783 & 0.0783 & 0.0783 & 0.495 & 0.495 & No \\
\hline
\end{tabular}

Figure 4-6 represents one test scenario listed in the abovementioned table in depth. The fault scenario is an N-1 contingency with adjacent Line 7 between Gainsvle and Center outaged. There is a TPH fault applied at $0 \%$ location (local close-in at Center substation).

The fault is cleared in 495 milliseconds during two sequential breaker events without any backup mis-coordination. Table 4-15 and Table 4-16 summarizes the event operations. During the first event, the primary protection at Center which is closest to the fault detects the abnormality and issues a trip using its fastest element 21P1 at 20 milliseconds. With the breaker opening time set at 58 milliseconds, the primary breaker at Center Line 1 terminal will open at a total of 78 milliseconds. 


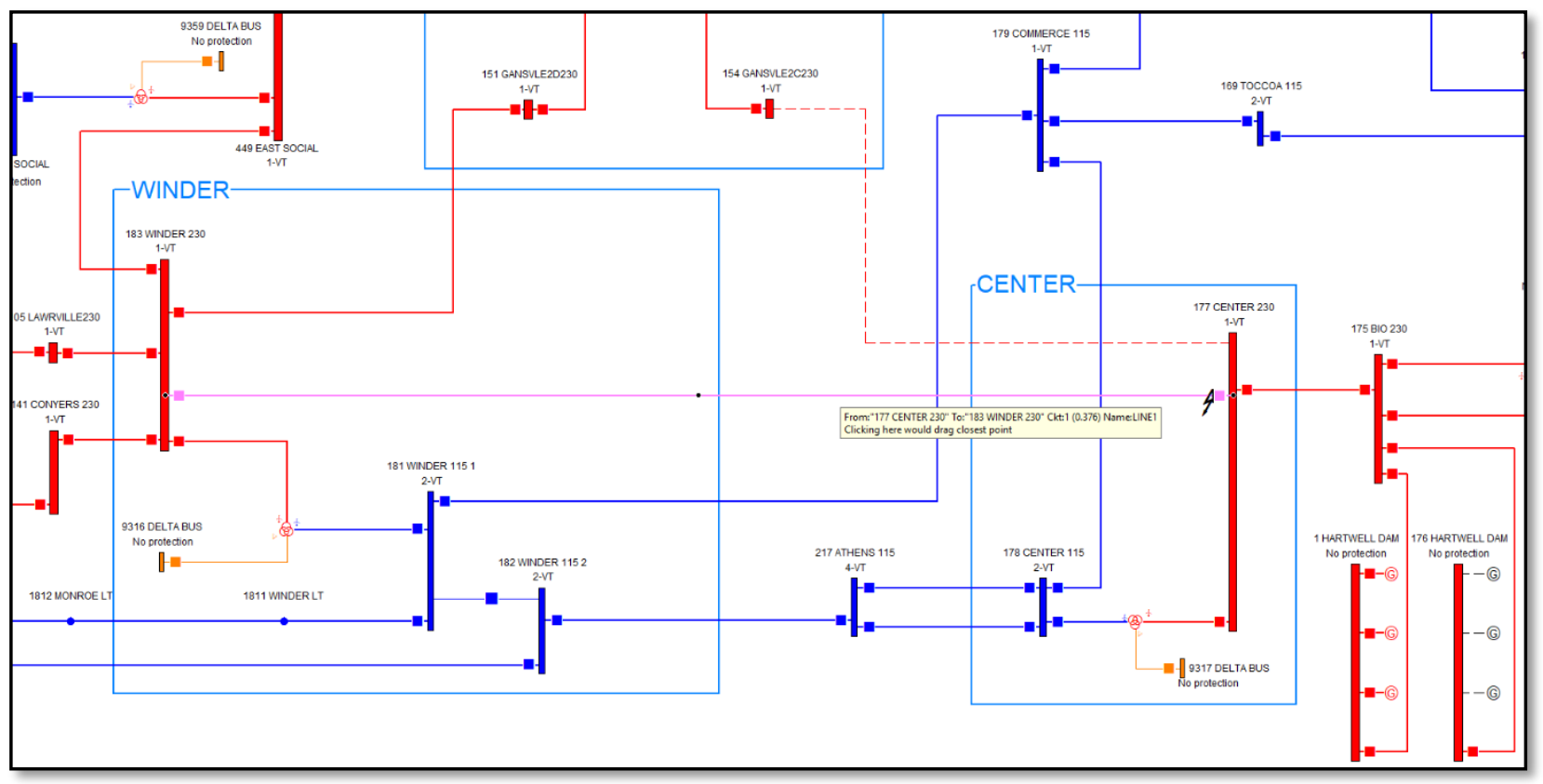

Figure 4-6 - Line 1 Test Condition: TPH Local Close-in, Pilot In

The fastest primary protection at remote Winder substation, a timed delayed phase distance zone 2 element (21P2T) observes the fault at 437 milliseconds. Considering the breaker opening time of 58 milliseconds results in a prediction of fault clearing time in event 2 at 495 milliseconds.

Since the fault is at close-in location of Center substation, it is observed that every backup phase distance zone 2 of adjacent substations looking towards the TPH fault predict to operate at delayed time of 440 milliseconds (Bio of Line 6). It is noted that the backup elements at Gainsvle Line 7 are unable to react to the fault due to the $\mathrm{N}-1$ contingency outage.

As expected, with the primary breaker of Center Line 1 opening during event 1, any backup phase distance zone 2 element times out and fails to mis-operate. Event 2 lists only the remaining primary protection at Winder Line 1 terminal operating at 495 milliseconds without any mis-coordination. 
Table 4-15 - Line 1 Test Results: TPH Local Close-in, Pilot Out, Event 1

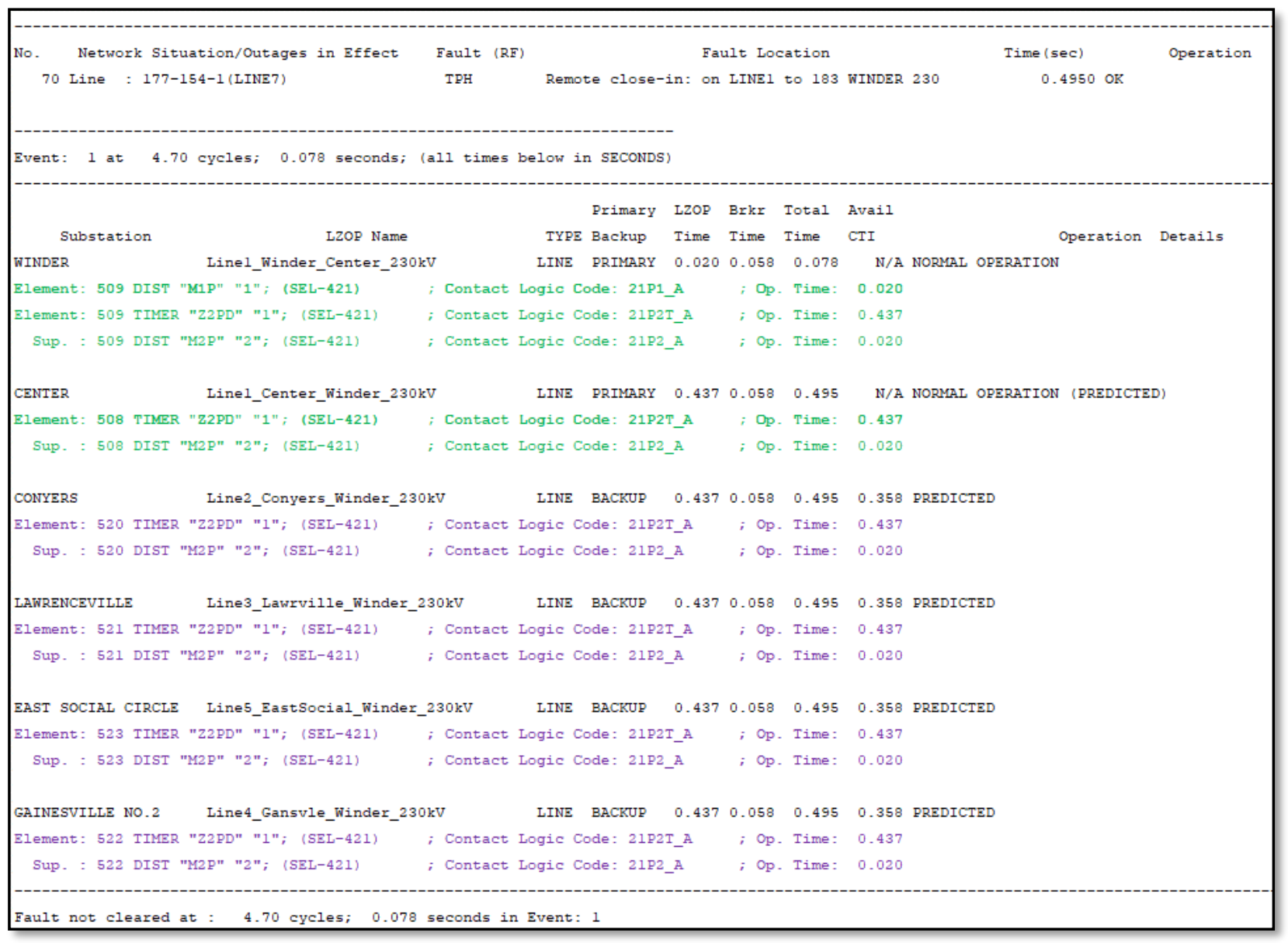

Table 4-16 - Line 1 Test Results: TPH Local Close-in, Pilot Out, Event 2

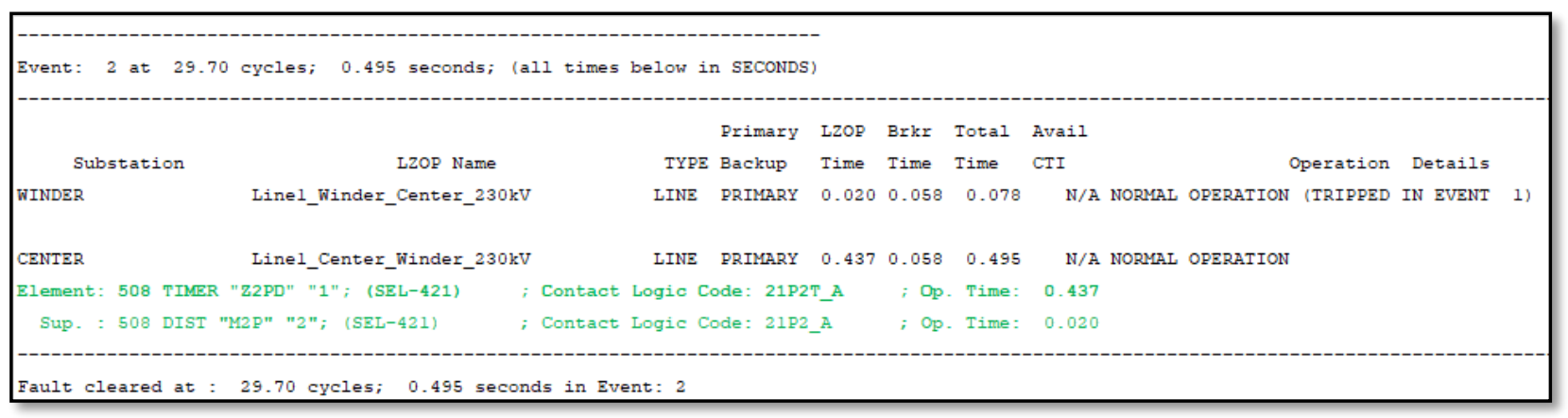


Using the fault clearing results of over 133 fault conditions described above, one can gain confidence in utilizing an optimized protection scheme to clear abnormalities within Line 1. However, the performance of the primary Line 1 protection requires to be setup in such a way that it does not interfere on faults on adjacent equipment as backup protection.

A total of 98 Three-Phase faults on Line 6 were applied while the POTT schemes were out of service. Table 4-17 lists the total fault clearing time for each simulation (Line 6 Pilots outaged). The average clearing time for these faults were 318.01 milliseconds.

Table 4-17 - Line 6 Fault Clearing Time Results (Pilot Out, TPH Bolted Faults)

\begin{tabular}{|c|c|c|c|c|c|c|c|c|c|c|}
\hline \multirow{2}{*}{ Outage } & \multirow{2}{*}{ Pilot } & \multirow{2}{*}{ Fault Type } & \multicolumn{7}{|c|}{ Fault Clearing Time (Seconds) } & \multirow{2}{*}{ Mis-coordination } \\
\hline & & & $0 \%$ & $15 \%$ & $30 \%$ & $50 \%$ & $70 \%$ & $85 \%$ & $100 \%$ & \\
\hline Primary System Normal & Out & TPH & 0.495 & 0.495 & 0.0783 & 0.0783 & 0.0783 & 0.495 & 0.495 & No \\
\hline XFMR : 177-1317-1( Bank A) & Out & TPH & 0.495 & 0.495 & 0.0783 & 0.0783 & 0.0783 & 0.495 & 0.495 & No \\
\hline Line : 177-154-1(LINE7) & Out & $\mathrm{TPH}$ & 0.495 & 0.495 & 0.0783 & 0.0783 & 0.0783 & 0.495 & 0.495 & No \\
\hline Line : 177-183-1(LINE1) & Out & TPH & 0.495 & 0.495 & 0.0783 & 0.0783 & 0.0783 & 0.495 & 0.495 & No \\
\hline XFMR : 175-1318-1( Bank \#1) & Out & TPH & 0.495 & 0.495 & 0.0783 & 0.0783 & 0.0783 & 0.5733 & 0.495 & Mis-Op \\
\hline XFMR : 175-1418-1( Bank \#3) & Out & TPH & 0.495 & 0.495 & 0.0783 & 0.0783 & 0.0783 & 0.495 & 0.495 & No \\
\hline Line : $175-176-1()$ & Out & $\mathrm{TPH}$ & 0.495 & 0.495 & 0.0783 & 0.0783 & 0.0783 & 0.495 & 0.495 & No \\
\hline
\end{tabular}

From the 98 TPH fault scenarios, it was observed that the backup phase distance zone 2 at Winder Line 1 terminal was misbehaving for only one of the simulations (see Table 4-18).

Table 4-18 - Line 6 TPH Test Results: Backup 21P2T Element of Line 1 at Winder

\begin{tabular}{|c|c|c|c|c|c|c|c|c|}
\hline Pilot & Outages/Test & $0.00 \%$ & $15.00 \%$ & $30.00 \%$ & $50.00 \%$ & $70.00 \%$ & $85.00 \%$ & $100.00 \%$ \\
\hline \multirow{7}{*}{ Enabled } & \multirow{7}{*}{$\begin{array}{l}\text { Primary System Normal } \\
\text { XFMR : 177-1317-1 ( Bank A) } \\
\text { Line : 177-154-1(LINE7) } \\
\text { Line : } 177-183-1 \text { (LINE1) } \\
\text { XFMR : 175-1318-1( Bank \#1) } \\
\text { XFMR : 175-1418-1 ( Bank \#3) } \\
\text { Line : } 175-176-1 \text { ( ) }\end{array}$} & Pass & Pass & Pass & Pass & Pass & Pass & Pass \\
\hline & & Pass & Pass & Pass & Pass & Pass & Pass & Pass \\
\hline & & Pass & Pass & Pass & Pass & Pass & Pass & Pass \\
\hline & & Pass & Pass & Pass & Pass & Pass & Pass & Pass \\
\hline & & Pass & Pass & Pass & Pass & Pass & Pass & Pass \\
\hline & & Pass & Pass & Pass & Pass & Pass & Pass & Pass \\
\hline & & Pass & Pass & Pass & Pass & Pass & Pass & Pass \\
\hline \multirow{7}{*}{ Disabled } & \multirow{7}{*}{$\begin{array}{l}\text { Primary System Normal } \\
\text { XFMR : 177-1317-1( Bank A) } \\
\text { Line : 177-154-1(LINE7) } \\
\text { Line : } 177-183-1 \text { (LINE1) } \\
\text { XFMR : 175-1318-1 ( Bank \#1) } \\
\text { XFMR : } 175-1418-1 \text { ( Bank \#3) } \\
\text { Line : } 175-176-1 \text { ( ) }\end{array}$} & Pass & Pass & Pass & Pass & Pass & Pass & Pass \\
\hline & & Pass & Pass & Pass & Pass & Pass & Mis-Op & Pass \\
\hline & & Pass & Pass & Pass & Pass & Pass & Pass & Pass \\
\hline & & Pass & Pass & Pass & Pass & Pass & Pass & Pass \\
\hline & & Pass & Pass & Pass & Pass & Pass & Pass & Pass \\
\hline & & Pass & Pass & Pass & Pass & Pass & Pass & Pass \\
\hline & & Pass & Pass & Pass & Pass & Pass & Pass & Pass \\
\hline
\end{tabular}


For the failed simulation, there exists a mis-operations of the backup phase distance zone 2 at Winder Line 1 terminal only when there is an N-1 contingency of Transformer Bank A outage. Also, the failed simulations only occurs at distinct location of $85 \%$.

Figure 4-7 represents the only flagged test scenarios listed in the abovementioned table in depth. The fault scenario is an N-1 contingency with Transformer Bank A outaged. There is a TPH fault applied at $85 \%$ location (measured from Center towards Bio substation).

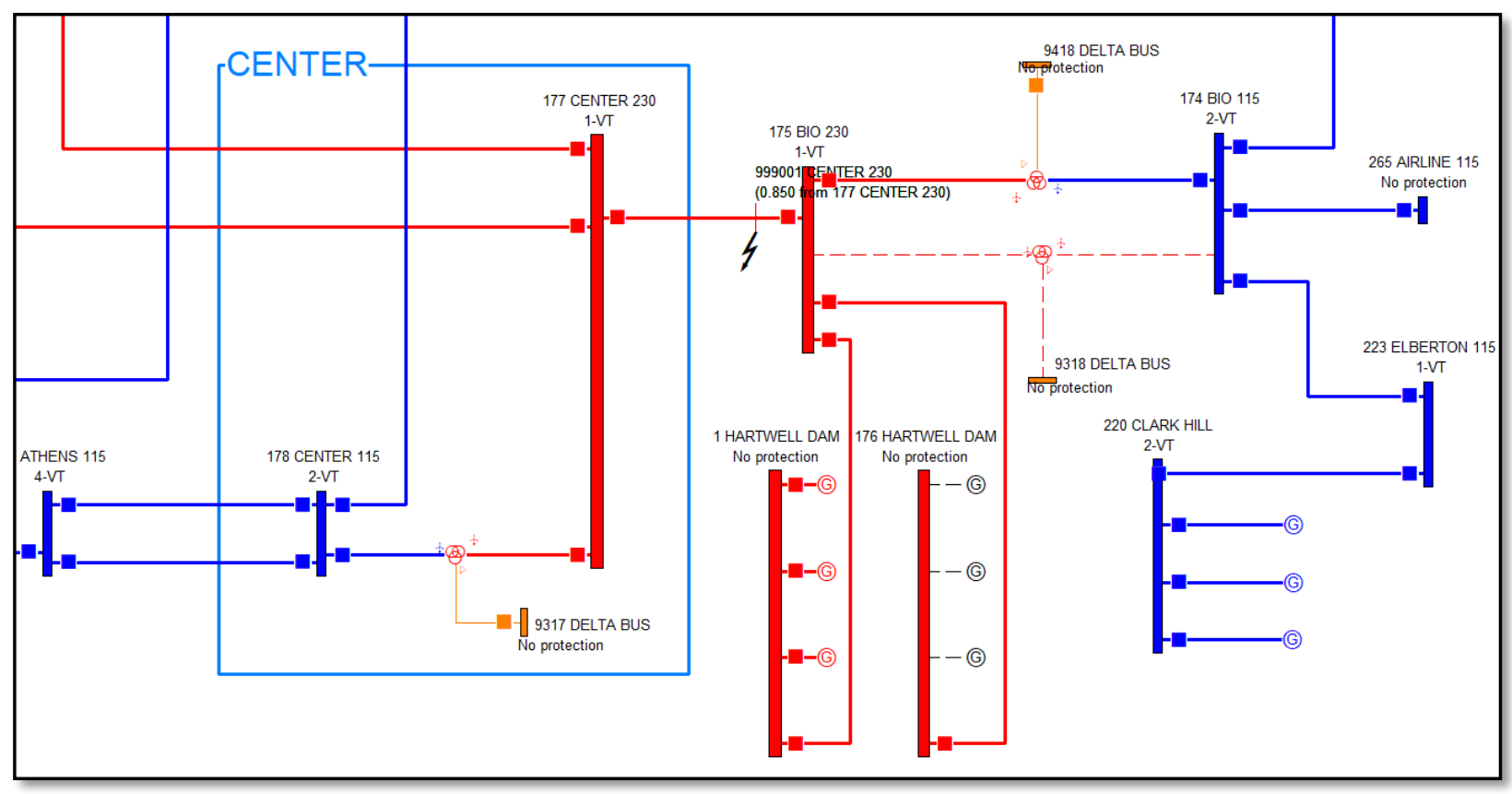

Figure 4-7 - Line 6 Test Condition: TPH 85\%, XFMR Bank A Outaged

The fault is cleared during two sequential breaker events, however, there is a backup miscoordination of phase distance zone 2 at Winder Line 1 terminal. Table 4-19 and Table 4-20 summarizes the event operations. During the first event, the primary protection at Bio which is closest to the fault detects the abnormality and issues a trip using its fastest element $21 \mathrm{P} 1$ at 20 milliseconds. With the breaker opening time set at 58 milliseconds, the primary breaker at Bio Line 6 terminal will open at a total of 78 milliseconds.

The fastest primary protection at remote Center substation, a time delayed 21P2T observes the fault at 437 milliseconds. Considering the breaker opening time of 58 milliseconds results in a prediction of fault clearing time in event 2 at 495 milliseconds. 
Table 4-19 - Line 6 Test Results: TPH 85\%, XFMR Bank A Outaged, Event 1

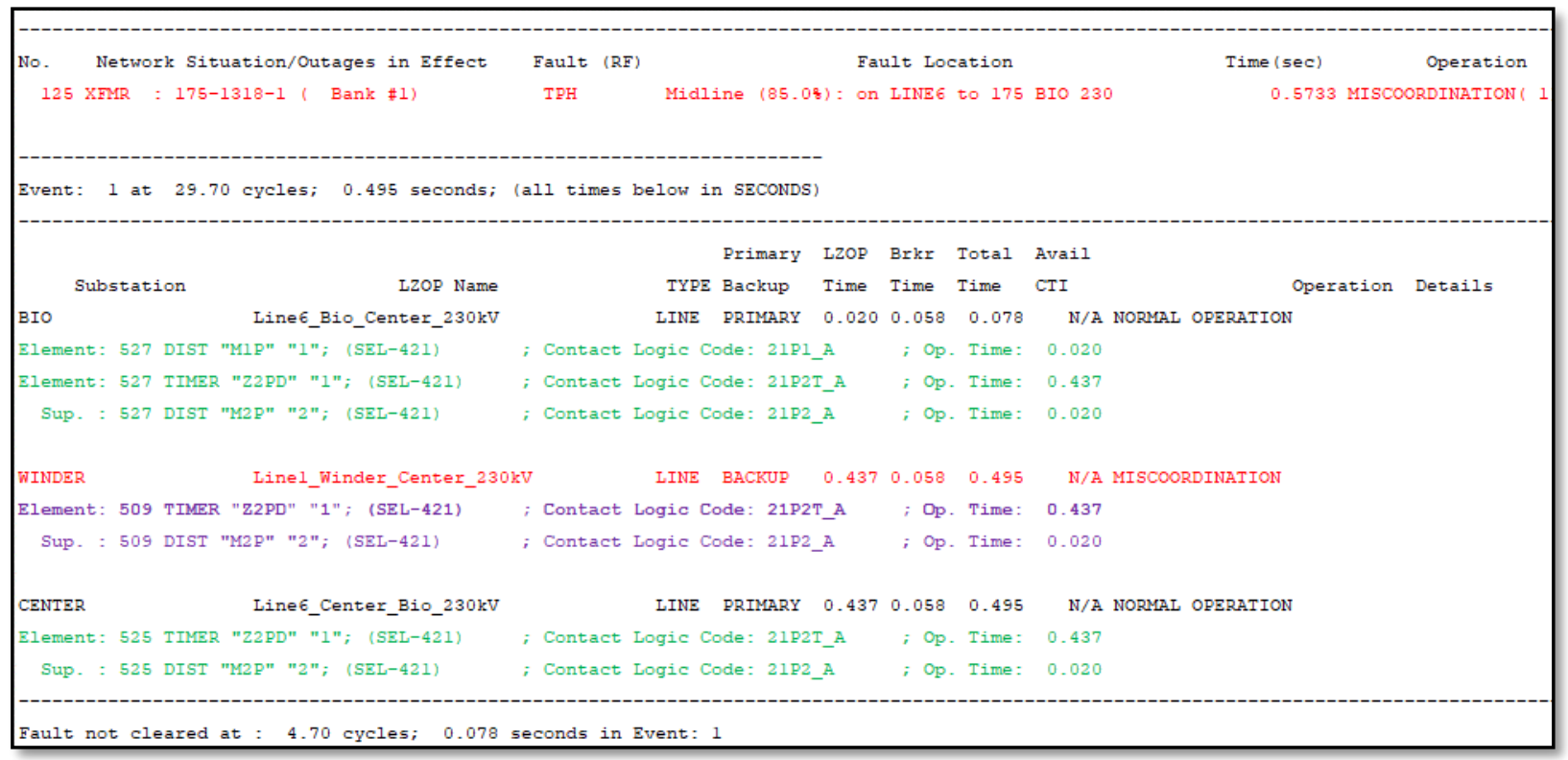

However, during Event 1, the backup phase distance zone 2 at Winder Line 1 terminal also reports an operation of 495 milliseconds (including breaker opening). This results in the prediction of misoperation in event 2 .

Table 4-20 - Line 6 Test Results: TPH 85\%, XFMR Bank A Outaged, Event 2

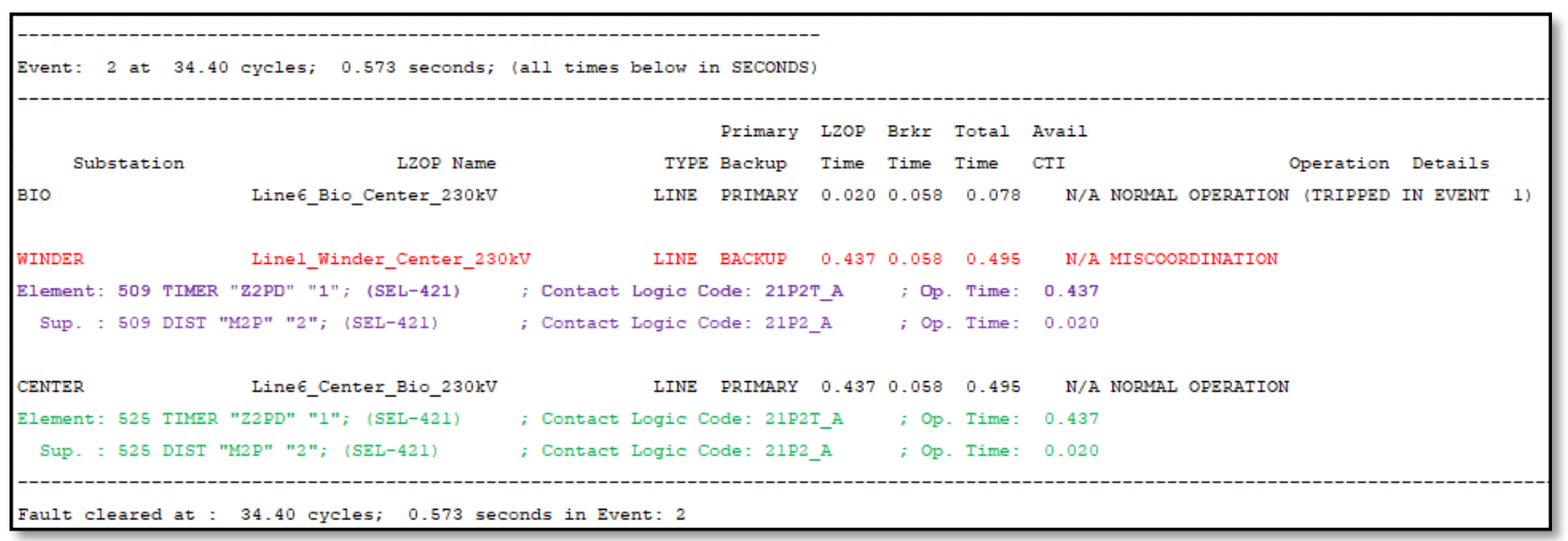

The reach of backup distance element was set based on the criteria described in chapter 2.2.3.3. Compared to Winder station, the fault is located at the opposite end of the adjacent Line 6 with an $\mathrm{N}-1$ contingency of a power transformer two substations away. Therefore, the backup 21P2T 
element should not be able to see beyond its $120 \%$ characteristic. Figure $4-8$ represents the Mho characteristics of Zone 1-2 of primary Line 6 protection at Center as well as the backup Zone 2 protection at Winder Line 1 terminals (all elements looking forward towards the fault). The fault at $85 \%$ is represented by cross point A (1 2) observed by primary protection. This results in Zone 2 primary operation with timed delay as the fault is outside of the Zone 1 characteristic. However, the same fault is observed by the backup Zone 2 protection in the fourth quadrant of the R-X plot represented by cross point A (3).

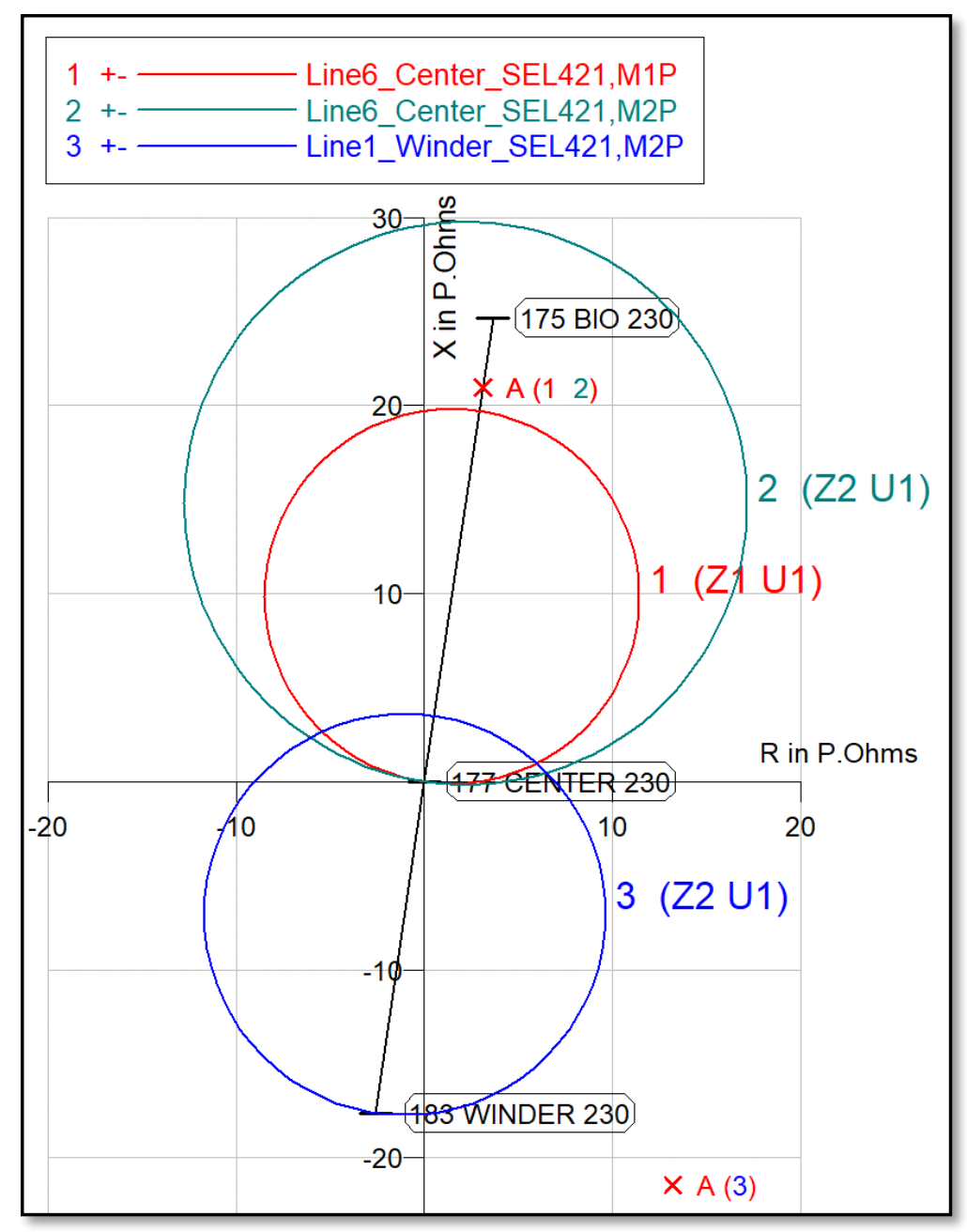

Figure 4-8 - Line 2 Test Result: TPH 85\%, XFMR Bank A Outaged - Primary/Backup Distance

This unusual reaction of a distance element to operate for a fault behind so far away is observed in case where an $\mathrm{N}-1$ contingency can result in a significant change in the topology. Digital relays often utilize symmetrical sequence components in their algorithm to decide on operation of a fault 
$[53,65]$. With the outage of Transformer Bank A in the study system, a large zero sequence contributor is no longer active which can result in such a mis-operation.

In order to further investigate the three distance elements on Figure 4-8, incremental TPH faults at every 5\% was applied using the same $\mathrm{N}-1$ contingency. Table 4-21 shows the operation of each distance element for every fault location (curves 1-2 are the primary zones 1-2 distance respectively, curve 3 represents the backup zone 2 protection). There is pocket of $71 \%$ of $89 \%$ which a mis-operation may occur. It is fortunate for this behavior to occur at exactly $85 \%$ mark since the Zone 1 primary protection could have masked the problem with fast clearing time for any lesser fault location. Additionally, if this error occurred at different step sizes such as $90 \%$, it would not have been caught by the 7 selected fault locations. This further justifies the need for automation to apply thousands of conditions with smaller step sizes.

Table 4-21 - Line 6 Test Results: Sliding TPH Faults at 5\% Increments, XFMR Bank A Outaged

\begin{tabular}{|c|c|c|c|c|c|c|c|c|c|c|}
\hline Fault & Fault & ------ CURV & $1--$ & --- & ------- CURV & $2--$ & --- & ------ CURV & $3--$ & ----- \\
\hline Location & Code & OPER. CYC & APP. & IMP & OPER. CYC & APP. & IMP & OPER. CYC & $\mathrm{APP}$ & P. IMP \\
\hline 0.050 & A & 1.00 & 1.250 & 81.6 & 26.00 & 1.250 & 81.6 & 26.00 & 20.10 & 82.0 \\
\hline 0.100 & B & 1.00 & 2.490 & 81.6 & 26.00 & 2.490 & 81.6 & 99999.90 & 22.30 & 82.3 \\
\hline 0.150 & $\mathrm{C}$ & 1.00 & $3.74 \mathrm{a}$ & 81.6 & 26.00 & 3.740 & 81.6 & 99999.90 & 24.30 & 82.3 \\
\hline 0.200 & D & 1.00 & 4.980 & 81.6 & 26.00 & 4.980 & 81.6 & 99999.90 & 26.10 & 82.2 \\
\hline 0.250 & $\mathrm{E}$ & 1.00 & 6.230 & 81.6 & 26.00 & 6.230 & 81.6 & 99999.90 & 27.60 & 82.0 \\
\hline 0.300 & $\mathrm{~F}$ & 1.00 & 7.480 & 81.6 & 26.00 & 7.480 & 81.6 & 99999.90 & $28.9 @$ & 81.7 \\
\hline 0.350 & G & 1.00 & $8.72 \mathrm{e}$ & 81.6 & 26.00 & 8.720 & 81.6 & 99999.90 & 29.90 & 81.2 \\
\hline 0.400 & $\mathrm{H}$ & 1.00 & $9.97 @$ & 81.6 & 26.00 & $9.97 @$ & 81.6 & 99999.90 & 30.60 & 80.5 \\
\hline 0.450 & I & 1.00 & 11.20 & 81.6 & 26.00 & 11.20 & 81.6 & 99999.90 & 30.80 & 79.6 \\
\hline 0.500 & $\mathrm{~J}$ & 1.00 & $12.5 \mathrm{a}$ & 81.6 & 26.00 & 12.50 & 81.6 & 99999.90 & 30.60 & 78.3 \\
\hline 0.550 & $\mathrm{~K}$ & 1.00 & $13.7 @$ & 81.6 & 26.00 & $13.7 @$ & 81.6 & 99999.90 & $29.7 @$ & 76.5 \\
\hline 0.600 & L & 1.00 & 15.00 & 81.6 & 26.00 & 15.00 & 81.6 & 99999.90 & $28.2 @$ & 74.0 \\
\hline 0.650 & M & 1.00 & $16.2 \mathrm{e}$ & 81.6 & 26.00 & 16.20 & 81.6 & 99999.90 & 25.90 & 70.2 \\
\hline 0.700 & $\mathrm{~N}$ & 1.00 & 17.40 & 81.6 & 26.00 & 17.40 & 81.6 & 99999.90 & 22.60 & 63.8 \\
\hline 0.750 & o & 1.00 & $18.7 @$ & 81.6 & 26.00 & $18.7 @$ & 81.6 & 26.00 & $18.7 @$ & 51.9 \\
\hline 0.800 & P & 99999.90 & $19.9 @$ & 81.6 & 99999.90 & $19.9 @$ & 81.6 & 26.00 & 15.10 & 27.2 \\
\hline 0.850 & $Q$ & 99999.90 & $21.2 @$ & 81.6 & 26.00 & $21.2 \mathrm{C}$ & 81.6 & 26.00 & 16.30 & -13.7 \\
\hline 0.900 & $\mathrm{R}$ & 99999.90 & $22.4 @$ & 81.6 & 26.00 & $22.4 @$ & 81.6 & 99999.90 & $26.7 @$ & -44.6 \\
\hline 0.950 & $\mathrm{~S}$ & 99999.90 & $23.7 @$ & 81.6 & 26.00 & $23.7 @$ & 81.6 & 99999.90 & 46.30 & -59.6 \\
\hline
\end{tabular}

Further hardware in the loop testing to validate the simulations with flagged mis-operations may be required. This reported mis-operation is considered a low risk as it only occurs during N-2 contingency. Both the primary pilot protection as well as a large power transformer must be outaged while the mis-operation occurs for only one fault location out of 98 reported. Therefore, it can be deemed acceptable for the protection engineer to consent the risk associated with the 
current protection scheme. A conservative solution can result in increasing the time delay of 21P2 at Winder Line 1 so the mis-operation gets downgraded to a CTI violation instead.

\subsubsection{Resistive Single Line to Ground Faults}

A total of 280 Single-Line-to-Ground resistive faults on Line 1 were applied, repeating the same simulations in chapters 4.3.1.1 and 4.3.1.2 (with and without the POTT scheme in service). The faults were repeated twice with $5 \mathrm{ohms}$ and $10 \mathrm{ohms}$ resistance between phase A and ground.

Table 4-22 and Table 4-23 lists the total fault clearing time for each simulation with the POTT in service. The average clearing time for these faults were quite fast at 69.16 milliseconds (comparable with bolted clearing time). No coordination issues were identified for any of the simulations on line 1 .

Table 4-22 - Line 1 Fault Clearing Time Results (Pilot In, SLG-5 Ohms Faults)

\begin{tabular}{|c|c|c|c|c|c|c|c|c|c|c|}
\hline \multirow{2}{*}{ Outage } & \multirow{2}{*}{ Pilot } & \multirow{2}{*}{ Fault Type } & \multicolumn{7}{|c|}{ Fault Clearing Time (Seconds) } & \multirow{2}{*}{ Mis-coordination } \\
\hline & & & $0 \%$ & $15 \%$ & $30 \%$ & $50 \%$ & $70 \%$ & $85 \%$ & $100 \%$ & \\
\hline Primary System Normal & In & SLG( 5) & 0.07 & 0.07 & 0.065 & 0.065 & 0.065 & 0.07 & 0.07 & No \\
\hline XFMR : 177-1317-1 ( Bank A) & In & SLG( 5) & 0.07 & 0.065 & 0.065 & 0.07 & 0.07 & 0.07 & 0.07 & No \\
\hline Line : 177-154-1(LINE7) & $\ln$ & SLG( 5) & 0.07 & 0.065 & 0.065 & 0.07 & 0.07 & 0.07 & 0.07 & No \\
\hline Line : 177-175-1(LINE6) & In & SLG( 5) & 0.07 & 0.07 & 0.065 & 0.065 & 0.07 & 0.07 & 0.07 & No \\
\hline XFMR : 183-1316-1( Bank C) & In & SLG( 5) & 0.07 & 0.07 & 0.065 & 0.065 & 0.065 & 0.07 & 0.07 & No \\
\hline Line : 183-105-1(LINE3) & In & SLG( 5) & 0.07 & 0.07 & 0.07 & 0.065 & 0.065 & 0.07 & 0.07 & No \\
\hline Line : 183-141-1(LINE2) & In & SLG( 5) & 0.07 & 0.07 & 0.065 & 0.065 & 0.065 & 0.07 & 0.07 & No \\
\hline Line : 183-151-1(LINE4) & In & SLG( 5) & 0.07 & 0.07 & 0.065 & 0.065 & 0.065 & 0.07 & 0.07 & No \\
\hline Line : 183-449-1(LINE5) & In & SLG( 5) & 0.07 & 0.07 & 0.065 & 0.065 & 0.065 & 0.07 & 0.07 & No \\
\hline Mutual: 179-181-1(LINE8) & In & SLG( 5) & 0.07 & 0.07 & 0.065 & 0.065 & 0.065 & 0.07 & 0.07 & No \\
\hline
\end{tabular}

Table 4-23 - Line 1 Fault Clearing Time Results (Pilot In, SLG-10 Ohms Faults)

\begin{tabular}{|c|c|c|c|c|c|c|c|c|c|c|}
\hline \multirow{2}{*}{ Outage } & \multirow{2}{*}{ Pilot } & \multirow{2}{*}{ Fault Type } & \multicolumn{7}{|c|}{ Fault Clearing Time (Seconds) } & \multirow{2}{*}{ Mis-coordination } \\
\hline & & & $0 \%$ & $15 \%$ & $30 \%$ & $50 \%$ & $70 \%$ & $85 \%$ & $100 \%$ & \\
\hline Primary System Normal & In & SLG( 10) & 0.07 & 0.07 & 0.07 & 0.065 & 0.07 & 0.07 & 0.07 & No \\
\hline XFMR : 177-1317-1( Bank A) & In & SLG( 10) & 0.07 & 0.065 & 0.07 & 0.07 & 0.07 & 0.07 & 0.1267 & No \\
\hline Line : 177-154-1(LINE7) & $\ln$ & SLG( 10) & 0.07 & 0.07 & 0.07 & 0.065 & 0.07 & 0.07 & 0.07 & No \\
\hline Line : 177-175-1(LINE6) & $\ln$ & $\operatorname{SLG}(10)$ & 0.07 & 0.07 & 0.07 & 0.07 & 0.07 & 0.07 & 0.07 & No \\
\hline XFMR : 183-1316-1( Bank C) & In & $\operatorname{SLG}(10)$ & 0.07 & 0.07 & 0.07 & 0.065 & 0.07 & 0.07 & 0.07 & No \\
\hline Line : 183-105-1(LINE3) & In & SLG( 10) & 0.07 & 0.07 & 0.07 & 0.065 & 0.07 & 0.07 & 0.07 & No \\
\hline Line : 183-141-1(LINE2) & $\ln$ & SLG( 10) & 0.07 & 0.07 & 0.07 & 0.065 & 0.07 & 0.07 & 0.07 & No \\
\hline Line : 183-151-1(LINE4) & In & SLG( 10) & 0.07 & 0.07 & 0.07 & 0.065 & 0.07 & 0.07 & 0.07 & No \\
\hline Line : 183-449-1(LINE5) & $\ln$ & SLG( 10) & 0.07 & 0.07 & 0.07 & 0.065 & 0.07 & 0.07 & 0.07 & No \\
\hline Mutual: 179-181-1(LINE8) & In & SLG( 10) & 0.07 & 0.07 & 0.07 & 0.065 & 0.07 & 0.07 & 0.07 & No \\
\hline
\end{tabular}


Table 4-24 - Line 1 Fault Clearing Time Results (Pilot Out, SLG-5 Ohms Faults)

\begin{tabular}{|c|c|c|c|c|c|c|c|c|c|c|}
\hline \multirow{2}{*}{ Outage } & \multirow{2}{*}{ Pilot } & \multirow{2}{*}{ Fault Type } & \multicolumn{7}{|c|}{ Fault Clearing Time (Seconds) } & \multirow{2}{*}{ Mis-coordination } \\
\hline & & & $0 \%$ & $15 \%$ & $30 \%$ & $50 \%$ & $70 \%$ & $85 \%$ & $100 \%$ & \\
\hline Primary System Normal & Out & SLG( 5) & 0.1267 & 0.1267 & 0.065 & 0.065 & 0.065 & 0.1267 & 0.4233 & No \\
\hline XFMR : 177-1317-1 ( Bank A) & Out & SLG( 5) & 0.1267 & 0.065 & 0.065 & 0.0817 & 0.14 & 0.5567 & 0.5567 & No \\
\hline Line : 177-154-1(LINE7) & Out & SLG( 5) & 0.1267 & 0.1267 & 0.065 & 0.065 & 0.1267 & 0.1267 & 0.4417 & No \\
\hline Line : 177-175-1(LINE6) & Out & SLG( 5) & 0.1267 & 0.1267 & 0.065 & 0.065 & 0.14 & 0.4633 & 0.5217 & No \\
\hline XFMR : 183-1316-1( Bank C) & Out & SLG( 5) & 0.1267 & 0.1267 & 0.065 & 0.065 & 0.065 & 0.1267 & 0.4233 & No \\
\hline Line : 183-105-1(LINE3) & Out & SLG( 5) & 0.1267 & 0.1267 & 0.1267 & 0.065 & 0.065 & 0.1267 & 0.42 & No \\
\hline Line : 183-141-1(LINE2) & Out & SLG( 5) & 0.1267 & 0.1267 & 0.065 & 0.065 & 0.065 & 0.1267 & 0.4217 & No \\
\hline Line : 183-151-1(LINE4) & Out & SLG( 5) & 0.1267 & 0.1267 & 0.065 & 0.065 & 0.065 & 0.1267 & 0.42 & No \\
\hline Line : 183-449-1(LINE5) & Out & SLG( 5) & 0.1267 & 0.1267 & 0.065 & 0.065 & 0.065 & 0.1267 & 0.4183 & No \\
\hline Mutual: 179-181-1(LINE8) & Out & $\operatorname{SLG}(5)$ & 0.1267 & 0.1267 & 0.065 & 0.065 & 0.065 & 0.1267 & 0.4267 & No \\
\hline
\end{tabular}

Table 4-25 - Line 1 Fault Clearing Time Results (Pilot Out, SLG-10 Ohms Faults)

\begin{tabular}{|c|c|c|c|c|c|c|c|c|c|c|}
\hline \multirow{2}{*}{ Outage } & \multirow{2}{*}{ Pilot } & \multirow{2}{*}{ Fault Type } & \multicolumn{7}{|c|}{ Fault Clearing Time (Seconds) } & \multirow{2}{*}{ Mis-coordination } \\
\hline & & & $0 \%$ & $15 \%$ & $30 \%$ & $50 \%$ & $70 \%$ & $85 \%$ & $100 \%$ & \\
\hline Primary System Normal & Out & SLG( 10) & 0.1267 & 0.1267 & 0.1267 & 0.065 & 0.1267 & 0.1267 & 0.455 & No \\
\hline XFMR : 177-1317-1( Bank A) & Out & SLG( 10) & 0.1267 & 0.065 & 0.0817 & 0.14 & 0.5517 & 0.5567 & 0.5567 & No \\
\hline Line : 177-154-1(LINE7) & Out & SLG( 10) & 0.1267 & 0.1267 & 0.1267 & 0.065 & 0.1267 & 0.4183 & 0.475 & No \\
\hline Line : 177-175-1(LINE6) & Out & SLG( 10) & 0.1267 & 0.1267 & 0.1267 & 0.14 & 0.4417 & 0.4933 & 0.5567 & No \\
\hline XFMR : 183-1316-1( Bank C) & Out & SLG( 10) & 0.1267 & 0.1267 & 0.1267 & 0.065 & 0.1267 & 0.405 & 0.4533 & No \\
\hline Line : 183-105-1(LINE3) & Out & SLG( 10) & 0.43 & 0.1267 & 0.1267 & 0.065 & 0.1267 & 0.1267 & 0.4467 & No \\
\hline Line : 183-141-1(LINE2) & Out & SLG( 10) & 0.4233 & 0.1267 & 0.1267 & 0.065 & 0.1267 & 0.1267 & 0.45 & No \\
\hline Line : 183-151-1(LINE4) & Out & SLG( 10) & 0.1267 & 0.1267 & 0.1267 & 0.065 & 0.1267 & 0.1267 & 0.45 & No \\
\hline Line : 183-449-1(LINE5) & Out & SLG( 10) & 0.4217 & 0.1267 & 0.1267 & 0.065 & 0.1267 & 0.1267 & 0.4483 & No \\
\hline Mutual: 179-181-1(LINE8) & Out & SLG( 10) & 0.1267 & 0.1267 & 0.1267 & 0.065 & 0.1267 & 0.4083 & 0.46 & No \\
\hline
\end{tabular}

Table 4-24 and Table 4-25 lists the total fault clearing time for each simulation with the POTT out of service. The average clearing time for these faults were 187.73 milliseconds (slightly slower than bolted clearing time). No coordination issues were identified for any of the found on line 1.

The main intention of activating ground overcurrent elements in the protection scheme was intended to clear resistive faults due to the blind spot of impedance based distance protection. However, any overcurrent element can become quite sensitive to a change in topology and requires extensive coordination study with its neighboring pairs. A further $5 \%$ increment study was conducted to ensure coordination of overcurrent elements between primary Line 1 at Center versus backup Line 6 at Bio substations. Table 4-28 shows the operation of each primary and backup ground overcurrent elements for every fault location (curves 1-2 are the primary IOC and TOC respectively, curves 3-4 represents the backup IOC and TOC respectively) . 
Table 4-26 - Line 1 and 6 Overcurrent Protection - Resistive SLG Faults (10 Ohms)

\begin{tabular}{|c|c|c|c|c|c|c|c|c|c|}
\hline $\begin{array}{l}\text { Fault } \\
\text { Location }\end{array}$ & $\begin{array}{l}\text { Fault } \\
\text { Code }\end{array}$ & $\begin{array}{l}------ \text { CURVE } \\
\text { OPER. CYC }\end{array}$ & $\begin{array}{l}\text { 1------- } \\
\text { A/PICKUP }\end{array}$ & $\begin{array}{l}------ \text { CURVE } \\
\text { OPER. CYC }\end{array}$ & $\begin{array}{l}\text { 2------- } \\
\text { A/PICKUP }\end{array}$ & $\begin{array}{l}------ \text { CURVE } \\
\text { OPER. CYC }\end{array}$ & $\begin{array}{l}\text { 3------- } \\
\text { A/PICKUP }\end{array}$ & $\begin{array}{l}------ \text { CURVE } \\
\text { OPER. CYC }\end{array}$ & $\begin{array}{l}\text { 4-------- } \\
\text { A/PICKUP }\end{array}$ \\
\hline 0.050 & A & 0.24 & 1.95 & 11.20 & 4.88 & 99999.90 & 0.57 & 47.70 & 1.43 \\
\hline 0.100 & B & 0.24 & 1.83 & 11.70 & 4.57 & 99999.90 & 0.54 & 57.90 & 1.34 \\
\hline 0.150 & $\mathrm{C}$ & 0.24 & 1.71 & 12.10 & 4.28 & 99999.90 & 0.51 & 72.80 & 1.26 \\
\hline 0.200 & D & 0.24 & 1.61 & 12.70 & 4.02 & 99999.90 & 0.48 & 97.10 & 1.19 \\
\hline 0.250 & E & 0.24 & 1.51 & 13.20 & 3.79 & 99999.90 & 0.45 & 143.10 & 1.13 \\
\hline 0.300 & $\mathrm{~F}$ & 0.24 & 1.43 & 13.80 & 3.57 & 99999.90 & 0.43 & 99999.90 & 1.07 \\
\hline 0.350 & G & 0.24 & 1.35 & 14.40 & 3.37 & 99999.90 & 0.40 & 99999.90 & 1.01 \\
\hline 0.400 & $\mathrm{H}$ & 0.24 & 1.27 & 15.10 & 3.18 & 99999.90 & 0.38 & 99999.90 & 0.96 \\
\hline 0.450 & I & 0.24 & 1.20 & 15.90 & 3.00 & 99999.90 & 0.37 & 99999.90 & 0.91 \\
\hline 0.500 & $\mathrm{~J}$ & 0.24 & 1.13 & 16.70 & 2.83 & 99999.90 & 0.35 & 99999.90 & 0.87 \\
\hline 0.550 & K & 0.24 & 1.07 & 17.70 & 2.67 & 99999.90 & 0.33 & 99999.90 & 0.83 \\
\hline 0.600 & L & 0.24 & 1.01 & 18.80 & 2.52 & 99999.90 & 0.31 & 99999.90 & 0.79 \\
\hline 0.650 & M & 99999.90 & 0.95 & 20.10 & 2.37 & 99999.90 & 0.30 & 99999.90 & 0.75 \\
\hline 0.700 & $\mathrm{~N}$ & 99999.90 & 0.89 & 21.60 & 2.22 & 99999.90 & 0.28 & 99999.90 & 0.71 \\
\hline 0.750 & 0 & 99999.90 & 0.83 & 23.60 & 2.08 & 99999.90 & 0.27 & 99999.90 & 0.67 \\
\hline 0.800 & P & 99999.90 & 0.77 & 26.10 & 1.93 & 99999.90 & 0.26 & 99999.90 & 0.64 \\
\hline 0.850 & Q & 99999.90 & 0.71 & 29.60 & 1.79 & 99999.90 & 0.24 & 99999.90 & 0.60 \\
\hline 0.900 & $\mathrm{R}$ & 99999.90 & 0.65 & 35.00 & 1.63 & 99999.90 & 0.23 & 99999.90 & 0.57 \\
\hline 0.950 & $\mathrm{~s}$ & 99999.90 & 0.59 & 44.30 & 1.47 & 99999.90 & 0.21 & 99999.90 & 0.53 \\
\hline
\end{tabular}

The IOC and TOC elements are set to work as a combined unit to clear majority of the faults under normal condition instantaneously while clearing end of line abnormalities similar to a zone 2 timed distance elements. Resistive faults reduce the magnitude of fault currents and therefore impact the reach of IOC elements. Furthermore, the time delay of inverse time overcurrent TOC elements are reduced. Figure 4-9 shows the behavior of IOC and TOC for both primary and backup protection on Line 1 faults SLG $10 \mathrm{ohm}$ resistive faults with 5\% increments. 


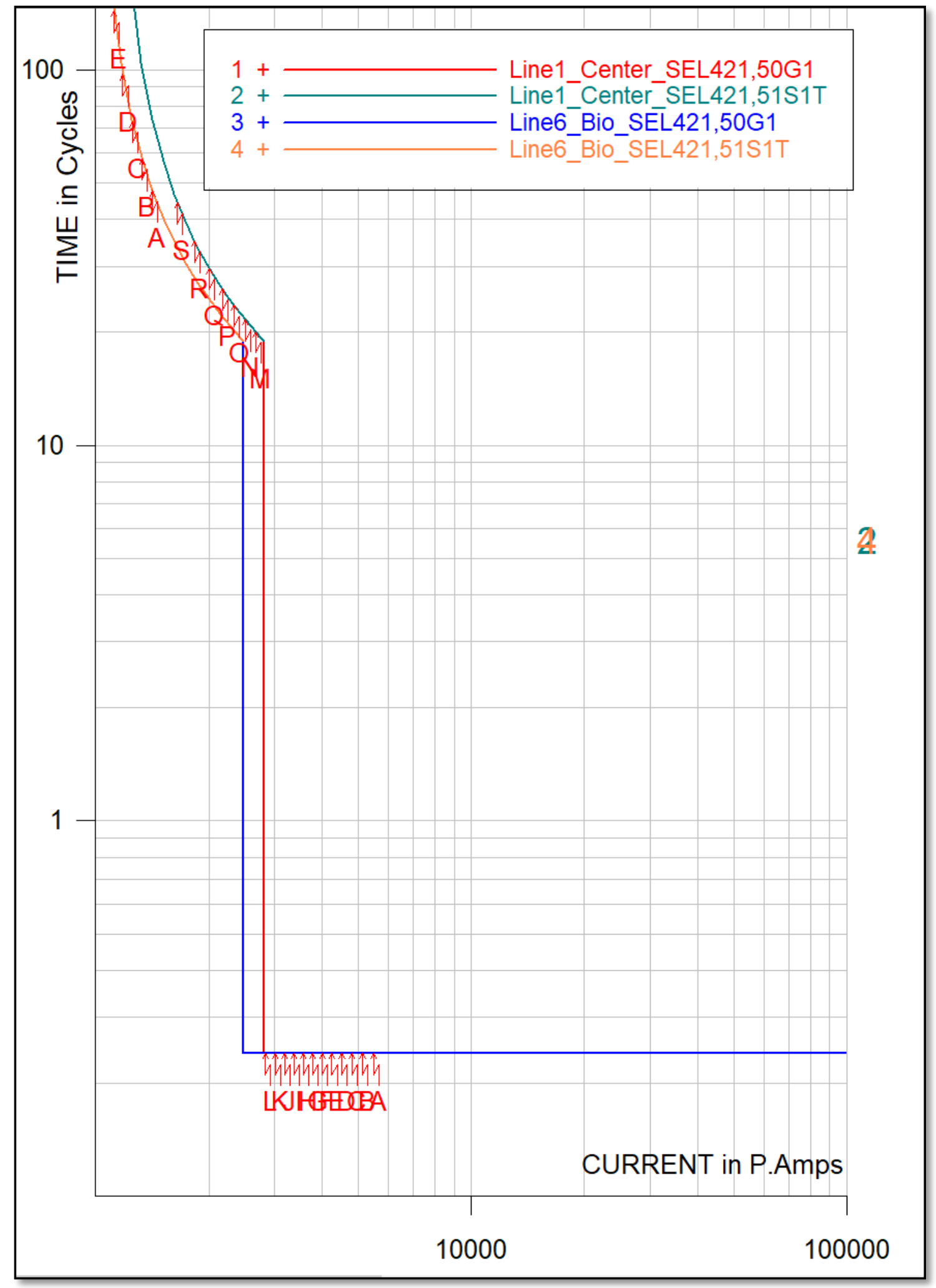

Figure 4-9 - Line 1 and 6 Overcurrent Protection - Resistive SLG Faults (10 Ohms) 
The primary ground IOC has a reach of $60-65 \%$ of the line and can clear a fault in 0.24 cycles. The primary ground TOC can detect faults on the entire line and clear at approximately 50 cycles for remote close-in fault. The backup ground IOC at Bio substation cannot see beyond its protecting line and therefore cannot operate. Furthermore, the backup ground TOC at Bio substation can reach into Line 1 for approximately $25-30 \%$. The operation of the backup TOC element is significantly slower and will not cause any mis-coordination.

Next, the behavior of the ground distance element is observed for SLG faults with 10 ohms resistance in Figure 4-10. As expected, the faults lie far right on the R plane and outside of the Mho characteristics.

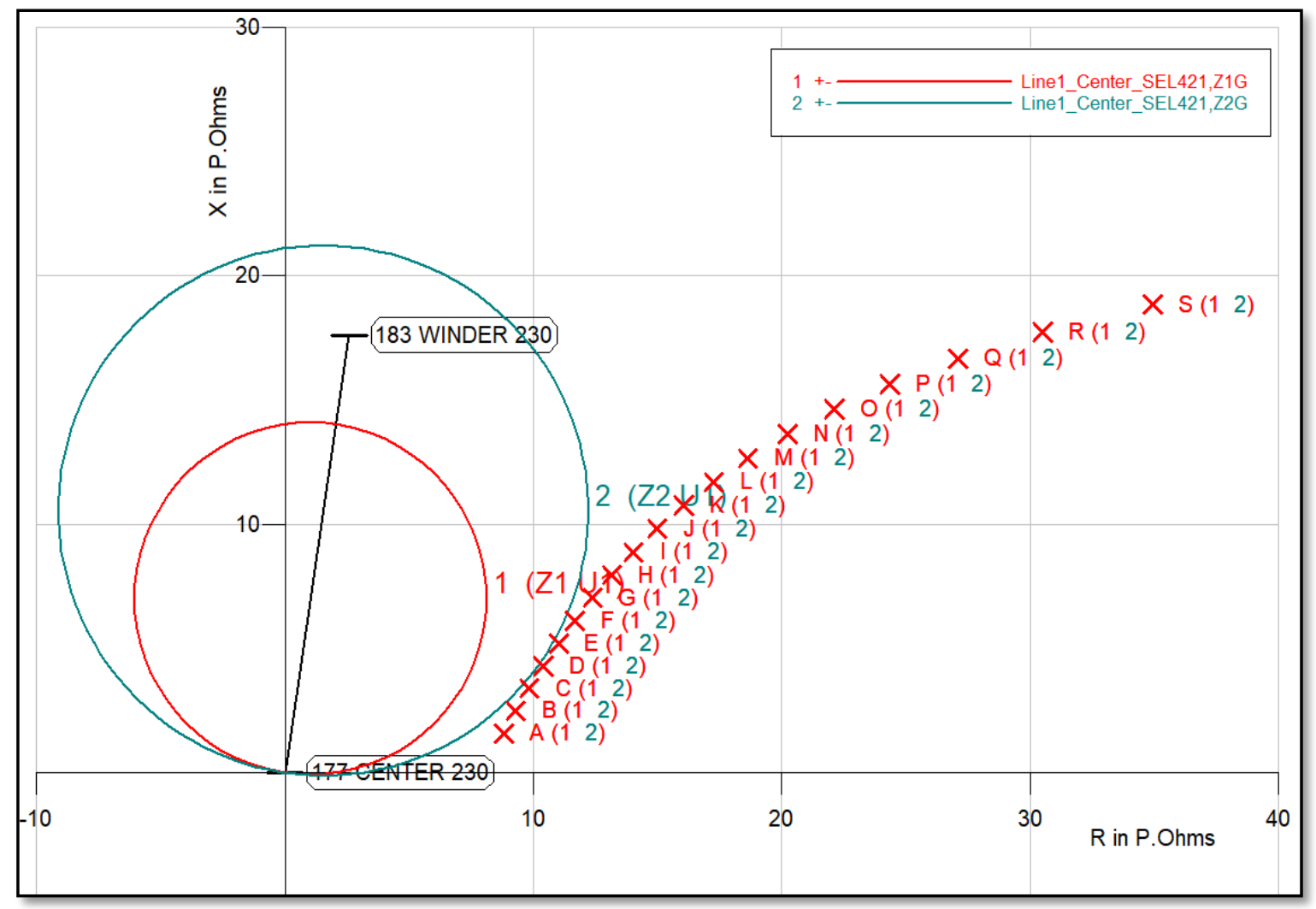

Figure 4-10 - Line 1 Distance Protection - Resistive SLG Faults (10 Ohms)

The summary of all primary ground protection sensitive to SLG resistive faults are observed in Table 4-27. The ground zone 1 (21G1) has a reach of less than $35 \%$ while zone 2 operates for less than $60 \%$ of the transmission line. This sensitivity is significantly less than the desired $85 \%$ and $120 \%$ reach respectively. The importance of inverse timed ground overcurrent element (67GT) is 
observed as without it a fault may never get cleared. The slower time clearing is of little concern as with one end of the line clear the other end will observe a higher fault current sequentially. This will result in an increased reach of the instantaneous element as well as a higher speed of operation for the inverse timed ground overcurrent protection.

Table 4-27 - Line 1 Overcurrent \& Distance Protection - Resistive SLG Faults (10 Ohms)

\begin{tabular}{|c|c|c|c|c|c|c|c|c|c|}
\hline \multirow{3}{*}{$\begin{array}{c}\text { Fault } \\
\text { Location }\end{array}$} & \multirow{3}{*}{$\begin{array}{l}\text { Fault } \\
\text { Code }\end{array}$} & \multicolumn{8}{|c|}{ Primary Protection - Center Line 1} \\
\hline & & \multicolumn{2}{|c|}{$67 \mathrm{GI} I O C$} & \multicolumn{2}{|c|}{ 67GT_TOC } & \multicolumn{2}{|c|}{$21 \mathrm{G} 1$} & \multicolumn{2}{|c|}{$21 \mathrm{G} 2 \mathrm{~T}$} \\
\hline & & $\begin{array}{c}\text { Operation } \\
\text { (Cycles) }\end{array}$ & A/Pickup & $\begin{array}{l}\text { Operation } \\
\text { (Cycles) }\end{array}$ & A/Pickup & $\begin{array}{l}\text { Operation } \\
\text { (Cycles) }\end{array}$ & $\begin{array}{l}\text { Apparent } \\
\text { Imd. }\end{array}$ & $\begin{array}{l}\text { Operation } \\
\text { (Cycles) }\end{array}$ & $\begin{array}{l}\text { Apparent } \\
\text { Imd. }\end{array}$ \\
\hline $5 \%$ & A & 0.24 & 1.95 & 11.2 & 4.88 & 1.0 & 8.96@10.2 & 26.0 & 8.96@10.2 \\
\hline $10 \%$ & B & 0.24 & 1.83 & 11.7 & 4.57 & 1.0 & 9.64@14.9 & 26.0 & 9.64@14.9 \\
\hline $15 \%$ & $\mathrm{C}$ & 0.24 & 1.71 & 12.1 & 4.28 & 1.0 & 10.4@19 & 26.0 & 10.4@19.0 \\
\hline $20 \%$ & D & 0.24 & 1.61 & 12.7 & 4.02 & 1.0 & 11.3@22.4 & 26.0 & 11.3@22.4 \\
\hline $25 \%$ & $\mathrm{E}$ & 0.24 & 1.51 & 13.2 & 3.79 & 1.0 & 12.2@25.3 & 26.0 & 12.2@25.3 \\
\hline $30 \%$ & $\mathrm{~F}$ & 0.24 & 1.43 & 13.8 & 3.57 & 1.0 & $13.2 @ 27.6$ & 26.0 & 13.2@27.6 \\
\hline $35 \%$ & G & 0.24 & 1.35 & 14.4 & 3.37 & 99999.9 & 14.2@29.6 & 26.0 & 14.2@29.6 \\
\hline $40 \%$ & $\mathrm{H}$ & 0.24 & 1.27 & 15.1 & 3.18 & 99999.9 & 15.4@31.1 & 26.0 & 15.4@31.1 \\
\hline $45 \%$ & 1 & 0.24 & 1.2 & 15.9 & 3 & 99999.9 & $16.6 @ 32.3$ & 26.0 & 16.6@32.3 \\
\hline $50 \%$ & J & 0.24 & 1.13 & 16.7 & 2.83 & 99999.9 & 17.9@33.2 & 26.0 & 17.9@33.2 \\
\hline $55 \%$ & $\mathrm{~K}$ & 0.24 & 1.07 & 17.7 & 2.67 & 99999.9 & 19.3@33.8 & 26.0 & 19.3@33.8 \\
\hline $60 \%$ & $\mathrm{~L}$ & 0.24 & 1.01 & 18.8 & 2.52 & 99999.9 & 20.9@34.1 & 99999.9 & 20.9@34.1 \\
\hline $65 \%$ & $\mathrm{M}$ & 99999.9 & 0.95 & 20.1 & 2.37 & 99999.9 & 22.5@34.2 & 99999.9 & 22.5@34.2 \\
\hline $70 \%$ & $\mathrm{~N}$ & 99999.9 & 0.89 & 21.6 & 2.22 & 99999.9 & 24.4@34 & 99999.9 & 24.4@34.0 \\
\hline $75 \%$ & 0 & 99999.9 & 0.83 & 23.6 & 2.08 & 99999.9 & 26.5@33.5 & 99999.9 & 26.5@33.5 \\
\hline $80 \%$ & $\mathrm{P}$ & 99999.9 & 0.77 & 26.1 & 1.93 & 99999.9 & 28.9@32.7 & 99999.9 & 28.9@32.7 \\
\hline $85 \%$ & $\mathrm{Q}$ & 99999.9 & 0.71 & 29.6 & 1.79 & 99999.9 & 31.8@31.6 & 99999.9 & $31.8 @ 31.6$ \\
\hline $90 \%$ & $\mathrm{R}$ & 99999.9 & 0.65 & 35 & 1.63 & 99999.9 & 35.3@30.2 & 99999.9 & 35.3@30.2 \\
\hline $95 \%$ & $\mathrm{~s}$ & 99999.9 & 0.59 & 44.3 & 1.47 & 99999.9 & 39.7@28.3 & 99999.9 & 39.7@28.3 \\
\hline
\end{tabular}

Using the fault clearing results of over 280 fault conditions described above, one can gain confidence in utilizing an optimized protection scheme to clear abnormalities within Line 1. However, the performance of the primary Line 1 protection requires to be setup in such a way that it does not interfere on faults on adjacent equipment as backup protection.

A total of 196 Single-Line-to-Ground resistive faults on Line 6 were applied while the POTT scheme of Line 1 and 2 were in and out of service. Table 4-28 Table 4-29 lists the total fault clearing time for each simulation (Line 6 Pilots outaged). The average clearing time for these faults were 225.19 milliseconds. 
Table 4-28 - Line 6 Fault Clearing Time Results (Pilot Out, SLG-5 Ohms Faults)

\begin{tabular}{|c|c|c|c|c|c|c|c|c|c|c|}
\hline \multirow{2}{*}{ Outage } & \multirow{2}{*}{ Pilot } & \multirow{2}{*}{ Fault Type } & \multicolumn{7}{|c|}{ Fault Clearing Time (Seconds) } & \multirow{2}{*}{ Mis-coordination } \\
\hline & & & $0 \%$ & $15 \%$ & $30 \%$ & $50 \%$ & $70 \%$ & $85 \%$ & $100 \%$ & \\
\hline Primary System Normal & Out & SLG( 5) & 0.405 & 0.1267 & 0.065 & 0.065 & 0.065 & 0.3917 & 0.4483 & Mis-Op \\
\hline XFMR : 177-1317-1 ( Bank A) & Out & SLG( 5) & 0.3933 & 0.065 & 0.065 & 0.0817 & INF & INF & 0.5567 & Mis-Op \\
\hline Line : 177-154-1(LINE7) & Out & SLG( 5) & 0.3983 & 0.1267 & 0.065 & 0.065 & 0.065 & 0.4017 & 0.46 & Mis-Op \\
\hline Line : 177-183-1(LINE1) & Out & SLG( 5) & 0.4067 & 0.1267 & 0.065 & 0.065 & 0.14 & 0.4617 & 0.5333 & No \\
\hline XFMR : 175-1318-1 ( Bank \#1) & Out & SLG( 5) & 0.1267 & 0.1267 & 0.065 & 0.065 & 0.065 & 0.1267 & 0.1267 & Mis-Op \\
\hline XFMR : 175-1418-1 ( Bank \#3) & Out & SLG( 5) & 0.1267 & 0.1267 & 0.065 & 0.065 & 0.1267 & 0.1267 & 0.1267 & Mis-Op \\
\hline Line : 175-176-1() & Out & SLG( 5) & 0.5567 & 0.4983 & 0.14 & 0.0817 & 0.0817 & 0.4117 & 0.4567 & No \\
\hline
\end{tabular}

Table 4-29 - Line 6 Fault Clearing Time Results (Pilot Out, SLG-10 Ohms Faults)

\begin{tabular}{|c|c|c|c|c|c|c|c|c|c|c|}
\hline \multirow{2}{*}{ Outage } & \multirow{2}{*}{ Pilot } & \multirow{2}{*}{ Fault Type } & \multicolumn{7}{|c|}{ Fault Clearing Time (Seconds) } & \multirow{2}{*}{ Mis-coordination } \\
\hline & & & $0 \%$ & $15 \%$ & $30 \%$ & $50 \%$ & $70 \%$ & $85 \%$ & $100 \%$ & \\
\hline Primary System Normal & Out & SLG( 10) & 0.4267 & 0.1267 & 0.1267 & 0.065 & 0.1267 & 0.415 & 0.4833 & Mis-Op \\
\hline XFMR : 177-1317-1( Bank A) & Out & SLG( 10) & 0.41 & 0.1267 & 0.065 & INF & 0.14 & INF & 0.5567 & Mis-Op \\
\hline Line : 177-154-1(LINE7) & Out & SLG( 10) & 0.42 & 0.1267 & 0.065 & 0.065 & 0.1267 & 0.425 & 0.4967 & Mis-Op \\
\hline Line : 177-183-1(LINE1) & Out & SLG( 10) & 0.425 & 0.1267 & 0.1267 & 0.065 & 0.14 & 0.49 & 0.5567 & No \\
\hline XFMR : 175-1318-1( Bank \#1) & Out & SLG( 10) & 0.1267 & 0.1267 & 0.1267 & 0.065 & 0.065 & 0.1267 & 0.4333 & Mis-Op \\
\hline XFMR : 175-1418-1( Bank \#3) & Out & SLG( 10) & 0.1267 & 0.1267 & 0.1267 & 0.065 & 0.1267 & 0.1267 & 0.43 & Mis-Op \\
\hline Line : 175-176-1( ) & Out & SLG( 10) & 0.5567 & 0.5567 & 0.14 & 0.14 & 0.1433 & 0.425 & 0.4833 & Mis-Op \\
\hline
\end{tabular}

From the 196 SLG fault scenarios, it was observed that both Winder and Center POTT schemes were misbehaving for 30 of the simulations (see Table 4-30 and Table 4-31).

Table 4-30 - Line 6 SLG (5 Ohms) Test Results: Backup POTT Scheme of Line 1 (Winder \& Center)

\begin{tabular}{|c|c|c|c|c|c|c|c|c|}
\hline Pilot & Outages/Test & $0.00 \%$ & $15.00 \%$ & $30.00 \%$ & $50.00 \%$ & $70.00 \%$ & $85.00 \%$ & $100.00 \%$ \\
\hline \multirow{7}{*}{ Enabled } & \multirow{7}{*}{$\begin{array}{l}\text { Primary System Normal } \\
\text { XFMR : 177-1317-1( Bank A) } \\
\text { Line : 177-154-1(LINE7) } \\
\text { Line : 177-183-1(LINE1) } \\
\text { XFMR : 175-1318-1( Bank \#1) } \\
\text { XFMR : 175-1418-1( Bank \#3) } \\
\text { Line : 175-176-1( ) }\end{array}$} & Pass & Pass & Mis-Op & Pass & Pass & Pass & Pass \\
\hline & & Pass & Pass & Pass & Pass & Mis-Op & Mis-Op & Pass \\
\hline & & Pass & Pass & Mis-Op & Pass & Pass & Pass & Pass \\
\hline & & Pass & Pass & Pass & Pass & Pass & Pass & Pass \\
\hline & & Pass & Pass & Mis-Op & Pass & Pass & Pass & Pass \\
\hline & & Pass & Pass & Mis-Op & Pass & Pass & Pass & Pass \\
\hline & & Pass & Pass & Pass & Pass & Pass & Pass & Pass \\
\hline \multirow{7}{*}{ Disabled } & \multirow{7}{*}{$\begin{array}{l}\text { Primary System Normal } \\
\text { XFMR : 177-1317-1( Bank A) } \\
\text { Line : 177-154-1(LINE7) } \\
\text { Line : 177-183-1(LINE1) } \\
\text { XFMR : 175-1318-1( Bank \#1) } \\
\text { XFMR : 175-1418-1( Bank \#3) } \\
\text { Line : 175-176-1( ) }\end{array}$} & Pass & Pass & Mis-Op & Pass & Pass & Pass & Pass \\
\hline & & Pass & Pass & Pass & Pass & Mis-Op & Mis-Op & Pass \\
\hline & & Pass & Pass & Mis-Op & Pass & Pass & Pass & Pass \\
\hline & & Pass & Pass & Pass & Pass & Pass & Pass & Pass \\
\hline & & Pass & Pass & Mis-Op & Pass & Pass & Pass & Pass \\
\hline & & Pass & Pass & Mis-Op & Pass & Pass & Pass & Pass \\
\hline & & Pass & Pass & Pass & Pass & Pass & Pass & Pass \\
\hline
\end{tabular}


Table 4-31 - Line 6 SLG (10 Ohms) Test Results: Backup POTT Scheme of Line 1 (Winder \& Center)

\begin{tabular}{|c|c|c|c|c|c|c|c|c|}
\hline Pilot & Outages/Test & $0.00 \%$ & $15.00 \%$ & $30.00 \%$ & $50.00 \%$ & $70.00 \%$ & $85.00 \%$ & $100.00 \%$ \\
\hline \multirow{7}{*}{ Enabled } & \multirow{7}{*}{$\begin{array}{l}\text { Primary System Normal } \\
\text { XFMR : 177-1317-1( Bank A) } \\
\text { Line : 177-154-1(LINE7) } \\
\text { Line : 177-183-1(LINE1) } \\
\text { XFMR : 175-1318-1( Bank \#1) } \\
\text { XFMR : 175-1418-1( Bank \#3) } \\
\text { Line : 175-176-1( ) }\end{array}$} & Pass & Mis-Op & Pass & Pass & Pass & Pass & Pass \\
\hline & & Pass & Pass & Mis-Op & Mis-Op & Mis-Op & Mis-Op & Pass \\
\hline & & Pass & Mis-Op & Mis-Op & Pass & Pass & Pass & Pass \\
\hline & & Pass & Pass & Pass & Pass & Pass & Pass & Pass \\
\hline & & Pass & Mis-Op & Pass & Pass & Pass & Pass & Pass \\
\hline & & Pass & Mis-Op & Pass & Pass & Pass & Pass & Pass \\
\hline & & Pass & Pass & Pass & Pass & Pass & Pass & Pass \\
\hline \multirow{7}{*}{ Disabled } & \multirow{7}{*}{$\begin{array}{l}\text { Primary System Normal } \\
\text { XFMR : 177-1317-1( Bank A) } \\
\text { Line : 177-154-1(LINE7) } \\
\text { Line : 177-183-1(LINE1) } \\
\text { XFMR : 175-1318-1( Bank \#1) } \\
\text { XFMR : 175-1418-1( Bank \#3) } \\
\text { Line : 175-176-1( ) }\end{array}$} & Pass & Mis-Op & Pass & Pass & Pass & Pass & Pass \\
\hline & & Pass & Pass & Mis-Op & Mis-Op & Mis-Op & Mis-Op & Pass \\
\hline & & Pass & Mis-Op & Mis-Op & Pass & Pass & Pass & Pass \\
\hline & & Pass & Pass & Pass & Pass & Pass & Pass & Pass \\
\hline & & Pass & Mis-Op & Pass & Pass & Pass & Pass & Pass \\
\hline & & Pass & Mis-Op & Pass & Pass & Pass & Pass & Pass \\
\hline & & Pass & Pass & Pass & Pass & Pass & Pass & Pass \\
\hline
\end{tabular}

The mis- coordination of the same POTT backup element at Line 1 has increased from $6 \%$ while studying bolted SLG faults in chapter 4.3.1.1 to more than $15 \%$ due to the impact of resistive faults. More importantly, of the failed conditions, there are mis-operations of these backup POTT elements during system normal conditions (more likely to occur). Also, the failed simulations occur at various locations ranging from $15 \%$ to $85 \%$ under five different contingencies.

Figure 4-11 represents one of the thirty test scenarios listed in the abovementioned table in depth. The fault scenario is a system normal condition. There is a SLG fault with $10 \mathrm{ohms}$ resistance applied at $15 \%$ location (measured from Center towards Bio substation). The fault is not cleared during two sequential breaker events as there is a backup mis-coordination of POTT schemes at Center and Winder Line 1 terminals. Table 4-32 and Table 4-33 summarizes the event operations. During the first event, the primary protection at Center which is closest to the fault detects the abnormality and issues a trip using its fastest element 67GI at 7 milliseconds. With the breaker opening time set at 58 milliseconds, the primary breaker at Center Line 6 terminal will open at a total of 65 milliseconds. However, during Event 1, both POTT schemes at Winder and Center Line 1 terminals report an operation of 70 milliseconds (including breaker opening). It is reported that the directional 50G2 elements at both Line 1 terminal ends tend to react to this out-of-zone fault. This results in the initiation of the POTT handshake and the prediction of mis-operation of both terminal ends. 


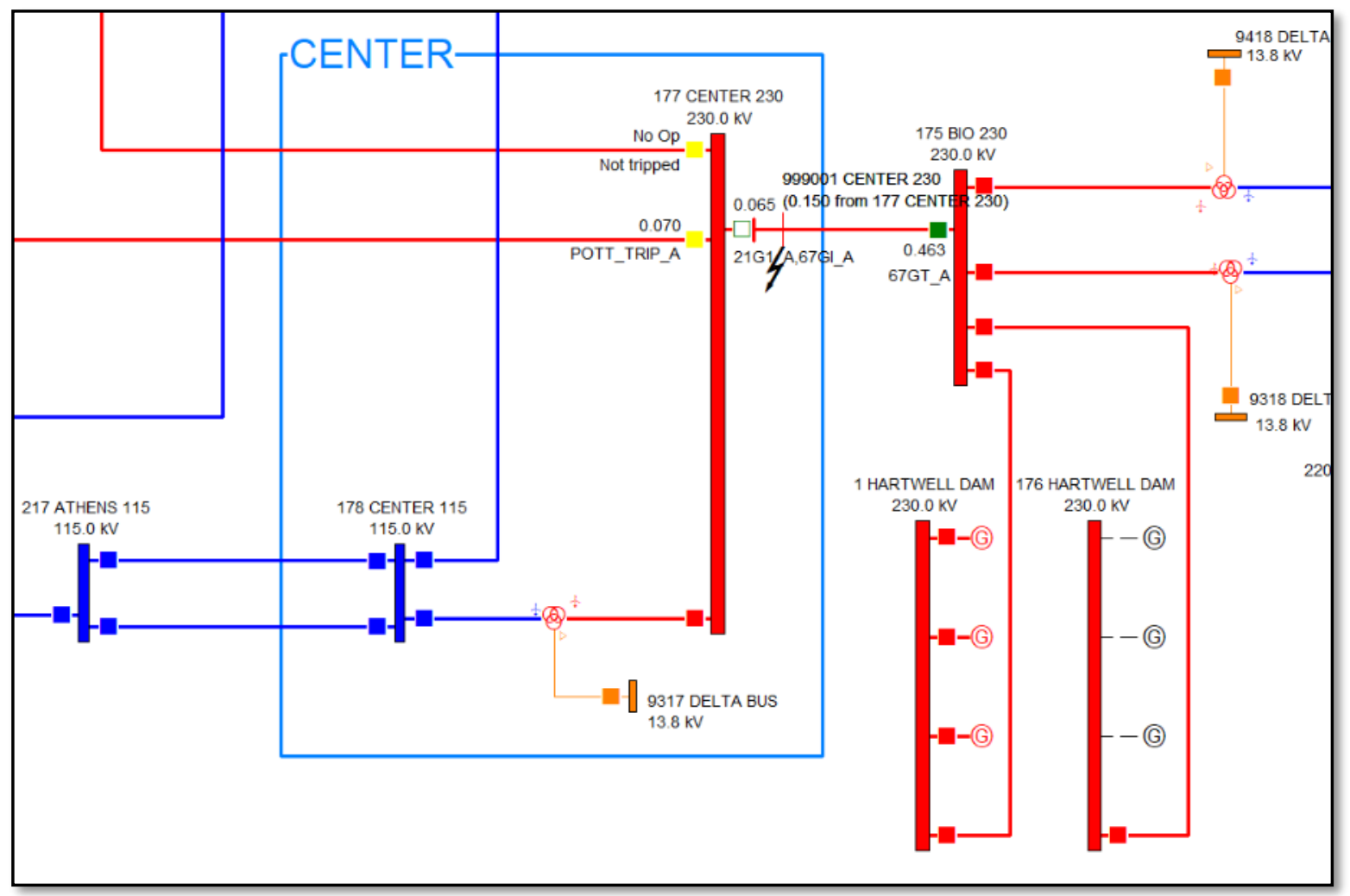

Figure 4-11 - Line 6 Test Condition: SLG 10 Ohms 15\%, System Normal

Table 4-32 - Line 6 Test Results: SLG 10 Ohms 15\%, System Normal, Event 1

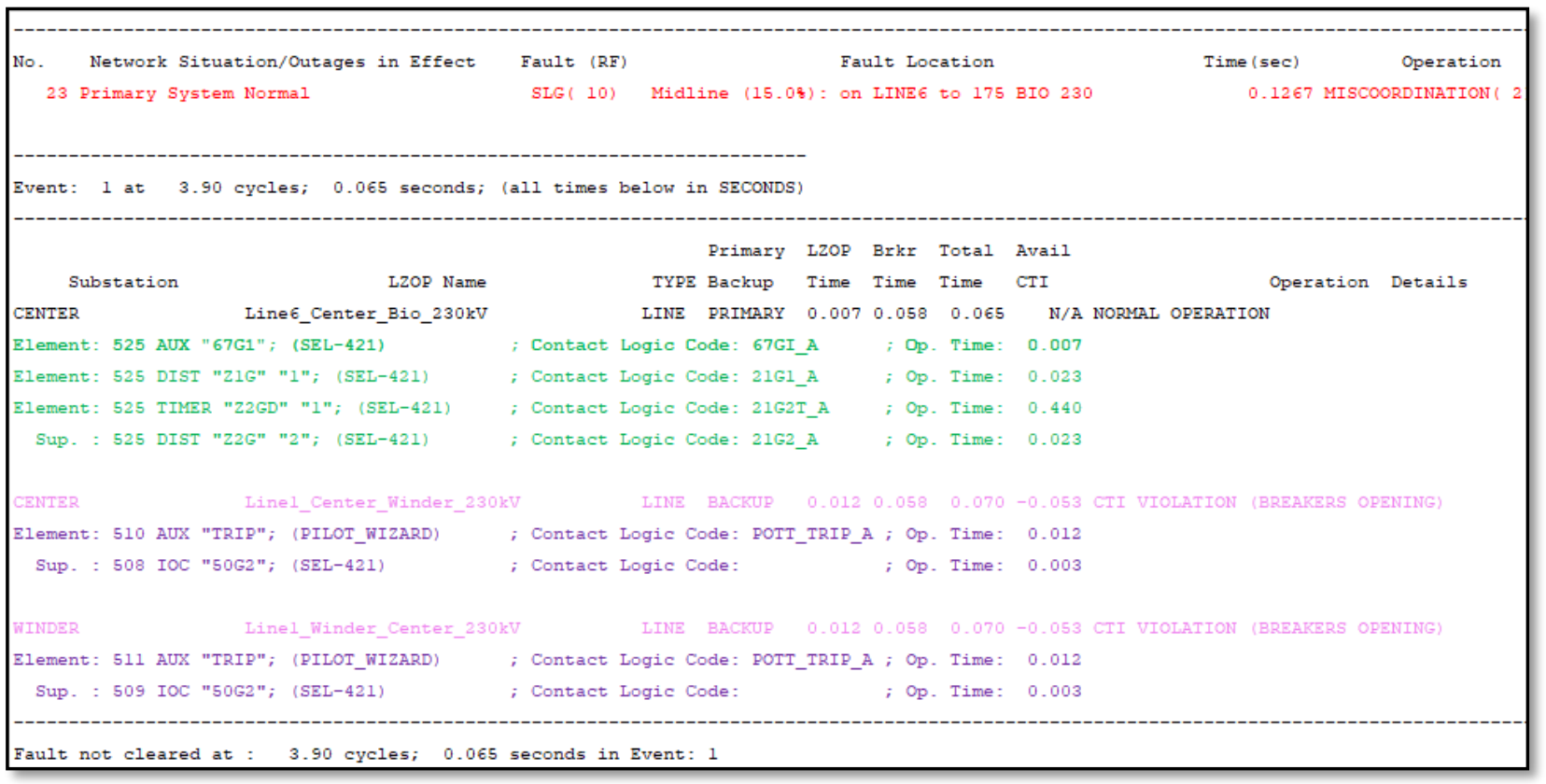


As expected, both Line 1 terminals report a mis-operation during Event 2, while the primary ground instantaneous overcurrent element at Bio substation is scheduled to clear at Event 3 at 127 milliseconds. Due to the fast reaction of backup POTT scheme, the same mis-operation will be reported even if primary POTT scheme of study Line 6 is activated.

Table 4-33 - Line 6 Test Results: SLG 10 Ohms 15\%, System Normal, Event 2

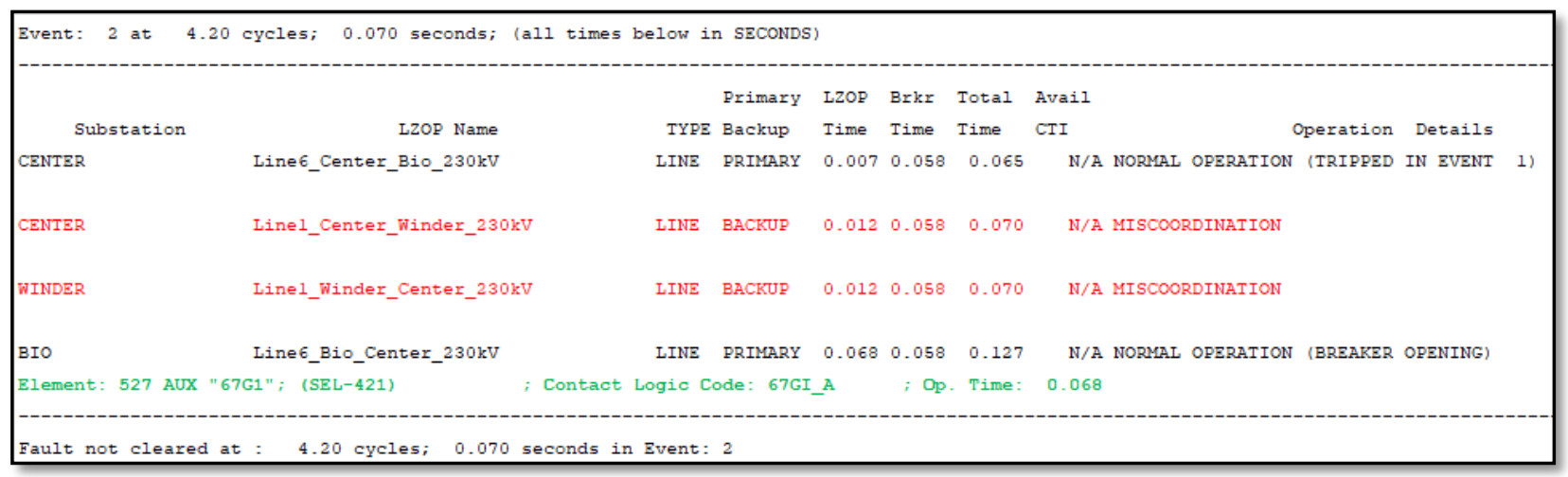

The solution to resolve this specific backup POTT scheme was presented in chapter 4.3.1.1. It is concluded that the introduction of resistive faults has highlighted the increased probability of the mis-operation to occur even during system normal conditions. Therefore, it is now absolutely crucial for the solution to replace the POTT scheme with a secure DCB scheme instead with a reverse directional ground overcurrent blocking to occur with highest priority.

\subsubsection{CASE 2: Incorrect Setting}

As expressed in chapter 1.3.1, one of the highest causes of mis-operations in North America is due to human errors. This high distribution has been steadily increasing due to the complexity of the digital protective relays. After performing their detailed studies and preparing calculation sheets for every transmission line, engineers are required to duplicate hundreds of individual tap settings in at least two redundant relays with different manufacturers. This task can be cumbersome and may result in uploading incorrect settings into the relays [24-28]. In order to investigate whether the proposed wide area protection coordination solution can catch such errors, a setting was purposely entered incorrectly on the SEL421 relay and uploaded to the CAPE model. The same studies as CASE 1 were performed and the results are presented. 
Figure 4-12 represents the setting error entered into one of the relays under review. The primary protection at Winder Line 1 terminal has both its phase and ground distance zone 1 with the same delay as its zone 2 protection as opposed to operating instantaneously.

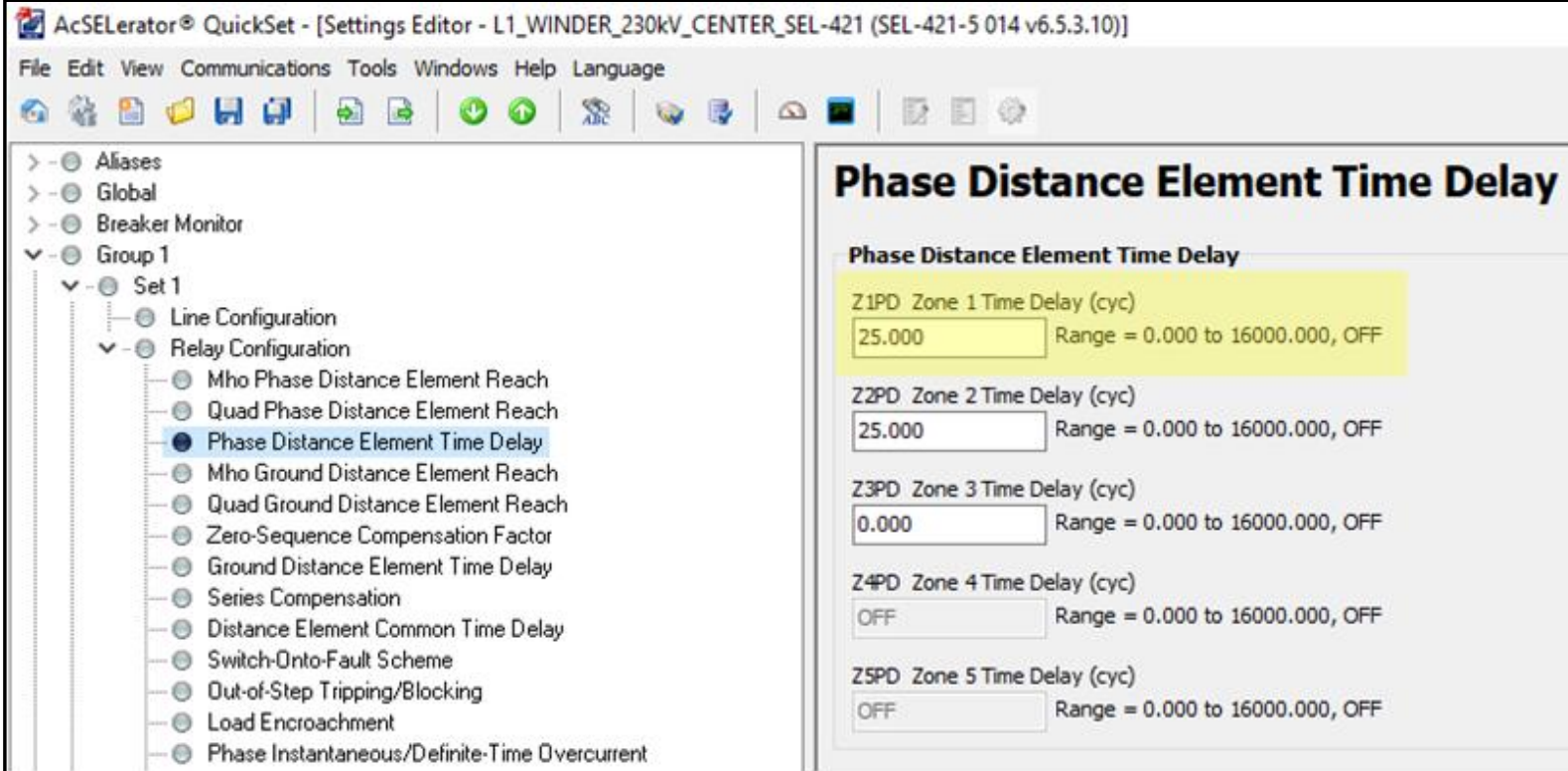

\section{Phase Distance Element Time Delay}

Phase Distance Element Time Delay

Z1PD Zone 1 Time Delay (cyc)

25.000 Range $=0.000$ to 16000.000 , OfF

22PD Zone 2 Time Delay (cyc)

25.000 Range $=0.000$ to 16000.000 , OFF

Z3PD Zone 3 Time Delay (cyc)

0.000 Range $=0.000$ to 16000.000 , OFF

Z4PD Zone 4 Time Delay (cyc)

OFF Range $=0.000$ to 16000.000 , OFF

Z5PD Zone 5 Time Delay (cyc)

OFF Range $=0.000$ to 16000.000 , OFF

Figure 4-12 - Incorrect Setting Simulation Scenario - Zone 1 Distance Timers

Similar to CASE 1 studies in chapter 4.3.1, a comprehensive coordination study was performed resulting in 546 fault simulations with the following criteria:

- $\quad$ System Normal and N-1 System Contingencies Outages

- System Normal and Pilot Protection Outages

- Fault types: SLG, TPH, SLG-5ohms, SLG-10ohms

- Fault locations: $0.01 \%, 15 \%, 30 \%, 50 \%, 70 \%, 85 \%$, and $99.99 \%$ of the line

Table 4-34 and Table 4-35 lists the total fault clearing time for each simulation with the pilot in and out of service. No coordination issues were identified for any of the simulations on line 1 while the POTT was in service. Without the assistance of the communication assisted protection, misoperations were observed on multiple backup relays for TPH faults. 
Table 4-34 - Line 1 Fault Clearing Time Results (Pilot In, All Faults) - Incorrect Setting

\begin{tabular}{|c|c|c|c|c|c|c|c|c|c|c|}
\hline \multirow{2}{*}{ Outage } & \multirow{2}{*}{ Pilot } & \multirow{2}{*}{ Fault Type } & \multicolumn{7}{|c|}{ Fault Clearing Time (Seconds) } & \multirow{2}{*}{ Mis-coordination } \\
\hline & & & $0 \%$ & $15 \%$ & $30 \%$ & $50 \%$ & $70 \%$ & $85 \%$ & $100 \%$ & \\
\hline Primary System Normal & In & SLG & 0.07 & 0.065 & 0.065 & 0.065 & 0.065 & 0.07 & 0.07 & No \\
\hline XFMR : 177-1317-1( Bank A) & In & SLG & 0.07 & 0.065 & 0.065 & 0.07 & 0.07 & 0.07 & 0.07 & No \\
\hline Line : 177-154-1(LINE7) & In & SLG & 0.07 & 0.065 & 0.065 & 0.07 & 0.07 & 0.07 & 0.07 & No \\
\hline Line : 177-175-1(LINE6) & In & SLG & 0.07 & 0.065 & 0.065 & 0.07 & 0.07 & 0.07 & 0.07 & No \\
\hline XFMR : 183-1316-1( Bank C) & In & SLG & 0.07 & 0.065 & 0.065 & 0.07 & 0.07 & 0.07 & 0.07 & No \\
\hline Line : 183-105-1(LINE3) & In & SLG & 0.07 & 0.065 & 0.065 & 0.07 & 0.07 & 0.07 & 0.07 & No \\
\hline Line : 183-141-1(LINE2) & In & SLG & 0.07 & 0.065 & 0.065 & 0.07 & 0.07 & 0.07 & 0.07 & No \\
\hline Line : 183-151-1(LINE4) & In & SLG & 0.07 & 0.065 & 0.065 & 0.07 & 0.07 & 0.07 & 0.07 & No \\
\hline Line : 183-449-1(LINE5) & In & SLG & 0.07 & 0.065 & 0.065 & 0.07 & 0.07 & 0.07 & 0.07 & No \\
\hline Mutual: 179-181-1(LINE8) & In & SLG & 0.07 & 0.065 & 0.065 & 0.07 & 0.07 & 0.07 & 0.07 & No \\
\hline \multirow{2}{*}{ Outage } & \multirow{2}{*}{ Pilot } & \multirow{2}{*}{ Fault Type } & \multicolumn{7}{|c|}{ Fault Clearing Time (Seconds) } & \multirow{2}{*}{ Mis-coordination } \\
\hline & & & $0 \%$ & $15 \%$ & $30 \%$ & $50 \%$ & $70 \%$ & $85 \%$ & $100 \%$ & \\
\hline Primary System Normal & In & TPH & 0.0867 & 0.0867 & 0.0783 & 0.0783 & 0.0783 & 0.0867 & 0.0867 & No \\
\hline XFMR : $177-1317-1$ ( Bank A) & In & TPH & 0.0867 & 0.0867 & 0.0783 & 0.0783 & 0.0783 & 0.0867 & 0.0867 & No \\
\hline Line : 177-154-1(LINE7) & In & TPH & 0.0867 & 0.0867 & 0.0783 & 0.0783 & 0.0783 & 0.0867 & 0.0867 & No \\
\hline Line : 177-175-1(LINE6) & In & TPH & 0.0867 & 0.0867 & 0.0783 & 0.0783 & 0.0783 & 0.0867 & 0.0867 & No \\
\hline XFMR : 183-1316-1( Bank C) & In & TPH & 0.0867 & 0.0867 & 0.0783 & 0.0783 & 0.0783 & 0.0867 & 0.0867 & No \\
\hline Line : 183-105-1(LINE3) & In & TPH & 0.0867 & 0.0867 & 0.0783 & 0.0783 & 0.0783 & 0.0867 & 0.0867 & No \\
\hline Line : 183-141-1(LINE2) & In & TPH & 0.0867 & 0.0867 & 0.0783 & 0.0783 & 0.0783 & 0.0867 & 0.0867 & No \\
\hline Line : 183-151-1(LINE4) & In & TPH & 0.0867 & 0.0867 & 0.0783 & 0.0783 & 0.0783 & 0.0867 & 0.0867 & No \\
\hline Line : 183-449-1(LINE5) & In & TPH & 0.0867 & 0.0867 & 0.0783 & 0.0783 & 0.0783 & 0.0867 & 0.0867 & No \\
\hline \multirow{2}{*}{ Outage } & \multirow{2}{*}{ Pilot } & \multirow{2}{*}{ Fault Type } & \multicolumn{7}{|c|}{ Fault Clearing Time (Seconds) } & \multirow{2}{*}{ Mis-coordination } \\
\hline & & & $0 \%$ & $15 \%$ & $30 \%$ & $50 \%$ & $70 \%$ & $85 \%$ & $100 \%$ & \\
\hline Primary System Normal & In & SLG( 5) & 0.07 & 0.07 & 0.065 & 0.065 & 0.065 & 0.07 & 0.07 & No \\
\hline XFMR : 177-1317-1( Bank A) & In & SLG( 5) & 0.07 & 0.065 & 0.065 & 0.07 & 0.07 & 0.07 & 0.07 & No \\
\hline Line : 177-154-1(LINE7) & In & SLG( 5) & 0.07 & 0.065 & 0.065 & 0.07 & 0.07 & 0.07 & 0.07 & No \\
\hline Line : 177-175-1(LINE6) & In & $\operatorname{SLG}(5)$ & 0.07 & 0.07 & 0.065 & 0.065 & 0.07 & 0.07 & 0.07 & No \\
\hline XFMR : 183-1316-1( Bank C) & In & SLG( 5) & 0.07 & 0.07 & 0.065 & 0.065 & 0.065 & 0.07 & 0.07 & No \\
\hline Line : 183-105-1(LINE3) & In & SLG( 5) & 0.07 & 0.07 & 0.07 & 0.065 & 0.065 & 0.07 & 0.07 & No \\
\hline Line : 183-141-1(LINE2) & In & SLG( 5) & 0.07 & 0.07 & 0.065 & 0.065 & 0.065 & 0.07 & 0.07 & No \\
\hline Line : 183-151-1(LINE4) & In & SLG( 5) & 0.07 & 0.07 & 0.065 & 0.065 & 0.065 & 0.07 & 0.07 & No \\
\hline Line : 183-449-1(LINE5) & In & SLG( 5) & 0.07 & 0.07 & 0.065 & 0.065 & 0.065 & 0.07 & 0.07 & No \\
\hline Mutual: 179-181-1(LINE8) & In & SLG( 5) & 0.07 & 0.07 & 0.065 & 0.065 & 0.065 & 0.07 & 0.07 & No \\
\hline \multirow{2}{*}{ Outage } & \multirow{2}{*}{ Pilot } & \multirow{2}{*}{ Fault Type } & \multicolumn{7}{|c|}{ Fault Clearing Time (Seconds) } & \multirow{2}{*}{ Mis-coordination } \\
\hline & & & $0 \%$ & $15 \%$ & $30 \%$ & $50 \%$ & $70 \%$ & $85 \%$ & $100 \%$ & \\
\hline Primary System Normal & In & SLG( 10) & 0.07 & 0.07 & 0.07 & 0.065 & 0.07 & 0.07 & 0.07 & No \\
\hline XFMR : 177-1317-1( Bank A) & In & SLG( 10$)$ & 0.07 & 0.065 & 0.07 & 0.07 & 0.07 & 0.07 & 0.1267 & No \\
\hline Line : 177-154-1(LINE7) & In & SLG( 10$)$ & 0.07 & 0.07 & 0.07 & 0.065 & 0.07 & 0.07 & 0.07 & No \\
\hline Line : 177-175-1(LINE6) & In & $\operatorname{SLG}(10)$ & 0.07 & 0.07 & 0.07 & 0.07 & 0.07 & 0.07 & 0.07 & No \\
\hline XFMR : 183-1316-1( Bank C) & In & $\operatorname{SLG}(10)$ & 0.07 & 0.07 & 0.07 & 0.065 & 0.07 & 0.07 & 0.07 & No \\
\hline Line : 183-105-1(LINE3) & In & $\operatorname{SLG}(10)$ & 0.07 & 0.07 & 0.07 & 0.065 & 0.07 & 0.07 & 0.07 & No \\
\hline Line : 183-141-1(LINE2) & In & $\operatorname{SLG}(10)$ & 0.07 & 0.07 & 0.07 & 0.065 & 0.07 & 0.07 & 0.07 & No \\
\hline Line : 183-151-1(LINE4) & In & $\operatorname{SLG}(10)$ & 0.07 & 0.07 & 0.07 & 0.065 & 0.07 & 0.07 & 0.07 & No \\
\hline Line : 183-449-1(LINE5) & In & $\operatorname{SLG}(10)$ & 0.07 & 0.07 & 0.07 & 0.065 & 0.07 & 0.07 & 0.07 & No \\
\hline Mutual: 179-181-1(LINE8) & In & $\operatorname{SLG}(10)$ & 0.07 & 0.07 & 0.07 & 0.065 & 0.07 & 0.07 & 0.07 & No \\
\hline
\end{tabular}


Table 4-35 - Line 1 Fault Clearing Time Results (Pilot Out, All Faults) - Incorrect Setting

\begin{tabular}{|c|c|c|c|c|c|c|c|c|c|c|}
\hline \multirow{2}{*}{ Outage } & \multirow{2}{*}{ Pilot } & \multirow{2}{*}{ Fault Typ } & \multicolumn{7}{|c|}{ Fault Clearing Time (Seconds) } & \multirow{2}{*}{ Mis-coordination } \\
\hline & & & $0 \%$ & $15 \%$ & $30 \%$ & $50 \%$ & $70 \%$ & $85 \%$ & $100 \%$ & \\
\hline Primary System Normal & Out & SLG & 0.1267 & 0.065 & 0.065 & 0.065 & 0.065 & 0.1267 & 0.4 & No \\
\hline XFMR : 177-1317-1( Bank A) & Out & SLG & 0.1267 & 0.065 & 0.065 & 0.0817 & 0.0817 & 0.4983 & 0.4983 & No \\
\hline Line : 177-154-1(LINE7) & Out & SLG & 0.1267 & 0.065 & 0.065 & 0.065 & 0.065 & 0.1267 & 0.4183 & No \\
\hline Line : 177-175-1(LINE6) & Out & SLG & 0.1267 & 0.1267 & 0.065 & 0.065 & 0.0817 & 0.4417 & 0.4933 & No \\
\hline XFMR : 183-1316-1( Bank C) & Out & SLG & 0.1267 & 0.1267 & 0.065 & 0.065 & 0.065 & 0.1267 & 0.4017 & No \\
\hline Line : 183-105-1(LINE3) & Out & SLG & 0.1267 & 0.1267 & 0.065 & 0.065 & 0.065 & 0.1267 & 0.4017 & No \\
\hline Line : 183-141-1(LINE2) & Out & SLG & 0.1267 & 0.1267 & 0.065 & 0.065 & 0.065 & 0.1267 & 0.4017 & No \\
\hline Line : 183-151-1(LINE4) & Out & SLG & 0.1267 & 0.1267 & 0.065 & 0.065 & 0.065 & 0.1267 & 0.3983 & No \\
\hline Line : 183-449-1(LINE5) & Out & SLG & 0.1267 & 0.1267 & 0.065 & 0.065 & 0.065 & 0.1267 & 0.4 & No \\
\hline Mutual: 179-181-1(LINE8) & Out & SLG & 0.1267 & 0.065 & 0.065 & 0.065 & 0.065 & 0.1267 & 0.405 & No \\
\hline \multirow{2}{*}{ Outage } & \multirow{2}{*}{ Pilot } & \multirow{2}{*}{ Fault Type } & \multicolumn{7}{|c|}{ Fault Clearing Time (Seconds) } & \multirow{2}{*}{ Mis-coordination } \\
\hline & & & $0 \%$ & $15 \%$ & $30 \%$ & $50 \%$ & $70 \%$ & $85 \%$ & $100 \%$ & \\
\hline Primary System Normal & Out & TPH & 0.495 & 0.495 & 0.495 & 0.495 & 0.495 & 0.495 & 0.495 & Mis-Op \\
\hline XFMR : 177-1317-1( Bank A) & Out & TPH & 0.495 & 0.495 & 0.495 & 0.495 & 0.495 & 0.495 & 0.495 & Mis-Op \\
\hline Line : 177-154-1(LINE7) & Out & TPH & 0.495 & 0.495 & 0.495 & 0.495 & 0.495 & 0.495 & 0.495 & Mis-Op \\
\hline Line : 177-175-1(LINE6) & Out & TPH & 0.495 & 0.495 & 0.495 & 0.495 & 0.495 & 0.495 & 0.495 & Mis-Op \\
\hline XFMR : 183-1316-1 ( Bank C) & Out & TPH & 0.495 & 0.495 & 0.495 & 0.495 & 0.495 & 0.495 & 0.495 & Mis-Op \\
\hline Line : 183-105-1(LINE3) & Out & TPH & 0.495 & 0.495 & 0.495 & 0.495 & 0.495 & 0.495 & 0.495 & Mis-Op \\
\hline Line : 183-141-1(LINE2) & Out & TPH & 0.495 & 0.495 & 0.495 & 0.495 & 0.495 & 0.495 & 0.495 & Mis-Op \\
\hline Line : 183-151-1(LINE4) & Out & TPH & 0.495 & 0.495 & 0.495 & 0.495 & 0.495 & 0.495 & 0.495 & Mis-Op \\
\hline Line : 183-449-1(LINE5) & Out & $\mathrm{TPH}$ & 0.495 & 0.495 & 0.495 & 0.495 & 0.495 & 0.495 & 0.495 & Mis-Op \\
\hline \multirow{2}{*}{ Outage } & \multirow{2}{*}{ Pilot } & \multirow{2}{*}{ Fault Type } & \multicolumn{7}{|c|}{ Fault Clearing Time (Seconds) } & \multirow{2}{*}{ Mis-coordination } \\
\hline & & & $0 \%$ & $15 \%$ & $30 \%$ & $50 \%$ & $70 \%$ & $85 \%$ & $100 \%$ & \\
\hline Primary System Normal & Out & SLG( 5) & 0.1267 & 0.1267 & 0.065 & 0.065 & 0.065 & 0.1267 & 0.4233 & No \\
\hline XFMR : 177-1317-1( Bank A) & Out & $\operatorname{SLG}(5)$ & 0.1267 & 0.065 & 0.065 & 0.0817 & 0.14 & 0.5567 & 0.5567 & No \\
\hline Line : 177-154-1(LINE7) & Out & $\operatorname{SLG}(5)$ & 0.1267 & 0.1267 & 0.065 & 0.065 & 0.1267 & 0.1267 & 0.4417 & No \\
\hline Line : 177-175-1(LINE6) & Out & SLG( 5) & 0.1267 & 0.1267 & 0.065 & 0.065 & 0.14 & 0.4633 & 0.5217 & No \\
\hline XFMR : 183-1316-1( Bank C) & Out & $\operatorname{SLG}(5)$ & 0.1267 & 0.1267 & 0.065 & 0.065 & 0.065 & 0.1267 & 0.4233 & No \\
\hline Line : 183-105-1(LINE3) & Out & SLG( 5) & 0.1267 & 0.1267 & 0.1267 & 0.065 & 0.065 & 0.1267 & 0.42 & No \\
\hline Line : 183-141-1(LINE2) & Out & SLG( 5) & 0.1267 & 0.1267 & 0.065 & 0.065 & 0.065 & 0.1267 & 0.4217 & No \\
\hline Line : 183-151-1(LINE4) & Out & SLG( 5) & 0.1267 & 0.1267 & 0.065 & 0.065 & 0.065 & 0.1267 & 0.42 & No \\
\hline Line : 183-449-1(LINE5) & Out & $\operatorname{SLG}(5)$ & 0.1267 & 0.1267 & 0.065 & 0.065 & 0.065 & 0.1267 & 0.4183 & No \\
\hline Mutual: 179-181-1(LINE8) & Out & SLG( 5) & 0.1267 & 0.1267 & 0.065 & 0.065 & 0.065 & 0.1267 & 0.4267 & No \\
\hline \multirow{2}{*}{ Outage } & \multirow{2}{*}{ Pilot } & \multirow{2}{*}{ Fault Type } & \multicolumn{7}{|c|}{ Fault Clearing Time (Seconds) } & \multirow{2}{*}{ Mis-coordination } \\
\hline & & & $0 \%$ & $15 \%$ & $30 \%$ & $50 \%$ & $70 \%$ & $85 \%$ & $100 \%$ & \\
\hline Primary System Normal & Out & SLG( 10) & 0.1267 & 0.1267 & 0.1267 & 0.065 & 0.1267 & 0.1267 & 0.455 & No \\
\hline XFMR : 177-1317-1( Bank A) & Out & SLG( 10) & 0.1267 & 0.065 & 0.0817 & 0.14 & 0.5517 & 0.5567 & 0.5567 & No \\
\hline Line : 177-154-1(LINE7) & Out & SLG( 10) & 0.1267 & 0.1267 & 0.1267 & 0.065 & 0.1267 & 0.4183 & 0.475 & No \\
\hline Line : 177-175-1(LINE6) & Out & SLG( 10) & 0.1267 & 0.1267 & 0.1267 & 0.14 & 0.4417 & 0.4933 & 0.5567 & No \\
\hline XFMR : 183-1316-1( Bank C) & Out & SLG( 10) & 0.1267 & 0.1267 & 0.1267 & 0.065 & 0.1267 & 0.405 & 0.4533 & No \\
\hline Line : 183-105-1(LINE3) & Out & SLG( 10) & 0.43 & 0.1267 & 0.1267 & 0.065 & 0.1267 & 0.1267 & 0.4467 & No \\
\hline Line : 183-141-1(LINE2) & Out & SLG( 10) & 0.4233 & 0.1267 & 0.1267 & 0.065 & 0.1267 & 0.1267 & 0.45 & No \\
\hline Line : 183-151-1(LINE4) & Out & SLG( 10) & 0.1267 & 0.1267 & 0.1267 & 0.065 & 0.1267 & 0.1267 & 0.45 & No \\
\hline Line : 183-449-1(LINE5) & Out & SLG( 10) & 0.4217 & 0.1267 & 0.1267 & 0.065 & 0.1267 & 0.1267 & 0.4483 & No \\
\hline Mutual: 179-181-1(LINE8) & Out & SLG( 10) & 0.1267 & 0.1267 & 0.1267 & 0.065 & 0.1267 & 0.4083 & 0.46 & No \\
\hline
\end{tabular}


A total of four backup phase zone 2 distance elements at remote stations of lines 2 to 5 resulted in mis-coordination. Table 4-36 lists all the backup terminals mis-operating for Line 1 simulations. This would be a catastrophic outage where 5 transmission lines and a major Winder substation is lost from a network for a single fault.

Table 4-36 - Line 1 Fault Clearing Time Results (Pilot In, All Faults) - Incorrect Setting

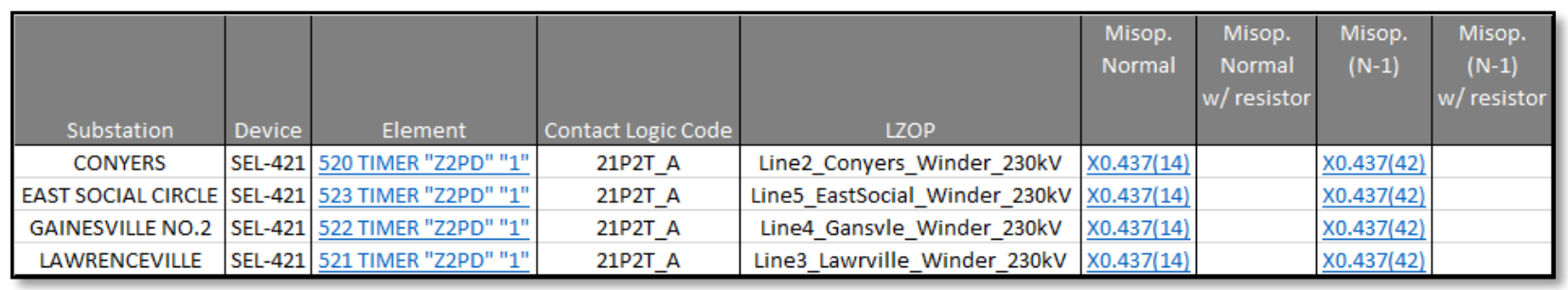

From the $126 \mathrm{TPH}$ fault scenarios, it was observed that each of the four backup elements were misbehaving for 8 of the simulations (see Table 4-37). More importantly, one of the failures happened during system normal conditions which has a higher probability of occurrence.

Table 4-37 - Line 1 TPH Test Results: All Backup Zone 2 Phase Distance near Winder Station

\begin{tabular}{|c|c|c|c|c|c|c|c|c|}
\hline Pilot & Outages/Test & $0.00 \%$ & $15.00 \%$ & $30.00 \%$ & $50.00 \%$ & $70.00 \%$ & $85.00 \%$ & $100.00 \%$ \\
\hline \multirow{9}{*}{ Enabled } & Primary System Normal & Pass & Pass & Pass & Pass & Pass & Pass & Pass \\
\hline & XFMR : 177-1317-1 ( Bank A) & Pass & Pass & Pass & Pass & Pass & Pass & Pass \\
\hline & Line : 177-154-1(LINE7) & Pass & Pass & Pass & Pass & Pass & Pass & Pass \\
\hline & Line : 177-175-1(LINE6) & Pass & Pass & Pass & Pass & Pass & Pass & Pass \\
\hline & XFMR : 183-1316-1 ( Bank C) & Pass & Pass & Pass & Pass & Pass & Pass & Pass \\
\hline & Line : 183-105-1(LINE3) & Pass & Pass & Pass & Pass & Pass & Pass & Pass \\
\hline & Line : 183-141-1(LINE2) & Pass & Pass & Pass & Pass & Pass & Pass & Pass \\
\hline & Line : 183-151-1(LINE4) & Pass & Pass & Pass & Pass & Pass & Pass & Pass \\
\hline & Line : 183-449-1(LINE5) & Pass & Pass & Pass & Pass & Pass & Pass & Pass \\
\hline \multirow{9}{*}{ Disabled } & Primary System Normal & Pass & Pass & Pass & Pass & Pass & Pass & Mis-Op \\
\hline & XFMR : 177-1317-1 ( Bank A) & Pass & Pass & Pass & Pass & Pass & Pass & Mis-Op \\
\hline & Line : 177-154-1(LINE7) & Pass & Pass & Pass & Pass & Pass & Pass & Mis-Op \\
\hline & Line : 177-175-1(LINE6) & Pass & Pass & Pass & Pass & Pass & Pass & Mis-Op \\
\hline & XFMR : 183-1316-1 ( Bank C) & Pass & Pass & Pass & Pass & Pass & Pass & Mis-Op \\
\hline & Line : 183-105-1(LINE3) & Pass & Pass & Pass & Pass & Pass & Pass & Mis-Op \\
\hline & Line : 183-141-1(LINE2) & Pass & Pass & Pass & Pass & Pass & Pass & Pass \\
\hline & Line : 183-151-1(LINE4) & Pass & Pass & Pass & Pass & Pass & Pass & Mis-Op \\
\hline & Line : 183-449-1(LINE5) & Pass & Pass & Pass & Pass & Pass & Pass & Mis-Op \\
\hline
\end{tabular}


Figure 4-13 represents the Mho characteristics of Zone 1-2 of primary Line 1 protection at Winder substation as well as the four backup Zone 2 protection at remote stations looking towards Winder Line 1 terminal (all elements looking forward towards the fault). The fault at remote close-in fault is represented by cross point A (1-6) observed by both zones of the primary protection. However, the Zone 1 primary operation has the same time delay as all Zone 2 elements due to a human error. Furthermore, the same fault is observed by the backup Zone 2 protection which result in issuing a trip to their respective terminals at the same time as the primary protection clearing time.

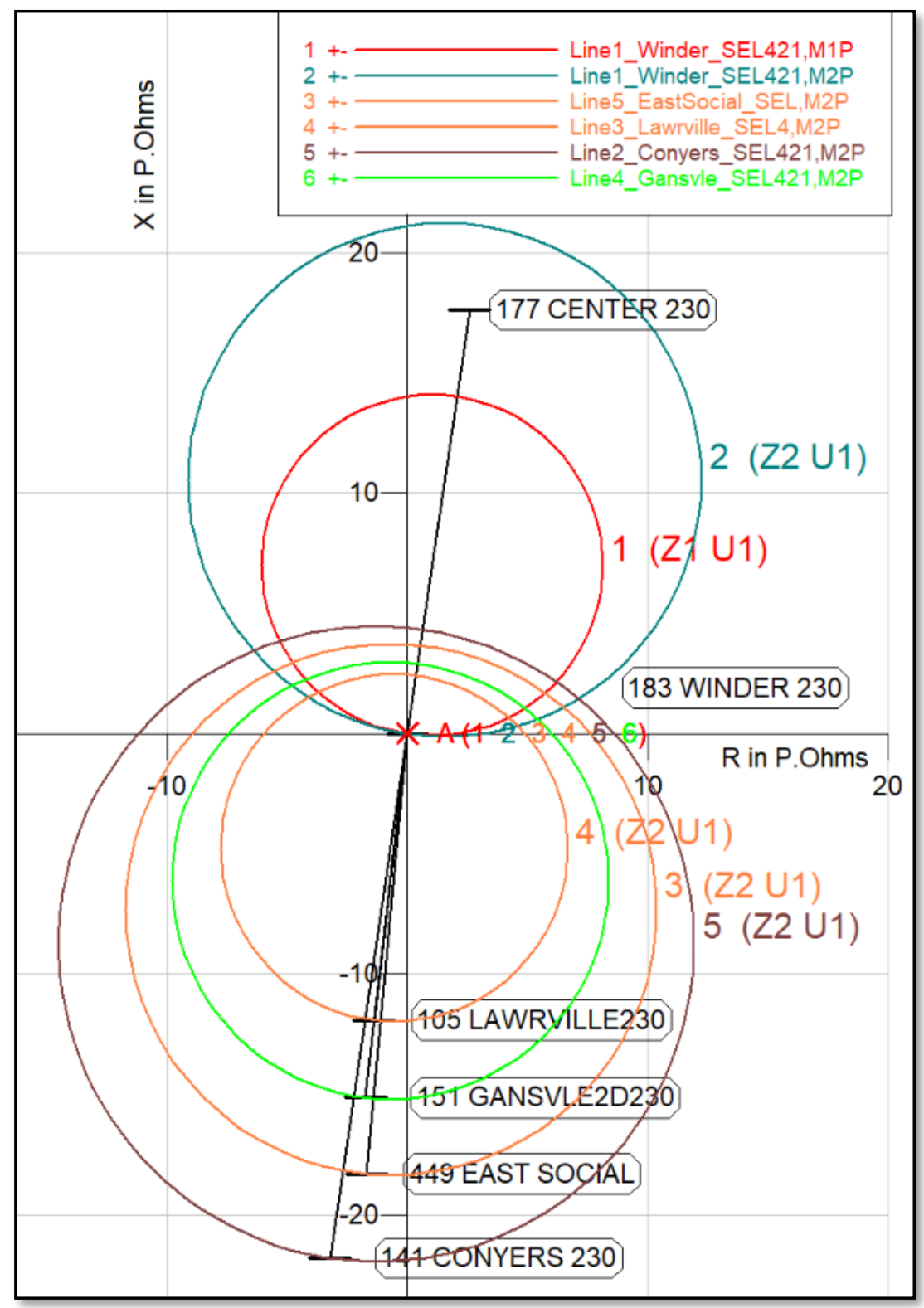

Figure 4-13 - Primary versus Backup Distance Protection - Winder Substation 
These mis-operations only occur in the absence of the POTT scheme as the pilot protection operates based on Zone 2 distance reach and communication between the primary terminals of Winder and Center, none of which were impacted by the Zone 1 time delay setting error.

An interesting observation was the absence of any zone 2 ground distance mis-operation for SLG faults at the same backup terminal locations. All 420 fault scenarios reported no violations with appropriate fault clearing times. After further review, the setting error for ground distance zone 1 time delay is masked due to existence of the ground overcurrent protection. All SLG related faults (bolted and resistive) are cleared using the 67GI and 67GT elements. Table 4-38 summarizes the event operation for a SLG fault at $85 \%$ with an N-1 contingency of Line 6 outage. During the first event, the primary protection at Winder which is closest to the fault detects the abnormality and issues a trip using its fastest element 67GI at 7 milliseconds. With the breaker opening time set at 58 milliseconds, the primary breaker at Center Line 6 terminal will open at a total of 65 milliseconds. Therefore, the ground distance Zone 1 time delay of 440 milliseconds will not be able to cause a mis-operation.

Table 4-38 - Line 1 Test Results: SLG 85\%, Line 6 Outaged, Event 1

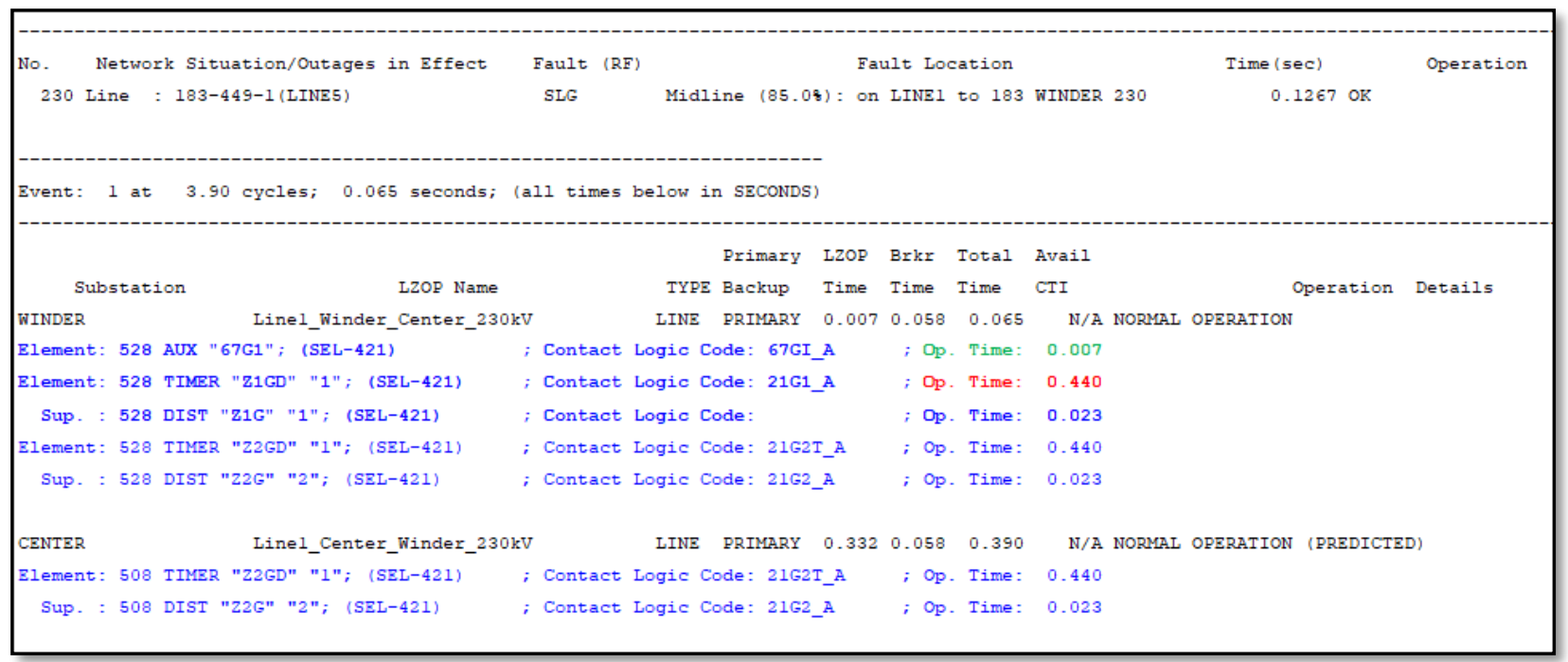

Older protection schemes using electromechanical relays may become a challenge as a valid N-1 contingency could be the loss of the 67GI relay. Additional individual relay outages can be supported by the utilization of automation routines to apply thousands of conditions in order to catch such scenarios with electromechanical relay installations. 


\subsubsection{CASE 3: Significant change in Fault Current}

As expressed in chapter 1.3.1, another typical cause of mis-operations in North America is due to a change in short circuit duty of the network over time. Power Systems are typically built a long time ago. Constant building of new transmission lines and urban development will cause significant localized impact to the fault distribution [13]. Therefore, many local areas can exist within the vast transmission network where its protective relay settings may not have been reviewed for years. Figure 4-14 represents a change in the short circuit duty for the study area. In study Case 3, a $230 \mathrm{kV}$ generation station has increased its generation and its impact to Line 1 primary protection scheme one substations away will be evaluated using the proposed wide area protection coordination solution. The same test conditions as Case 2 are performed resulting in 546 fault simulations.

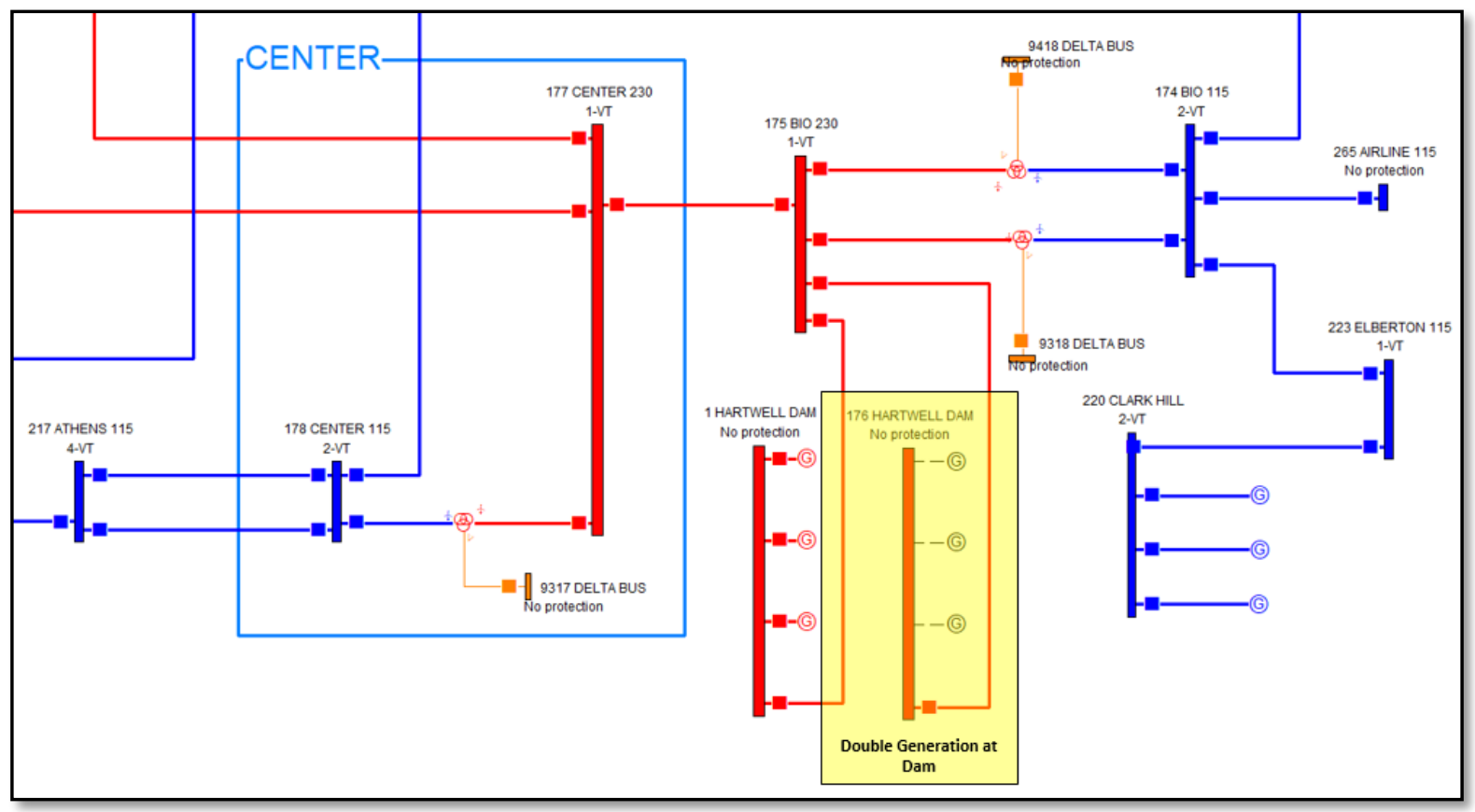

Figure 4-14 - Increased Generation Simulation Scenario - Hartwell Dam GSUs

Table 4-39 and Table 4-40 lists the total fault clearing time for each simulation with the pilot in and out of service. A coordination issue was identified for only one specific N-1 contingency. There was a mis-operation reported for SLG bolted faults when transformer bank A was outaged. This violation occurred when the POTT protection was in and out of service. 
Table 4-39 - Line 1 Fault Clearing Time Results (Pilot In, All Faults) - Gen Change

\begin{tabular}{|c|c|c|c|c|c|c|c|c|c|c|}
\hline \multirow{2}{*}{ Outage } & \multirow{2}{*}{ Pilot } & \multirow{2}{*}{ Fault Type } & \multicolumn{7}{|c|}{ Fault Clearing Time (Seconds) } & \multirow{2}{*}{ Mis-coordination } \\
\hline & & & $0 \%$ & $15 \%$ & $30 \%$ & $50 \%$ & $70 \%$ & $85 \%$ & $100 \%$ & \\
\hline Primary System Normal & In & SLG & 0.07 & 0.065 & 0.065 & 0.065 & 0.065 & 0.065 & 0.07 & No \\
\hline XFMR : 177-1317-1 ( Bank A) & In & SLG & 0.065 & 0.065 & 0.065 & 0.07 & 0.07 & 0.07 & 0.07 & Mis-Op \\
\hline Line : 177-154-1(LINE7) & In & SLG & 0.07 & 0.065 & 0.065 & 0.065 & 0.065 & 0.07 & 0.07 & No \\
\hline Line : 177-175-1(LINE6) & In & SLG & 0.07 & 0.07 & 0.065 & 0.065 & 0.065 & 0.07 & 0.07 & No \\
\hline XFMR : 183-1316-1( Bank C) & In & SLG & 0.07 & 0.065 & 0.065 & 0.065 & 0.065 & 0.065 & 0.07 & No \\
\hline Line : 183-105-1(LINE3) & In & SLG & 0.07 & 0.07 & 0.065 & 0.065 & 0.065 & 0.065 & 0.07 & No \\
\hline Line : 183-141-1(LINE2) & In & SLG & 0.07 & 0.07 & 0.065 & 0.065 & 0.065 & 0.065 & 0.07 & No \\
\hline Line : 183-151-1(LINE4) & In & SLG & 0.07 & 0.065 & 0.065 & 0.065 & 0.065 & 0.065 & 0.07 & No \\
\hline Line : 183-449-1(LINE5) & In & SLG & 0.07 & 0.065 & 0.065 & 0.065 & 0.065 & 0.065 & 0.07 & No \\
\hline Mutual: 179-181-1(LINE8) & In & SLG & 0.07 & 0.065 & 0.065 & 0.065 & 0.065 & 0.065 & 0.07 & No \\
\hline \multirow{2}{*}{ Outage } & \multirow{2}{*}{ Pilot } & \multirow{2}{*}{ Fault Type } & \multicolumn{7}{|c|}{ Fault Clearing Time (Seconds) } & \multirow{2}{*}{ Mis-coordination } \\
\hline & & & $0 \%$ & $15 \%$ & $30 \%$ & $50 \%$ & $70 \%$ & $85 \%$ & $100 \%$ & \\
\hline Primary System Normal & In & TPH & 0.0867 & 0.0867 & 0.0783 & 0.0783 & 0.0783 & 0.0867 & 0.0867 & No \\
\hline XFMR : 177-1317-1( Bank A) & In & TPH & 0.0867 & 0.0867 & 0.0783 & 0.0783 & 0.0783 & 0.0867 & 0.0867 & No \\
\hline Line : 177-154-1(LINE7) & In & TPH & 0.0867 & 0.0867 & 0.0783 & 0.0783 & 0.0783 & 0.0867 & 0.0867 & No \\
\hline Line : 177-175-1(LINE6) & In & TPH & 0.0867 & 0.0867 & 0.0783 & 0.0783 & 0.0783 & 0.0867 & 0.0867 & No \\
\hline XFMR : 183-1316-1( Bank C) & In & TPH & 0.0867 & 0.0867 & 0.0783 & 0.0783 & 0.0783 & 0.0867 & 0.0867 & No \\
\hline Line : 183-105-1(LINE3) & In & TPH & 0.0867 & 0.0867 & 0.0783 & 0.0783 & 0.0783 & 0.0867 & 0.0867 & No \\
\hline Line : 183-141-1(LINE2) & In & TPH & 0.0867 & 0.0867 & 0.0783 & 0.0783 & 0.0783 & 0.0867 & 0.0867 & No \\
\hline Line : 183-151-1(LINE4) & In & TPH & 0.0867 & 0.0867 & 0.0783 & 0.0783 & 0.0783 & 0.0867 & 0.0867 & No \\
\hline Line : 183-449-1(LINE5) & In & TPH & 0.0867 & 0.0867 & 0.0783 & 0.0783 & 0.0783 & 0.0867 & 0.0867 & No \\
\hline \multirow{2}{*}{ Outage } & \multirow{2}{*}{ Pilot } & \multirow{2}{*}{ Fault Type } & \multicolumn{7}{|c|}{ Fault Clearing Time (Seconds) } & \multirow{2}{*}{ Mis-coordination } \\
\hline & & & $0 \%$ & $15 \%$ & $30 \%$ & $50 \%$ & $70 \%$ & $85 \%$ & $100 \%$ & \\
\hline Primary System Normal & In & SLG( 5) & 0.07 & 0.07 & 0.065 & 0.065 & 0.065 & 0.07 & 0.07 & No \\
\hline XFMR : 177-1317-1 ( Bank A) & In & SLG( 5) & 0.07 & 0.065 & 0.065 & 0.07 & 0.07 & 0.07 & 0.07 & No \\
\hline Line : 177-154-1(LINE7) & In & $\operatorname{SLG}(5)$ & 0.07 & 0.065 & 0.065 & 0.065 & 0.065 & 0.07 & 0.07 & No \\
\hline Line : 177-175-1(LINE6) & In & SLG( 5) & 0.07 & 0.07 & 0.065 & 0.065 & 0.07 & 0.07 & 0.07 & No \\
\hline XFMR : 183-1316-1( Bank C) & In & SLG( 5) & 0.07 & 0.07 & 0.065 & 0.065 & 0.065 & 0.07 & 0.07 & No \\
\hline Line : 183-105-1(LINE3) & In & SLG( 5) & 0.07 & 0.07 & 0.065 & 0.065 & 0.065 & 0.07 & 0.07 & No \\
\hline Line : 183-141-1(LINE2) & In & $\operatorname{SLG}(5)$ & 0.07 & 0.07 & 0.065 & 0.065 & 0.065 & 0.07 & 0.07 & No \\
\hline Line : 183-151-1(LINE4) & In & $\operatorname{SLG}(5)$ & 0.07 & 0.07 & 0.065 & 0.065 & 0.065 & 0.07 & 0.07 & No \\
\hline Line : 183-449-1(LINE5) & In & SLG( 5) & 0.07 & 0.07 & 0.065 & 0.065 & 0.065 & 0.07 & 0.07 & No \\
\hline Mutual: 179-181-1(LINE8) & In & SLG( 5) & 0.07 & 0.07 & 0.065 & 0.065 & 0.065 & 0.07 & 0.07 & No \\
\hline \multirow{2}{*}{ Outage } & \multirow{2}{*}{ Pilot } & \multirow{2}{*}{ Fault Type } & \multicolumn{7}{|c|}{ Fault Clearing Time (Seconds) } & \multirow{2}{*}{ Mis-coordination } \\
\hline & & & $0 \%$ & $15 \%$ & $30 \%$ & $50 \%$ & $70 \%$ & $85 \%$ & $100 \%$ & \\
\hline Primary System Normal & In & SLG(10) & 0.07 & 0.07 & 0.07 & 0.065 & 0.07 & 0.07 & 0.07 & No \\
\hline XFMR : $177-1317-1$ ( Bank A) & In & SLG( 10$)$ & 0.07 & 0.065 & 0.07 & 0.07 & 0.07 & 0.07 & 0.07 & No \\
\hline Line : 177-154-1(LINE7) & In & $\operatorname{SLG}(10)$ & 0.07 & 0.07 & 0.065 & 0.065 & 0.07 & 0.07 & 0.07 & No \\
\hline Line : 177-175-1(LINE6) & In & SLG( 10$)$ & 0.07 & 0.07 & 0.07 & 0.07 & 0.07 & 0.07 & 0.07 & No \\
\hline XFMR : 183-1316-1 ( Bank C) & In & $\operatorname{SLG}(10)$ & 0.07 & 0.07 & 0.07 & 0.065 & 0.07 & 0.07 & 0.07 & No \\
\hline Line : 183-105-1(LINE3) & In & SLG( 10$)$ & 0.07 & 0.07 & 0.07 & 0.065 & 0.07 & 0.07 & 0.07 & No \\
\hline Line : 183-141-1(LINE2) & In & SLG(10) & 0.07 & 0.07 & 0.07 & 0.065 & 0.07 & 0.07 & 0.07 & No \\
\hline Line : 183-151-1(LINE4) & In & $\operatorname{SLG}(10)$ & 0.07 & 0.07 & 0.07 & 0.065 & 0.07 & 0.07 & 0.07 & No \\
\hline Line : 183-449-1(LINE5) & In & SLG( 10$)$ & 0.07 & 0.07 & 0.07 & 0.065 & 0.07 & 0.07 & 0.07 & No \\
\hline Mutual: 179-181-1(LINE8) & In & $\operatorname{SLG}(10)$ & 0.07 & 0.07 & 0.065 & 0.065 & 0.07 & 0.07 & 0.07 & No \\
\hline
\end{tabular}


Table 4-40 - Line 1 Fault Clearing Time Results (Pilot Out, All Faults) - Gen Change

\begin{tabular}{|c|c|c|c|c|c|c|c|c|c|c|}
\hline \multirow{2}{*}{ Outage } & \multirow{2}{*}{ Pilot } & \multirow{2}{*}{ Fault Typ } & \multicolumn{7}{|c|}{ Fault Clearing Time (Seconds) } & \multirow{2}{*}{ Mis-coordination } \\
\hline & & & $0 \%$ & $15 \%$ & $30 \%$ & $50 \%$ & $70 \%$ & $85 \%$ & $100 \%$ & \\
\hline Primary System Normal & Out & SLG & 0.1267 & 0.065 & 0.065 & 0.065 & 0.065 & 0.065 & 0.1267 & No \\
\hline XFMR : 177-1317-1( Bank A) & Out & SLG & 0.065 & 0.065 & 0.065 & 0.0817 & 0.0817 & 0.4867 & 0.4983 & Mis-Op \\
\hline Line : 177-154-1(LINE7) & Out & SLG & 0.1267 & 0.065 & 0.065 & 0.065 & 0.065 & 0.1267 & 0.1267 & No \\
\hline Line : 177-175-1(LINE6) & Out & SLG & 0.1267 & 0.1267 & 0.065 & 0.065 & 0.065 & 0.4183 & 0.465 & No \\
\hline XFMR : 183-1316-1( Bank C) & Out & SLG & 0.1267 & 0.065 & 0.065 & 0.065 & 0.065 & 0.065 & 0.1267 & No \\
\hline Line : 183-105-1(LINE3) & Out & SLG & 0.1267 & 0.1267 & 0.065 & 0.065 & 0.065 & 0.065 & 0.1267 & No \\
\hline Line : 183-141-1(LINE2) & Out & SLG & 0.1267 & 0.1267 & 0.065 & 0.065 & 0.065 & 0.065 & 0.1267 & No \\
\hline Line : 183-151-1(LINE4) & Out & SLG & 0.1267 & 0.065 & 0.065 & 0.065 & 0.065 & 0.065 & 0.1267 & No \\
\hline Line : 183-449-1(LINE5) & Out & SLG & 0.1267 & 0.065 & 0.065 & 0.065 & 0.065 & 0.065 & 0.1267 & No \\
\hline Mutual: 179-181-1(LINE8) & Out & SLG & 0.1267 & 0.065 & 0.065 & 0.065 & 0.065 & 0.065 & 0.1267 & No \\
\hline \multirow{2}{*}{ Outage } & \multirow{2}{*}{ Pilot } & \multirow{2}{*}{ Fault Type } & \multicolumn{7}{|c|}{ Fault Clearing Time (Seconds) } & \multirow{2}{*}{ Mis-coordination } \\
\hline & & & $0 \%$ & $15 \%$ & $30 \%$ & $50 \%$ & $70 \%$ & $85 \%$ & $100 \%$ & \\
\hline Primary System Normal & Out & TPH & 0.495 & 0.495 & 0.0783 & 0.0783 & 0.0783 & 0.495 & 0.495 & No \\
\hline XFMR : 177-1317-1( Bank A) & Out & TPH & 0.495 & 0.495 & 0.0783 & 0.0783 & 0.0783 & 0.495 & 0.495 & No \\
\hline Line : 177-154-1(LINE7) & Out & TPH & 0.495 & 0.495 & 0.0783 & 0.0783 & 0.0783 & 0.495 & 0.495 & No \\
\hline Line : 177-175-1(LINE6) & Out & TPH & 0.495 & 0.495 & 0.0783 & 0.0783 & 0.0783 & 0.495 & 0.495 & No \\
\hline XFMR : 183-1316-1( Bank C) & Out & TPH & 0.495 & 0.495 & 0.0783 & 0.0783 & 0.0783 & 0.495 & 0.495 & No \\
\hline Line : 183-105-1(LINE3) & Out & TPH & 0.495 & 0.495 & 0.0783 & 0.0783 & 0.0783 & 0.495 & 0.495 & No \\
\hline Line : 183-141-1(LINE2) & Out & TPH & 0.495 & 0.495 & 0.0783 & 0.0783 & 0.0783 & 0.495 & 0.495 & No \\
\hline Line : 183-151-1(LINE4) & Out & TPH & 0.495 & 0.495 & 0.0783 & 0.0783 & 0.0783 & 0.495 & 0.495 & No \\
\hline Line : 183-449-1(LINE5) & Out & TPH & 0.495 & 0.495 & 0.0783 & 0.0783 & 0.0783 & 0.495 & 0.495 & No \\
\hline \multirow{2}{*}{ Outage } & \multirow{2}{*}{ Pilot } & \multirow{2}{*}{ Fault Type } & \multicolumn{7}{|c|}{ Fault Clearing Time (Seconds) } & \multirow{2}{*}{ Mis-coordination } \\
\hline & & & $0 \%$ & $15 \%$ & $30 \%$ & $50 \%$ & $70 \%$ & $85 \%$ & $100 \%$ & \\
\hline Primary System Normal & Out & SLG( 5) & 0.1267 & 0.1267 & 0.065 & 0.065 & 0.065 & 0.1267 & 0.1267 & No \\
\hline XFMR : 177-1317-1( Bank A) & Out & $\operatorname{SLG}(5)$ & 0.1267 & 0.065 & 0.065 & 0.0817 & 0.14 & 0.51 & 0.5567 & No \\
\hline Line : 177-154-1(LINE7) & Out & SLG( 5) & 0.1267 & 0.065 & 0.065 & 0.065 & 0.065 & 0.1267 & 0.415 & No \\
\hline Line : 177-175-1(LINE6) & Out & SLG( 5) & 0.1267 & 0.1267 & 0.065 & 0.065 & 0.14 & 0.4383 & 0.49 & No \\
\hline XFMR : 183-1316-1( Bank C) & Out & SLG( 5) & 0.1267 & 0.1267 & 0.065 & 0.065 & 0.065 & 0.1267 & 0.1267 & No \\
\hline Line : 183-105-1(LINE3) & Out & $\operatorname{SLG}(5)$ & 0.1267 & 0.1267 & 0.065 & 0.065 & 0.065 & 0.1267 & 0.1267 & No \\
\hline Line : 183-141-1(LINE2) & Out & SLG( 5) & 0.1267 & 0.1267 & 0.065 & 0.065 & 0.065 & 0.1267 & 0.1267 & No \\
\hline Line : 183-151-1(LINE4) & Out & SLG( 5) & 0.1267 & 0.1267 & 0.065 & 0.065 & 0.065 & 0.1267 & 0.1267 & No \\
\hline Line : 183-449-1(LINE5) & Out & SLG( 5) & 0.1267 & 0.1267 & 0.065 & 0.065 & 0.065 & 0.1267 & 0.1267 & No \\
\hline Mutual: 179-181-1(LINE8) & Out & $\operatorname{SLG}(5)$ & 0.1267 & 0.1267 & 0.065 & 0.065 & 0.065 & 0.1267 & 0.4017 & No \\
\hline \multirow{2}{*}{ Outage } & \multirow{2}{*}{ Pilot } & \multirow{2}{*}{ Fault Type } & \multicolumn{7}{|c|}{ Fault Clearing Time (Seconds) } & \multirow{2}{*}{ Mis-coordination } \\
\hline & & & $0 \%$ & $15 \%$ & $30 \%$ & $50 \%$ & $70 \%$ & $85 \%$ & $100 \%$ & \\
\hline Primary System Normal & Out & $\operatorname{SLG}(10)$ & 0.1267 & 0.1267 & 0.1267 & 0.065 & 0.1267 & 0.1267 & 0.4283 & No \\
\hline XFMR : 177-1317-1( Bank A) & Out & $\operatorname{SLG}(10)$ & 0.1267 & 0.065 & 0.0817 & 0.14 & 0.4883 & 0.5433 & 0.5567 & No \\
\hline Line : 177-154-1(LINE7) & Out & SLG( 10$)$ & 0.1267 & 0.1267 & 0.065 & 0.065 & 0.1267 & 0.1267 & 0.445 & No \\
\hline Line : 177-175-1(LINE6) & Out & $\operatorname{SLG}(10)$ & 0.1267 & 0.1267 & 0.1267 & 0.1267 & 0.42 & 0.465 & 0.5267 & No \\
\hline XFMR : 183-1316-1( Bank C) & Out & SLG( 10$)$ & 0.1267 & 0.1267 & 0.1267 & 0.065 & 0.1267 & 0.1267 & 0.4267 & No \\
\hline Line : 183-105-1(LINE3) & Out & $\operatorname{SLG}(10)$ & 0.1267 & 0.1267 & 0.1267 & 0.065 & 0.1267 & 0.1267 & 0.42 & No \\
\hline Line : 183-141-1(LINE2) & Out & SLG(10) & 0.1267 & 0.1267 & 0.1267 & 0.065 & 0.1267 & 0.1267 & 0.4233 & No \\
\hline Line : 183-151-1(LINE4) & Out & $\operatorname{SLG}(10)$ & 0.1267 & 0.1267 & 0.1267 & 0.065 & 0.1267 & 0.1267 & 0.4233 & No \\
\hline Line : 183-449-1(LINE5) & Out & SLG(10) & 0.1267 & 0.1267 & 0.1267 & 0.065 & 0.1267 & 0.1267 & 0.4217 & No \\
\hline Mutual: 179-181-1(LINE8) & Out & $\operatorname{SLG}(10)$ & 0.1267 & 0.1267 & 0.065 & 0.065 & 0.1267 & 0.1267 & 0.4317 & No \\
\hline
\end{tabular}


From the 140 SLG fault scenarios, it was observed that the instantaneous ground overcurrent protection of Line 6 at Bio substation mis-operates for 2 of fault simulations (see Table 4-41).

Table 4-41 - Line 1 SLG Test Results: Instantaneous Ground Overcurrent at Bio Station

\begin{tabular}{|c|c|c|c|c|c|c|c|c|}
\hline Pilot & Outages/Test & $0.00 \%$ & $15.00 \%$ & $30.00 \%$ & $50.00 \%$ & $70.00 \%$ & $85.00 \%$ & $100.00 \%$ \\
\hline \multirow{10}{*}{ Enabled } & \multirow{10}{*}{$\begin{array}{l}\text { Primary System Normal } \\
\text { XFMR : 177-1317-1 ( Bank A) } \\
\text { Line : 177-154-1(LINE7) } \\
\text { Line : 177-175-1(LINE6) } \\
\text { XFMR : 183-1316-1( Bank C) } \\
\text { Line : 183-105-1(LINE3) } \\
\text { Line : } 183-141-1 \text { (LINE2) } \\
\text { Line : 183-151-1(LINE4) } \\
\text { Line : 183-449-1(LINE5) } \\
\text { Mutual: } 179-181-1 \text { (LINE8) }\end{array}$} & Pass & Pass & Pass & Pass & Pass & Pass & Pass \\
\hline & & Mis-Op & Pass & Pass & Pass & Pass & Pass & Pass \\
\hline & & Pass & Pass & Pass & Pass & Pass & Pass & Pass \\
\hline & & Pass & Pass & Pass & Pass & Pass & Pass & Pass \\
\hline & & Pass & Pass & Pass & Pass & Pass & Pass & Pass \\
\hline & & Pass & Pass & Pass & Pass & Pass & Pass & Pass \\
\hline & & Pass & Pass & Pass & Pass & Pass & Pass & Pass \\
\hline & & Pass & Pass & Pass & Pass & Pass & Pass & Pass \\
\hline & & Pass & Pass & Pass & Pass & Pass & Pass & Pass \\
\hline & & Pass & Pass & Pass & Pass & Pass & Pass & Pass \\
\hline \multirow{10}{*}{ Disabled } & \multirow{10}{*}{$\begin{array}{l}\text { Primary System Normal } \\
\text { XFMR : 177-1317-1 ( Bank A) } \\
\text { Line : 177-154-1(LINE7) } \\
\text { Line : 177-175-1(LINE6) } \\
\text { XFMR : 183-1316-1( Bank C) } \\
\text { Line : 183-105-1(LINE3) } \\
\text { Line : 183-141-1(LINE2) } \\
\text { Line : 183-151-1(LINE4) } \\
\text { Line : 183-449-1(LINE5) } \\
\text { Mutual: } 179-181-1 \text { (LINE8) }\end{array}$} & Pass & Pass & Pass & Pass & Pass & Pass & Pass \\
\hline & & Mis-Op & Pass & Pass & Pass & Pass & Pass & Pass \\
\hline & & Pass & Pass & Pass & Pass & Pass & Pass & Pass \\
\hline & & Pass & Pass & Pass & Pass & Pass & Pass & Pass \\
\hline & & Pass & Pass & Pass & Pass & Pass & Pass & Pass \\
\hline & & Pass & Pass & Pass & Pass & Pass & Pass & Pass \\
\hline & & Pass & Pass & Pass & Pass & Pass & Pass & Pass \\
\hline & & Pass & Pass & Pass & Pass & Pass & Pass & Pass \\
\hline & & Pass & Pass & Pass & Pass & Pass & Pass & Pass \\
\hline & & Pass & Pass & Pass & Pass & Pass & Pass & Pass \\
\hline
\end{tabular}

Figure 4-15 represents one of the two test scenarios listed in the abovementioned table in depth. The fault scenario is an N-1 Contingency of transformer Bank A outage. There is a SLG bolted fault applied at local close-in location. The fault is not cleared during two sequential breaker events as there is a backup mis-coordination of 67GI element at Bio terminals looking forward towards the fault. During the first event, the primary protection at Center which is closest to the fault detects the abnormality and issues a trip using its fastest element 67GI at 7 milliseconds. With the breaker opening time set at 58 milliseconds, the primary breaker at Center Line 6 terminal will open at a total of 65 milliseconds. However, during Event 1, the instantaneous ground overcurrent element at Bio is over-reaching its own transmission line and issues a trip to the backup terminal. 


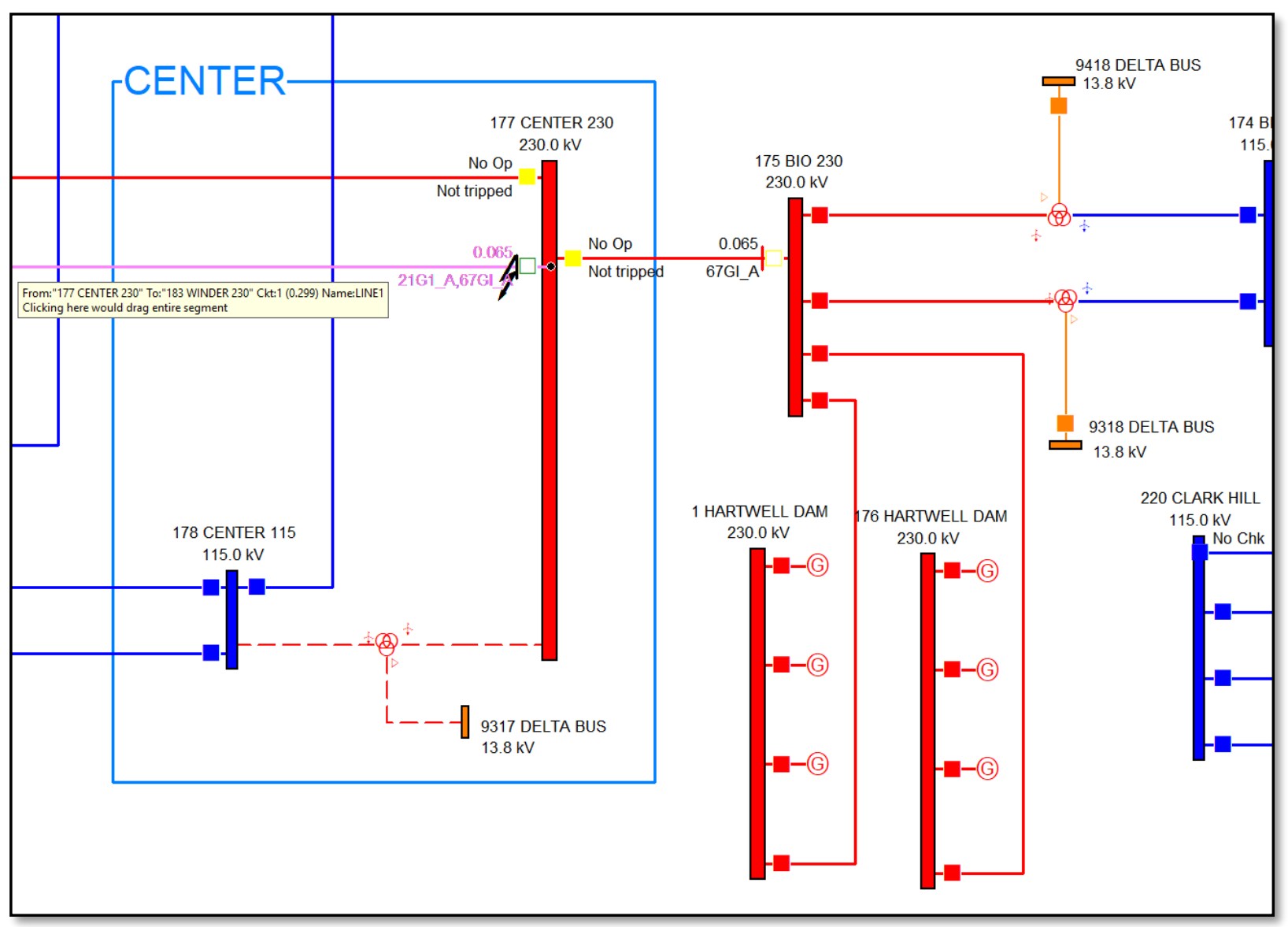

Figure 4-15 - Line 1 Test Condition: SLG 0\%, XFMR Bank A Outaged

Overcurrent elements can become quite sensitive to a change in topology and requires extensive coordination study with its neighboring pairs. A further $5 \%$ increment study was conducted to review this mis-coordination of backup overcurrent elements of Line 6 at Bio substations. Figure 4-16 shows the behavior of IOC and TOC for backup protection of Line 6 faults SLG bolted faults with $5 \%$ increments using the same $\mathrm{N}-1$ contingency outage of transformer Bank A. The backup IOC element designed to under-reach its own transmission line is able to over-reach up to 5-9\% of adjacent Line 1 due to the change in fault current. 


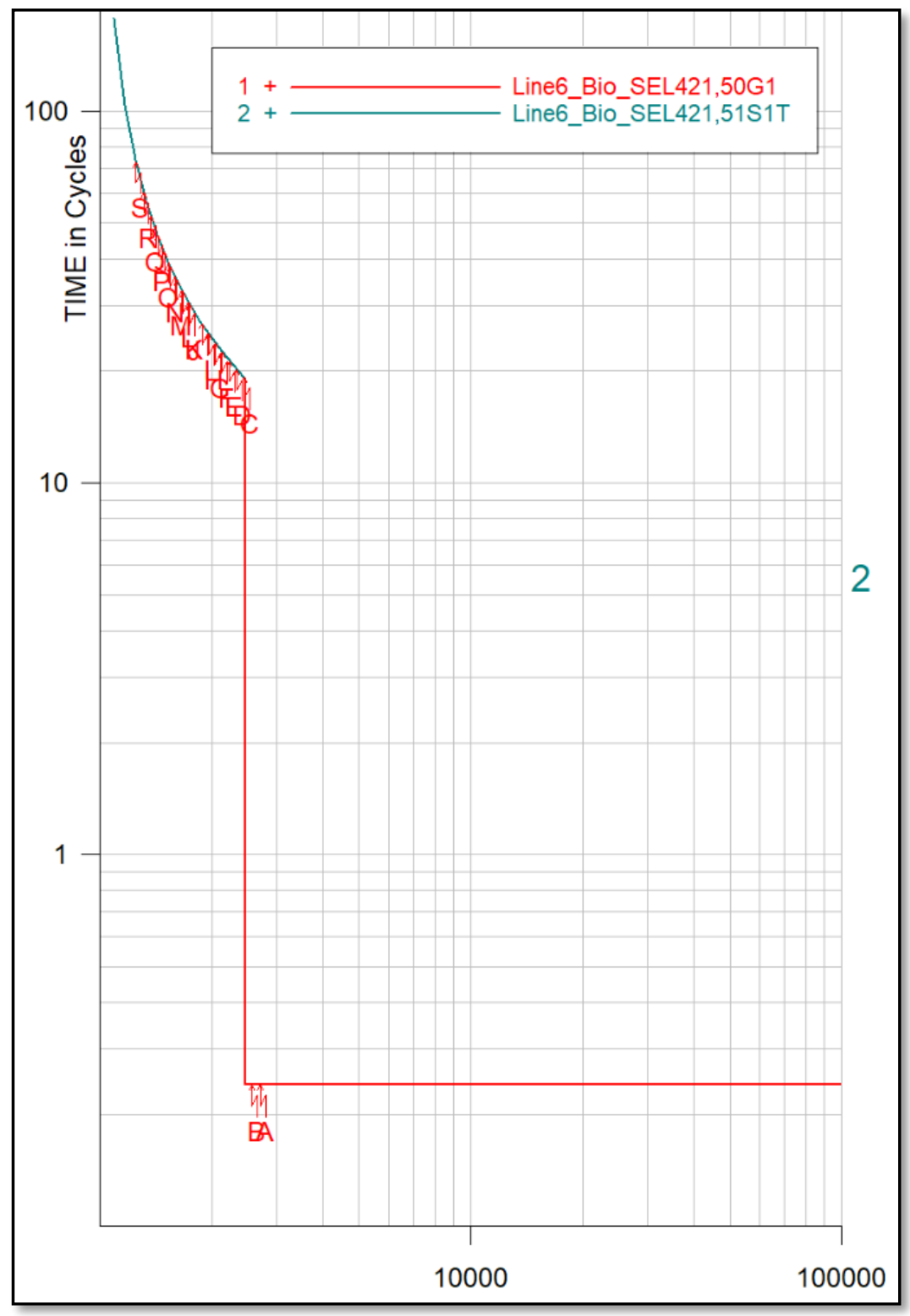

Figure 4-16 - Backup IOC \& TOC Protection - Bio Substation

The impact of the increased short circuit to the sensitivity of both backup overcurrent elements of Line 6,67GI_IOC and 67GT_TOC are further investigated for multiple fault scenarios. Table 4-42 and Table 4-43 illustrate the time of operation and the sensitivity of the overcurrent element pickup to its measured fault current. A bolted and $10 \mathrm{ohms}$ resistance SLG fault for system normal condition as well as a bolted SLG fault for transformer Bank A outage were investigated at 5\% location increments. These fault scenarios were conducted for both the normal generation of study case 1 and repeated for the increased generation of study case 3. 
Table 4-42 - Line 1 Test Results: Backup Line 6 Ground 67GI_IOC Element

\begin{tabular}{|c|c|c|c|c|c|c|c|c|c|c|c|c|c|}
\hline \multirow{3}{*}{$\begin{array}{c}\text { Fault } \\
\text { Location }\end{array}$} & \multirow{3}{*}{$\begin{array}{l}\text { Fault } \\
\text { Code }\end{array}$} & \multicolumn{6}{|c|}{ Normal Generation } & \multicolumn{6}{|c|}{ Increased Generation } \\
\hline & & \multicolumn{2}{|c|}{$\begin{array}{c}\text { SLG } 10 \text { Ohms } \\
\text { (System Normal) }\end{array}$} & \multicolumn{2}{|c|}{$\begin{array}{c}\text { SLG Bolted } \\
\text { (System Normal) }\end{array}$} & \multicolumn{2}{|c|}{$\begin{array}{c}\text { SLG Bolted } \\
\text { (XFMR Bank A Outage) }\end{array}$} & \multicolumn{2}{|c|}{$\begin{array}{c}\text { SLG } 10 \text { Ohms } \\
\text { (System Normal) }\end{array}$} & \multicolumn{2}{|c|}{$\begin{array}{c}\text { SLG Bolted } \\
\text { (System Normal) }\end{array}$} & \multicolumn{2}{|c|}{$\begin{array}{c}\text { SLG Bolted } \\
\text { (XFMR Bank A Outage) }\end{array}$} \\
\hline & & $\begin{array}{c}\text { Operation } \\
\text { (Cycles) }\end{array}$ & A/Pickup & $\begin{array}{c}\text { Operation } \\
\text { (Cycles) }\end{array}$ & A/Pickup & $\begin{array}{c}\text { Operation } \\
\text { (Cycles) }\end{array}$ & A/Pickup & $\begin{array}{c}\text { Operation } \\
\text { (Cycles) }\end{array}$ & A/Pickup & $\begin{array}{c}\text { Operation } \\
\text { (Cycles) }\end{array}$ & A/Pickup & \begin{tabular}{|c|} 
Operation \\
(Cycles)
\end{tabular} & A/Pickup \\
\hline $5 \%$ & $\mathrm{~A}$ & 99999.9 & 0.57 & 99999.9 & 0.77 & 99999.9 & 0.97 & 99999.9 & 0.61 & 99999.9 & 0.83 & 0.24 & 1.09 \\
\hline $10 \%$ & B & 99999.9 & 0.54 & 99999.9 & 0.72 & 99999.9 & 0.92 & 99999.9 & 0.57 & 99999.9 & 0.77 & 0.24 & 1.04 \\
\hline $15 \%$ & C & 99999.9 & 0.51 & 99999.9 & 0.67 & 99999.9 & 0.88 & 99999.9 & 0.54 & 99999.9 & 0.72 & 99999.9 & 0.99 \\
\hline $20 \%$ & D & 99999.9 & 0.48 & 99999.9 & 0.63 & 99999.9 & 0.84 & 99999.9 & 0.51 & 99999.9 & 0.67 & 99999.9 & 0.94 \\
\hline $25 \%$ & $E$ & 99999.9 & 0.45 & 99999.9 & 0.59 & 99999.9 & 0.81 & 99999.9 & 0.48 & 99999.9 & 0.63 & 99999.9 & 0.9 \\
\hline $30 \%$ & $\mathrm{~F}$ & 99999.9 & 0.43 & 99999.9 & 0.56 & 99999.9 & 0.77 & 99999.9 & 0.45 & 99999.9 & 0.59 & 99999.9 & 0.86 \\
\hline $35 \%$ & G & 99999.9 & 0.4 & 99999.9 & 0.53 & 99999.9 & 0.74 & 99999.9 & 0.43 & 99999.9 & 0.56 & 99999.9 & 0.83 \\
\hline $40 \%$ & $\mathrm{H}$ & 99999.9 & 0.38 & 99999.9 & 0.5 & 99999.9 & 0.71 & 99999.9 & 0.41 & 99999.9 & 0.53 & 99999.9 & 0.79 \\
\hline $45 \%$ & 1 & 99999.9 & 0.37 & 99999.9 & 0.47 & 99999.9 & 0.68 & 99999.9 & 0.39 & 99999.9 & 0.51 & 99999.9 & 0.76 \\
\hline $50 \%$ & $\mathrm{~J}$ & 99999.9 & 0.35 & 99999.9 & 0.45 & 99999.9 & 0.63 & 99999.9 & 0.37 & 99999.9 & 0.48 & 99999.9 & 0.71 \\
\hline $55 \%$ & $\mathrm{~K}$ & 99999.9 & 0.33 & 99999.9 & 0.43 & 99999.9 & 0.63 & 99999.9 & 0.35 & 99999.9 & 0.46 & 99999.9 & 0.7 \\
\hline $60 \%$ & $\mathrm{~L}$ & 99999.9 & 0.31 & 99999.9 & 0.42 & 99999.9 & 0.61 & 99999.9 & 0.33 & 99999.9 & 0.44 & 99999.9 & 0.68 \\
\hline $65 \%$ & $\mathrm{M}$ & 99999.9 & 0.3 & 99999.9 & 0.4 & 99999.9 & 0.59 & 99999.9 & 0.32 & 99999.9 & 0.42 & 99999.9 & 0.65 \\
\hline $70 \%$ & $\mathrm{~N}$ & 99999.9 & 0.28 & 99999.9 & 0.38 & 99999.9 & 0.57 & 99999.9 & 0.3 & 99999.9 & 0.41 & 99999.9 & 0.63 \\
\hline $75 \%$ & 0 & 99999.9 & 0.27 & 99999.9 & 0.37 & 99999.9 & 0.54 & 99999.9 & 0.29 & 99999.9 & 0.39 & 99999.9 & 0.6 \\
\hline $80 \%$ & $\mathrm{P}$ & 99999.9 & 0.26 & 99999.9 & 0.36 & 99999.9 & 0.52 & 99999.9 & 0.27 & 99999.9 & 0.38 & 99999.9 & 0.58 \\
\hline $85 \%$ & $\mathrm{Q}$ & 99999.9 & 0.24 & 99999.9 & 0.35 & 99999.9 & 0.5 & 99999.9 & 0.25 & 99999.9 & 0.37 & 99999.9 & 0.55 \\
\hline $90 \%$ & $R$ & 99999.9 & 0.23 & 99999.9 & 0.34 & 99999.9 & 0.48 & 99999.9 & 0.24 & 99999.9 & 0.36 & 99999.9 & 0.53 \\
\hline $95 \%$ & s & 99999.9 & 0.21 & 99999.9 & 0.33 & 99999.9 & 0.46 & 99999.9 & 0.22 & 99999.9 & 0.35 & 99999.9 & 0.5 \\
\hline
\end{tabular}

Table 4-43 - Line 1 Test Results: Backup Line 6 Ground 67GT_TOC Element

\begin{tabular}{|c|c|c|c|c|c|c|c|c|c|c|c|c|c|}
\hline \multirow{3}{*}{$\begin{array}{c}\text { Fault } \\
\text { Location }\end{array}$} & \multirow{3}{*}{$\begin{array}{l}\text { Fault } \\
\text { Code }\end{array}$} & \multicolumn{6}{|c|}{ Normal Generation } & \multicolumn{6}{|c|}{ Increased Generation } \\
\hline & & \multicolumn{2}{|c|}{$\begin{array}{c}\text { SLG } 10 \text { Ohms } \\
\text { (System Normal) }\end{array}$} & \multicolumn{2}{|c|}{$\begin{array}{c}\text { SLG Bolted } \\
\text { (System Normal) }\end{array}$} & \multicolumn{2}{|c|}{$\begin{array}{c}\text { SLG Bolted } \\
\text { (XFMR Bank A Outage) }\end{array}$} & \multicolumn{2}{|c|}{$\begin{array}{l}\text { SLG } 10 \text { Ohms } \\
\text { (System Normal) }\end{array}$} & \multicolumn{2}{|c|}{$\begin{array}{c}\text { SLG Bolted } \\
\text { (System Normal) }\end{array}$} & \multicolumn{2}{|c|}{$\begin{array}{c}\text { SLG Bolted } \\
\text { (XFMR Bank A Outage) }\end{array}$} \\
\hline & & $\begin{array}{c}\text { Operation } \\
\text { (Cycles) }\end{array}$ & A/Pickup & $\begin{array}{c}\text { Operation } \\
\text { (Cycles) }\end{array}$ & A/Pickup & $\begin{array}{c}\text { Operation } \\
\text { (Cycles) }\end{array}$ & A/Pickup & $\begin{array}{c}\text { Operation } \\
\text { (Cycles) }\end{array}$ & A/Pickup & $\begin{array}{c}\text { Operation } \\
\text { (Cycles) }\end{array}$ & A/Pickup & $\begin{array}{c}\text { Operation } \\
\text { (Cycles) }\end{array}$ & A/Pickup \\
\hline $5 \%$ & $\mathrm{~A}$ & 47.7 & 1.43 & 26.1 & 1.94 & 19.6 & 2.42 & 40.5 & 1.53 & 23.5 & 2.09 & 17.3 & 2.73 \\
\hline $10 \%$ & $\mathrm{~B}$ & 57.9 & 1.34 & 29.4 & 1.79 & 20.7 & 2.31 & 47.7 & 1.43 & 26.2 & 1.93 & 18.2 & 2.59 \\
\hline $15 \%$ & $\mathrm{C}$ & 72.8 & 1.26 & 33.4 & 1.67 & 21.9 & 2.2 & 57.6 & 1.34 & 29.4 & 1.79 & 19.2 & 2.47 \\
\hline $20 \%$ & D & 97.1 & 1.19 & 38.2 & 1.56 & 23.2 & 2.1 & 71.9 & 1.27 & 33.2 & 1.67 & 20.2 & 2.36 \\
\hline $25 \%$ & $E$ & 143.1 & 1.13 & 44.3 & 1.47 & 24.6 & 2.01 & 94.7 & 1.2 & 37.8 & 1.57 & 21.3 & 2.25 \\
\hline $30 \%$ & $\mathrm{~F}$ & 99999.9 & 1.07 & 52.1 & 1.39 & 26.2 & 1.93 & 136.9 & 1.13 & 43.5 & 1.48 & 22.5 & 2.16 \\
\hline $35 \%$ & G & 99999.9 & 1.01 & 62.5 & 1.31 & 27.9 & 1.85 & 99999.9 & 1.07 & 50.6 & 1.4 & 23.8 & 2.07 \\
\hline $40 \%$ & $\mathrm{H}$ & 99999.9 & 0.96 & 77 & 1.25 & 29.8 & 1.78 & 99999.9 & 1.02 & 60 & 1.33 & 25.2 & 1.98 \\
\hline $45 \%$ & 1 & 99999.9 & 0.91 & 98.9 & 1.19 & 32 & 1.71 & 99999.9 & 0.97 & 72.7 & 1.26 & 26.8 & 1.9 \\
\hline $50 \%$ & $\mathrm{~J}$ & 99999.9 & 0.87 & 135.7 & 1.13 & 37.3 & 1.58 & 99999.9 & 0.92 & 91.2 & 1.2 & 30.2 & 1.76 \\
\hline $55 \%$ & $\mathrm{~K}$ & 99999.9 & 0.83 & 99999.9 & 1.08 & 37.2 & 1.58 & 99999.9 & 0.87 & 120.2 & 1.15 & 30.4 & 1.76 \\
\hline $60 \%$ & $\mathrm{~L}$ & 99999.9 & 0.79 & 99999.9 & 1.04 & 40.5 & 1.52 & 99999.9 & 0.83 & 172.7 & 1.1 & 32.6 & 1.69 \\
\hline $65 \%$ & $M$ & 99999.9 & 0.75 & 99999.9 & 1 & 44.5 & 1.47 & 99999.9 & 0.79 & 99999.9 & 1.06 & 35.2 & 1.63 \\
\hline $70 \%$ & $\mathrm{~N}$ & 99999.9 & 0.71 & 99999.9 & 0.96 & 49.3 & 1.41 & 99999.9 & 0.75 & 99999.9 & 1.02 & 38.2 & 1.56 \\
\hline $75 \%$ & 0 & 99999.9 & 0.67 & 99999.9 & 0.93 & 55.5 & 1.36 & 99999.9 & 0.71 & 99999.9 & 0.98 & 41.9 & 1.5 \\
\hline $80 \%$ & $\mathrm{P}$ & 99999.9 & 0.64 & 99999.9 & 0.89 & 63.6 & 1.31 & 99999.9 & 0.67 & 99999.9 & 0.95 & 46.4 & 1.44 \\
\hline $85 \%$ & $Q$ & 99999.9 & 0.6 & 99999.9 & 0.87 & 75.2 & 1.25 & 99999.9 & 0.64 & 99999.9 & 0.92 & 52.3 & 1.38 \\
\hline $90 \%$ & $\mathrm{R}$ & 99999.9 & 0.57 & 99999.9 & 0.84 & 93.2 & 1.2 & 99999.9 & 0.6 & 99999.9 & 0.89 & 60.5 & 1.32 \\
\hline $95 \%$ & $\mathrm{~S}$ & 99999.9 & 0.53 & 99999.9 & 0.82 & 126.6 & 1.14 & 99999.9 & 0.56 & 99999.9 & 0.86 & 73 & 1.26 \\
\hline
\end{tabular}

As observed, resistive faults decrease the sensitivity of the IOC and TOC elements and therefore will not impact the mis-operation of these backup protection elements. They can however, become 
an issue for other study cases when the short circuit duty is decreased and the primary protection is not able to detect high resistive faults for its own transmission line.

The impact of increased generation on the TOC element is also observed with a higher reach into the adjacent line and increased time of operation for all three fault scenarios.

There is a significant impact to the ratio of measured to pick-up fault current of IOC element at Bio when the power transformer is outaged. The ratio increases during normal generation condition from 0.77 to 0.97 . This element has a high risk of mis-operating with a small safety margin during the study case 1. With the increased generation near Bio substation during study case 3 , the ratio is slightly increased to 1.09 . The solution to resolve this specific over-reach is to decrease the pick-up of the IOC element so the ratio is at least less than $80 \%$ for a remote close-in fault.

Coordination of overcurrent elements can be a challenge due to sudden changes of the fault current when system equipment are outaged. Extensive testing of not just coordination but the sensitivity and time of operation for every overcurrent element is required and can be supported by the utilization of automation routines to apply thousands of conditions in order to optimize their respective settings.

\subsection{Summary}

Chapter 4 presented the results obtained from the simulation of the proposed process described in chapter 3. The CAPE model described in chapter 2 was utilized. The case studies selected were designed to subject the model to significant stressed conditions. The case studies were divided into three groups. First, correct settings recently calculated for the model in chapter 2 were stressed under system normal and N-1 contingency conditions with/without POTT scheme activated for bolted and resistive faults. Next, a human error scenario for one of the relay elements with incorrect settings was reviewed using the proposed solution. Lastly, the same protection system utilized in case 1 was reviewed under a significant change in the primary fault current simulating the future changes in the Transmission topology. The amount of results were overwhelming requiring a prioritization method described in chapter 5 as a proposed risk assessment approach. 


\section{Risk Assessment}

\subsection{Introduction}

The extent of data produced in wide area coordination studies is very large. Each line coordination study could simulate an average of 500 fault scenarios. Additional coordination studies for busses or transformers could simulate an average of 100 fault scenarios. Results from each line study contain approximately 1500 pages of data with an average of 1500 sequential events. The data obtained for transformers and bus studies is of similar order. When multiplied with the hundreds of lines, transformers and buses that are studied in a typical transmission network, the results quickly become overwhelming. Reviewing the results and implementing the recommendations in a reasonable time-frame becomes an enormous challenge due to a limited number of resources being available. Therefore, assessment of risk associated with issues reported in the study, and prioritization of them, is a critical step for electric utilities before using the results in a meaningful way and to formulate a strategy to maximize the impact of any investments in resolving the issues. Instead of just being a secondary process performed at the end of the coordination study, risk assessment can become one of the primary objectives of wide area protection coordination solution. The WAPC study is an opportunity to improve asset planning for $\mathrm{P} \& \mathrm{C}$ equipment replacements/upgrades by quantitatively prioritizing which upgrades would provide the most value from a system safety and reliability perspective. By performing a detailed risk assessment and prioritization, protection replacement/upgrade programs can be optimized to ensure that they are mitigating the most risk to the system. The risk scoring system also facilitated the integration of the work that was required to fix the vulnerabilities from the study, with other planned and corrective maintenance work.

The following sections describe the proposed methodology behind quantification of relative risk scores for transmission sensitivity, transmission coordination, the philosophy behind the manipulation of the risk data and the classification into risk categories. 


\subsection{Transmission Line Sensitivity Risk Assessment}

All the elements flagged by the sensitivity studies are allocated a risk score based on certain criteria. This is summarized as follows:

$$
\text { Risk Score }=f(\text { Element Multiplier,Condition Weight, Element Reach Weight })
$$

Element Multiplier is a value assigned to each element (e.g. Phase Zone 1, Ground IOC) based on the probability and severity of a mis-coordination happening for that element.

Condition Weight is a value assigned based on the probability of a mis-coordination happening in certain scenario. Min and Max condition based on the N-1 contingency and Normal condition is based on a system normal scenario.

Element Reach Weight is a value assigned to flagged elements based on how severe a miscoordination within a certain range would be.

The criteria values which can be used in risk calculations are summarized in Table 5-1.

Table 5-1 - Sensitivity Risk Summary

\begin{tabular}{|c|c|c|c|c|c|c|c|c|c|c|c|c|}
\hline \multicolumn{13}{|c|}{ Sensitivity - Risk Weights } \\
\hline & Ground Z1 & Phase Z1 & Ground Z2 & Phase Z2 & Ground Z3 & Phase Z3 & Ground Z4 & Phase Z4 & Ground IOCF & se $10 \mathrm{C}$ & Ground TOI & е TOC \\
\hline Element Multiplier & 1.00 & 0.90 & 0.80 & 0.75 & 0.20 & 0.25 & 0.00 & 0.00 & 1.00 & 0.95 & 0.80 & 0.80 \\
\hline \multicolumn{13}{|l|}{ Condition Factor } \\
\hline Min & 0.20 & 0.20 & 0.20 & 0.20 & 0.05 & 0.05 & 0.05 & 0.05 & 0.20 & 0.20 & 0.20 & 0.20 \\
\hline Max & 0.20 & 0.20 & 0.20 & 0.20 & 0.10 & 0.10 & 0.10 & 0.10 & 0.20 & 0.20 & 0.20 & 0.20 \\
\hline Normal & 0.60 & 0.60 & 0.60 & 0.60 & 0.85 & 0.85 & 0.85 & 0.85 & 0.60 & 0.60 & 0.60 & 0.60 \\
\hline \multicolumn{13}{|l|}{ Element Reach Factors } \\
\hline Too Low & 0.30 & 0.30 & 1.00 & 1.00 & 1.00 & 1.00 & 0.90 & 0.90 & 1.00 & 1.00 & 0.30 & 0.60 \\
\hline Little Low & 0.05 & 0.05 & 0.60 & 0.60 & 0.20 & 0.20 & 0.20 & 0.20 & 0.80 & 0.80 & 0.10 & 0.50 \\
\hline Little High & 0.80 & 0.80 & 0.05 & 0.05 & 0.20 & 0.20 & 0.20 & 0.20 & 0.10 & 0.10 & 0.80 & 0.80 \\
\hline Too High & 1.00 & 1.00 & 0.50 & 0.50 & 0.30 & 0.30 & 1.00 & 1.00 & 0.20 & 0.20 & 1.00 & 1.00 \\
\hline \multicolumn{13}{|c|}{ Element Reach Ranges } \\
\hline & Ground Z1 & Phase Z1 & Ground Z2 & Phase Z2 & Ground Z3 & Phase Z3 & Ground Z4 & Phase Z4 & Ground IOCF & se $10 \mathrm{C}$ & Ground TOI & е TOC \\
\hline Too Low & 50 & 50 & 105 & 105 & 105 & 105 & 105 & 105 & 110 & 110 & 5 & 5 \\
\hline Little Low & 75 & 75 & 115 & 115 & 115 & 115 & 115 & 115 & 120 & 120 & 10 & 10 \\
\hline Little High & 90 & 90 & 150 & 150 & 400 & 400 & 400 & 400 & 150 & 150 & 50 & 50 \\
\hline Too High & 95 & 95 & 200 & 200 & 800 & 800 & 800 & 800 & 190 & 190 & 70 & 70 \\
\hline
\end{tabular}




\subsubsection{Criteria}

The risk criteria and corresponding weights are described in the sections below.

\section{Element Multiplier}

Elements considered are distance Zone 1, Zone 2, Zone 3, and overcurrent IOC and TOC elements. The risk value associated to these elements is biased to reflect the probability and severity of a mis-coordination happening for that element. The higher the severity of the element miscoordination, the higher the risk. Similarly, the higher the probability of mis-coordination, the higher the risk. The weights assigned for these multipliers are decided based on research on probability of fault types and system outages. Additionally, the severity weight factor is adjusted based on how fast the backup element can mis-operate.

For example, a Ground Z1 mis-coordination is deemed more consequential than a Ground Z3 miscoordination so it has a higher weight. However, a Ground Z1 and Phase Z1 mis-coordination have the same severity but Ground Z1 fault have a higher probability of occurring (Single Line to Ground faults are most common) hence Ground Z1 has a higher risk weight then Phase Z1 [54].

The final risk values for element multiplier are summarized in Table 5-2:

Table 5-2 - Sensitivity Risk Weight - Element Multiplier

\begin{tabular}{|l|c|c|c|c|c|c|c|c|c|c|}
\hline & Ground Z1 & Phase Z1 & Ground Z2 & Phase Z2 & Ground Z3 & Phase Z3 & $\begin{array}{c}\text { Ground } \\
\text { TOC }\end{array}$ & $\begin{array}{c}\text { Phase } \\
\text { TOC }\end{array}$ & $\begin{array}{c}\text { Ground } \\
\text { IOC }\end{array}$ & \begin{tabular}{l} 
Phase IOC \\
\hline $\begin{array}{l}\text { Element } \\
\text { Multiplier }\end{array}$
\end{tabular} \\
\hline
\end{tabular}

\section{Condition Weight (Min, Max, Normal)}

The weights for the min, max and normal conditions are assigned based on the probability of occurrence of each of these conditions. The higher the probability of occurrence, the higher the weight associated to the condition. Min and max condition are obtained from $\mathrm{N}-1$ contingencies hence have a lesser probability of occurrence than a normal condition which is obtained from system normal. Since each test would have a min, max and normal, the sum of the weights assigned to min, max and normal would add up to 1 . 
The condition factors are summarized in Table 5-3:

Table 5-3 - Sensitivity Risk Weight - Condition Multiplier

\begin{tabular}{|l|c|c|c|c|c|c|c|c|c|c|}
\hline & Ground Zl & Phase Z1 & Ground Z2 & Phase Z2 & Ground Z3 & Phase Z3 & $\begin{array}{c}\text { Ground } \\
\text { TOC }\end{array}$ & $\begin{array}{c}\text { Phase } \\
\text { TOC }\end{array}$ & $\begin{array}{c}\text { Ground } \\
\text { IOC }\end{array}$ & $\begin{array}{c}\text { Phase IOC } \\
\text { Min }\end{array}$ \\
\hline Max & 0.2 & 0.2 & 0.2 & 0.2 & 0.05 & 0.05 & 0.2 & 0.2 & 0.2 & 0.2 \\
\hline Normal & 0.6 & 0.2 & 0.2 & 0.2 & 0.1 & 0.1 & 0.2 & 0.2 & 0.2 & 0.2 \\
\hline
\end{tabular}

\section{Element Reach Weight}

The reach obtained from the sensitivity studies can be categorized into 4 range categories with each range category having a weight. The range categories are:

- Too Low: Severe under-reach compared to the ideal reach

- Little Low: Mild under-reach compared to the ideal reach

- Little High: Mild over-reach compared to the ideal reach

- Too High: Severe over-reach compared to the ideal reach

The range categories are set using limits. For the too low and little low cases, the reach must be less that the limits to be assigned to these categories and for the too high and little high cases, the reach must be higher than the limits to be assigned to these categories. The region between the limits for little low to little high do not have and risk factor assigned to them.

The final limits for element reach multiplier are summarized in Table 5-4:

Table 5-4 - Sensitivity Risk Weight - Element Reach Ranges

\begin{tabular}{|c|c|c|c|c|c|c|c|c|c|c|}
\hline & Ground $\mathrm{Zl}$ & Phase $\mathrm{Zl}$ & Ground $\mathrm{Z2}$ & Phase Z2 & Ground Z3 & Phase Z3 & Ground IOd & Phase IOC & Fround Tod & Phase TOC \\
\hline Too Low & 50 & 50 & 105 & 105 & 105 & 105 & 110 & 110 & 5 & 5 \\
\hline Little Low & 75 & 75 & 115 & 115 & 115 & 115 & 120 & 120 & 10 & 10 \\
\hline Little High & 90 & 90 & 150 & 150 & 400 & 400 & 150 & 150 & 50 & 50 \\
\hline Too High & 95 & 95 & 200 & 200 & 800 & 800 & 190 & 190 & 70 & 70 \\
\hline
\end{tabular}

For example, Ground Zone 2 reach of $100 \%$ would be classified as too low and a Phase TOC reach of $60 \%$ would be classified as little high. 
The weights associated to the range categories are defined by element type and the severity of an under-reaching or over-reaching reach for that element in the absence of pilot protection.

For example, an over-reaching Zone 1 element (too high) is more severe than an under-reaching Zone 1 element (too low), so over-reaching Zone 1 has a higher weight associated with it as it can instantaneously mis-operate on adjacent line faults. In contrast, an under-reaching Zone 2 element (too low) is the more severe than an over-reaching Zone 2 element (too high) as it can result in not operating for its own primary line (fault never clears), so under-reaching Zone 2 has a higher weight associated with it.

The weights for these categories are summarized in Table 5-5 :

Table 5-5 - Sensitivity Risk Weight - Element Reach Multiplier

\begin{tabular}{|c|c|c|c|c|c|c|c|c|c|c|}
\hline & Ground $\mathrm{Zl}$ & Phase $\mathrm{Zl}$ & Ground Z2 & Phase Z2 & Ground Z3 & Phase $\mathbf{Z 3}$ & Ground IOd & Phase IOC & Ground Tod & Phase TOC \\
\hline Too Low & 0.3 & 0.3 & 1 & 1 & 1 & 1 & 1 & 1 & 0.3 & 0.6 \\
\hline Little Low & 0.05 & 0.05 & 0.6 & 0.6 & 0.2 & 0.2 & 0.8 & 0.8 & 0.1 & 0.5 \\
\hline Little High & 0.8 & 0.8 & 0.05 & 0.05 & 0.2 & 0.2 & 0.1 & 0.1 & 0.8 & 0.8 \\
\hline Too High & 1 & 1 & 0.5 & 0.5 & 0.3 & 0.3 & 0.2 & 0.2 & 1 & 1 \\
\hline
\end{tabular}

\subsubsection{Calculation of Risk}

The sensitivity data can be arranged by flagged elements. For each of these elements, the reach for min, max and normal conditions are given. The reach for min, max and normal reach is extracted and compared to the reach limits and classified under range categories. The range categories are used to obtain the first set of weights which are then multiplied by their condition multiplier. These are then added together and multiplied by the element multiplier.

This process can be summarized by using the following:

Risk Score = Element Multiplier

$$
\times \sum_{\text {Conditions }} \text { Conditions Weight } \times \text { Element Reach Weight }
$$

The risk score for the worst-case scenario can be totaled to a value of 1 . This was decided to be an over-reaching Ground Z1 (too high Ground Z1) and an under-reaching Ground IOC (too low Ground IOC). Ground elements were chosen as ground faults have the highest probability of 
happening (Single Line to Ground). Zone 1 and IOC elements were chosen as the consequences for mis-operation of these elements in the absence of pilots is the most severe.

For an example of a general case, take a Ground IOC element with min reach $=58 \%$, max reach $=177 \%$ and normal reach $=158 \%$. The risk is calculated as follows:

- Element is Ground IOC. Multiplier is 1.

- Reach of normal case $=158 \%$. Thus, risk is little high $=0.10 * 0.60$.

- Reach of min case $=58 \%$. Thus, risk is too low $=1.00 * 0.20$.

- Reach of $\max$ case $=177 \%$. Thus, risk is too high $=0.10 * 0.20$.

- The risk is evaluated as $1.00 \times((0.10 \times 0.60)+(1.00 \times 0.20)+(0.10 \times 0.20))=0.28$

The prioritization of each study will assist the engineer to focus their time on the most relevant protective element with a flag for the most relevant fault scenarios. The benefits of this process can be justified when reviewing study Case 3 in chapter 4.3.3 (see Table 4-42 and Table 4-43).

\subsection{Coordination Risk Assessment}

The results from each individual coordination study (one study per transmission line) can be combined into one database. Each row of data can represent the behavior of one backup element on a specific line with a simulation flag.

Each data row is allocated a calculated risk number using the following criteria:

- Mis-operation versus CTI violation (the number of cycles within which it occurred)

- Locations within a transmission line with issues

- Fault types

- Time after fault the element misbehaved (or planned to misbehave)

- Type of fault contingencies

For example, a mis-operation of a backup element on multiple fault locations for a SLG fault (higher probability of occurrence) during system normal condition is a high risk violation (See Figure 5-1). 


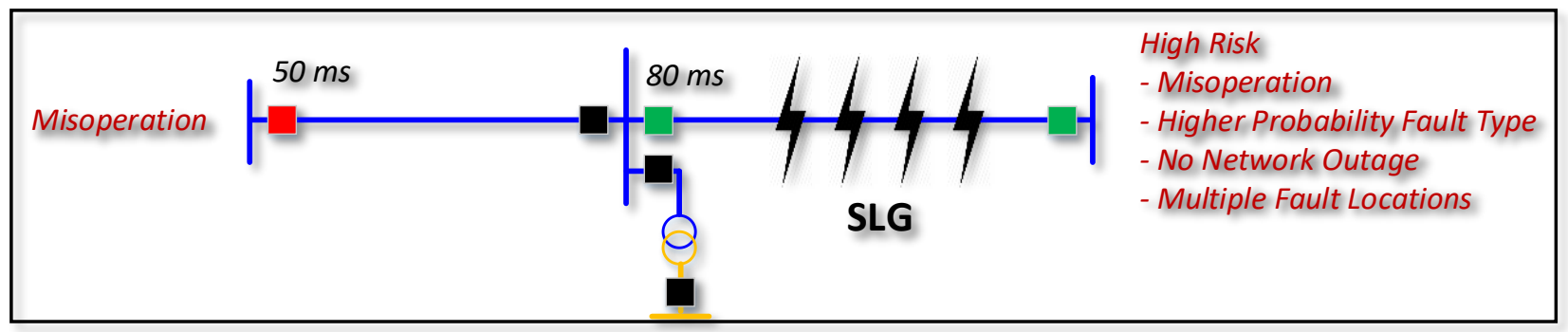

Figure 5-1 - Example of High Risk Coordination Violation

In contrast, a CTI violation for a single fault location for a TPG fault (lower probability of occurrence) during a power transformer N-1 contingency is a low risk violation (See Figure 5-2)

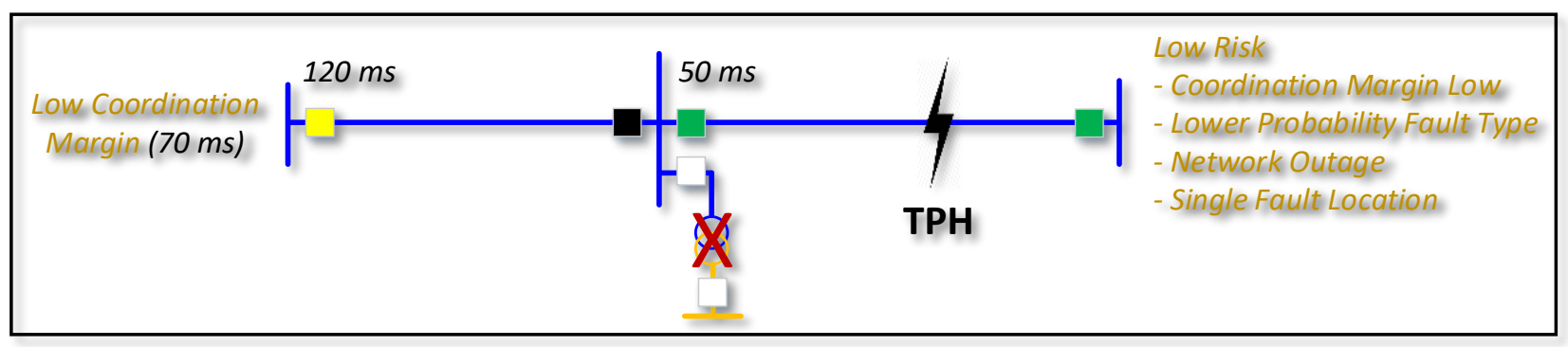

Figure 5-2 - Example of Low Risk Coordination Violation

\subsubsection{Criteria}

The objective is to calculate a single relative risk factor for each misbehaving element identified by the coordination study of every transmission line. This section will describe how the final relative risk factor is achieved using available information documented in each study report. This relative risk factor attempts to quantify the probability of the fault scenario occurring based on the available wide area coordination study results. Cost and consequence risk factors for each miscoordination are not included due to limitation of data. The risk mechanism can be further improved if electric utilities collect historical risk data which can correlate consequence factors.

Similar to sensitivity risk factors, the relative coordination risk factor of each protective element will range between 0 and 1 . In order to achieve the higher score of 1 , the protective element will require to mis-operate within the first 10 cycles after the initiation of the fault for all contingencies (system normal and every $\mathrm{N}-1$ ), all fault types (bolted \& resistive), and for every fault location within the study line. 
Each individual study criteria has a weighting factor associated with it, as follows:

\section{$\underline{\text { CTI Risk Multiplier }}$}

The risk associated for each fault scenario is corrected by the severity of the mis-coordination. The relative risk factor is reduced by a CTI factor based on the severity of the mis-operations. For example, a backup element planning to operate 10 cycles slower than the primary while the philosophy requires 12 cycles would have a very little risk association compared to the same element mis-operating (negative CTI).

CTI risk multiplier is summarized in Figure 5-3:

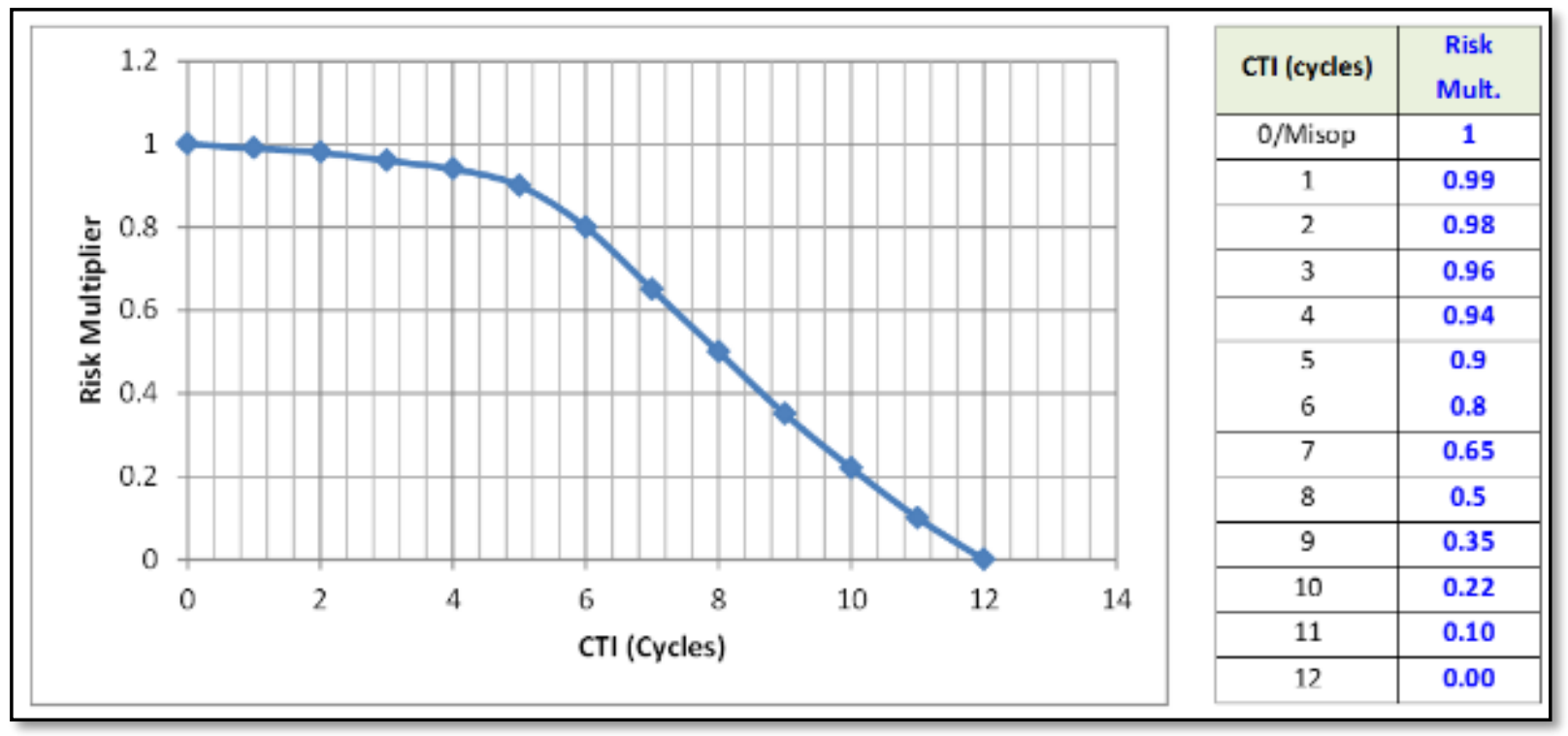

Figure 5-3 - Coordination Risk Weight - CTI Risk Multiplier

\section{Exposure Risk Multiplier}

The risk associated for each fault scenario is corrected by the fault range of the mis-coordination. Fault range is defined as the percentage of the line that a fault represents when applied at a particular fault location. It is calculated as the sum of half of line segments extending to the adjacent faults. For example, for a fault at $35 \%$ of the line, Fault Type Factor will be $17.5 \%$ and at remote end it will be $7.5 \%$ as shown in Figure 5-4: 


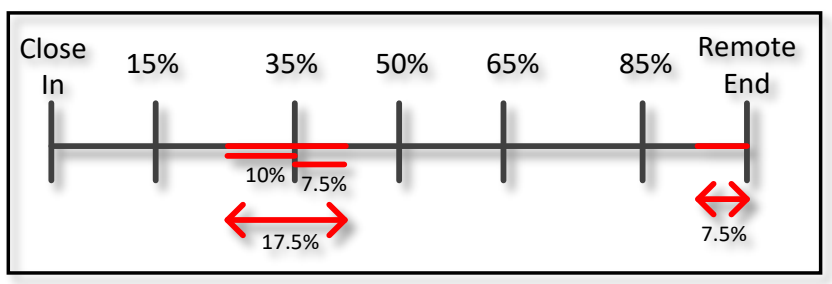

Figure 5-4 - Exposure Risk Multiplier Example

This risk factor can be eliminated by the means of automation as faults can potentially be applied for $1 \%$ increments.

Exposure risk multiplier is summarized in Table 5-6:

Table 5-6 - Coordination Risk Weight - Exposure Risk Multiplier

\begin{tabular}{|c|c|}
\hline Fault Locations & Risk Weight \\
\hline Close-in & $\mathbf{0 . 0 7 5}$ \\
\hline $15 \%$ & $\mathbf{0 . 1 5}$ \\
\hline $30 \%$ & $\mathbf{0 . 1 7 5}$ \\
\hline $50 \%$ & $\mathbf{0 . 2}$ \\
\hline $70 \%$ & $\mathbf{0 . 1 7 5}$ \\
\hline $85 \%$ & $\mathbf{0 . 1 5}$ \\
\hline Remote & $\mathbf{0 . 0 7 5}$ \\
\hline Total & $\mathbf{1}$ \\
\hline
\end{tabular}

\section{Mis-coordination Time Risk Multiplier}

The risk associated for each fault scenario is corrected by the time which a mis-coordination occurs relative to the fault. For example, an instantaneous element mis-operating 1 cycle after the fault is of higher risk compared to a timed overcurrent element mis-operating 35 cycles after fault has occurred. The Mis-coordination Time risk multiplier is summarized in Table 5-7:

Table 5-7 - Coordination Risk Weight - Mis-Coordination Time Risk Multiplier

\begin{tabular}{|c|c|c|}
\hline Type of Mis-coordination & Time of Mis-coordination after Fault & Risk Weight \\
\hline \multirow{2}{*}{ Mis-operation } & $0-10$ Cycles & $\mathbf{1}$ \\
\cline { 2 - 3 } & $10+$ Cycles & $\mathbf{0 . 8}$ \\
\hline CTI Violation & Anytime & $\mathbf{0 . 8}$ \\
\hline
\end{tabular}




\section{$\underline{\text { Fault Type Risk Multiplier }}$}

The risk associated for each fault scenario is corrected by probability of the fault type actually occurring for the mis-coordinating element. Fault type risk multiplier is defined based on research conducted on historical observations [66-67].

Fault type risk multiplier is summarized in Table 5-8:

Table 5-8 - Coordination Risk Weight - Fault Type Risk Multiplier

\begin{tabular}{|c|c|}
\hline Fault Type & Risk Weight \\
\hline TPH & $\mathbf{0 . 0 5}$ \\
\hline LTL & $\mathbf{0 . 1 5}$ \\
\hline SLG & $\mathbf{0 . 6 7 2}$ \\
\hline SLG (resistive & $\mathbf{0 . 0 2 8}$ \\
\hline DLG & $\mathbf{0 . 0 9 6}$ \\
\hline DLG (resistive) & $\mathbf{0 . 0 0 4}$ \\
\hline Total & $\mathbf{1}$ \\
\hline
\end{tabular}

\section{Contingency Risk Multiplier}

The risk associated for each fault scenario is corrected by the type of contingency the miscoordination occurs for each fault. Any issues found in system normal condition with all protection, communication, and system equipment in service will have the highest priority.

The Contingency risk multiplier is summarized in Table 5-9 :

Table 5-9 - Coordination Risk Weight - Fault Type Risk Multiplier

\begin{tabular}{|r|r|c|}
\hline \multicolumn{2}{|c|}{ Fault Condition } & Risk Multi. \\
\hline & System Normal & 0.85 \\
\hline \multirow{3}{*}{ N-1 Outage } & Relay Package & 0.03 \\
\cline { 2 - 3 } & Communication & 0.07 \\
\cline { 2 - 3 } & Transformer & 0.01 \\
\cline { 2 - 3 } & Line/Feeder & 0.01 \\
\cline { 2 - 3 } & Mutual Coupling & 0.01 \\
\cline { 2 - 3 } & Bus Tie & 0.01 \\
\hline Generator & 0.01 \\
\hline
\end{tabular}


The probability risk factor is for the total number of elements for each individual coordination study. Therefore, the risk multiplier will be divided by the number of system elements for each condition. For example the multiplier will be 0.005 for transformer outages if the study 2 adjacent transformers as system outages.

\subsubsection{Calculation of Risk}

The relative risk factor attempts to quantify the probability and severity of the misbehaving protective elements. The risk will be calculated by accumulating the 5 partial risk multipliers mentioned above. An example below will illustrate how a mis-operation can potentially result in a lower risk than a CTI violation.

Figure 5-5 represents a mis-operation of a backup element after 80 cycles from initiation of a SLG fault with resistance at location $100 \%$ while a transformer is outaged. The partial risk factor for this one fault scenario is calculated at 0.0000084 .

\begin{tabular}{|c|c|c|c|c|c|c|c|c|}
\hline \multicolumn{9}{|l|}{ SLG (5) } \\
\hline Pilot & Outages/Test & $0.00 \%$ & $15.00 \%$ & $30.00 \%$ & $50.00 \%$ & $70.00 \%$ & \multicolumn{2}{|c|}{$85.00 \% \quad 100.00 \%$} \\
\hline \multirow{9}{*}{ Enabled } & Primary System Normal & Pass & Pass & Pass & Pass & Pass & Pash & Pass \\
\hline & XFMR : $177-1317-1$ ( Bank A) & Pass & Pass & Pass & Pass & Pass & Pass & Mis-Op \\
\hline & Line : 177-154-1(ㄴII)E7) & Pass & Pass & Pass & Pass & Mis-Op & Mis-Op & Pass \\
\hline & Line : 177-175-1(LIIE6) & Pass & Pass & Pass & Pass & Pash & Pass & Pass \\
\hline & \begin{tabular}{|l|l|} 
XFMR : 183-1316-1 & Bank C) \\
\end{tabular} & Pass & Pass & Pass & Pass & Pass & Pass & Mis-Op \\
\hline & Line : 183-105-1(ㄴINE3) & Pass & Pass & Pass & Pass & Pass & Pass & Mis-Op \\
\hline & Line : 183-141-1(LINE2) & Pass & Pass & Pass & Pacs & Pass & Pas & Mis-Op \\
\hline & Line : 183-151-1(LIIE4) & Pass & Pass & Pass & Pass & Pass & Pass & Pass \\
\hline & Line : 183-449-1(LINE5) & Pass & Pass & Pass & Pass & Pass & Pass & Pass \\
\hline \multicolumn{9}{|c|}{$\begin{array}{l}\text { Contingency Risk }=0.01 / 2=0.005 \\
\text { (Risk for XFMR outage }=1 \text {, There } \\
\text { are } 2 \text { total XFMRs as outages) }\end{array}$} \\
\hline & & & & & \multicolumn{4}{|c|}{$\begin{array}{c}\text { CTI Risk }=1 \\
\text { Mis-coordination Time Risk }=0.8\end{array}$} \\
\hline \multicolumn{2}{|c|}{ Fault Type Risk = 0.028 (SLG resistive) } & & & & & & & \\
\hline \multicolumn{4}{|c|}{ Partial Risk Factor $=0.5 \times 0.028 \times 0.075 \times 1 \times 0.8=0.0000084$} & & & & & \\
\hline
\end{tabular}

Figure 5-5 - Coordination Relative Risk Summary - Low Risk Mis-operation 
Furthermore, Figure 5-6 represents a CTI violation of 3.9 cycles of a backup element after initiation of a bolted SLG fault at location 70\% during system normal condition. The partial risk factor for this one fault scenario is calculated at 0.0751699 .

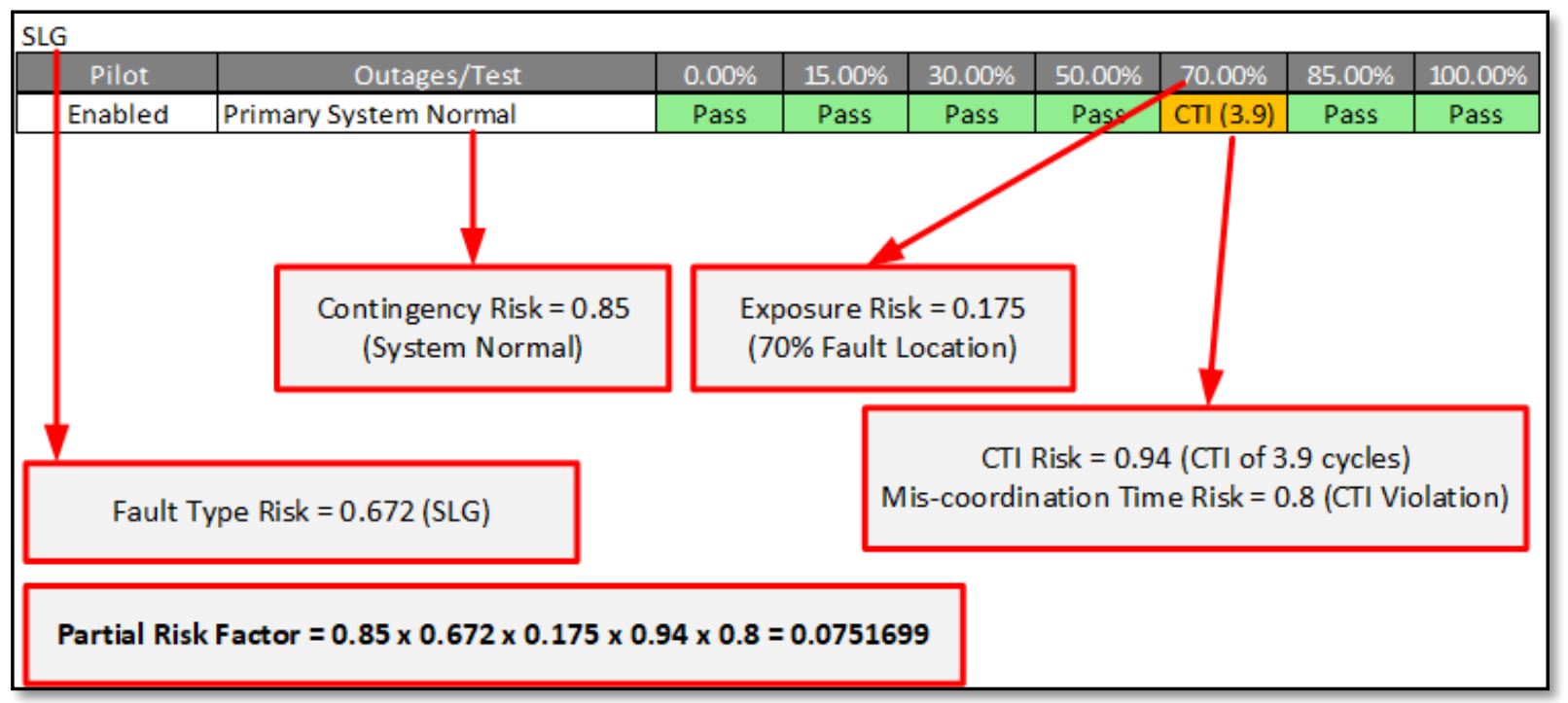

Figure 5-6 - Coordination Relative Risk Summary - High Risk CTI Violation

The final relative risk number of each flagged element is then calculated by taking the sum of all partial risk factors. Since the same protective element can mis-coordination on multiple adjacent line's coordination studies, their total risk can be summed to a value higher than one.

\subsection{Total Risk}

Risk score calculation gives an idea of how risky an element is. However, unless the data can be combined and displayed, it is still too abstract to be used. Combining and grouping this data is done for the transmission network. This section will further explain how the risk data are combined.

Transmission data include both coordination and sensitivity simulations which are combined by assigning weight to each of the studies. Since sensitivity flags are more critical, it has a higher weight assigned. When displaying the data, sensitivity (70\%) and coordination (30\%) risks are added together to give the proper risk for that element. Hence, they should add up to 1. 
The combined risk data for transmission generated many risk scores. When looking at the sum of all risk at a location, it might be misleading to assume that a larger risk score is directly associated with a riskier location. It might happen that a location has many small risks sum up to equal to one single serious risk. To display these differences, the risk scores can be further categorized into 5 . Careful review of all the data and risk scores can assist in defining the limits of the 5 categories (see Figure 5-7). As an example, a risk of 0.9 will be a category 5 while a risk of 0.01 would be a risk category of 1 . The categorization of risk score limits are summarized in Table 5-10:

Table 5-10 - Total Risk Categorization Limits

\begin{tabular}{|c|c|}
\hline Risk Category & Min Limit (i.e. >) \\
\hline 5 & 0.7 \\
\hline 4 & 0.3 \\
\hline 3 & 0.1 \\
\hline 2 & 0.05 \\
\hline 1 & 0 \\
\hline
\end{tabular}

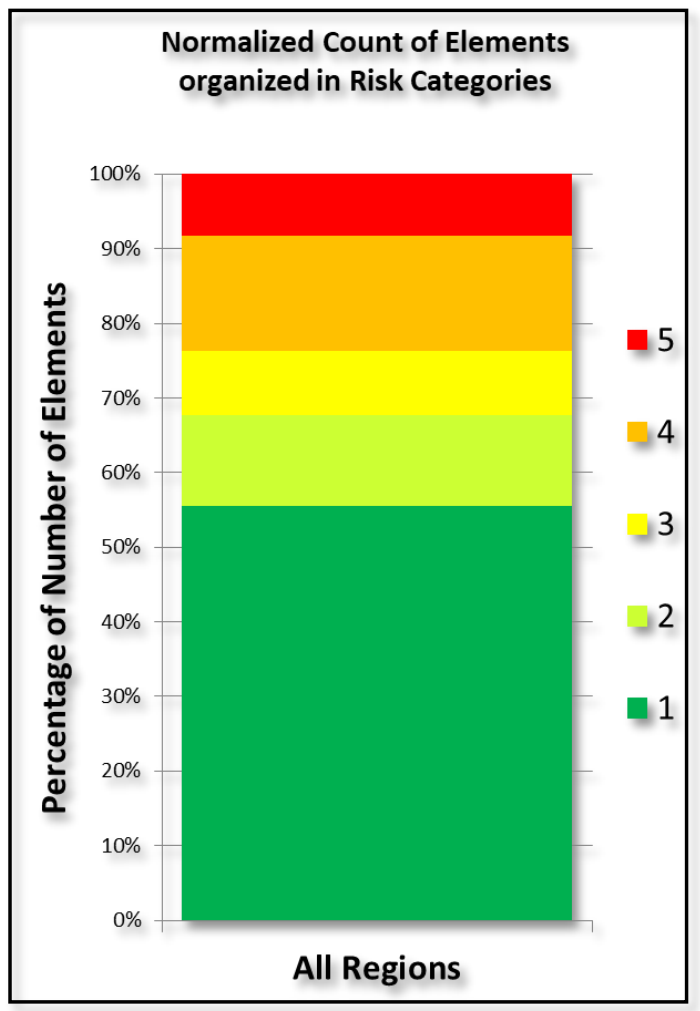

Figure 5-7 - Total Risk Distribution Sample 
Ultimately, the severity of the every protective function with a violation is defined by a function of probability and consequence. Probability can be based on factors such as fault occurrence and equipment outage. Historical data collection for every equipment can assist in a more refined risk scoring mechanism rather than the proposed generalized approach. For example, a flagged violation on a fault for a given transmission line which is typically on storm patterns resulting in many faults every year can have a higher risk compared to an element with a simulation flag on a fault for a transmission line without any abnormalities for the past 10 years. Furthermore, consequence can also be based on additional transient simulations conducted by utilities were an outage of a specific equipment due to protection mis-operations can cause stability concerns on the transmission network and result in cascading generation loss [9].

The proposed solution considers transforming simulation results for millions of fault scenarios into a summary of protective devices with a possible mis-coordination violations. By building a database which can capture such big data throughout the study stage, further risk assessment methods can help prioritize each protective function which requires a solution. The recommendations captured can be grouped together for every device, terminal, or substation. The data can also be broken down by most common element type or relay style. It can then be further analyzed to highlight patterns which can be avoided in the future.

\subsection{Summary}

Chapter 5 discussed the proposed methodology behind quantification of relative risk scores for transmission sensitivity, transmission coordination, the philosophy behind the management of the risk data and the classification into risk categories. This approach is beneficial to manage all protective relay element violations for the hundreds of thousands of fault simulations of a typical transmission network. 


\section{Conclusion and Future Work}

The previous chapters of this thesis highlighted the challenges of the existing approach in the industry for transmission line protection coordination, an innovative automated holistic wide area protection coordination solution, and simulation results of the proposed solution. This chapter represents the achieved conclusions of this research. Furthermore, possible areas for further enhancing the practical proposed solution are highlighted.

\subsection{Conclusions}

Ensuring protection systems coordinate under different operating contingencies has always been a challenge for transmission companies. The growing complexity of modern protection and control systems, makes it even more challenging for transmission companies to maintain and audit the reliable operation of their protection systems.

The objective of this thesis is to propose a practical solution for protection engineers of transmission owned utilities to achieve coordination among all their protective devices. As a result, this thesis recommended a process focusing on a series of automation assisted techniques to relieve the protection engineer from the tedium of running individual fault conditions and instead focus their attention on mitigating problems found. This allows actionable recommendations and optimized protection settings to be issued for correction as a direct cause of performing such holistic wide area protection coordination studies.

A transmission network model with associated protection relays was prepared in detail within the CAPE software environment. The proposed solution was then evaluated using the prepared model by applying hundreds of simulation scenarios for three distinct study cases. The following general conclusions were drawn from the studies:

- The systematic wide area protection coordination solution does achieve its primary goal of highlighting coordination violations for each simulation. By increasing the number of fault scenario permutations, the chance of identifying backup protective elements with mis- 
coordination will also grow significantly. This direct relationship was observed when the same violating backup device in study case 1 was flagged with additional mis-operations during application of resistive faults.

- The flagged violations are very sensitive to the health of the protection model. A simple modeling error or a lack of a single relay in the CAPE database can make the raw simulation results impractical. This sensitive result of violations to the protection model is due to the nature of mis-coordination formulation as a relationship of time difference between primary and backup protection.

- Transmission protection is often secured by multiple redundant protection schemes such as a minimum of two exact devices with the same settings as well as inclusion of pilot protection. The combination of redundant systems at each protective terminal can result in masking setting errors as the simulations evaluate all active devices at once. Therefore, outaging one relay at a time while repeating all fault scenarios will increase the probability of flagging additional mis-operations.

- Transmission network is looped for increased reliability. However, an outage of a strong source or a mutually coupled line can result in a significant change in the behavior of the protection scheme. Performing N-1 system outages are an essential part of the proposed solution to ensure capturing all possible violations.

- By performing all proposed permutations, a significant number of fault scenarios are required for evaluating each protective function. The simulation results compiled in chapter 4 for just a few transmission lines were quite challenging and time consuming. This can result in the entire solution being impractical when performing wide area coordination for the entire transmission network. A quantitative risk assessment approach is required to focus the engineer's time in resolving coordination violations with high probability of occurrence and their severe consequence.

- The use of extensive automation is required to maintain the integrity of the results. Automation routines can be achieved for data entry and validation, applying thousands of fault scenarios for each study, processing of the simulation results, application of risk assessment, and providing statistics.

- A large collection of data will be produced after modeling hundreds of thousands of devices in a short circuit program and performing thousands of fault scenarios for each transmission 
line. Efficient data management will become an integral requirement of the proposed solution.

The accomplishments of this proposed solution can provide substantial long-term benefits to electric utilities.

The overall tangible benefits of the solution include the following:

- Accurate power system network and protection models

- Automatic bridging of relay database, computer-aided protection engineering software, and wide area coordination study database

- Increasing the overall key performance indices for the power system network availability for the whole network

The overall intangible benefits of the solution include the following:

- Efficiency and accuracy gained from automated processes is noticeable in comparison to manual entry, which is slower and prone to human error

- The exposure of new tools and different practices adopted in Wide Area Protection to young engineers

- Increased reliability of the power system network and protection model

- Compliance with regulatory requirements and reduction in the penalties of mis-operation and blackout from incorrect relay settings

\subsection{Future Works}

This solution can help electric utilities in establishing a strong foundation for future initiatives to improve security and reliability of its protection systems. The following future initiatives and improvement opportunities are recommended:

- Continue Improvements to Primary Network and Protection Model: Although, an extraordinary effort is required to put into model preparation, validating all aspects of the model can become very challenging while respecting schedule constraints

- Establish Process to Repeat Wide-area Protection Coordination Solution Periodically: Every system is evolving at a fast pace; therefore, the fault current levels and the subsequent protection coordination margins will change at a relatively faster pace. There 
will be tangible benefits from conducting wide-area protection coordination study periodically

- Further Invest in Modernizing Protection Review Process: Electric utilities should further invest in automation tools to take full advantage of the protection asset management and protection software tools. Automation tools can help to streamline protection modeling, protection settings development/review process, and can minimize the effort required for future periodic wide-area protection coordination studies

Furthermore, the proposed offline simulation solution has a potential to be implemented on operational online systems. The methods described in this thesis can be applied to distribution protection systems and potential result in automatic setting calculations of a rather radial system during different operational conditions. Ultimately, the proposed solution can become the foundation required for the concept of adaptive protection. 


\section{Bibliography}

[1] Committee on America's Energy Future, "America's Energy Future: Technology and Transformation" Washington DC: The National Academies Press, 2009

[2] Electricity Consumers Resource Council, "The Economic Impacts of the august 2003 Blackout" Electricity Consumers Resource Council, Feb.9, 2004. [Online]. Available: https://elcon.org/wpcontent/uploads/Economic20Impacts20of20August20200320Blackout1.pdf. [Accessed Nov.14, 2017].

[3] S.H. Horowitz, A.G. Phadke, "Power System Relaying" John Wiley and Sons Ltd., Chennai, India, 2014

[4] J.L. Blackburn, T.J. Domin, "Protective Relaying - Principles and Applications" CRC Press Taylor \& Francis Group, Boca Raton, FL, 2014

[5] North American Electric Reliability Council, "2000 System Disturbances" North American Electric Reliability Council, Sept.2001. [Online]. Available: https://www.nerc.com/pa/rrm/ea/System\%20Disturbance\%20Reports\%20DL/2000 SystemDisturbance.pdf [Accessed Dec.11, 2017]

[6] Committee on Determinants of Market Adoption of Advanced Energy Efficiency and Clean Energy Technologies, Board on Science, Technology, and Economic Policy; Policy and Global Affairs; Board on Energy and Environmental Systems; Division on Engineering and Physical Sciences, "The Power of Change: Innovation for Development and Deployment of Increasingly Clean Electric Power Technologies" Washington DC: The National Academies Press, 2016

[7] North American Electric Reliability Council, "Reliability Fundamentals of System Protection" North American Electric Reliability Council, Dec.2010. [Online]. Available: https://www.nerc.com/comm/PC/System\%20Protection\%20and\%20Control\%20Su bcommittee\%20SPCS\%20DL/Protection\%20System\%20Reliability\%20Fundamen tals_Approved_20101208.pdf [Accessed Feb.18, 2018]

[8] L.Messing, S.Lindahl, B.Svensson, "Protection system design for assurance of dependability and security" $A B B, 2006$. [Online]. Available: https://library.e.abb.com/public/c1256d32004634bac1256e19006fccc3/PAPER_20 00_06_en_Protection_System_Design_for_Assurance_of_Dependability_and_Secu rity.pdf [Accessed Jan.4, 2018]

[9] P.Pourbeik, P.S.Kundur, and C.W.Taylor, "The Anatomy of a Power Grid Blackout" IEEE Power and Energy Magazine, pp.22-29, Sept.2006 
[10] Buchholz, B.-M., Krebs, R., Styczynski, Z., "Advanced Protection and Control Solutions for Prevention of Disturbance Enlargement" Regional CIGRE, Moscow, Russia, 2009

[11] American Society of Civil Engineers, "2017 Infrastructure Report Card - Energy" American Society of Civil Engineers, 2017. [Online]. Available: https://www.infrastructurereportcard.org/wp-content/uploads/2017/01/EnergyFinal.pdf [Accessed Oct.28, 2018]

[12] Ordacgi, M. and Solero, R.B. "Minimizing Risks of Cascade Tripping, A Systematic Analysis of Component Protection" Cigre Conference, Paris, Report B5-202, 2006

[24] North American Electric Reliability Corporation, "Misoperations Report" North American Electric Reliability Corporation, Apr.2013. [Online]. Available: https://www.nerc.com/comm/PC/Protection\%20System\%20Misoperations\%20Tas k\%20Force\%20PSMTF\%202/PSMTF_Report.pdf [Accessed Mar.12, 2018]

[25] North American Electric Reliability Corporation, "NERC Staff Analysis of system Protection Misoperations," North American Electric Reliability Corporation, Dec.2014. [Online]. Available:

https://www.nerc.com/pa/RAPA/PA/Performance\%20Analysis\%20DL/NERC\%20 Staff\%20Analysis\%20of\%20Reported\%20Misoperations\%20-\%20Final.pdf [Accessed Feb.14, 2018]

[26] North American Electric Reliability Corporation, "NERC Staff Analysis of system Protection Misoperations" North American Electric Reliability Corporation, Dec.2015. [Online]. Available:

https://www.nerc.com/pa/RAPA/PA/Performance\%20Analysis\%20DL/2015_Anal ysis_of_System_Protection_Misoperations_Final.pdf [Accessed Mar.11, 2018]

[27] Midwest Reliability Organization, "Protection System Misoperations" Midwest Reliability Organization, Apr.18, 2016. [Online]. Available: https://www.mro.net/MRODocuments/PRS\%20White\%20Paper.FINAL.pdf [Accessed Dec.22, 2017]

[28] Western Electricity Coordinating Council, "Protection System Miscoordinations Report and Mitigation Approaches." Western Electricity Coordinating Council, Midwest Reliability Organization, Jan., 2017. [Online]. Available: https://www.wecc.biz/Reliability/2017_ProtectionSystemMisoperations_Report.pdf [Accessed Nov.15, 2017]

[13] U.S.-Canada Power System Outage Task Force, "Final Report on the Implementation of the Task Force Recommendations" Natural Resources Canada and U.S. Department of Energy, Sept.2006. [Online]. Available: https://www.energy.gov/sites/prod/files/oeprod/DocumentsandMedia/BlackoutFina IImplementationReport\%282\%29.pdf [Accessed Jan.16, 2018]. 
[14] North American Electric Reliability Corporation, "PRC-027-1 Draft 6" North American Electric Reliability Corporation, Sept.2015. [Online]. Available: https://www.nerc.com/pa/Stand/Project\%20200706\%20System\%20Protection\%20 Coordination\%20DL/PRC-027-1_Draft_6_clean_07292015.pdf [Accessed Mar.22, 2018]

[15] US Department of Energy, "The Potential Benefits of Distributed Generation and Rate-Related Issues That May Impede Their Expansion" US Department of Energy, 2007. [Online]. Available: https://www.ferc.gov/legal/fed-sta/exp-study.pdf. [Accessed Oct.28, 2017].

[16] U.S. Energy Information Administration, "Electricity Data" U.S Energy Information Administration, 2018. [Online]. Available: https://www.eia.gov/electricity/data.php\#gencapacity [Accessed: Mar.19, 2018].

[17] California Legislative Information, "SB-100 California Renewables Portfolio Standard Program: Emissions of greenhouse gases" California Legislative Information, 2018. [Online]. Available:

https://leginfo.legislature.ca.gov/faces/billNavClient.xhtml?bill_id=201720180SB1 00. [Accessed Feb.22, 2018].

[18] J.Suh, S.Hwang, and G.Jang, "Development of a Transmission and Distribution Integrated Monitoring and Analysis system for High Distributed Generation Penetration" Energies, Aug.2017. [Online serial]. Available: https://www.mdpi.com/1996-1073/10/9/1282. [Accessed Mar.13, 2018].

[19] U.Shahzad, S.Kahrobaee, S.Asgarpoor, "Protection of Distributed Generation: Challenges and Solutions" Energy and Power Engineering, pp.614-653, 2017.

[20] U.S. Department of Energy, "United State Electricity Industry Primer" U.S. Department of Energy, July 2015. [Online]. Available: https://www.energy.gov/sites/prod/files/2015/12/f28/united-states-electricityindustry-primer.pdf. [Accessed Dec.2, 2017]

[21] S.Patel, "A New Record for the Longest Transmission Link" Power Magazine, Oct.1, 2014. [Online], Available:https://www.powermag.com/a-new-record-forthe-longest-transmission-link/. [Accessed Dec.9, 2017].

[22] U.S. Department of Energy, "Annual U.S. Transmission Data Review" U.S. Department of Energy, Aug. 2015. [Online]. Available: https://www.energy.gov/sites/prod/files/2015/08/f26/Transmission\%20Data\%20Re view\%20August\%202015.pdf. [Accessed Jan.14, 2018].

[23] North American Electric Reliability Corporation, "Comments of the North American Electric Reliability Corporation in response to notice of proposed rulemaking" North American Electric Reliability Corporation, Jan.2018. [Online]. Available: https://www.nerc.com/FilingsOrders/us/NERC\%20Filings\%20to\%20FERC\%20DL /Final\%20PRC-027-1\%20NOPR\%20Comments.pdf. [Accessed Mar.17, 2018]. 
[29] L.C.Gross, Jr, "Practical Challenges and Solutions for Protection Engineering" relay application.com, October 23, 2003. [Online]. Available:

https://relayapplication.com/docs/PracProtPaper.pdf. [Accessed Nov.15, 2017].

[30] A.Grice, J.M.Peer, and G.T.Morris, "Today's Aging Workforce - Who Will Fill their Shoes?" cdn.selinc.com, Feb.2017 [Online]. Available:

https://cdn.selinc.com/assets/Literature/Publications/Technical\%20Papers/6429_To daysAgingWork_JP_20110217_Web.pdf?v=20151202-192536 [Accessed Feb.22, 2018].

[31] A.Grice, J.M.Peer, and G.T.Morris, "Today's Power Engineering Shortage - An Alarming Problem With a Powerful Upside" cdn.selinc.com, Jan.2008. [Online]. Available:

https://cdn.selinc.com/assets/Literature/Publications/Technical\%20Papers/6303_To daysEngineeringShortage_JP_20071026_Web.pdf?v=20151202-215825 [Accessed Feb.22, 2018].

[32] US Power and Energy Engineering Workforce Collaborative, "Preparing the U.S. Foundation for Future Electric Energy Systems: A Strong Power and Energy Engineering Workforce" US Power and Energy Engineering Workforce Collaborative, Apr.2009. [Online]. Available:

https://www.google.com/url? sa=t\&rct=j\&q=\&esrc=s\&source=web\&cd=11\&ved=2 ahUKEwj-q52i-

9XeAhWx1FkKHXGPDX0QFjAKegQICBAC\&url=https\%3A\%2F\%2Fpserc.wisc .edu\%2Fdocuments\%2Fpublications\%2Fspecial_interest_publications\%2Fworkfor ce\%2FUS_Power_and_Energy_Collaborative_Action_Plan_April_2009.pdf\&usg= AOvVaw3emDSVWPdvBguBWuzpzUl3 [Accessed Nov.28, 2017].

[33] American Public Power Association, "Work Force Planning for Public Power Utilities: Ensuring Resources to Meet Projected Needs" American Public Power Association, Washington, DC, 2005, [Online]. Available: https://www.google.com/url? sa=t\&rct=j\&q=\&esrc=s\&source=web\&cd=1\&ved=2a hUKEwjr8KXb_NXeAhXOqlkKHfgtBbgQFjAAegQIAhAC\&url=https\%3A\%2F $\% 2$ Fpserc.wisc.edu\%2Fdocuments\%2Fpublications\%2Fspecial_interest_publicatio ns\%2Fworkforce\%2FWorkForcePlanningforPublicPowerUtilities_2007.pdf\&usg= AOvVaw3NJORd6xSxuOYwq9109szj. [Accessed: Jan. 25, 2018].

[34] Canmet Energy Technology Center, "Protection Coordination Planning With Distributed Generation" Canmet Energy Technology Center, Jun.2007 [Online]. Available:

https://www.nrcan.gc.ca/sites/www.nrcan.gc.ca/files/canmetenergy/files/pubs/2007 -149e.pdf [Accessed Dec.20, 2017].

[35] V.N.Rajput and K.S.Pandya, "On 8-Bus Test System for Solving Challenges in Relay Coordination" in 2016 IEEE 6th International Conference on Power Systems, Mar.2016

[36] J.Moirangthem, S.S.Dash, R.Ramaswami, "System-Wide Protective Relay Setting and coordination in Large-Scale Transmission systems-A Review" Journal of Electrical Engineering, 2011. 
[37] R.Ramaswami, M.J.Damborg, S.S.Venkata, A.K.Jampala, "Enhanced Algorithms for Transmission Protective Relay Coordination" In IEEE Transaction on Power Delivery, Vol.PWRD-1, No.1, Jan.1986, pp.280-287

[38] M.J.Damborg, R.Ramaswami, A.K.Jampala, S.S.Venkata, "Application of Relational Database for Computer-Aided-Engineering of Transmission Protection Systems" In IEEE Transaction on Power Systems, Vol.PWRS-1, No.2, May 1986, pp.187-193

[39] V.Azbe and R.Mihalic, "Computer-aided Coordination of power system Protection" In Proc. IEEE Region 8 EUROCON 2003, 2003, pp.268-272.

[40] B.Barman, J.Clack, V.Padaca, "A Practical Guide to Performing Wide-Area Coordination Analysis" presented at WPRC 2014, Spokane, WA, 2014.

[41] B.Barman, J.Clack, V.Padaca, "A Practical Guide to Performing Wide-Area Coordination Analysis" presentation slides from MIPYSCON 2015, Saint Paul, MN, Nov.10, 2015

[42] T.Keil, J.Jager, N.Sollner, T.Bopp, and R.Krebs, "Software Assisted Development of Protection Coordination Concepts in Nationwide Power Systems" 9th IEEE International Conference on Developments in Power System Protection, 2008.

[43] J.Jaeger, X.-P.Liang, R.Krebs, and T.Bopp, "Automated Protection Performance Assessment and Enhancement" Journal of Power and Energy Engineering, pp.525$531,2014$.

[44] Jaeger, J. and Krebs, R. "Automated Protection Security Assessment of Today's and Future Power Grids" IEEE PES General Meeting, 2010.

[45] Red Electrica De Espana, "REE Wide Area Coordination study" presentation slides from CAPE User Group Meeting 2007, Ann Arbor, MI, Jun. 2007.

[46] Electrocon International Incorporated, "CAPE Software The power that protection engineers need" Electrocon International Incorporated, 2018. [Online]. Available: https://www.electrocon.com/capeintro.php. [Accessed Dec.14, 2017].

[47] Schweitzer Engineering Laboratories, Inc., "AcSELerator QuickSet SEL-5030 Software" Schweitzer Engineering Laboratories, Inc., 2014-2017.

[48] P.M. Anderson, "Power System Protection" IEEE Press Series on Power Engineering, Piscataway, NJ, 1998.

[49] FECIME, "Network Protection \& Automation Guide - Overcurrent Protection for Phase and Earth Faults" Guset User, 2015.

[50] Idaho Power, "Introduction to system protection" Hands-On Relay School, IDACORP Company, 2012. [Online]. Available: https://www.eiseverywhere.com/file_uploads/aaf42a76a5588f69c7a1348d6f77fe0f _Introduction_to_System_Protection-_Protection_Basics.pdf [Accessed Dec.16, 2017].

[51] GE Industrial Systems, "L90 Instruction Manual for 7.6x product version (Rev. AE3)" GE Multilin, Markham, Ontario,2017. 
[52] J. Hubertus, Public Service Electric and Gas Company, "Application Considerations for Distance Relays on Impedance-Grounded Systems" presented at 61st Annual Conference for Protective Relay Engineers, College Station, Texas, April 1, 2008.

[53] GE Industrial Systems, "D60 Line Distance Relay UR Series Instruction Manual" GE Multilin, Markham, Ontario, 2008. [Online]. Available: http://www.gegridsolutions.com/products/manuals/d60/d60man-f4.pdf [Accessed: Jan. 20, 2018]

[54] M.Thompson, D.Heidfeld, "Transmission Line Setting Calculations - Beyond the Cookbook" Schweitzer Engineering Laboratories, Inc., Pullman, WA, 2016, [Online]. Available: http://www.cce.umn.edu/documents/CPEConferences/MIPSYCON-

Papers/2015/TransmissionLineSettingCalculationsBeyondtheCookbook.pdf [Accessed: Jan. 22, 2018].

[55] M. Thompson, A. Somani, "A Tutorial on Calculating Source Impedance Ratios for Determining Line Length" Schweitzer Engineering Laboratories, Inc., presented at 68th Annual Conference for Protective Relay Engineers, College Station, Texas, March 30, 2015.

[56] North American Electric Reliability Corporation, "Standard PRC-023-4 Transmission Relay Loadability" North American Electric Reliability Corporation, Nov.2015. [Online]. Available: https://www.nerc.com/pa/Stand/Reliability\%20Standards/PRC-023-4.pdf [Accessed Mar.12, 2018]

[57] North American Electric Reliability Corporation, "NERC Case Notes: Reliability Standard PRC-023-1" North American Electric Reliability Corporation, Feb.2008. [Online]. Available: https://www.whitecase.com/nerc-prc-023-1 [Accessed Mar.4, 2018]

[58] Electrocon International, Inc., "An Introduction to the CAPE Relay Library User's Tutorial" Electrocon International, Inc., Ann Arbor, MI, Jun.2003.

[59] J.Mooney, J.Peer, "Application Guidelines for Ground Fault Protection" presented at 1998 International Conference Modern Trends in Protection Schemes of Electric Power Apparatus and Systems, New Delhi, India, Oct 28, 1998.

[60] F. Calero, "Mutual Impedance in Parallel Lines - Protective Relaying and Fault Location Considerations" Schweitzer Engineering Laboratories, Inc., presented at 34th Annual Western Protective Relay Conference, October 2007.

[61] A. Guzman, J. Roberts, K. Zimmerman, "Applying the SEL-321 Relay to Permissive Overreaching Transfer Trip (POTT) Schemes" Schweitzer Engineering Laboratories, Inc., Pullman, WA, 1995.

[62] IEEE, "C37.2-2008 - IEEE Standard Electrical Power System Device Function Numbers, Acronyms, and Contact Designations" IEEE, Oct.2008.

[63] Schweitzer Engineering Laboratories, Inc., "SEL-421 Relay Protection and Automation System Instruction Manual" Schweitzer Engineering Laboratories, Inc., Pullman, WA, Oct 2011. 
[64] S. Cary, "High voltage circuit breaker standards - comparative guide" White Paper WP012001EN, Eaton Power Business Worldwide, Cleveland, OH, May 2013.

[65] Schweitzer Engineering Laboratories, Inc., "SEL-311L-1, -7 Relay Protection and Automation System Instruction Manual" Schweitzer Engineering Laboratories, Inc., Pullman, WA, Oct 2011.

[66] J. Grainger, W. Stevenson, JR., "Power System Analysis" McGraw-Hill, Inc., Raleigh, NC, 1994.

[67] D. Wong, T. Tong, "Estimation of Fault Resistance from Fault Recording Data" AltaLink Utility, Calgary, AB, Nov. 2014, [Online]. Available: http://www.ece.ualberta.ca/ apic/uploads/Forum/P2014_6.pdf [Accessed: Jan. 19, 2018]. 